\title{
IV. Die christliche Gemeinde Roms: Märtyrermemoria und innerkirchliche Auseinandersetzungen
}

Das kaiserzeitliche und spätantike Rom war bis zum Beginn des 5. Jh., als die Stadt mit der Eroberung durch die Goten im Jahr 410 in eine neue Phase der städtebaulichen und demographischen Entwicklung eintrat, ${ }^{1}$ eine Großstadt von außergewöhnlichen Dimensionen - eine der wenigen „Megapoleis“ der antiken Mittelmeerwelt, deren Einwohnerzahl um die Millionengrenze lag, und die eine vergleichsweise inhomogene, durch hohe Zuwanderung und Fluktuation geprägte Bevölkerungsstruktur aufwies. ${ }^{2}$ Der Bürgerbegriff war unter solchen Bedingungen nur bedingt identitätsrelevant. Er wurde zwar durch Rituale wie die ausgeprägte Spielkultur des populus Romanus und durch Lebensmittelzuwendungen an die plebs frumentaria in intensiver Form symbolisch vermittelt, ${ }^{3}$ doch muss es jenseits dessen zu einer vielfältigen Ausbildung kollektiver Identitäten gekommen sein, die eine konkreter erfahrbare und handlungsrelevantere Gruppenzugehörigkeit begründeten als die abstrakte Teilhabe an einer Stadtgemeinde, deren Zahl in die Hunderttausende ging. Das Spektrum der Möglichkeiten kann hier nur in wenigen Worten umrissen werden: Es reicht von regional begründeten Identitäten (vici, städtische Viertel mit ihren Portiken und Plätzen, Gewerbetopographie) ${ }^{4}$ über primär berufliche oder religiöse Zusammenschlüsse (collegia), ${ }^{5}$ Ethnizität und gemeinsame Herkunft ${ }^{6}$ bis hin zu anderen Formen gesellschaftlicher Organisation wie den

1 Zur Bevölkerungsentwicklung von der severischen Zeit bis ins 5. Jh. vgl. zuletzt Lo Cascio 2000, 56-61, dessen demographische Schätzungen auf eine Zahl von 650.000 bis 700.000 Einwohnern im 3. und 4. Jh. hinauslaufen. Für die einschneidenden Veränderungen in der Bevölkerungszahl und Urbanistik Roms während des 5. Jh. vgl. u., S. 404-407.

2 Zu Segmentierung und Immigration als wesentlichen Charakteristika antiker „Megapolen“ vgl. Nicolet 2000, 17.

3 Die Wirksamkeit der dadurch begründeten Identitätsstiftung des populus Romanus im spätantiken Rom stellt Brown 1982, bes. 124-129 heraus.

4 Für die damit verbundenen topographischen Aspekte und ihre Bedeutung für das soziale Leben der Stadtbewohner vgl. Kolb 1995, bes. 409-425, 496-507, 510-513; Coarelli 2000, bes. 233-235.

5 Zur topographischen Verteilung der Vereinsgebäude von Kollegien in Rom vgl. Bollmann 1998, 180-195.

6 Vgl. das bekannte Diktum des Athenaios, wonach Rom wegen der Städte und Völkerschaften der ganzen Welt, die es in sich aufgenommen habe, eine غ̇лı 20, b-c). Zu Fremden in Rom vgl. zuletzt Noy 2000; Dresken-Weiland 2003. 
aristokratischen Haushalten mit ihren ausgeprägten Klientel- und Patronagebeziehungen. $^{7}$

Die mit der Großstadtsituation verbundene Tendenz zur Ausbildung segmentierter und auf unterschiedlichen Ebenen vermittelter Identitäten hatte Auswirkungen nicht nur auf die städtische Bürgergemeinde, sondern auch auf die kirchliche Gemeinde Roms, die ecclesia. Die zu Beginn des 2. Jh. von Ignatius von Antiochia begründete Vorstellung von der Einheit der christlichen Gemeinde unter der Leitung eines einzigen Bischofs hatte sich in der Folgezeit zum bestimmenden Modell des Kirchenverständnisses und der Kirchenorganisation entwickelt und spätestens seit der 2. Hälfte des 2. Jh. auch in Rom Fuß gefasst. ${ }^{8}$ Der damit einhergehende Leitungsanspruch des römischen Bischofs traf dort jedoch auf einzelne christliche Gruppen und Gemeinschaften, die über eigene Organisationsformen und Traditionen verfügten, bis dahin weitgehend eigenständig agierten und nur lose miteinander verbunden waren. ${ }^{9}$ Nicht nur für eine historische Übergangsphase, in der sich die monepiskopale Struktur in Rom durchzusetzen begann, sondern auch für die anschließende Zeit bleibt es eine weitgehend offene Frage, wie es der römischen Bischofsgemeinde unter den Voraussetzungen einer Großstadtsituation gelingen konnte, symbolische Strukturen auszubilden, die eine effektive Integration unterschiedlicher Gruppen in die eine christliche Gemeinde bewerkstelligten, die um die Mitte des 3. Jh. bereits mehrere Zehntausend Mitglieder umfasst haben dürfte. ${ }^{10}$ Auch mit Blick auf die unterschiedlichen christlichen Gruppen und Gemeinden Roms ist nur schwer zu erschließen, welche identitätsstiftenden Faktoren deren kollektives Leben bestimmt haben. ${ }^{11}$ Dies betrifft vor allem

$7 \quad$ Zur Rolle von Patronage- und Klientelbeziehungen, die besonders im 4. Jh. nach der Reorganisation des Senatorenstandes durch Konstantin und der dauerhaften Abwesenheit der Kaiser von Rom erneut an Bedeutung gewannen, vgl. Cracco Ruggini 2003, 367; Lizzi Testa 2004 (a), 86-89 u. passim.

8 In Rom vollzog sich der Übergang zur monepiskopalen Kirchenordnung zwischen Soter (ca. 170) und Victor (189-199). Zu dieser communis opinio vgl. zuletzt Simonetti 1996, 33-36 (gegen Brent 1995, der eine monepiskopale Struktur in Rom erst nach der Beilegung des - von Brent nicht als Schisma bewerteten - Konflikts mit der Gemeinde des Hippolytos, also nach 235, als erreicht ansieht).

$9 \quad$ Einen Überblick über die unterschiedlichen Gruppen und ihre Charakterisierung für die Zeit bis zum Ende des 2. Jh. vermittelt Lampe 21989, dessen Darstellung allerdings in zahlreichen Punkten kritisch zu bewerten ist (s. o., S. 38, Anm. 3).

10 Harnack ${ }^{4} 1924$, Bd. 2, 806 rechnet für die Mitte des 3. Jh. mit ca. 30000 Gemeindemitgliedern. Grundlage für diese Schätzung ist der berühmte Brief des römischen Bischofs Cornelius (251253), der 46 Presbyter, 7 Diakone, 7 Subdiakone, 42 Akoluthen, 52 Exorzisten, Lektoren und Türwächter und mehr als 1500 Witwen und Hilfsbedürftige aufführt (Eus., h. e. 6, 43, 11). Hopkins 1998, 202 veranschlagt die Zahl mit 5000 bis 10000 deutlich geringer.

11 Bis zu einem gewissen Grad dürfte auch die regionale Herkunft eine Rolle gespielt haben. Ein Teil der Forschung fasst den Osterfeststreit unter Bischof Victor I. (189-199), in dem der römische Bischof die Gemeinschaft mit den kirchlichen Gemeinden Asiens aufkündigte, weil sie als 
die räumlichen Aspekte dieser kollektiven Identitätsstiftung. Der Umstand, dass die Organisation der Gruppen im wesentlichen auf der Basis von Hausgemeinschaften oder Schulen erfolgte, deutet nur vage auf domus oder suburbane Villen als räumliche und soziale Kontexte hin, deren präzisere Verortung im städtischen Raum allerdings in der Regel nicht möglich ist. ${ }^{12}$

Diese allgemeinen Erkenntnisvorbehalte gelten a fortiori auch für die speziellere Frage danach, welche Rolle Grablegen und die Totenkommemoration als Faktoren der kollektiven Identitätsstiftung gespielt haben mögen. Nähere Einblicke sind hier allenfalls für die Zeit des frühen 3. Jh. möglich, als sich unter maßgeblicher Leitung des Kirchenlehrers und römischen Presbyters Hippolytos eine Opposition zu den monarchianistischen Tendenzen der Bischöfe Zephyrin (199-217) und Kallixt (217-222) bildete, die in ihrem Selbstverständnis stark vom Vorbild hellenistischer Philosophenschulen geprägt war. ${ }^{13}$ Man kann davon ausgehen, dass für die Identität beider Gruppen - der Bischofsgemeinde um Zephyrin und Kallixt ebenso wie der Schule des Hippolytos - der Traditions- und Sukzessionsgedanke eine fundamentale

\footnotetext{
Quartodecimaner das Osterfest an einem anderen Termin feierten, nicht als einen Konflikt der römischen Kirche mit den Kirchen Kleinasiens auf, sondern als eine innerrömische Auseinandersetzung des römischen Bischofs mit Gemeinden kleinasiatischer Herkunft (La Piana 1925, bes. 232-234; Jalland 1944, 116-122; Simonetti 1989, 115-122; Brent 1995, 412-415). Auch wenn man sich dieser Position nicht anschließt (vgl. die berechtigten Einwände bei Wojtowytsch 1981, 380f.), ist dennoch zu berücksichtigen, dass unter Victors Vorgänger Anictet (154/155? - 166?) gemeindeinterne Differenzen bezüglich des Osterfesttermins oder des Osterfastens auftraten, weil Teile der Gemeinde in diesem Punkt Traditionen ihrer Herkunftsgemeinden bewahrten; im Unterschied zu Victor hatte Anictet jedoch diese Gemeindemitglieder nicht ausgeschlossen, sondern durch die Übersendung der Eucharistie an sie die Gemeinschaft mit ihnen bekräftigt (vgl. Eus., h. e. 5, 24, 12-17). Vermutlich waren es solche innerrömischen Auseinandersetzungen um die Observanz des Osterfestes, die auch den Anlass dafür bildeten, dass Victor die lokalen Traditionen der kleinasiatischen Kirchen rügte und eine einheitliche Regelung herbeiführen wollte.

12 Zwei der wenigen bekannten Beispiele führen zugleich die Bandbreite der lokalen Kontexte vor: Ein an der via Latina gefundenes Inschriftenfragment (vermutlich aus antoninischer Zeit) mit unverkennbar gnostischem Gedankengut, das nicht der Funeralepigraphik zuzurechnen ist, deutet auf einen Versammlungsort gnostischer Valentinianer hin, die möglicherweise in einer suburbanen Villa an der via Latina zusammenkamen (vgl. Guarducci 1973, bes. 188f.; dies. 1974). Der Philosoph Justin (gest. ca. 165) wiederum scheint seine Schüler in einer städtischen Mietwohnung ,oberhalb des Bades von Myrtinos“ versammelt zu haben (acta Iustini 3, 3).

13 Vgl. Brent 1995, bes. 368-457, der daraus ableitet, dass es im ersten Drittel des 3. Jh. noch keine monepiskopale Gemeindestruktur in Rom gegeben habe. Das Selbstverständnis der Schule oder Gemeinde des Hippolytos ist jedoch nicht allein maßgeblich für die Beurteilung dieses Sachverhalts. Es lässt sich kaum bestreiten, dass sich in Rom der Monepiskopat als ein kirchenorganisatorisches Modell spätestens zu Beginn des 3. Jh. sehr deutlich bemerkbar machte - vermittelt durch entsprechende Strukturen und Institutionen (monepiskopale Sukzession; gemeindeeigener Besitz); inwieweit dieses Modell allgemein akzeptiert wurde, ist eine andere Frage. - Die unter dem Namen des Kirchenlehrers Hippolytos bekannten Schriften dürften mindestens zwei Autoren zuzuschreiben sein; einer von ihnen ist mit dem römischen Presbyter Hippolytos gleichzusetzen, der im Jahr 235 gemeinsam mit Bischof Pontianus verbannt wurde (vgl. dazu u., Anm. 195).
} 
Rolle spielte, und dass dieser wiederum symbolisch in elementarer Weise durch identitätsstiftende Orte vermittelt wurde. Deren Charakter war allerdings unterschiedlich. Die Bischofsgemeinde verfügte vermutlich bereits seit Bischof Victor (189-199) über ein coemeterium, eine kollektive Gemeindegrablege, in der sich seit dem Beginn des 2. Jh. auch die römischen Bischöfe bestatten ließen und damit der Vorstellung einer bischöflichen Sukzession sichtbaren Ausdruck verliehen. ${ }^{14}$ Die Gemeinschaft des Hippolytos hingegen orientierte sich offensichtlich am Modell der epikureischen Philoso-

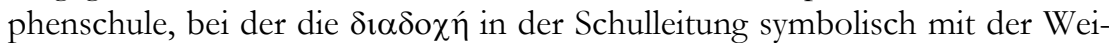
tergabe des Gartens, des $\kappa \tilde{\eta} \pi \mathrm{s}$, verbunden war, der auch als Versammlungsort diente. ${ }^{15}$ Einen deutlichen Hinweis auf dieses Moment der Identitätsstiftung enthält eine epikureische Philosophenstatue, die an der via Tiburtina, im Bereich der Gegend, in der sich auch das Grab des Hippolytos befand, aufgefunden wurde, und auf deren Seitenflächen mehrere Werke des Hippolytos und jeweils ein Oster- und Passahzyklus verzeichnet sind. ${ }^{16}$ Wen dieses Monument darstellte, ist stark umstritten, da die ursprüngliche Gestalt der Statue aufgrund frühneuzeitlicher Umarbeitungen nicht mehr sicher rekonstruierbar ist. ${ }^{17}$ An einer Bezugnahme auf Formen der Traditions- und Identi-

$14 \quad$ Vgl. dazu o., S. 41f. Dass gemeindeeigene Grablegen wie die an der via Appia eine identitätsstiftende Bedeutung als Versammlungsorte erlangten, wird aus dem erstmals von Valerian verhängten Verbot ersichtlich, die coemeteria zu betreten (s. o., S. 35). Für das Coemeterium an der via Appia lässt sich diese Funktion als Versammlungsort unmittelbar nachweisen: Infolge des valerianischen Edikts wurde Bischof Sixtus II. mit vier seiner Diakone am 6. August 258 im coemeterium an der via Appia festgenommen (Cypr., epist. 80, 1, 4).

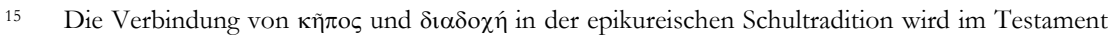
Epikurs ersichtlich, in dem er den Garten seinem Nachfolger Hermarch vermacht und ihn zur

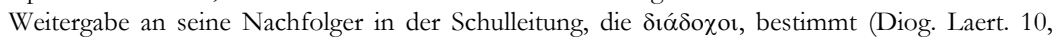
16f.).

16 Dass es sich um eine epikureische Statue handelt, ist durch den Thron mit Löwenprotomen gesichert (s. die Vergleichsbeispiele bei Guarducci 1974-1975, 174-179 mit den korrigierenden Bemerkungen von Wrede 1982, 235f., Anm. 4). Die beiden Zyklen beginnen jeweils mit dem ersten Regierungsjahr des Alexander Severus (222-235) und weichen in ihren Berechnung bereits im Jahr 236 erstmals vom tatsächlichen Ostertermin ab; sie sind daher im Jahr 222 oder bald danach entstanden (Brent 1995, 4, vgl. auch ebd., 65-69). - Die Fundumstände der 1551 von Pirro Ligorio entdeckten Statue sind in der Forschung umstritten; es besteht jedoch kein begründeter Anlass, an der Angabe Ligorios zu zweifeln, er habe die Statue zwischen der via Nomentana und der via Tiburtina, in geringer Entfernung von den Überresten des antiken Lagers der Prätorianergarde, entdeckt (vgl. die ausführliche Forschungsdiskussion von Brent 1995, 5-50).

17 Guarducci 1974-1975, 171-173, 181-186; dies. 1977, bes. 19f., 29f. leitet aus der Gewandung der Statue ab, dass ursprünglich eine weibliche Person dargestellt gewesen sei, die sie mit der epikureischen Philosophin Themista v. Lampsakos identifiziert und die von den christlichen Betrachtern als eine Personifikation der Arithmetik aufgefasst worden sei. Weitgehend zustimmend Brent, der in der Statue jedoch eine ,icon of a community's self identity” und ein „,community artefact“ erkennen möchte (Brent 1995, 79f. u. ö.). Da die Statue bei ihrer Auffindung stark zerstört war und nicht klar ist, in welchen Teilen sie ihre heute sichtbare Gestalt den Ergänzungen durch Pirro Ligorio verdankt, bleibt dies jedoch eine problematische Hypothese (so auch Wrede 1982, 235f., Anm. 4, geht davon aus, dass die Statue ursprünglich einen Mann dargestellt habe). 
tätsstiftung hellenistischer Philosophenschulen ist jedoch nicht zu zweifeln: Ähnlich wie vergleichbare Sitzstatuen epikureischer Philosophen im $\kappa \tilde{\eta} \pi \mathrm{\sigma} \varsigma$ der epikureischen Philosophenschule ihren Platz fanden, deutet der suburbane Fundort der Statue auf den Garten einer Villa als ursprünglichen Aufstellungsort hin. ${ }^{18}$

Dass die Gemeinschaft um Hippolytos - ähnlich wie die römische Bischofsgemeinde - auch über ein coemeterium verfügte, lässt sich hingegen nicht nachweisen. Zwar wurde der Presbyter Hippolytos an der via Tiburtina in unmittelbarer Nähe des Ortes, an dem sich auch seine Schule befunden haben muss, bestattet, doch deuten die archäologischen Überreste der Katakombenregion, in der Hippolytos beigesetzt wurde, nicht darauf hin, dass sein Grab Teil einer Gemeindegrablege gewesen ist. ${ }^{19}$ Ähnliche Vorbehalte gelten auch bezüglich anderer Gruppen und Gemeinden außerhalb der römischen Großkirche. Sicher haben manche von ihnen über kollektive Grablegen verfügt, doch haben sich darauf - von einer Gemeindegrablege der seit der Mitte des 3. Jh. bestehenden Novatianer abgesehen ${ }^{20}$ - keine Hinweise erhalten. Ob-

Die mit der Statue verbundenen Fragen - Personifikation oder konkrete Person; Bedeutung des Monuments für die Hippolytosgemeinde - können hier nicht im Detail weiter verfolgt werden; als sicher kann jedoch gelten, dass die Statue von der Hippolytosgemeinde als ein identitätsstiftendes Symbol in Anlehnung an eine hellenistische Philosophenschule verstanden wurde.

18 Für die Aufstellung von Sitzstatuen Epikurs und weiterer Schulhäupter im athenischen $\kappa \tilde{\pi} \pi \mathrm{\varsigma}$ und für die Rezeption dieses Aufstellungskontextes in kaiserzeitlichen römischen Villen vgl. Wrede 1982, 237. Zur Lokalisierung der Hippolytosstatue in einer suburbanen Villa vgl. auch Guarducci 1974-1975, 186f.; dies. 1977, 28. Guarducci ist später davon abgerückt und hat die Statue in der Bibliothek des Pantheon lokalisiert (dies. 1989, 66-74), doch gibt es dafür keine Veranlassung (zum Fundort s. o., Anm. 16).

19 Gegen de Rossi 1882, 13-16, der von der Existenz eines solchen Coemeteriums ausgeht. Im Unterschied zur area I des Kallixtcoemeteriums und zu vergleichbaren Gemeindegrablegen Roms, die eine planmäßige Anlage mit langen Gängen und einer auf systematische Erweiterung ausgelegten geometrischen Struktur der Gangsysteme aufweisen (Brandenburg 1984, 31-41; 45f.; Fiocchi Nicolai 1998, 16-19, 27-31), scheint das Katakombensystem um das Hippolytosgrab an der via Tiburtina nicht aus einer solchen weiträumig geplanten Anlage hervorgegangen zu sein: Auch wenn die Entwicklung der Katakombe wegen der späteren Umbauten um das Hippolytosgrab und der Unzugänglichkeit weiter Katakombenbereiche nur schwer zu rekonstruieren ist, dürfte die Region, in der sich das Hippolytosgrab befindet - die Region a, ,a small and irrgular network of galleries“, - ein ursprünglich eigenständiger Kern sein, der erst sekundär mit dem weiter ausgreifenden und strukturierteren Gangsystem der Region d verbunden wurde (durch den sogenannten „Iter“ und den Gang a7); vgl. zum ganzen Bertonière 1985, 90-96. Dies deutet darauf, dass sich das Hippolytosgrab in einem der zahlreichen vergleichsweise klein dimensionierten Hypogäen befunden hat, die erst im Laufe der Entwicklung zu den ausgedehnten Katakombensystemen Roms zusammengewachsen sind (exemplarisch Spera 1999, 403). - Dass die Hippolytstatue von den Christen ihrer symbolischen Bezüge als Philosophenstatue entkleidet und auf die Funktion eines Pfeilers oder Architekturelements in einem funeralen Kontext reduziert wurde (so Testini 1977, 46-51), ist nicht zu erweisen.

20 Das Grab des novatianischen Gemeindegründers Novatianus ist in einer Katakombe an der via Tiburtina entdeckt worden (s. u., S. 254f.), deren Struktur auf einen Gemeindefriedhof hindeutet (zum archäologischen Befund vgl. Brandenburg 1984, 38; Fiocchi Nicolai 1998, 19 mit Abb. 11). 
wohl die Sepukralepigraphik und -ikonographie die zentralen Quellen für die Existenz häretischer Gemeinschaften in Rom bilden, ${ }^{21}$ lässt sich für die Zeit des 3. Jh. kein weiterer Bestattungsplatz einer häretischen Gemeinde in Rom nachweisen. ${ }^{22}$

Diese insgesamt ernüchternde Bilanz bezüglich der Möglichkeit, Gemeinschaften außerhalb der Großkirche in Rom räumlich zu verorten, ändert sich auch für die nachkonstantinische Zeit nur graduell: Auch für diesen Zeitraum gilt insgesamt das, was Charles Pietri mit Blick auf den Episkopat des Damasus (366-384), der in besonders intensiver Weise von Auseinandersetzungen mit schismatischen und häretischen Gruppen geprägt war, festgehalten hat: „On doit souvent se contenter de quelques informations elliptiques. "23 Im folgenden soll dennoch der Versuch unternommen werden, die Fragmente dieser Spurensuche einer Analyse zu unterziehen. Dies verlangt allerdings zunächst eine präzisere Eingrenzung des Untersuchungsgegenstandes, indem der amorphe und inhaltlich wenig aussagekräftige Häresiebegriff auf Gruppierungen eingeengt wird, die vergleichbare Strukturmerkmale aufweisen. Dafür erscheint es - auch mit Blick auf die Quellensituation - naheliegend, sich auf schismatische Gruppierungen und auf ursprünglich aus Schismen hervorgegangene Sondergemeinden wie die der Novatianer und Donatisten zu konzentrieren. Sie sind insofern miteinander vergleichbar, als sie über dasselbe Selbstverständnis verfügten. Die schismatischen Konfliktparteien, die in den mehrfach auftretenden Doppelwahlen und -besetzungen während des 4. und 5. Jh. auftraten, und zu schismata inveterata ${ }^{24}$ verstetigte Sondergemeinden in Rom konkurrierten in gleicher Weise um die Identität der römischen Gemeinde: Die rivalisierenden Protagonisten und ihre Anhängerschaften vertraten den Anspruch, dass sich dort, wo sie sich befanden, auch die römische Gemeinde unter ihrem rechtmäßigen Bischof befand. Dies stellt ein verbin-

Skeptisch Rebillard 1997, 755-758, dessen durchgängige Übersetzung von coemeteria mit „Heiligengräbern“ jedoch nicht überzeugt (s. o., S. 39, Anm. 4). Vgl. in diesem Zusammenhang auch das konstantinische Reskript an den vicarius Italiae Bassus aus dem Jahr 326, in dem der Kaiser anordnete, dass die Novatianer über eigene Kirchen und coemeteria verfügen dürften (CTh 16, 5, 2; zum Adressaten vgl. Chastagnol 1962, 70f.).

21 Vgl. die Studie von C. Cecchelli 1944, die allerdings in ihrer Interpretation des epigraphischen und ikonographischen Materials als Indizien für häretische Gruppierungen teilweise über das Ziel hinausschießt (vgl. die kritischen Stellungnahmen von Ferrua 1944, ders. 1944/1945, 214 220 [Inschriften]; Rebillard 1997, 758 [Ikonographie]).

22 In Rom existierten neben dem coemeterium Callisti zwar weitere kollektive Grablegen, deren Gründung auf die Initiative privater Stifter zurückging und die möglicherweise erst durch das Restitutionsedikt Gallienus in Gemeindebesitz überführt wurden (vgl. Fiocchi Nicolai 2003, 382 386), doch lässt sich über ihr Verhältnis zur römischen Gemeinde in der Zeit davor nichts aussagen.

23 Pietri 1986, 40. Zu diesen Auseinandersetzungen des Damsus vgl. dens., 1976, Bd. 1, 423-427.

24 Der Begriff ist in Anlehnung an Aug., c. Cresc. 2, 7, 9. 8, 10 gebildet. 
dendes Element dar, das es erlaubt, die beiden Phänomene - Schismen und schismatische Sondergemeinden - zueinander in Beziehung zu setzen. Andere für das spätantike Rom bezeugte Häresien, wie die Mänichäer, Montanisten, Pelagianer und Jovinianer finden hingegen keine Berücksichtigung. Bei ihnen handelte es sich um rigoristische oder elitäre Gruppen, die über konventikelartige Organisationsstrukturen verfügten, jedoch nicht mit dem Anspruch und Ziel auftraten, eine an der Großkirche orientierte Gemeinde zu bilden. ${ }^{25}$ In diesem Sinne sind sie rein strukturell nicht mit Schismen und schismatischen Sondergemeinden vergleichbar und spielen für die folgenden Überlegungen keine Rolle.

Im folgenden wird die Frage untersucht, welche Bedeutung der Heiligenerinnerung in Konflikten um die Identität der römischen Bischofsgemeinde zukam und inwieweit die Heiligentopographie Roms für die Legitimation schismatischer Gruppierungen und Sondergemeinden von Interesse gewesen ist. Zeitlich beschränkt sich die Untersuchung auf die Phase zwischen der Mitte des 4. und dem beginnenden 5. Jh. Dieser zeitliche Rahmen ist einerseits dadurch bedingt, dass die in diesem Zeitraum auftretenden Schismen gemeinsame Strukturmerkmale aufweisen, die deutlich andere sind als die des ausgehenden 5. Jh. ${ }^{26}$ Andererseits hatte das frühe 5. Jh. aber auch für die schismata inveterata der Novatianer und Donatisten Zäsurcharakter: Im Jahr 405 verloren die Donatisten ihren Status als schismatische Kirchengemeinschaft und wurden von der staatlichen Gesetzgebung offiziell unter die Häretiker eingereiht ${ }^{27}$ - eine Maßnahme, die nur wenige Jahre später auch auf die Novatianer ausgedehnt wurde. Die damit einhergehenden Veränderungen (Verlust der Kirchengebäude, Zerschlagung der Organisation) schufen eine gänzlich neue Situation, die es diesen Sondergemeinden nicht mehr ermög-

25 Die sogenannte „Kirche“ der Manichäer, die aus einer Hierarchie von Bischöfen, Presbytern und Diakonen bestand, war ein abstraktes Organisationsprinzip, das ohne erkennbare Auswirkungen auf die Ordnungen der manichäischen Gemeinden blieb (Lim 1989). Ein philosophisch geprägter Manichäismus, wie ihm der frühe Augustinus anhing, scheint besonders bei der Oberschicht ein aufnahmebereites Publikum gefunden zu haben; dasselbe gilt auch für die Lehren von Jovinian, die dem Manichäismus nahe standen (Curran 2000, 295-297). Das von Pelagius propagierte christliche Vollkommenheitsideal formulierte eine Elitenethik, deren Forderungen vor allem in den Kreisen der römischen Aristokratie Anklang fand (Brown 1968; Markus 1990, 40-43); ein ähnlich begrenzter Einfluss ist für die ebenfalls rigoristisch ausgerichteten Montanisten vorauszusetzen, die in Karthago zwar über eine eigene Basilika verfügten (Arnob. Iun., praedest. 1, 86), in Rom jedoch nur konventikelartige Versammlungen in domus gebildet zu haben scheinen (Maier 1995, 238f.).

26 Vgl. u., S. 482f.

27 CTh 16, 6, 4 (405) mit unmittelbaren Auswirkungen auf die Situation der Donatisten auch in Rom. In einem an den römischen Stadtpräfekten adressierten Gesetz werden die Donatisten als Häretiker bezeichnet und in einem Atemzug mit den Manichäern und den - als Prizillianisten bezeichneten - Montanisten genannt (CTh 16, 5, 40 [407]; vgl. auch CTh 16, 5, 43 [vermutlich 407]). 
lichte, ihren Anspruch darauf, die rechtmäßige Gemeinde Roms zu sein, im städtischen Raum zu artikulieren und aufrecht zu erhalten. ${ }^{28}$

Aufgrund der begrenzten Quellenlage ist es nur in sehr eingeschränktem Maße möglich, Rückschlüsse auf die identitätsstiftende Funktion der römischen Heiligentopographie in innerkirchlichen Auseinandersetzungen zu ziehen. Eine signifikante Ausnahme bilden die Heiligenepigramme des römischen Bischofs Damasus (366-384), denen daher ein eigenes umfangreiches Teilkapitel gewidmet ist. Diese quellenbedingte Ausrichtung der Perspektive auf Damasus bedeutet jedoch nicht, dass im folgenden ausschließlich die Damasusepigramme diskutiert werden sollen. Vielmehr geht es darum, die Art und Weise, in der Damasus die römischen Heiligen zu räumlichen Bezugspunkten kollektiver Identitätsstiftung machte, aus den historischen und kulturellen Voraussetzungen bischöflicher Autoritätsbildung und gemeindebezogener Identitätsstiftung im städtischen Raum heraus zu verstehen. Aus diesem Grund soll zunächst untersucht werden, welche Erkenntnisse sich aus dem Handeln der historischen Akteure in schismatischen Situationen ableiten lassen, und in welcher Form das Verhältnis von städtischem Raum, Heiligentopographie und gemeindebezogener Identitätsstiftung in Äußerungen über Sondergemeinden in Rom thematisiert wurde. Die daraus gezogenen Schlussfolgerungen liefern einen Interpretationsrahmen, der auch für die Deutung der Damasusepigramme von richtungweisender Bedeutung ist.

\section{1. Schismen}

In der Zeit von der konstantinischen Wende bis zum ausgehenden 5. Jh. kam es viermal aufgrund von Doppelwahlen bzw. -besetzungen des römischen Bischofsamts zu schismatischen Gemeindespaltungen, die zum Teil erst nach jahrelangen Auseinandersetzungen beigelegt werden konnten. ${ }^{29}$ Der von Kaiser Constantius II. im Zuge seiner homöischen Religionspolitik abgesetzte und im Sommer 356 aus Rom entfernte Bischof Liberius (352-366) wurde in seiner Abwesenheit durch den römischen Archidiakon Felix ersetzt, der nach

28 In CTh 16, 5, 59 (423) erscheinen die Novatianer an der Seite von Manichäern und anderen häretischen Gruppen. Ihre Einstufung unter die Häretiker muss ein wenig früher erfolgt sein; in Rom ließ bereits Innnozenz I. (401-417) den Novatianern ihre Kultgebäude wegnehmen (vgl. Socr., h. e. 7, 9, 2). Der Häretikerstatus der Novatianer wurde später dahingehend relativiert, dass ihnen nur die Errichtung neuer Kirchengebäude untersagt wurde (CTh 16, 5, 65, 2 [428]); in Rom war diese gesetzliche Einschränkung jedoch offenbar nur von geringer Wirkung, da sich unter Bischof Caelestinus (422-432) die Enteignung der novatianischen Kultgebäude, die bereits unter Innozenz I. begonnen hatte, fortsetzte (Socr., h. e. 7, 11, 2-5).

29 Einen konzisen historischen Überblick über die drei aus Doppelwahlen hervorgegangenen Gemeindespaltungen (Damasus/Ursinus; Bonifatius/Eulalius; Symmachus/Laurentius) vermittelt Wirbelauer 1994, 407-416. 
der Rückberufung des Liberius nach Rom im August 358 seine Position als Gemeindeleiter nur widerstrebend räumte. Vermutlich waren es die nicht völlig verarbeiteten Brüche innerhalb des römischen Klerus, die wenige Jahre später erneut zu einer schismatischen Situation führten: Nach dem Tod des Liberius kam es infolge einer Doppelwahl zweier Bischöfe, Damasus (366384) und Ursinus, zu einem erneuten Schisma, in dem sich Damasus nur nach langwierigen Auseinandersetzungen durchsetzen konnte und das trotz mehrmaliger Verbannungen des Ursinus erst mit dem Ende von Damasus' Episkopat als beigelegt angesehen wurde. Während in diesen beiden Konflikten die jeweiligen Anwärter auf das Bischofsamt dem Kreis der römischen Diakone entstammten, ist für die beiden Schismen des 5. Jh. kennzeichnend, dass sich in ihnen jeweils ein Angehöriger des bischöflichen Diakonenkollegiums und des presbyteralen Klerus, der im Unterschied zu den Diakonen nicht unmittelbar dem Bischof zugeordnet war, sondern an den römischen Titelkirchen eine vom römischen Bischof unabhängigere Existenz führte, gegenüberstanden. Nach dem Tod des Bischofs Zosimos (417-418) stand dem Mitglied des Bischofsklerus und Archidiakon Eulalius der im wesentlichen vom Titelklerus gestützte Presbyter Bonifatius gegenüber, der zwar anfänglich gegenüber dem Leiter des Diakonenkollegiums, das bis dahin traditionell den Nachfolger eines verstorbenen Bischofs gestellt hatte, das Nachsehen hatte, sich aber im Laufe des Jahres 419 gegen seinen Konkurrenten durchsetzen konnte. Eine formal ähnliche Konstellation ergab sich erneut im November des Jahres 498, als der Titelpresbyter Laurentius und der Diakon Symmachus zum Nachfolger von Anastasius II. (496-498) gewählt wurden, woraus sich ein mehrere Jahre andauerndes Schisma entwickelte, in dessen Verlauf sich schließlich Symmachus gegen seinen Konkurrenten Laurentius durchsetzen konnte.

Es kann im folgenden nicht darum gehen, in umfassender Weise die Hintergründe und Konfliktlagen dieser einzelnen Schismen zu erörtern. Vielmehr steht die Frage im Vordergrund, inwieweit die Akteure durch die Besetzung von Räumen und Orten Legitimationsstrategien erkennen lassen, die auf die Existenz identitätsrelevanter räumlicher Zentren der römischen Gemeinde hindeuten. Unter diesem Gesichtspunkt ist es sinnvoll, das Schisma zwischen Felix II. und Liberius aus der Reihe der Schismen des 4. Jh. auszuklammern. Seine topographischen Aspekte sind im wesentlichen durch Quellen dokumentiert, die erst einer wesentlich späteren Zeit, nämlich dem ausgehenden 5. Jh., angehören und weniger etwas über die historischen Abläufe dieses Schismas verraten als darüber, wie man sich um 500 den Verlauf eines Schismas und die räumlichen Legitimationsstrategien seiner Akteure vorstellte. Da diese legendarischen Überformungen des Schismas zwischen Liberius und Felix II. zeitnah zum Schisma zwischen Symmachus und Laurentius entstanden sind und zum Teil sogar als legitimierende Texte eine Rolle 
in diesem Konflikt gespielt haben, sollen sie - gemeinsam mit dem symmachianisch-laurentianischen Schisma - erst an späterer Stelle behandelt werden. ${ }^{30}$

\section{1. 1. Damasus und Ursinus}

Unter den Schismen, die während des 4. und 5. Jh. in der römischen Gemeinde ausbrachen, ist das zwischen Damasus und Ursinus zweifellos dasjenige, bei dem die Besetzung städtischer Räume durch die verfeindeten Parteien am genauesten dokumentiert ist. ${ }^{31}$ Der römische Bischof Liberius (352-366) war während seiner Verbannung durch Constantius II. durch seinen eigenen Archidiakon Felix ersetzt worden. Infolge dieser Doppelbesetzung des römischen Bischofssitzes kam es nach der Rückberufung des Liberius im Jahr 358 zu Auseinandersetzungen mit Felix II. (357-365), die möglicherweise erst kurz vor dem Tod des Liberius durch eine Aussöhnung mit den Anhängern Felix' II. und ihre Aufnahme in den Klerus des Liberius beigelegt wurden. ${ }^{32}$ Auf den Tod des Liberius am 24. September 366 folgte eine Doppelwahl, die nur wenige Jahre nach den Konflikten zwischen Liberius und Felix erneut zu einer tiefen Spaltung innerhalb der römischen Gemeinde führte: Zwei Diakone aus dem Klerus des Liberius, Ursinus und Damasus, machten sich gegenseitig den Bischofsrang streitig und mobilisierten ihre Anhänger zu langanhaltenden und blutigen Auseinandersetzungen, die Damasus schließlich für sich entschied.

Anders als im Fall von Liberius und Felix II., wo sich die Überlieferungen $\mathrm{zu}$ den topographischen Aspekten der Auseinandersetzungen vor allem den legendarischen Überformungen einer wesentlich späteren Zeit verdanken, liegen zum Konflikt zwischen Damasus und Ursinus eine ganze Reihe von Angaben vor, die Anhaltspunkte für eine Verortung des Schismas im städtischen und suburbanen Raum liefern. ${ }^{33}$ Aus ihnen lässt sich folgender Ablauf

\footnotetext{
Vgl. u., S. 447-481.

Zum Schisma zwischen Damasus und Ursinus und seinen topographischen Aspekten vgl. Künzle 1961; Lippold 1965, bes. 112-119 u. 122-126; Pietri 1976, Bd. 1, 407-423; Geertman 1986-1987, 76-78; Verrando 1981, 100-102; McLynn 1992, 16-19; de Spirito 1994; Cracco Ruggini 1997, 169-178; Curran 2000, 137-142; Coşkun 2003, bes. 18-27; Lizzi Testa 2004 (a), $129-170$.

32 Dies suggeriert coll. Avell., epist. 1, 4; s. aber auch u., S. $238 \mathrm{f}$.

33 Die wichtigste Quelle für die Ereignisse von 366 bis 368 sind die sogenannten gesta inter Liberium et Felicem episcopos (= coll. Avell., epist. 1), ein von einem Anhänger des Ursinus verfasstes Protestschreiben, das die collectio Avellana eröffnet und vom Kompilator dieser Briefsammlung als eine Art Vorwort zum nachstehenden libellus zweier luciferianischer Kleriker aufgefasst wurde, obwohl sich - abgesehen von der gemeinsamen Feindschaft gegenüber Damasus - keine direkten Verbindungen zwischen Ursinern und Luciferianern nachweisen lassen. Eine Zusammenstellung
} 
der Ereignisse rekonstruieren: Etwa zeitgleich wurden Damasus und Ursinus an unterschiedlichen Orten gewählt und geweiht: ${ }^{34}$ Damasus in Lucinis, der später als titulus Lucinae bekannten Titelkirche, ${ }^{35}$ Liberius in einer basilica Iulii, die höchstwahrscheinlich nicht mit der Titelkirche des Bischofs Iulius (337352) in Trastevere, sondern mit der Basilika zu identifizieren ist, die derselbe Bischof in der Nähe des Trajansforums errichtet hatte. ${ }^{36}$ Während der -

der einschlägigen Quellen und eine sehr ausführliche - wenn auch in zentralen Punkten nicht überzeugende und eher suggestive - Diskussion bei Künzle 1961.

34 Vgl. zum folgenden coll. Avell., epist. 1, 5: tunc presbyteri et diacones Ursinus Amantius et Lupus cum plebe sancta, quae Liberio fidem servaverat in exilio constituto, coeperunt in basilica Iuli procedere et sibi Ursinum diaconum pontificem in loco Liberii ordinare deposcunt; periuri vero in Lucinis Damasum sibi episcopum in loco Felicis expostulant.

35 Lucinis ist von Ferrua 1954 als ein griechischer Genitiv von Lucina erwiesen worden und auf den titulus Lucinae/S. Lorenzo in Lucina zu beziehen, dessen Existenz erstmals in der Unterschriftenliste der römischen Synode von 499 sicher belegt ist (MGH AA XII, 414). In jüngster Zeit hat man die Angabe nicht auf den titulus Lucinae, sondern auf den titulus Marcelli bezogen, der ebenfalls an der via Lata, nur wenige hundert Meter stadteinwärts von der Titelkirche der Lucina entfernt, gelegen ist (so de Spirito 1995, ders. 1996; ebenso Lizzi Testa 2004 [a], 146f.). Grundlage dafür ist die passio Marcelli, nach der die Titelkirche des Marcellus ursprünglich eine domus der Lucina war, die der römische Bischof Marcellus zur Kirche weihte (passio Marcelli 22; davon abhängig LP I, 164). Plausibler ist jedoch die Annahme, dass der Verfasser der passio Marcelli die nicht weit entfernte Titelkirche der Lucina zum Anlass nahm, die Geschichte des titulus Marcelli mit der Matrone Lucina, einer prominenten Figur der römischen Heiligenlegenden (s. u., S. 265f.), in Verbindung zu bringen (so auch Kirsch 1918, 78). Auch die von de Spirito angebotene Erklärung, der titulus Lucinae sei mit einer in der passio Anthimi genannten Lucina in Verbindung zu bringen und um die Wende vom 4. zum 5. Jh. gegründet worden, überzeugt nicht: Die Lucina der passio Anthimi ist eine vergleichsweise späte Hinzufügung, angeregt durch ein in unterschiedlichen römischen Heiligenlegenden begegnendes Motiv (Mara 1964, 21, 73 und u., Anm. 172); ein historischer Wert kann ihr - trotz des Namens von Lucinas Mann, Faltonius Pinianus, der Reminiszenzen an Valerius Pinianus, den Mann Melanias d. J., und an die gens Anicia enthält - in keinem Fall beigemessen werden. An der Identität des damasianischen Wahlortes in Lucinis mit dem titulus Lucinae ist demnach bis auf weiteres festzuhalten. Problematisch ist allerdings, dass das Mauerwerk der frühchristlichen Basilika unter S. Lorenzo in Lucina allgemein erst in die erste Hälfte des 5. Jh. datiert wird (vgl. Krautheimer, in: Corpus II, 175f., 184f.; zuletzt Bertoldi 2003); ob allein das Mauerwerk ein hinreichend sicheres und aussagekräftiges Kriterium darstellt, um eine Datierung des Baus in die Mitte des 4. Jh. definitiv auszuschließen, erscheint jedoch fraglich.

36 Aus dem Catalogus Liberianus im Chronographen von 354 sind 5 Basilikalbauten des Iulius bekannt, von denen sich zwei in der Stadt befinden, eine basilica Iulia, quae est regione VII iuxta forum divi Traiani und eine basilica trans Tiberim regione XIIII iuxta Callistum (MGH AA IX, 76). Unmittelbar bevor der Verfasser der gesta inter Liberium et Felicem auf die Versammlung der Ursinusanhänger in der basilica Iulii zu sprechen kommt, ist in den gesta von einer statio des Felix in Iuli trans Tiberim die Rede (coll. Avell., epist. 1, 3). Daher geht eine Reihe von Forschern davon aus, dass es sich bei der basilica Iuli in c. 5 um dasselbe Gebäude, also die Basilika und spätere Titelkirche des Iulius in Trastevere, handeln müsse (so Lippold 1965, 112f.; Pietri 1976, Bd. 1, 412; Curran 2000, 138 mit - trotz gegenteiliger Versicherungen - denselben Argumenten wie Lippold). Demgegenüber hat man jedoch zurecht geltend gemacht, dass es sich bei den Ortsbezeichnungen in Iuli und in basilica Iuli um zwei unterschiedliche Gebäude handeln müsse (Verrando 1985, 1024-1026; Geertman 1986-1987, 78f.; de Spirito 1994, 264-266; Cracco Ruggini 1997, 170; in der Sache auch schon Künzle 1961, 37-42, allerdings ohne eine sinnvolle Begrün- 
offensichtlich am Wahlort vollzogenen - Weihe des Ursinus versuchte Damasus, gestützt auf eine schlagkräftige Anhängerschaft aus Wagenlenkern, Zirkuspersonal und Katakombenbestattern, ${ }^{37}$ seinen Konkurrenten mit physischer Gewalt auszuschalten, indem er die Ursiner in der basilica Iulii für drei Tage belagerte und dort ein Blutbad unter den Anhängern des Ursinus anrichtete. Seine eigene Weihe ließ Damasus erst sieben Tage nach diesem (vergeblichen) Versuch, sich seines Rivalen zu entledigen, in der Lateranbasilika vornehmen. Auch die Ursiner scheinen ihrerseits in der Zwischenzeit nicht untätig geblieben zu sein, da nach den Worten des Verfassers der gesta inter Liberium et Felicem Damasus die Lateranbasilika mit seinen Anhängern „behauptete“ (tenuit) - vermutlich gegen entsprechende Übergriffe der Ursiner. ${ }^{38}$

Die gewaltsamen Auseinandersetzungen fanden nach der (vermutlich am 8. 10. 366 erfolgten) Weihe des Damasus offenbar eine nahtlose Fortsetzung, da es noch im Oktober 366 zu weiteren Ausschreitungen kam. Allerdings scheinen die Ursiner in der Zwischenzeit einen neuen Standort bezogen zu haben, nämlich die basilica Liberii, die von nun an den Brennpunkt anhaltender Konflikte bildete: An der basilica Liberii, die in den Quellen auch unter dem Namen basilica Sicinini erscheint, ${ }^{39}$ kam es zu mindestens zwei gewaltsamen

dung). Die parallel zu in Iuli auftauchende Wendung in Lucinis signalisiert, dass der Verfasser des Briefes bei bestimmten Kirchengebäuden auf die Bezeichnung ecclesia oder basilica anscheinend bewusst verzichtete, während er bei der basilica Iuli, ebenso wie bei der basilica Liberii und der basilica Lateranensis die Bezeichnung basilica immer anführt. Da kein Grund besteht, c. 3 zu in $<$ basilica $>$ Iuli trans Tiberim zu emendieren, ist davon auszugehen, dass der Verfasser von coll. Avell., epist. 1 hier ein anderes Gebäude im Sinn hatte als bei der basilica Iuli, die konsequenterweise mit der Basilika in der Nähe des Trajansforums identisch sein muss.

37 Damasus' Rückgriff auf bezahlte, gewaltbereite Schlägertrupps aus dem Umfeld der Zirkusparteien und des Bestattungspersonals wird vom Verfasser der gesta an mehreren Stellen seines Berichtes hervorgehoben, vgl. coll. Avell. epist. 1, 5 (quadrigarii), 6 (arenarii), 7 (arenarii, quadrigarii et fossores).

38 Coll. Avell., epist. 1, 5f., bes. 6: post dies septem cum omnibus periuris et arenariis, quos ingenti corrupit pretio, Lateranensem basilicam tenuit. Der Ablauf der Ereignisse nach dem Tod des Liberius am 24. 9. 366 bis zur Weihe des Damasus am 1. 10. oder - wahrscheinlicher - am 8. 10. lässt sich aus diesen Angaben der gesta inter Liberium et Felicem nicht mit letzter Sicherheit rekonstruieren; für einen entsprechenden Versuch vgl. zuletzt Coşkun 2003, 19.

39 Hier., chron. ad. ann. 366 (Helm ${ }^{31984, ~ 244 f .): ~ U r s i n u s ~ a ~ q u i b u s d a m ~ e p i s c o p u s ~ c o n s t i t u t u s ~ S i c i n i n u m ~ c u m ~}$ suis invadit, ähnlich vermeidet auch Rufin., hist. 11, 10, jegliche Bezugnahme auf die Gründung der Basilika durch Liberius und verwendet, wie Hieronymus, eine profane Verwaltungsbezeichnung (Ursinus quidam... collecta turbulentorum et seditiosorum manu in basilica quae Sicinini appellatur episcopum se fieri extorqueret). Dass es sich bei der Bezeichnung basilica Sicinini um einen Ausdruck der Verwaltungssprache handelt, legt Ammianus Marcellinus nahe, der die innergemeindlichen Auseinandersetzungen aus der Perspektive der städtischen Verwaltungsorgane darstellt und das Bauwerk ebenfalls basilica Sicinini nennt (Amm. 27, 3, 13). Nicht hinreichend berücksichtigt wird dieser Umstand von Lippold 1965, 122-126, Coşkun 2003, 23-26, die die basilica Liberii und die basilica Sicinini für Bezeichnungen für unterschiedliche Bauwerke halten. Für eine Gleichsetzung der basilica Liberii mit der basilica Sicinini spricht insbesondere der Umstand, dass die Anhängerschaft des Ursinus, die für die Zeit zwischen September und November 367 eine zwischenzeitliche Rückkehr des Ursinus erwirken konnte, sich zuvor beständig in der basilica Liberii versam- 
Zusammenstößen, bei denen jeweils mehr als 100 Menschen ihr Leben ließen. ${ }^{40}$

Die anhaltende Bedeutung der basilica Liberii als Zentrum der Auseinandersetzungen wird auch aus den Ereignissen der Folgezeit ersichtlich. Nach der Verbannung des Ursinus im Oktober 366 kamen seine Anhänger weiterhin in der basilica Liberii zusammen, um Vorwürfe gegen Damasus zu erheben und die Rückberufung ihres Kandidaten zu erwirken. ${ }^{41}$ Die Proteste hatten Erfolg: Ursinus erhielt ein knappes Jahr nach seiner Verbannung die Erlaubnis, nach Rom zurückzukehren und traf am 15. 9. 367 erneut in Rom ein. ${ }^{42}$ Nach der Rückkehr des Ursinus flammten die alten Konflikte sofort wieder auf, und obwohl Ursinus schon bald nach der Aufhebung seiner Verbannung am 16. 11. 367 erneut der Stadt verwiesen wurde, ${ }^{43}$ blieb die Lage zwischen den verfeindeten Lagern auch weiterhin angespannt. Als Reaktion darauf erging zwischen November 367 und Januar 368 ein kaiserlicher Befehl an den praefectus urbi Praetextatus, der angewiesen wurde, Damasus den Zu-

melt hatte, um dieses Ziel zu erreichen, und kurz nach der zweiten Verbannung des Ursinus die basilica Sicinini als letzte von den dissentientes noch gehaltene Kirche räumen musste (s. u. Anm. 44). Auch die Nachrichten zu den Auseinandersetzungen des Oktober 366 lassen sich so folgerichtig zu einem Konflikt um die basilica Liberii/Sicinini verbinden, dass man von einer unzulässigen Harmonisierung der Quellen nicht sprechen kann. Die Identität von basilica Liberii und basilica Sicinini/Sicininum gilt dementsprechend mittlerweile als communis opinio der Forschung (vgl. zuletzt Saxer 2001, 26 u. die von Coşkun 2003, 24, Anm. 23 aufgeführte Literatur); ältere Auffassungen hatten das Sicininum mit einer Gegend in Trastevere gleichgesetzt und auf die Ortsangabe auf die dortige basilica Iulii bezogen (vgl. Ferrua 1938 [b], 55-61).

40 Vgl. Lippold 1965, 122-126, der aus den Angaben bei Ammianus Marcellinus und Hieronymus auf der einen Seite und dem Schreiben der Ursiner auf der anderen Seite zwischen zwei unterschiedlichen Konflikten im Oktober 366 differenziert: Vor der Verbannung des Ursinus stürmten die Ursiner gewaltsam die basilica Sicinini/Liberii und brachten sie unter ihre Kontrolle (Hier., chron. ad ann. 366 [Helm ${ }^{31984,244 f .]: ~ U r s i n u s . . . ~ S i c i n i n u m ~ c u m ~ s u i s ~ i n v a d i t, ~ q u o ~ D a m a s i a n a e ~ p a r t i s ~}$ populo confluente crudelissimae interfectiones diversi sexus perpetratae; vgl. Amm. 27, 3, 12f.). Nach der Verbannung des Ursinus, am 26. Oktober 366, wendeten die Anhänger des Damasus ihrerseits Gewalt an, um sich erneut in den Besitz des Gebäudes zu setzen (coll. Avell., epist. 1, 7: tunc Damasus cum perfidis invitat arenarios quadrigarios et fossores omnemque clerum cum securibus gladiis et fustibus et obsedit basilicam hora diei secunda septimo Kalendarum Novembrium... et grave proelium concitavit.). Lippolds Auffassung, bei diesen Nachrichten handele es sich nicht um die Darstellung derselben Auseinandersetzung aus unterschiedlicher Perspektive, sondern um zwei unterschiedliche Zusammenstöße, ist überzeugend; allerdings fasst Lippold die basilica Liberii und die basilica Sicinini als unterschiedliche Gebäude auf, obwohl es sich nur um zwei Bezeichnungen für dasselbe Bauwerk handelt (vgl. die vorige Anm.): Beide Auseinandersetzungen im Oktober 366 fanden demnach in der Basilika des Liberius auf dem Esquilin statt.

41 Der Verfasser der gesta inter Liberium et Felicem hebt hervor, dass die Gemeinde sich nach den Konflikten vom Herbst 366 regelmäßig (saepe) in der Liberiusbasilika versammelt und bei diesen Gelegenheiten eine Verurteilung des Damasus und die Rückberufung des Ursinus gefordert habe (Coll. Avell., epist. 1, 9).

42 Vgl. coll. Avell., epist. 1, 10 (Rückkehr in die Stadt am 15. September 367); epist. 5 (Anweisung der Kaiser an den praefectus urbi, Praetextatus, die Ursiner wieder in die Stadt zu lassen).

43 Coll. Avell., epist. 1, 11. 
gang zur basilica Sicinini (= Liberii) als der letzten Kirche, die den Anhängern des Ursinus noch verblieben war, zu öffnen. ${ }^{44}$ Der Umstand, dass die basilica Liberii im Winter 367/368 die letzte Bastion der Ursiner in Rom war, bestätigt die Bedeutung, die sie bereits im Herbst 366 und während der Verbannung des Ursinus als Zentrum seiner Anhänger gebildet hatte.

Die auch nach der Übereignung der basilica Liberii an Damasus unverändert anhaltenden Spannungen führten schließlich dazu, dass am 12. Januar 368 auch der Klerus und die Anhänger (socii ac ministri) des Ursinus ihrem Prätendenten folgen und ebenfalls die Stadt verlassen mussten. ${ }^{45}$ Damit verloren die Ursiner die Möglichkeit, sich in der Stadt zu versammeln und wichen auf die Coemeterien aus, wo sie Versammlungen ohne ihre Kleriker abhielten. ${ }^{46}$ Dies hatte offenkundig eine dauerhafte Verlagerung der Schauplätze des Konfliktes aus der Stadt in das Suburbium zur Folge: Zu einem nicht genauer bestimmbaren Zeitpunkt nach der Verbannung des Ursinus kam es bei S. Agnese erneut zu einem blutigen Zusammenstoß zwischen den Ursinern und den Anhängern des Damasus. ${ }^{47}$ Dass sich die

44 Coll. Avell., epist. 6. In dem kaiserlichen Mandat selbst ist nur unbestimmt von una ecclesia die Rede, die den abtrünnigen Ursinern noch gehörte. Die Identifizierung dieser Kirche mit der basilica Sicinini erfolgt nur durch die Überschrift ubi redditur basilica Sicinini, doch besteht kein Anlass, die Richtigkeit dieser Angabe zu bezweifeln. Der Hinweis auf die basilica Sicinini dürfte - ähnlich wie vergleichbare Briefüberschriften mit kurzen Inhaltsangaben (u. a. zu coll. Avell., epist. 3: de constructione basilicae sancti apostoli Pauli) - nicht erst auf das Konto des Kompilators der collectio Avellana bzw. einer Vorgängersammlung gehen, sondern bereits bei der Archivierung der Schreiben im officium der Stadtpräfektur, aus dem das Avellana-Dossier ausgezogen wurde, eingetragen worden sein (so auch Günther 1896, 3-27, bes. 17f.). Wenig überzeugend ist demgegenüber die zuletzt von Curran 2000, 141; Coşkun 2003, 26, geäußerte Ansicht, erst der Kompilator der collectio Avellana habe die Information des Schreibens mit externen Quellennachrichten (aus Hieronymus oder Rufin) kombiniert und auf diese Weise eine Identifizierung mit der basilica Sicinini vorgenommen (so auch schon Lippold 1966, 124). - Die kaiserliche Anweisung zur Restitution der basilica Sicinini/Liberii ist nicht datiert, setzt jedoch die am 16. November 367 erfolgte Ausweisung des Ursinus bereits voraus (coll. Avell., epist. 6, 1: dissensionis auctore sublato) und ist im Dossier der collectio Avellana, deren epistulae 5-13 einer chronologischen Ordnung folgen, unmittelbar vor einem Schreiben vom 12. Januar (coll. Avell., epist. 7) plaziert worden; eine nähere zeitliche Eingrenzung ist nicht möglich.

45 Coll. Avell., epist. 7 (Anweisung der Kaiser an den Stadtpräfekten Praetextatus vom 12. Januar 368).

46 Coll. Avell., epist. 1, 12: populus timens Deum... per coemeteria martyrum stationes sine clericis celebrabat.

47 Coll. Avell., epist. 1, 12. Sághy 2000, 280, legt die Vorgänge in den November des Jahres 366 (!); Künzle 1961, 18, grenzt den Vorfall auf den Zeitraum zwischen Dezember 367 (Verbannung des Ursinus) und Januar 368 (Verbannung des ursinischen Klerus) ein. Da jedoch in coll. Avell., epist. 1,12 , ausdrücklich von Versammlungen der Ursinusanhänger die Rede ist, die ohne ihren Klerus stattfinden mussten, wird man den Zusammenstoß in die Zeit nach Januar 368 datieren müssen. Die in der folgenden Anmerkung genannten Maßnahmen der Kaiser vom Herbst 368 sind eine Reaktion auf Auseinandersetzungen wie die bei S. Agnese. Der in den gesta erwähnte Vorfall dürfte daher in der Zeit zwischen Januar und Oktober 368 erfolgt sein; zu der Annahme, die Ursiner hätten sich an einem Jahrestag der Heiligen Agnes (dem 21. Januar) versammelt, was eine Datierung in das Jahr 369 zur Folge hätte (so Lizzi Testa 2004 [a], 165), besteht kein Anlass. 
Präsenz der Ursinusanhänger und die dadurch ausgelösten Unruhen seit dieser Zeit vor allem auf das außerhalb der Stadtmauern gelegene Umfeld Roms konzentrierten, wird auch daraus ersichtlich, dass die Kaiser Valentinian I., Valens und Gratian gegen Ende des Jahres 368 den Stadtpräfekten und den vicarius urbis instruierten, Versammlungen der Ursiner innerhalb des zwanzigsten Meilensteins zu verbieten ${ }^{48}$ - eine ungewöhnliche Begrenzung, da (auch nach der tetrarchischen Neuorganisation Italiens) der hundertste Meilenstein als traditionelle Verwaltungsgrenze des römischen Stadtgebietes fungierte. ${ }^{49}$ Dies macht deutlich, dass es den Kaisern hier um eine Kontrolle der in der Umgebung Roms gelegenen Coemeterien ging: Der Distrikt mit Märtyrern, die im römischen Heiligenkalender kommemoriert wurden, reichte nicht über die zwanzigste Meile vor der Stadt hinaus. ${ }^{50}$

Soweit das Gerüst der Handlungsabläufe aus den Anfangsjahren dieses Schismas, das sich zwar auch nach der Ausweisung des Ursinus über die gesamte Dauer von Damasus' Pontifikat hinzog, ${ }^{51}$ jedoch für die Zeit nach 368 in seinen räumlichen Ausprägungen nicht mehr näher zu erfassen ist. Bezogen auf die Frage nach der identitätsstiftenden Bedeutung von Räumen und Orten der Heiligenmemoria für die Bildung schismatischer Gruppen lassen sich die Vorgänge seit dem Herbst 366 zu folgenden Beobachtungen verbinden:

1. Die Märtyrertopographie im Suburbium Roms spielte für die Positionierung der schismatischen Anhängerschaften allenfalls eine zweitrangige Rolle. Für beide Parteien - Ursiner wie Damasianer - war es in erster Linie

48 In coll. Avell., epist. 8f. reagierten die Kaiser auf eine Anzeige des vicarius urbis, wonach die Ursiner in Versammlungen außerhalb der Stadtmauern häufig Unruhen erregten (epist. 8, 1: extramuranisque conventibus frequens strepitus excitatur), und verfügten ein Versammlungsverbot der Ursiner zu religiösen Zwecken innerhalb des 20. Meilensteins (coll. Avell., epist. 8, 2 und 9, 1, gerichtet an den PUR Olybrius und den vicarius Aginatius; zur Datierung der Schreiben [Oktober/November 368] vgl. Lizzi Testa 2004 [a], 163).

49 Chastagnol 1960, 25, 179, 387 u. passim. Dass die urbs und die suburbicariae regiones bis zum 100. Meilenstein reichten, geht auch aus einer Ende 370/Anfang 371 erlassenen Verfügung hervor, wonach das Exil des Ursinus, der am 12. 1. 386 an einen Ort in Gallien verbannt worden war, dadurch gelockert wurde, dass ihm Freizügigkeit gewährt wurde, wovon jedoch Rom und die zur Stadt gehörige Region ausgenommen blieb (coll. Avell., epist. 11, 2; 12, 2; für die Reichweite der Stadt ad centesimum miliarium vgl. 13, 2).

$50 \quad$ Vgl. Kirsch 1924, 188-218.

51 Angeblich auf Initiative der Ursiner hin strengte ein Jude namens Isaak (vermutlich 371/2 oder 373) einen erfolglosen Kriminalprozess gegen Damasus an, was eine römische Synode im Jahr 378 dazu veranlasste, ein Petitum an die Kaiser zu richten, um in Zukunft ein Gericht über den Bischof von Rom ohne die Beteiligung einer Synode (als alleinige Entscheidungsinstanz oder als consilium principis) auszuschließen (vgl. die synodale relatio ad Gratianum et Valentinianum imperatores 8-11 [CSEL 82, 3, S. 195-197] und die Antwort der Kaiser in Coll. Avell., epist. 13, 9-14). Kurz vor 381 agitierte ein Ursiner namens Paschasius in Rom (vgl. das Schreiben der Synode von Aquileia [381] = Ambr., epist. extr. coll. 5 (11), 5f. [CSEL 82, 3, S. 185]). Zu den Vorgängen vgl. Pietri 1976, Bd. 1, 420-423; Girardet 1994, 16-22. 
von Bedeutung, innerhalb der Stadt ein Zentrum zu besetzen, in dem der jeweilige Kandidat seinen Anspruch darauf, Bischof der römischen Gemeinde zu sein, untermauern konnte: Damasus brachte nach dem vergeblichen Versuch, Ursinus direkt auszuschalten, den Lateran unter seine Kontrolle; die Ursiner setzten dieser Besetzung der von Konstantin gestifteten Bischofskirche mit der basilica Liberii ein Zentrum entgegen, das über einen vergleichbaren Rang als Bischofskirche verfügt zu haben scheint, ${ }^{52}$ und das vom Beginn der Auseinandersetzungen im Herbst 366 bis zur endgültigen Verbannung des ursinischen Klerus im Jahr 368 den zentralen Bezugspunkt der ursinischen Gemeinde bildete. Erst nachdem die Ursiner ihre Position innerhalb der Stadt infolge der zweiten Verbannung des Ursinus und seines Klerus endgültig hatten räumen müssen - also nach dem Januar 368 - begann sich ihr Augenmerk verstärkt auf die Coemeterien außerhalb der Mauern zu richten, in denen sie nun, ihres Klerus beraubt, Zusammenkünfte organisierten. ${ }^{53}$ Verglichen mit der Möglichkeit, kirchliche Versammlungsräume innerhalb der Stadtmauern zu besetzen, erscheint diese Konzentration der Ursiner auf die Coemeterien eindeutig als eine schlechtere Alternative, die nicht von vornherein gezielt angestrebt wurde, sondern erst in Betracht kam, nachdem man aus der Stadt verdrängt worden war. Dies lässt sich zu der Hypothese zuspitzen, dass die Coemeterial- und Heiligentopographie im Suburbium Roms aufgrund ihrer Randlage denkbar ungeeignet war, als symbolischer Bezugspunkt für die Legitimation eines Anwärters auf den römischen Bischofsthron zu dienen: Wichtiger als die durch die Grablegen der Heiligen und der Apostel vermittelten Traditions- und Erinnerungsbezüge war offenbar das legitimatorische Leitbild von der gemeindebezogenen Aufgabe des Bischofs, der Hirt seiner bischöflichen Herde zu sein - und dieser Anspruch ließ sich in einer Coemeterialbasilika außerhalb der Stadtmauern nicht glaubhaft aufrechterhalten.

2. Auch für die Besetzung der Räume innerhalb der Stadt scheinen legitimatorische Erinnerungsbezüge auf den bischöflichen Vorgänger, Liberius, keine vorrangige Bedeutung gehabt zu haben. ${ }^{54}$ Die Anhänger des Damasus sicherten nach der Wahl ihres Kandidaten zum Bischof zuerst die Lateranbasilika, um dort die Bischofsweihe vornehmen zu lassen. Auch die Ursiner, die sich explizit in die Tradition des Liberius stellten und dies als ein

\footnotetext{
Vgl. dazu auch u., S. 232-234.

53 Eine besondere Ausrichtung der Ursiner auf bestimmte Heilige oder Regionen in der Zeit seit Jahresbeginn 368 lässt sich dabei angesichts der schmalen Quellenlage nicht ausmachen. Anders Sághy 2000, 280f., die aus einer vereinzelten Nachricht - dem Zusammenstoß zwischen Ursinern und Damasianern bei S. Agnese - darauf schließen möchte, dass die Ursiner sich vorzugsweise in Mausoleen und Coemeterialbasiliken, die von der kaiserlichen Familie errichtet wurden, versammelt und dort Schutz gesucht hätten.

54 So aber - mit Blick auf die Ursiner - Pietri 1976, Bd. 1, 413, Anm. 6; Curran 2000, 140-142.
} 
zentrales Argument für die Rechtmäßigkeit der Ansprüche, die Ursinus auf den römischen Bischofsthron erhob, geltend machten, führten die Wahl und Weihe ihres Kandidaten in der basilica Iulii am Trajansforum durch, während die basilica Liberii erst später in den Brennpunkt der Konflikte rückte. Auch wenn über die Architektur und Ausdehnung der basilica Liberii nichts sicheres bekannt ist, liegt die Vermutung nahe, dass die Anhänger des Ursinus sich mit der Basilika auf dem Esquilin vor allem ein Gebäude sichern wollten, das in seinem Rang mit der Lateranbasilika konkurrieren und dem Anspruch des Ursinus, als Bischof an der Spitze einer Gemeinde zu stehen, Ausdruck verleihen konnte. ${ }^{55}$ Symbolische Bezugnahmen auf Liberius, die auch beim unmittelbaren Ausbruch des Schismas nicht handlungsleitend gewesen waren, erscheinen demgegenüber sekundär.

Offensichtlich haben demnach Versuche der beiden Protagonisten, die eigene Position durch die Besetzung von Orten mit Traditionsbezügen zu legitimieren, die im Heiligengedenken oder der Erinnerung an den bischöflichen Vorgänger bestanden, keine bestimmende Rolle gespielt. Auch sonst scheint das Handeln der Akteure auf den ersten Blick nicht darauf hinzudeuten, dass mit der Besetzung bestimmter Sakralräume auch symbolische und legitimierende Funktionen verbunden waren, sondern rein pragmatischen Motiven zu folgen. In der Forschung ist dies vor allem mit Blick auf die Frage eines möglichen Weiheortes betont worden: Weder das Verhalten der Protagonisten noch die Bewertung des ursinischen Verfassers der gesta inter Liberium et Felicem lasse die Vorstellung von einem traditionsgestützten, legitimierenden Weiheort erkennen; insbesondere lasse sich der Lateranbasilika keine derartige Funktion zuweisen. ${ }^{56}$ Dieser Hinweis ist zwar berechtigt, jedoch wenig aussagekräftig, da er sich zu sehr auf einen einzelnen Ort und punktuellen Akt - die Bischofsweihe - konzentriert. ${ }^{57}$ Im Verlauf des Schismas zwischen Ursinus und Damasus wird aber durchaus mehr sichtbar als nur ein reiner Pragmatismus in der Besetzung von Sakralräumen, der ganz ohne Bezugnahme

$55 \quad$ Zur Gleichrangigkeit der basilica Liberii und der Lateranbasilika, die beide bischöfliche Basiliken waren, s. u., S. 233. Möglicherweise waren auch Größe und Lage der basilica Liberii von ausschlaggebender Bedeutung. In jüngster Zeit wurde mehrfach die Vermutung geäußert, dass die basilica Liberii als Vorgängerbau von S. Maria Maggiore eine ähnliche Dimension wie die unter Sixtus III. (432-440) errichtete Marienbasilika gehabt habe (so zuletzt Saxer 2001, 26-29). Mit diesen räumlichen Dimensionen und ihrer Lokalisierung in einem der am dichtesten besiedelten Gebiete der Stadt erfüllte die basilica Liberii ideale Voraussetzungen, um als symbolisches Gemeindezentrum mit dem Lateran zu konkurrieren.

56 So Lippold 1965, 119; auch mit Blick auf die übrigen Schismen des 4. bis 6. Jh. betont von Wirbelauer 1993, 14, dems. 1994, bes. 437. Die Rekonstruktion von Künzle 1961, 41f., wonach die Damasusanhänger die Ursiner in der basilica Iulii deswegen belagert hätten, um selbst ungehinderten Zugang zum Lateran zu erhalten und ihrerseits den Ursinern den Weg zur Lateranbasilika als dem regulären Weiheort zu versperren (ähnlich Verrando 1985, 1025), legt mehr in den Text hinein, als er hergibt.

$57 \quad$ Vgl. dazu auch u., S. 244-250. 
auf deren Semantik erfolgt wäre. Verständlich wird dies, wenn man den Blick nicht allein auf die Lateranbasilika als die Bischofskirche Roms richtet, sondern die beginnende Ausdifferenzierung der städtischen Sakraltopographie in Bischofskirchen und presbyterale Titelkirchen in die Überlegungen mit einbezieht.

Den entscheidenden Hinweis in dieser Richtung hat Herman Geertman gegeben, ${ }^{58}$ der erkannt hat, dass in der Terminologie, die der Verfasser gesta inter Liberium et Felicem für die Bezeichnung von Kultgebäuden verwendet, eine liturgische Funktionsteilung der christlichen Sakraltopographie Roms in bischöfliche Patriarchal- und presbyterale Titelkirchen erkennbar wird, die seit dem 5. Jh. die Grundlage für die Organisation einer bischöflichen Stationsliturgie bildete und die Sakraltopographie des städtischen Raums strukturierte und hierarchisierte. Während der österlichen Fastenzeit und anderer liturgischer Zeiten des Kirchenjahres (Weihnachten, Oster- und Pfingstwoche, Quatembertage) feierte der römische Bischof in bischöflichen Kirchen, die sich gleichmäßig auf den städtischen Raum (Lateranbasilika, S. Maria Maggiore, basilica apostolorum, S. Stefano Rotondo) und das Suburbium (S. Pietro in Vaticano, S. Paolo f.l.m., S. Lorenzo f.l.m.) verteilten, die sonn- und feiertäglichen Gottesdienste, wohingegen den Titelkirchen nur die bischöfliche Feier der Wochentage während der österlichen Fastenzeit vorbehalten blieb. ${ }^{59}$ Diese Stationsliturgie ist in ihrer entwickelten Form nicht vor dem zweiten Viertel des 5. Jh. nachweisbar und trug erst in dieser Zeit mit dazu bei, dass die traditionelle Abgrenzung zwischen Stadt und Suburbium durch eine neue Raumwahrnehmung, in der eine Vielzahl punktueller, miteinander verbundener Zentren dominierte, relativiert wurde. ${ }^{60}$ Die dafür charakteristische intensive Vernetzung dieser liturgischen Zentren, wie sie für die entwickelte Stationsliturgie des 5. Jh. kennzeichnend ist, kann für die Zeit des 4. Jh. noch nicht vorausgesetzt werden. Dies gilt jedoch nicht für die Differenzierung von Titel- und Bischofskirchen, die ein wesentliches Strukturelement der bischöflichen Stationsliturgie bildete. Vielmehr besteht aller Grund zu der Annahme, dass sich bereits im 4. Jh. neben der Lateranbasilika zwei weitere

$58 \quad$ Vgl. Geertman 1986-1987, bes. 76-78.

59 Zum Stationskirchensystem in Rom grundlegend Baldovin 1987, 105-166; zusammenfassend Saxer 1989, 938-952.

60 Vgl. dazu, u., S. 408-413. Anders als die Funktionsteilung zwischen bischöflichen und presbyteralen Kirchen, die sich bereits seit konstantinischer Zeit entwickelte, war die Stationsliturgie, die eine symbolische Vernetzung zwischen den liturgischen Zentren der Bischofs- und (in geringerem Maße auch der) Titelkirchen herstellte, im 4. Jh. noch nicht sehr ausgeprägt. Einzig die viermal im Jahr gefeierten Quatembertage dürften schon im 4. Jh. in derselben Form einer stationalen Liturgie begangen worden sein, wie sie auch in den liturgiegeschichtlichen Quellen für die Zeit ab der zweiten Hälfte des 5. Jh. bezeugt ist (vgl. Geertman 1986-1987, 69f., Verstrepen 1993). Bei den Herrenfesten kam es erst seit dem ausgehenden 5. Jh. zur Entfaltung einer Stationsliturgie, vgl. Baldovin 1987, 149 f. (österliche Fastenzeit); ebd. 157 (Advent und Weihnachten). 
Kirchen in Rom befanden, die im Unterschied zu den Titelkirchen, die der Leitung von Presbytern unterstanden, unmittelbar dem römischen Bischof zugeordnet waren. Dabei handelt es sich um die von Bischof Iulius (337-352) gegründete basilica Iulii iuxta forum Traiani - ein an einer der wichtigsten Verkehrsachsen des Marsfeldes, der via Lata, errichteter Bau, der um 560 durch die basilica apostolorum Philippi et Iacobi (SS. Apostoli) ersetzt wurde ${ }^{61}$ - und die unter seinem Nachfolger Liberius (352-366) errichtete basilica Liberii, die einen Vorgängerbau der später unter Sixtus III. errichten basilica sanctae Mariae (S. Maria Maggiore) bildete. ${ }^{62} \mathrm{Da}$ die basilica Iulii und S. Maria Maggiore in den Quellen zur Stationsliturgie des 5. Jh. als bischöfliche Kirchen erscheinen, liegt die Schlussfolgerung nahe, dass auch ihre Vorgängerbauten im 4. Jh. einen solchen Status hatten und nicht als Titelkirchen gegründet worden waren. ${ }^{63}$

Hinzu kommt, dass auch die gesta inter Liberium et Felicem eine Differenzierung zwischen den bischöflichen und den presbyteralen Kirchen Roms erkennen lassen. Von den fünf Kirchen Roms, die der Verfasser der gesta in seinem Bericht erwähnt, belegt er nur die Lateranbasilika, die basilica Iulii beim Trajansforum und die basilica Liberii mit dem Attribut basilica, während bei den Titelkirchen des Iulius in Trastevere und der Lucina im nördlichen Marsfeld ein entsprechender Hinweis unterbleibt und nur die Namen ihrer Gründer im Genitiv erscheinen (in Iuli, in Lucinis). Diese Sprachregelung ist in der älteren Forschung als ein Versuch des ursinischen Verfassers der gesta gedeutet worden, die Verbindung der Ursiner zu Sakralbauten hervorzuheben, indem er sie als basilica bezeichnete und damit ausdrücklich als nichtprofane Bauwerke kennzeichnete (basilica Iulii, basilica Liberii), während den Räumlich-

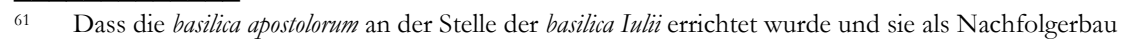
ablöste, lässt sich nicht durch archäologische Hinweise erhärten, kann jedoch aufgrund der ähnlichen Lage der beiden Bauten und ihrer identischen Funktion als Bischofskirchen als so gut wie sicher gelten (vgl. Geertman 1986-1987, 68f.; Pietri 1989, 1040f.).

62 Auch dafür fehlen eindeutige archäologische Hinweise, doch wird mittlerweile allgemein angenommen, dass die Basilika S. Maria Maggiore unter Sixtus III. (432-440) an der Stelle der früheren basilica Liberii errichtet wurde (vgl. zuletzt Geertman 1986-1987, 69; Saxer 2001, 26-29).

63 Zu den Indizien dafür, dass eine Funktionsteilung zwischen den presbyteralen Titelkirchen, der Bischofskirche innerhalb der Stadt und den Coemeterialbasiliken im Suburbium bereits in konstantinischer Zeit begründet wurde, vgl. u., S. 333, Anm. 8. Durch die Gründung der basilica Iulii iuxta forum divi Traiani fügte Bischof Iulius (337-352) der Lateranbasilika eine weitere Bischofskirche hinzu, während die in Trastevere errichtete basilica Iulii iuxta Callistum den Status einer Titelkirche erhielt, den sie auch im 5. Jh. innehatte (die Gründungsnotiz im Catalogus Liberianus [MGH AA IX, 76] bezeichnet diese beiden Bauten und drei weitere, die Iulius im Suburbium errichten ließ, unterschiedslos als basilicae, ohne die administrative Differenzierung zu berücksichtigen [vgl. auch o., S. 167, Anm. 330]); Liberius erweiterte dieses Ensemble mit der basilica Liberii noch um eine dritte Bischofskirche. - Anders M. Cecchelli 1985, 297f., Pietri 1989, 1040f. mit Anm. 10, die davon ausgehen, dass es im 4. Jh. neben der Lateranbasilika keine weiteren Bischofskirchen in Rom gegeben habe und die basilica Iulii iuxta forum Traiani und die Liberiusbasilika sich in ihrem Status nicht von den Titelkirchen der Stadt unterschieden hätten. 
keiten, in denen Damasus und Felix II. agierten (in Iuli, in Lucinis), eine dementsprechende Kennzeichnung als sakrale Bauten gezielt verweigert worden sei. ${ }^{64}$ Abgesehen davon, dass diese Zuordnung jedoch nicht völlig aufgeht, da Damasus in der basilica Lateranensis zum Bischof geweiht wurde, liegt es näher, die Terminologie der gesta mit ihrer seit dem 5. Jh. explizit bezeugten Eigenschaft als Bischofs- bzw. Titelkirchen in Verbindung zu bringen: Was der ursinische Verfasser der gesta mit seiner Sprachregelung zum Ausdruck brachte, war keine polemische Verschleierung des Umstandes, dass auch die Anhänger von Felix II. und Damasus in Kirchengebäuden zusammengekommen waren, ${ }^{65}$ sondern eine rein deskriptive Differenzierung zwischen bischöflichen und presbyteralen Kirchen in Rom.

Vor dem Hintergrund dieser Ausdifferenzierung der römischen Sakraltopographie stellt sich erneut die Frage, inwieweit die topographischen Angaben zum Schisma zwischen Ursinus und Damasus Rückschlüsse auf räumlich vermittelte Legitimierungsstrategien der beiden Protagonisten und auf die Struktur ihrer jeweiligen Anhängerschaften zulassen. Vor allem die letzte Frage ist in der jüngeren Forschung wiederholt thematisiert worden. So begegnet man verschiedentlich der Ansicht, die jeweiligen Anhängerschaften des Ursinus und des Damasus hätten sich in einen diakonalen, sich auf die Patriarchalbasiliken Roms konzentrierenden Bischofsklerus auf der einen sowie in einen überwiegend presbyteralen Klerus auf der anderen Seite geteilt, der in den zumeist aus aristokratischen domus hervorgegangenen Titelkirchen agiert und eine größere Nähe zum senatorischen Establishment aufgewiesen habe. ${ }^{66}$ Grundlage für diese Hypothese ist die Darstellung der gesta inter Liberium et Felicem, wonach die Anhänger des Damasus in der Titelkirche der Lucina ihren Kandidaten als Nachfolger des Felix (in loco Felicis) zum Bischof gewählt hätten - also des im August 358 bei der Rückkehr von Liberius aus der Stadt vertriebenen Gegenbischofs, von dem die gesta berichten, er habe sich auf Drängen des während seines Exils von Liberius abgefallenen Klerus nochmals nach Rom begeben und für kurze Zeit in der Titelkirche des Iulius in Trastevere (in Iuli) Quartier bezogen, bevor er erneut aus der Stadt weichen musste. ${ }^{67}$ Die Verbindungen von Damasus und dem felicianischen Klerus, der nach der Darstellung der gesta im Schisma von 366 Damasus unterstützte,

64 Zu dieser vermeintlichen „rhetorischen Strategie“ vgl. Pietri 1976, Bd. 1, 411.

65 Diese polemische Tendenz des Verfassers der gesta inter Liberium et Felicem wird übersehen von Geertman 1986-1987, 78, der von „umgangssprachlichen Bezeichnungen“ ausgeht, ebenso von de Spirito 1994, 266f.

66 Vgl. de Spirito 1994, 269-273; ähnlich Cracco Ruggini 1997, 170-178, die neben dem strukturellen Gegensatz von Bischofs- und Titelkirchen vor allem die regionalen Verbindungen des Damasus mit Trastevere hervorhebt (vgl. u., Anm. 68).

67 Coll. Avell., epist. 1, 3: Felix notatus a senatu vel populo de urbe propellitur. et post parum temporis impulsu clericorum, qui peiuraverant, inrumpit in urbem et stationem in Iuli trans Tiberim dare praesumit und 1, 5: periuri vero in Lucinis Damasum sibi episcopum in loco Felicis expostulant. 
mit den beiden Titelkirchen des Iulius und der Lucina hat Lellia Cracco Ruggini zu weitreichenden Schlussfolgerungen bezüglich der sozialen Struktur und der Lokalisierung der damasianischen Anhängerschaft veranlasst: Während Ursinus in den bischöflichen Basiliken, der basilica Iulii und der basilica Liberii, nur auf die Unterstützung der Gemeinde, der plebs sancta, habe zählen können, sei Damasus - vermittelt durch seinen starken Rückhalt im Titelklerus - die Unterstützung der römischen Aristokratie sicher gewesen, die ihre Klientelen (Wagenlenker, Zirkuspersonal) für Damasus mobilisiert habe und deren Einfluss in der Region Trastevere, in der Cracco Ruggini ein „Epizentrum“ der Anhängerschaft des Damasus ausmacht, besonders ausgeprägt gewesen sei. ${ }^{68}$

Diese Deutung kann jedoch - abgesehen davon, dass sie zum Teil auf Behauptungen ohne sachliche Grundlage basiert ${ }^{69}$ - nicht erklären, warum die vermeintliche Konstellation aus Titelklerus und Senatsaristokratie im Herbst 358 wirkungslos blieb, als Felix II. nach der Rückkehr des Liberius rasch dem Druck weichen musste und nach nur kurzem Widerstand seine Ansprüche auf das römische Bischofsamt fallen ließ, ${ }^{70}$ wohingegen sein „Nachfolger“ Damasus nur acht Jahre später - angeblich gestützt auf dieselben Voraussetzungen - sich gegen seinen Konkurrenten durchzusetzen vermochte. Auch lässt sich eine besonders enge Verbindung des Felix zur Senatsaristokratie nicht ausmachen. Vielmehr war es nach dem übereinstimmenden Zeugnis unterschiedlicher Quellen sein Gegenspieler Liberius, der mit der senatorischen Oberschicht auf besonders vertrautem

68 Cracco Ruggini 1997, 170-178; dies. 2003, 373-376.

69 Dies gilt vor allem für die von Cracco Ruggini postulierte Existenz eines felicianisch-damasianischen „Epizentrums“ in Trastevere. So gibt es keinerlei Anhaltspunkt dafür, dass Felix II. in der Titelkirche des Iulius in Trastevere zum Bischof gewählt wurde (Cracco Ruggini 1997, 170, Anm. 44). Auch die - nicht weiter begründete - Identifizierung des Ortes in Lucinis, wo Damasus gewählt wurde, mit „einer einfachen Titelkirche in Trastevere“ (ebd., 171) anstatt mit der Titelkirche der Lucina an der via Lata ist kaum nachvollziehbar; offensichtlich beruht diese Lokalisierung auf einer wörtlichen Interpretation der Nachricht, die Anhänger des Damasus hätten ihn in loco Felicis zum Bischof wählen wollen (coll. Avell., epist. 1, 5), obwohl in loco hier eindeutig in einem übertragenen Sinne (,anstelle, in der Nachfolge von“) zu verstehen ist (vgl. dazu Maccarrone 1991, 275f.). Die Hinweise auf ein Zentrum in Trastevere beschränken sich damit auf die Bemerkung des Verfassers der gesta, Felix II. habe sich im Herbst 358 für kurze Zeit in der Titelkirche des Iulius in Trastevere aufgehalten - eine isolierte Information, die zudem mit Blick auf Damasus und seine Anhängerschaft praktisch keinen Aussagewert hat (vgl. u., S. 238).

$70 \quad$ Nach coll. Avell., epist. 1, 3f. kehrte Felix kurze Zeit (post parum temporis) nach der Rückkehr des Liberius im August 358 in die Stadt zurück, wurde jedoch erneut von den proceres vertrieben und starb acht Jahre später. Da Felix am 22. 11. des Jahres 365 starb, führt diese Zeitangabe - das Anfangsjahr, wie in Rom üblich, in der Zählung mitgerechnet - auf das Jahr 358; die Widerstände müssen sich also auf eine kurze Phase im Herbst 358 beschränkt haben. 
Fuß stand: ${ }^{71}$ Ihrem Einfluss verdankte er es auch, dass sich Kaiser Constantius II. nach seinem Rombesuch vom Sommer 357, als er sich den entsprechenden Bitten mehrerer Senatorengattinnen und des populus Romanus gegenüber sah, zur Rückberufung des Liberius auf den römischen Bischofsstuhl bereit erklärte, und dass eine - wohl durch Patronagebeziehungen mobilisierte - circensische Öffentlichkeit sich gegen die Pläne des Kaisers, neben Liberius auch Felix als Bischof in Rom bestehen zu lassen, aussprach. ${ }^{72}$

Die Differenzierung in einen felicianisch-damasianischen Titelklerus mit starkem Rückhalt in der Senatsaristokratie und in einen liberisch-ursinischen Bischofsklerus mit enger Beziehung zur plebs sancta kann also, was die Verhältnisse unter Liberius und Felix II. betrifft, nicht überzeugen. Dasselbe gilt jedoch auch, wenn man sich auf die schismatischen Auseinandersetzungen zwischen Damasus und Ursinus konzentriert und die vermeintlichen - nur durch die tendenziöse Darstellung der gesta suggerierten - Kontinuitäten zwischen Felix II. und Damasus bzw. Liberius und Ursinus ausblendet. Es besteht kein Grund zur Annahme, dass Damasus sich in den Konflikten seit

71 Die guten Kontakte des Liberius zur aristokratischen Familie des Ambrosius sind bekannt: Liberius weihte Ambrosius' Schwester Marcellina persönlich zur virgo und gehörte sicher zu den sacerdotes, mit denen die Familie nach Ausweis von Ambrosius' Biograph Paulinus eine enge Verbindung pflegte (Ambr., virg. 3, 1; Paul. Med., vita Ambr. 4, 1). Der Bischof Epiktet von Civitavecchia konfrontierte Liberius vor Constantius II. mit dem Vorwurf, dass sich der römische Bischof mit seiner unnachgiebigen Haltung in der Arianerfrage vor den römischen Senatoren brüsten wolle (Thdt., b. e. 2, 16, 12).

72 Thdt., h. e. 2, 17 berichtet, dass Constantius II. während seines Rombesuchs von Aristokratinnen um die Rückberufung des Liberius gebeten worden sei, da sein Nachfolger Felix keine Akzeptanz bei der Bevölkerung genieße. Constantius habe diesem Wunsch entsprechen, gleichzeitig aber Felix nicht opfern wollen und daher während einer Zirkusvorstellung verkünden lassen, es solle künftig zwei Bischöfe geben. Die im Zirkus versammelte Menge habe darauf zunächst mit der ironischen Bemerkung reagiert, wenn es zwei Zirkusparteien gebe, könne Rom ja auch zwei Bischöfe haben, um daraufhin einstimmig einen Bischof für eine Gemeinde zu fordern. Daraus mit Lizzi Testa 2004 (a), 134 zu schließen, im Zirkus hätten sich bei dieser Gelegenheit zwei unterschiedliche Faktionen für Felix und Liberius gebildet, geht am Zeugnis der Quelle vorbei: Theodoret gibt eindeutig zu verstehen, dass sich der populus Romanus ungeteilt für Liberius aussprach. In seiner Darstellung hat Theodoret die Reaktion des populus Romanus auf die Pläne des Kaisers mit dem Rombesuch des Constantius im Sommer 357 verbunden, obwohl die Rückberufung des Liberius erst nach der Annahme der zweiten sirmischen Formel im Herbst 357 beschlossen wurde (zur Rekonstruktion der Ereignisse vgl. Brennecke 1984, 270-292). Dass es jedoch auch schon während des Romaufenthalts von Constantius zu Kundgebungen für Liberius gekommen sein muss, bezeugen die gesta inter Liberium et Felicem (coll. Avell., epist. 1, 3: venit Romam Constantius imperator; pro Liberio rogatur a populo...); gestützt wird dieses - wegen der proursinischen Haltung seines Verfassers mit Vorsicht zu behandelnde - Zeugnis durch Philost., h. e. 4, 3; Soz., h. e. 4, 11, 12. Dieselbe Verbindung von Senatsaristokratie und populus Romanus tritt auch beim Empfang des Liberius am 2. August 358 hervor (coll. Avell., epist. 1, 3: redit Liberius, cui obviam cum gaudio populus Romanus exivit. Felix notatus a senatu vel populo de urbe propellitur). - Die Einflussnahme senatorischer Patrone auf die Zirkusparteien hat zuletzt Lim 2002 mit Blick auf die im Jahr 509 ausgebrochenen Unruhen innerhalb der pars prasina herausgearbeitet. 
Oktober 366 auf strukturell andere Anhängerschaften stützte als Ursinus. Damasus verfügte zwar über Verbindungen zum senatorischen Establishment und zu „pressure-groups“ aus dem Umfeld der Zirkusparteien: Diese Kontakte waren es, die nach Angaben des ursinischen Verfassers der gesta Damasus den Rücken stärkten und ihm im späteren Verlauf seines Episkopats die innerkirchliche Kritik von Rigoristen und den Spott von seiten nichtchristlicher Bevölkerungskreise einbrachten. ${ }^{73}$ Dass freilich auch Ursinus über ähnliche Beziehungen verfügte wie sein Gegenspieler Damasus, darf zumindest vermutet werden: Auch wenn die gesta inter Liberium et Felicem Damasus einseitig als den alleinigen Aggressor darstellen, waren auch die Ursiner willens und vor allem in der Lage, ihrerseits aktiv gegen die Anhänger des Damasus vorzugehen. ${ }^{74}$ Dies deutet ebenso auf schlagkräftige Klientelen und einflussreiche Verbindungen zur römischen Oberschicht hin wie der Umstand, dass es den Ursinern gelang, zwischenzeitlich die Rückkehr ihres Kandidaten nach Rom zu erwirken und nach der erneuten Verbannung des Ursinus einen Strafprozess gegen Damasus anzustrengen. Strukturelle Unterschiede in den Anhängerschaften beider Parteien werden nicht erkennbar. Beide Protagonisten standen auf dem Boden, den ihnen der Episkopat des Iulius (337-352) und des Liberius (352-366) bereitet hatte: ${ }^{75}$ Sie waren Leiter einer christlichen Gemeinde, in der die römische Aristokratie eine zunehmend wichtigere Rolle zu spielen begonnen hatte. ${ }^{76}$

73 Der Verfasser der gesta hebt beide Aspekte - Unterstützung durch professionelle Schlägertrupps aus dem Umfeld des Zirkus und durch die Matronen (coll. Avell., epist. 1, 9: quem in tantum matronae diligebant, ut matronarum auriscalpius diceretur) - ausdrücklich hervor. Für die spätere Kritik vgl. die Vorwürfe der luciferianischen Presbyter Marcellinus und Faustus, die sich gegen die avaritia, das Streben nach Besitz und Ämtern, die prunkvolle Ausstattung der Kirchengebäude und der Gewandung richteten (Coll. Avell., epist. 2, 117 und 121); ähnliche Kritik am aristokratischen Lebens- und Repräsentationsstil des römischen Klerus formuliert Amm. 27, 3, 14.

74 S. o., S. 226.

75 So auch Lizzi Testa 2004 (a), bes. 133-135, 142-144, 162f., 170, für die sich hinter den beiden Protagonisten des Schismas von 366 unterschiedliche Faktionen der Senatsaristokratie formieren. In der Charakterisierung dieser Faktionen - auf der Seite des Ursinus die bereits seit längerer Zeit christlichen Familien, die vor allem unter Liberius an Einfluss innerhalb der Gemeinde gewonnen hatten, auf der Seite des Damasus neubekehrte und pagane Familien, die diesen Kandidaten aktiv unterstützten bzw. tolerierten - ist ihr allerdings nicht ohne weiteres zuzustimmen. Diese Zuordnung beruht wesentlich auf der Angabe der gesta inter Liberium et Felicem, wonach die Ursiner in der Tradition des Liberius standen, während die Damasusanhänger sich auf den unter Felix abgefallenen Klerus gestützt hätten. Da es hier jedoch um eine in tendenziöser Absicht vorgenommene Traditionsbildung handelt, ist ihr aus methodischen Gründen kein Wert beizumessen (vgl. u., S. 238).

76 In der Zeit der Bischöfe Iulius und Liberius begann die asketischen Bewegung in den aristokratischen Haushalten Roms Fuß zu fassen; zu dieser mit der Person des Athanasius von Alexandria verbundenen Entwicklung vgl. Gordini 1956, 225-233. Dass zahlreiche Angehörige der römischen Aristokratie bereits seit konstantinischer Zeit zum Christentum konvertiert waren, hat in den letzten Jahren insbesondere Timothy Barnes nachzuweisen versucht (vgl. Barnes 1995). 
Ähnliche Überlegungen lassen sich auch für den römischen Klerus anstellen: Auch hier lassen sich keine strukturellen Unterschiede in den jeweiligen Anhängerschaften des Damasus und des Ursinus nachweisen. Die in der Forschung vielfach vertretene These, Damasus habe sich auf einen nach der Rückkehr des Liberius in Opposition zu ihm verharrenden Klerus gestützt, während Ursinus nur die Unterstützung der Gemeinde geblieben sei, ${ }^{77} \mathrm{krankt}$ daran, dass sie den methodischen Anforderungen im Umgang mit den gesta inter Liberium et Felicem nicht gerecht wird. Der Verfasser der gesta bemühte sich, eine Verbindung zwischen Damasus und Felix II. herzustellen (Ursinum in loco Liberii ordinari deposcunt; Damasum in loco Felicis expostulant), um auf diese Weise Ursinus als den Nachfolger des rechtmäßigen Bischofs, Liberius, erscheinen zu lassen. Eine Verbindung zwischen Felix II. und Damasus wurde durch den - übrigens nicht weiter nach Titelpresbytern und bischöflichen Diakonen differenzierten - „gesamten Klerus“ (omnis clerus) geschaffen, der während Liberius' Exil keine erkennbaren Anstalten unternommen hatte, eine Rückberufung des Bischofs zu erwirken ${ }^{78}$ und den der Verfasser der gesta bemühte, um Damasus als „Nachfolger“ des illegitimen Felix erscheinen zu lassen. Ob eine solche Verbindung auch jenseits der rhetorischen Zuschreibung existierte, ist jedoch mehr als fraglich. ${ }^{79}$ Felix II. war bereits unmittelbar nach der Rückkehr des Liberius auf den Rang einer quantité négligeable reduziert worden: Der kurzzeitig aufflackernde Widerstand gegen Liberius fand noch im Jahr 358 sein Ende. ${ }^{80}$ Dass der römische Klerus danach mehrheitlich in Opposition zu Liberius verharrt hätte, ist unwahrscheinlich und nicht durch glaubwürdige Quellen belegt. ${ }^{81}$ Sollten durch die Rückkehr des Liberius

77 So u. a. Caspar 1930/1933, Bd. 1, 592; Künzle 1961; Verrando 1981, 101; Cracco Ruggini 1997, 173; Lizzi Testa 2004 (a), 133-135.

78 Dass im Sommer 357 die Initiativen zur Rückberufung des Liberius nicht vom Klerus, sondern vor allem von der römischen Aristokratie ausgingen, wird auch durch das Zeugnis des Theodoret bestätigt, s. o., Anm. 72 .

79 Zurecht betont von Lippold 1965, 111f. (der allerdings die polemische Aussageabsicht des Schreibens insgesamt nicht hinreichend berücksichtigt); ebenso von Pietri 1976, Bd. 1, 413f., dems. 1986, 35f. Anders Lizzi Testa 2004 (a), 132-134, die eine Verbindung zwischen Liberius und Ursinus bzw. Felix II. und Damasus zum Ausgangspunkt ihrer Deutung des Schismas macht.

80 S. o., Anm. 70.

81 Der einzige Hinweis in diese Richtung entstammt bezeichnenderweise den gesta inter Liberium et Felicem: Ihre Darstellung suggeriert, dass eine Aussöhnung des Liberius mit dem römischen Klerus erst nach dem Tod des Felix im Jahr 365 erfolgt sei (vgl. coll. Avell., epist. 1, 3f.: quem (scil. Felicem) omnis multitudo fidelium et proceres de urbe iterum magno cum dedecore proiecerunt. post annos octo $V$ alentiniano et Valente consulibus X Kalendarum Decembrium die defunctus est Felix. Liberius misericordiam fecit in clericos, qui peiuraverant, eosque locis propriis suscepit). Dass der Ausgleich des Liberius mit dem römischen Klerus erst nach Felix Tod erfolgte, wird vom Verfasser der gesta nicht explizit gesagt; durch die Anordnung der Informationen suggeriert er jedoch eine Abfolge der Ereignisse, die seiner Darstellungsabsicht entspricht: Ein bereits nach Felix Rückzug aus Rom mit Liberius versöhnter Klerus hätte sich kaum überzeugend mit einem acht Jahre später ausbrechenden 
Gegensätze und Distanzen zu seinem römischen Klerus entstanden sein, müssen sie sich in den acht Jahren zwischen der Rückkehr des Liberius und seinem Tod deutlich abgeschliffen haben. Eine Bedeutung für das Schisma zwischen Damasus und Ursinus gewann der Konflikt zwischen Liberius und Felix erst aus der Retrospektive: Er diente den Ursinern als willkommenes Argument, die Rechtmäßigkeit ihres eigenen Kandidaten herauszustellen, indem sie ihre Gegner in eine Tradition mit dem im Jahr 358 abgesetzten Felix stellten und dadurch disqualifizierten. ${ }^{82}$

Wie sich die jeweiligen Anhängerschaften von Damasus und Ursinus auf den Presbyter- und Bischofsklerus der römischen Gemeinde verteilten, lässt sich nicht sicher sagen. ${ }^{83}$ Der Umstand, dass Damasus in einer Titelkirche (in Lucinis) gewählt wurde und dass vermutlich bereits sein Vater in Rom Presbyter gewesen war, ${ }^{84}$ könnte darauf hindeuten, dass er über einen stärkeren Rückhalt im presbyteralen Titelklerus verfügte. Entscheidend ist jedoch, dass dies keine erkennbaren Auswirkungen auf seine Legitimationsstrategie hatte, die sich von der des Ursinus strukturell nicht unterschied: Beide Kandidaten versuchten, ihre enge Beziehung zur Gemeinde herauszustellen und Räume zu besetzen, die in der Lage waren, diesen Anspruch symbolisch zum Ausdruck zu bringen. ${ }^{85}$ Der ursinische Verfasser der gesta hat dieses Bestreben mit Blick auf Ursinus dadurch herausgestellt, dass er seine gesamte Darstellung auf der engen Verbindung zwischen Ursinus und der - meist als

Schisma in Verbindung bringen lassen. - Die zu Beginn des 6. Jh. entstandene Liberiusvita des Liber Pontificalis, die von blutigen Verfolgungen des felicianischen Klerus durch Liberius berichtet (LP I, 208), ist unter dem Einfluss einer sich erst wesentlich später entwickelnden Legendenbildung verfasst worden (vgl. dazu u., S. 449-473).

82 Die Vorstellung, dass auch Felix ein regulärer Bischof gewesen sei, begann sich erst nach der Mitte des 5. Jh. in Rom durchzusetzen (vgl. u., S. 458-462).

83 Ursinus konnte mit seiner eigenen Person, Amantius und Lupus knapp die Hälfte des Diakonenkollegiums (drei der sieben Diakone) auf sich vereinigen (coll. Avell., epist. 1, 5). Über die Zahl der ihn unterstützenden Presbyter lässt sich nichts sagen; aus den sieben Presbytern, die während der Unruhen vom Oktober 366 inhaftiert wurden (ebd., 1, 7) lässt sich nicht auf die Gesamtzahl schließen (zurecht betont von Lippold 1965, 111). Ein struktureller Gegensatz zwischen presbyteralem und diakonalem Klerus, wie ihn Teile der Forschung voraussetzen, scheint jedenfalls nicht gegeben, schon deswegen, weil Damasus und Ursinus beide dem römischen Diakonenkollegium entstammten. Erst gegen Ende des 4. Jh. formierte sich eine deutlich erkennbare Kritik der römischen Presbyter, die sich durch die Bischofsnähe und beherrschende Stellung der Diakone in ihrem Rang zurückgesetzt sahen und auf der Überordnung des Presbyterats über das Diakonat in der Klerushierarchie beharrten (vgl. Domagalski 1980).

84 Dies scheint aus den Anfangszeilen eines Epigramms hervorzugehen, das Damasus in der nach ihm benannten Titelkirche anbringen ließ: hinc pater exceptor, lector, levita, sacerdos / creverat... (Damas., epigr. 57, 1f.). Offenkundig war bereits Damasus' Vater, dessen Laufbahn ihn bis zum Presbyterat führte (sacerdos ist hier - trotz der Bedenken von Ferrrua [1942], in: Epigrammata damasiana 211 - wohl nicht mit Bischof, sondern mit Presbyter gleichzusetzen), an dieser Kirche Kleriker gewesen.

85 Das Bild, das Maier 1995, 244f. von den Vorgängen zeichnet, ist stark verkürzt und bringt just diesen Aspekt nicht zur Sprache. 
plebs sancta oder fidelis bezeichneten ${ }^{86}$ - Gemeinde aufbaute. Dieser Schlüsselausdruck hat in den gesta weder eine soziale (plebs) noch eine rigoristische (sancta) Konnotation: ${ }^{87}$ Er bezeichnet den Gegensatz zwischen der durch den Bischof konstituierten christlichen Gemeinde und den gekauften Anhängerschaften des Damasus, den quadrigarii, arenarii und fossores. ${ }^{88}$ Dass die Bezugnahme auf die sancta plebs jedoch auch für Damasus - entgegen der tendenziösen Darstellung der gesta - eine zentrale legitimatorische Funktion hatte, geht aus seinen Epigrammen hervor, die der Bischof in großer Zahl an den Gräbern der Heiligen anbringen ließ: In ihnen stellte sich der römische Bischof nicht als ein Klient der Heiligen dar, der seine Autorität auf die Annäherung an sie und an den heiligen Ort des Grabes gründete, sondern akzentuierte seine Rolle als bischöflicher Gemeindeleiter, der die Gräber für die plebs Romana zugänglich machte und die Märtyrer als den „Ruhm der römischen Gemeinde" bezeichnete. ${ }^{89}$

Diese legitimatorische Bezugnahme auf die plebs und die mit dem Bischofsamt verbundene Funktion als Gemeindeleiter wird auch aus den Auseinandersetzungen vom Oktober 366 und den Strategien der Raumbesetzung ersichtlich. Aus dem Bericht der gesta geht hervor, dass beide Konkurrenten um die cathedra Petri die Nähe nicht etwa des Petrusgrabes oder ihres Vorgängers Liberius suchten, um die Legitimität ihrer bischöflichen Stellung durch den apostolischen Sukzessions- und Traditionsgedanken zu untermauern: Ursinus ließ sich in der basilica Iulii zum Bischof weihen, Damasus in der basilica Lateranensis. Das verbindende Element zwischen diesen beiden Kirchen und auch der basilica Liberii, die noch bis zur zweiten Verbannung des Ursinus im November 367 als Hauptkirche der Ursiner fungierte, bestand darin, dass es sich um Kirchen handelte, die nicht wie die Titelkirchen über einen eigenen presbyteralen Klerus verfügten, sondern unmittelbar dem römi-

86 Vgl. coll. Avell., epist. 1, 5 (plebs sancta), 6 (Romana plebs, plebs fidelis), 8 (sancta plebs), 11 (plebs). Äquivalent dazu verwendet der Verfasser der gesta auch den Begriff des populus, in dem die Grenzen zwischen ziviler und christlicher Gemeinde verschwimmen und durch den die Traditionsbezüge zwischen Liberius und Ursinus auch terminologisch hervortreten: So wie Liberius über die Unterstützung des populus Romanus verfügte (ebd. 1, 2f.), hat Ursinus den populus Dei hinter sich (ebd. 1, 9. 12).

87 So aber Pietri 1976, Bd. 1, 413 („le petit reste“) bzw. de Spirito 1994, 271 („strati medio e basso dei cristiani romani“). Plebs hat die inhaltlich nicht näher qualifizierte oder eingeschränkte Bedeutung von „Gemeinde“ und entspricht damit auch dem allgemein üblichen Sprachgebrauch bei christlichen Autoren, wo plebs meist die Gemeinde der Laien im Gegensatz zum Klerus bezeichnet (vgl. Kötting, in: Herrmann u. a. 1978, 149).

88 S. o., Anm. 37.

89 Damas., epigr. 44, 2 (Damasus als rector plebis); 25, 6 (die Heiligen sind der Ruhm der plebs Romana). Als Adressat der Epigramme wird die plebs in 472, 6 und 351, 1 angesprochen. Die Wendung populus erscheint in den Damasusepigrammen auffälligerweise vor allem in Verbindung mit Verfolgungen und Schismen, in denen die Einheit der römischen Gemeinde gefährdet ist (vgl. Damas., epigr. 18,$4 ; 35,5 ; 40,8)$. 
schen Bischof unterstanden. In dieser Eigenschaft waren diese Bauten besonders geeignet, die für das Selbstverständnis und die Legitimierung des Bischofs entscheidende Voraussetzung - seine Verwurzelung in der plebs sancta - sichtbar zu machen. Wie sehr die Bischofskirchen Roms dieses Selbstverständnis versinnbildlichten, zeigt insbesondere der Nachfolgerbau der basilica Liberii, die unter Sixtus III. (432-440) errichtete Basilika S. Maria Maggiore. Im Scheitel des auf dem dortigen Triumphbogen angebrachten Mosaiks erhob sich eine Widmungsinschrift, die dem Besucher diesen Sachverhalt in zugleich monumentaler und prägnanter Form vor Augen führte: Xystus episcopus plebi Dei. ${ }^{90}$ Diese Art der Selbstinszenierung erlaubt - mit aller methodisch gebotenen Zurückhaltung - auch Rückschlüsse darauf, welches bischöfliche Selbstverständnis der Vorgängerbau von S. Maria Maggiore und die übrigen bischöflichen Basiliken während des 4. Jh. kommunizierten: Es waren Orte, in denen sich die Bischöfe in ihrer Bezogenheit auf die Gemeinde, als Leiter der plebs sancta präsentierten.

Lässt man das Schisma zwischen Damasus und Ursinus abschließend mit Blick auf die Frage Revue passieren, welche Bedeutung die Heiligentopographie und räumlich vermittelte Traditions- und Erinnerungsbezüge in schismatischen Auseinandersetzungen um die Identität der römischen Gemeinde hatten, ist das Ergebnis in mehrfacher Hinsicht bemerkenswert. Insgesamt deutet das Verhalten der Akteure darauf hin, dass das symbolische Potential von Tradition, Erinnerung und Gedenken nur von nachrangiger Bedeutung gewesen ist. Die Orte der Heiligenerinnerung lagen außerhalb der städtischen Mauern und spielten daher für die Auseinandersetzungen zu Beginn des Schismas, die sich vollständig auf die innerhalb der Stadt gelegene Sakraltopographie konzentrierten, keine Rolle. Erst nach der endgültigen Verdrängung der Ursiner aus der Stadt scheinen die Coemeterien eine gewisse Bedeutung als Versammlungsorte erlangt zu haben - freilich eher als Rückzugsgebiete denn als identitätsstiftende Zentren. Insbesondere gibt es keine Hinweise darauf, dass die apostolischen Kommemorationsstätten am Vatikan und an der via Ostiensis eine legitimierende Funktion gehabt hätten: Die Kontrahenten versuchten nicht, durch symbolische Bezugnahmen auf die apostolischen Gemeindegründer und den apostolischen Sukzessionsgedanken die Rechtmäßigkeit ihrer Stellung zu behaupten: Nicht dieser Traditionszusammenhang war für die Begründung des Bischofsamtes konstitutiv, sondern die Vorstellung vom Bischof als Leiter der Gemeinde und dieser Personenver-

90 ILCV 975a. Zur Bedeutung von plebs Dei als Gemeinde der römischen ecclesia vgl. Martin 2003, 33-35. Auf das Triumphbogenmosaik von S. Maria Maggiore und seine komplexe Programmatik kann hier nicht näher eingegangen werden; vgl. dazu zuletzt Warland 2003, (a) und vor allem Martin 2003, der die heilsgeschichtliche Konzeption des Bilderzyklus überzeugend herausarbeitet. Zur inschriftlichen Bezugsnahme auf die plebs Dei in den römischen Bischofskirchen des 5. Jh. vgl. auch u., Anm. 121. 
band hatte seinen symbolischen Ort - anders als die Apostelgräber - innerbalb der Stadt.

In ähnlicher Weise deutet nichts darauf hin, dass die Ursiner durch die Besetzung der basilica Iulii und der basilica Liberii in einen Traditionszusammenhang mit den beiden unmittelbaren Amtsvorgängern treten wollten. Die Wahl dieser Orte war nicht durch das Gedenken an die Vorgänger, sondern durch das Bemühen diktiert, die personale Beziehung zwischen Bischof und Gemeinde symbolisch zum Ausdruck zu bringen. Auch hier tritt der Aspekt der Erinnerung und Traditionsstiftung in den Hintergrund und stattdessen die Gemeindeidentität als legitimierendes Moment hervor: So wie die Stadt im Gegensatz zum Suburbium waren es innerhalb der Stadt die bischöflichen Kirchen, die - im Unterschied zu den Titelkirchen - nicht nur Bezugspunkte kollektiver Identitätsstiftung auf lokaler Ebene bildeten, sondern vielmehr die ganze Gemeinde Roms, die plebs sancta, symbolisch abbildeten. ${ }^{91}$

\section{1. 2. Eulalius und Bonifatius}

Bestätigt und präzisiert werden diese Schlussfolgerungen und Hypothesen durch das Schisma zwischen Eulalius und Bonifatius, das - ähnlich wie das Schisma zwischen Damasus und Ursinus - durch eine Doppelwahl nach dem Tod des Bischofs Zosimos (417-418) im Dezember 418 ausgelöst wurde. ${ }^{92}$ Schon vor dem Ausbruch des Schismas hatte sich Zosimos über die Unbotmäßigkeit römischer Presbyter beklagt, die hinter seinem Rücken Reisen an den Kaiserhof nach Ravenna unternommen hatten und dafür mit dem Ausschluss aus der Kirchengemeinschaft belegt wurden. ${ }^{93}$ Die konkreten Hintergründe für das tief gehende Zerwürfnis zwischen dem Bischof und seinem Presbyterium sind unklar, doch dürften die Spannungen in den umfassenderen Zusammenhang struktureller Differenzen zwischen dem diakonalen Bischofsklerus und dem römischen Presbyterialklerus gehören, die bereits seit dem ausgehenden 4. Jh. zutage getreten waren. ${ }^{94}$ Diese interne Spaltung spie-

91 Die pfarrkirchenartige Bedeutung der tituli als Bezugspunkte regional begründeter Identitäten tritt auch in der Namensgebung hervor, die sich zum Teil an den Vierteln orientiert, in denen die Kirchen errichtet wurden. So bezeichnete sich in einer Inschrift des Jahres 348 ein lector des titulus Marci nach der Gegend, in der Bischof Marcus seine Titelkirche errichtet hatte, als lector de Pallacine (ICUR IX, 24861; zur Gründung der Kirche s. LP I, 202: hic (scil. Marcus) fecit duas basilicas, unam via Ardeatina ubi requiescit et aliam in urbe Roma iuxta Pallacinis). Für weitere Beispiele sowie zum Befund und seiner Deutung vgl. Pietri 1989, 1062.

92 Zum Schisma zwischen Eulalius und Bonifatius vgl. Caspar 1930/1933, Bd. 1, 360-365; Pietri 1976, Bd. 1, 452-460; Chantraine 1988; Wirbelauer 1994, 410-415.

93 Zosimos, epist. 14 (PL 20, 678-680) vom 3. Oktober 418; vgl. Caspar 1930/1933, Bd. 1, 360.

$94 \quad Z u$ den Rangkonflikten zwischen Diakonen und Presbytern, die sich seit dem ausgehenden 4. Jh. innerhalb des römischen Klerus abzuzeichnen beginnen, s. o., Anm. 83. 
gelt sich auch in den beiden Lagern wider, die sich nach dem Tod des Zosimos in der umstrittenen Nachfolgefrage bildeten. Während der Presbyter Bonifatius mit etwa 70 Presbytern nahezu den gesamten Titelklerus auf sich vereinte, konnte sich Eulalius, der unter Zosimos Archidiakon gewesen war, auf nur sehr wenige Presbyter, dafür aber vermutlich das gesamte Diakonenkollegium stützen. ${ }^{95}$

Die Eulaliusanhänger, die schon unmittelbar nach der Bestattung des Zosimos die Handlungsinitiative ergriffen, brachten rechtzeitig den Lateran unter ihre Kontrolle und weihten dort ihren Kandidaten zum Bischof. Demgegenüber verständigten sich die Wähler des Bonifatius in einer nicht weiter bekannten ecclesia Theodorae auf ihren Kandidaten, nahmen danach die Weihe in einer Titelkirche, der ecclesia Marcelli, vor und zogen schließlich mit dem neugeweihten Bischof aus der Stadt hinaus zur Peterskirche am Vatikan. ${ }^{96}$ Anders als die rivalisierenden Parteien im Oktober des Jahres 366 hatten die Anhänger des Bonifatius also keine Möglichkeit, die Weihe ihres Kandidaten in einer der innerhalb der Stadt gelegenen Bischofskirchen vorzunehmen. Die Quellenlage erlaubt keinen sicheren Aufschluss darüber, ob dies aus einem Mangel an Interesse oder aus fehlender Gelegenheit geschah, doch legt die historische Situation letzteres nahe. Der Stadtpräfekt Aurelius Anicius Symmachus hatte sich frühzeitig für Eulalius als den rechtmäßigen Bischof Roms entschieden und versuchte, die sich abzeichnende Wahl eines Gegenbischofs bereits im Keim zu ersticken, indem er die abtrünnigen Presbyter vorführen ließ und sie ermahnte, nicht unbesonnen zu handeln. ${ }^{97}$ Die sich daran anschließende Weihe im titulus Marcelli an der via Lata und das Hinausziehen aus der Stadt zum nicht weit entfernten Vatikan sind als Reaktion auf das feindliche Verhalten des praefectus urbi zu verstehen: Von der zivilen Autorität in

95 So die Darstellung der Bonifatiusanhänger in ihrem Protestschreiben an Kaiser Honorius vom 6. oder 7. Januar 419 (coll. Avell., epist. 17, 2f.), die durch die Vorgeschichte des Schismas und das Schreiben des PUR Symmachus bestätigt wird (vgl. coll. Avell., epist. 14, 5, wo allerdings verzerrend nur von aliquanti presbyteri als Anhängern des Bonifatius die Rede ist, da Symmachus Eulalius begünstigte). Dass 70 Presbyter beinahe das gesamte Presbyterium Roms ausmachten, wird aus einer Synode des Jahres 499 ersichtlich, auf der 74 Presbyter - vermutlich der gesamte Titelklerus der Stadt - anwesend waren (MGH AA XII, 401f.; zur Unterschriftenliste dieser Synode, die allerdings nur die Namen von 67 Titelpresbytern enthält, s. u., S. 338).

96 Zu den Vorgängen vgl. den Bericht des Stadtpräfekten Symmachus an Kaiser Honorius vom 29. Dezember 418 (coll. Avell., epist. 14, 4-7). Die Darstellung des Liber Pontificalis, wonach Eulalius in der Lateranbasilika, Bonifatius in der basilica Iulia (gemeint ist die basilica, die Bischof Iulius in der Nähe des Trajansforms errichten ließ) ordiniert worden sei (LP I, 227), ist offenkundig fehlerhaft; nach einer ansprechenden Vermutung von Duchesne (1886), in: LP I, LXII beruht sie auf einer irrigen Übertragung der im Schisma zwischen Bonifatius II. und Dioscorus (530) entstandenen Situation (vgl. LP I, 281: Dioscorus ordinatur in basilica Constantiniana, Bonifatius vero in basilica Iulii) auf das Schisma zwischen Bonfatius I. und Eulalius, wozu sich der Verfasser der 2. Redaktion des Liber Pontificalis vermutlich aufgrund der Namensgleichheit der beiden Protagonisten veranlasst sah.

${ }_{97}$ Coll. Avell., epist. 14, 6. 
das Suburbium Roms abgedrängt, überließen Bonifatius und seine Anhänger zunächst dem in der Kooperation mit der lokalen Behörde erfolgreicheren Eulalius das Feld.

Dass die Bonifatianer mit der schlechteren Alternative vorlieb nehmen mussten und sich Eulalius mit der Wahl und Weihe in der Lateranbasilika einen strategischen Vorteil verschafft hatte, wird auch aus dem weiteren Gang der Ereignisse ersichtlich. Aus der Sicht des Kaisers Honorius, der vom Stadtpräfekten Symmachus über den Ausbruch des Schismas unterrichtet worden war und ihm anfangs in seiner Interpretation der Vorgänge folgte, sprach neben anderen Faktoren auch die qualitas loci für den in der Lateranbasilika geweihten Eulalius. ${ }^{98} \mathrm{Ob}$ Symmachus und Honorius damit die Vorstellung von der Lateranbasilika als einem regulären Weiheort der Stadt verbanden, ist jedoch fraglich: An der durch den Klerus der Nachbargemeinden vollzogenen Ordination zeigte sich zumindest der Stadtpräfekt Symmachus nur am Rande interessiert. Ihn beschäftigte vor allem die Einmütigkeit der Gemeinde, die nach traditioneller Vorstellung die göttliche Erwählung des Kandidaten zum Ausdruck brachte. ${ }^{99}$ Auch mit Blick auf den Wahlvorgang war es weniger der römische Klerus als der Konsens innerhalb der städtischen Bevölkerung, der im Bericht des Stadtpräfekten an den Kaiser in den Vordergrund rückte: Symmachus verzichtete auf eine eingehendere Differenzierung zwischen Titel- und bischöflichem Diakonalklerus, ${ }^{100}$ hob dafür aber ausführlich den innerhalb der Gemeinde erzielten consensus universorum hervor, indem er seinem Schreiben eigens die gesta acclamationum populi in einem gesonderten Anhang hinzufügte. ${ }^{101}$

$98 \quad$ Coll. Avell., epist. 15, 3: cui (scil. Eulalius) competens numerus ordinantum, legitimi sollemnitas temporis locique qualitas recte venerandi nominis apicem contulerunt. cum autem constet Bonifatio omnia defuisse... Auch auf der im Februar 419 einberufenen Synode von Ravenna (vgl. u., Anm. 110) machte Eulalius gegen Bonifatius geltend, dass er in der Lateranbasilika erhoben worden sei; dies geht aus einem Brief der Galla Placidia an Paulinus von Nola vom (vermutlich) 20. März 419 hervor, in dem die Kaiserin moniert, dass Eulalius meine, er könne ,gegen die guten Vorgänge einer apostolischen Einsetzung auf die von ihm gewaltsam angemaßten Mauern (scil. der Lateranbasilika) vertrauen “ (coll. Avell., epist. 25, 1: contra haec apostolicae institutionis bona de praesumptis per vim parietibus existimet confidendum; zur Interpretation der Stelle vgl. auch Chantraine 1988, 85f., Anm. 20).

99 Zur Differenzierung dieser beiden Vorgänge - „Wahl“ (im Sinne eines Konsensrituals) und Weihe - in der antiken Bischofserhebung vgl. prägnant Kötting 1988 (a), 468-472. Für die Weihe sind die Bischöfe der Nachbardiözesen bzw. der Metropolitanbischof zuständig, das Presbyterium der Gemeinde ist im strengen Sinne nur an der Wahl beteiligt, indem es dem Kandidaten ein autorisierendes Zeugnis für dessen Eignung ausstellt. Symmachus kommt auf den Weihevorgang nur indirekt zu sprechen, indem er sagt, dass eine sehr große Menge zusammen mit mehreren Bischöfen (sacerdotes) in der Lateranbasilika den üblichen Tag der Bischofsweihe, den Sonntag, abgewartet hätte.

100 Symmachus spricht vom populus und clerici, die Eulalius nach der Beisetzung des Zosimos zum Lateran begleitet hätten (coll. Avell., epist. 14, 4), ohne auf diese Kleriker näher einzugehen.

101 Coll. Avell., epist. 14, 8. Dasselbe Vorgehen praktizierte Symmachus in einem wenige Tage später verfassten Schreiben, in dem er den Kaiser von einem fehlgeschlagenen Versuch des Bonifatius, 
Diese Perspektive des praefectus urbi, der die schismatischen Vorgänge mit Blick auf die öffentliche Ruhe beurteilte und für den daher das Verhalten der Bevölkerung und der consensus eine besondere Bedeutung haben musste, ist zwar nicht ohne weiteres auch auf den Bischof Eulalius übertragbar, den Symmachus als Kandidaten favorisierte. Es ist jedoch naheliegend, dass die Legitimationsstrategie des Eulalius auf einer Grundlage basierte, die dem Bild, das der Präfekt von den Vorgängen in Rom zeichnete, entsprach. Eulalius hatte mit der Lateranbasilika - anders als sein Kontrahent Bonifatius - einen Ort besetzen können, der, wie im vorigen deutlich geworden ist, für die römische Gemeinde von identitätsrelevanter Bedeutung war und Anlass dazu gab, deren Beteiligung am Erhebungsvorgang in besonderer Weise hervortreten zu lassen. Welche Bedeutung der consensus der plebs für das Gelingen einer Bischofserhebung hatte, ist - nur acht Jahre nach dem Schisma zwischen Bonifatius und Eulalius - für das Vorgehen des Augustinus dokumentiert, der, gleichsam in einer vorgezogenen Bischofswahl, seinen Nachfolger auf dem Bischofsstuhl von Hippo designierte. In dem Wissen, dass ein ähnlicher Designationsversuch in einer Nachbargemeinde beinahe daran gescheitert war, dass der Amtsvorgänger vor seinem Tod nur den Klerus instruiert hatte, ohne jedoch die Gemeinde mit einzubeziehen, inszenierte Augustinus seine Nachfolgeregelung als ein sorgfältig vorbereitetes Konsensritual: Augustinus trat in eine intensive Kommunikation mit der in der Bischofskirche versammelten Gemeinde, deren Akklamationen der Bischof von Hippo - ebenso wie der Stadtpräfekt Symmachus - von Notaren aufzeichnen ließ, um die Gültigkeit der vorgezogenen Erhebung zu dokumentieren. ${ }^{102}$ Es liegt nahe, dass auch Eulalius im Dezember 418 seine Erhebung in der Lateranbasilika, inmitten der römischen plebs, in ähnlicher Weise in Szene setzte - was wiederum auch ein plausibler Grund dafür ist, dass er derjenige Kandidat war, der sich die Unterstützung durch den praefectus urbi sichern konnte: ${ }^{103}$ Die dem Symmachus aus der politischen Kultur Roms vertrauten ${ }^{104}$ Konsensrituale mussten dem Eulalius in den Augen des Stadtpräfekten eine

mit seinen Anhängern in die Stadt zu gelangen, berichtete (vgl. dazu u., S. 250): unde ea, quae populus Romanus publico gaudio diversis acclamationibus agens gratias maiestati vestrae credidit publicanda, relationi meae universa subieci... (coll. Avell., epist. 16, 8).

102 Aug., epist. 213; vgl. dazu Kötting 1988.

103 Persönliche Verbindungen zwischen Eulalius und Symmachus, die die Parteinahme des Stadtpräfekten für Eulalius erklären könnten, sind nicht bekannt (Chantraine 1988, 81f.). Für die Hypothese von L. Pietri/Y. Duval/ C. Pietri 1992, 386, Eulalius habe einen stärkeren Rückhalt in der römischen Aristokratie gehabt als sein Kontrahent Bonifatius, finden sich keine überzeugenden Anhaltspunkte.

104 Zur traditionellen Bedeutung von Konsensritualen in der politischen Kultur Roms vgl. die Bemerkungen von Flaig 1992, bes. 59-67; dens. 1995 (a). Zur Bedeutung des inszenierten consensus universorum in den politischen Ritualen des spätantiken Rom und zur Rolle der Stadtpräfekten, die insbesondere bei Kaiserjubiläen als „collettori di consenso pubblico“ fungierten s. Lizzi Testa 2004 (a), 403. 
Legitimität verleihen, über die Bonifatius, dessen Erhebung nicht in einer Bischofskirche vorgenommen wurde und dem eine vergleichbare rituelle Publizität fehlte, nicht verfügte.

Die Bonifatiusanhänger verfolgten dementsprechend eine andere Strategie. Auch sie erkannten zwar die Einbeziehung der plebs als Akklamationsorgan prinzipiell an und hatten ihrerseits versucht, die Erhebung ihres Kandidaten in der Lateranbasilika durchzuführen. ${ }^{105}$ Insgesamt macht sich bei ihnen jedoch eine deutlich stärkere Klerikalisierung der Amtsauffassung bemerkbar: In einem Protestschreiben der römischen Presbyter an Kaiser Honorius gingen diese ausführlich auf den Weihevorgang und die an ihm beteiligten Presbyter und Bischöfe ein und stellten sie der nur geringen Zahl an Klerikern gegenüber, die Eulalius auf sich hatte vereinigen können. ${ }^{106}$ Die klerusinterne Hierarchisierung zwischen den als clerus maior bezeichneten Presbytern und dem diakonalen Klerus ${ }^{107}$ kommt in diesem Brief ebenso zur Sprache wie das Selbstverständnis des römischen Presbyteriums, die entscheidende Instanz des Erhebungsvorgangs gewesen zu sein, die den Akklamationen für ihren Kandidaten Geltung zuerkannte. ${ }^{108}$ In diesen Angaben der Bonifatiusanhänger spiegeln sich dementsprechend nicht nur die Spannungen innerhalb des römischen Klerus wider, die zum Ausbruch des Schismas geführt hatten, sondern auch unterschiedliche Legitimationsstrategien, die durch diese Ausgangslage bedingt waren: Während die Bonifatiusanhänger den Rückhalt ihres Kandidaten innerhalb des römischen Klerus, der zahlenmäßig vom presbyteralen Titelklerus deutlich dominiert wurde, ${ }^{109}$ betonten, war für Eulalius - soweit man dies aus dem Bericht des Stadtpräfekten Symmachus erschließen kann - die demonstrative Verankerung in der Gemeinde vorrangig. Damit aber wuchs auch dem Ort der Bischofserhebung aus Sicht der Eulaliusanhänger eine besondere Bedeutung zu. Denn im Unterschied zu den Titelkirchen, die eine Vielzahl eigenständiger Zentren bildeten, verfügte die

105 Die Erhebung des Bonifatius vollzog sich nach Darstellung seiner Presbyter acclamatione totius populi et consensu melioris civitatis (coll. Avell., epist. 17, 3). Auch die Bonifatiusanhänger hatten versucht, den Erhebungsakt in der basilica Lateranensis zu vollziehen, waren daran jedoch durch Eulalius gehindert worden (ebd., 17, 2).

106 Coll. Avell., epist. 17, 3f.

107 Die Presbyter bezeichnen sich in ihrem Schreiben als sacerdotes und stellen damit gezielt eine Eigenschaft heraus, die den nicht über die Priesterweihe verfügenden Diakonen nicht zukam. Auf den Umstand, dass Eulalius zwar Diakone, aber nur sehr wenige (paucissimi) Presbyter hinter sich hatte, wird von den Verfassern ausdrücklich hingewiesen; die Einbeziehung dieser - als consacerdotes (!) bezeichneten - Presbyter wird von den Bonifatiusanhängern als stillschweigendes Eingeständnis des Eulalius gedeutet, dass der clerus maior (= Presbyterium) die ausschlaggebende Bedeutung für die Gültigkeit einer Bischofserhebung habe.

108 Ebd. 17, 2: habita omnium collatione... participato cum Christiana plebe consilio, quem deus iussit, ele gimus; ebd. 17, 3: acclamatione totius populi et consensu melioris civitatis a scivimus.

109 Den etwa siebzig bis achtzig Titelpresbytern stand das siebenköpfige Diakonenkollegium des Bischofs gegenüber. 
Bischofsgemeinde in den bischöflichen Basiliken über Orte, die symbolisch wirksame Kristallisationspunkte der Gemeindeidentität bildeten. Dass der Erhebungsort des Eulalius - die qualitas loci - vom Stadtpräfekten Symmachus in besonderer Weise als Legitimationsfaktor herausgestellt wurde, ist demnach Teil einer bestimmten Strategie, der die Bonifatianer nichts Vergleichbares entgegenzusetzen hatten.

Dass diese unterschiedlichen Legitimationsstrategien über den unmittelbaren Ausbruch des Schismas hinaus Bestand hatten, zeigt der weitere Verlauf der Ereignisse. Kaiser Honorius hatte auf die Eingabe der Bonifatiusanhänger hin beide Prätendenten an den Hof nach Ravenna gerufen, wo eine vom Kaiser geleitete Synode über den rechtmäßigen Bischof entscheiden sollte. ${ }^{110}$ Da die Entscheidung sich über einen längeren Zeitraum hinzog und man Mitte März 419 noch zu keinem Ergebnis gelangt war, setzte Honorius die Beratungen über die bevorstehenden Ostertage aus und beauftragte den Bischof Achilleus von Spoleto damit, die Feier der Osterfestes in Rom zu übernehmen, ${ }^{111}$ während den beiden Prätendenten, Eulalius und Bonifatius, das Betreten der Stadt untersagt wurde. ${ }^{112}$ Eulalius vereitelte diese Pläne jedoch, indem er unverzüglich nach Rom eilte und am 18. März 419, zwei Tage vor dem Eintreffen des Bischofs von Spoleto in Rom, in die Stadt einzog, um dort die Osterfeierlichkeiten zu begehen. ${ }^{113}$ Die Auseinandersetzungen zwischen beiden Parteien flammten sofort wieder auf: Nach anfänglichen Ausschreitungen beim Vespasiansforum drohten die Konflikte sich an den bevorstehenden Osterfeierlichkeiten selbst auf die Lateranbasilka zu konzentrieren, da, so der Stadtpräfekt Symmachus in seinem Bericht über die Ereignisse an Honorius, beide Parteien ,glaubten, sie müssten einander wechselseitig von der Lateranbasilika ausschließen. " 114 Honorius stellte daraufhin

110 Zur Form dieses Verfahrens, in dem der Kaiser als Richter und die Synode als consilium principis fungierte, vgl. Girardet 1994, $23 \mathrm{f}$.

111 Erhalten sind die kaiserlichen Briefe an Achilleus v. Spoleto und an den praefectus urbi, den Senat und den populus Romanus (Coll. Avell., epist. 21-24).

112 Dies geht hervor aus coll. Avell., epist. 31, 1; 33, 2. Die Bonifatiusvita gibt die Aufenthaltsorte mit Antium für Eulalius und dem Felicitascoemeterium an der via Salaria für Bonifatius an (LP I, 227). Letzteres ist wegen der unmittelbaren Nähe zur Stadt und des damit gegebenen Unruhepotentials äußerst unwahrscheinlich; der Verfasser des Liber Pontificalis ist hier inspiriert durch die besondere Felicitasverehrung des Bonifatius, die sich in der Errichtung eines Oratoriums im Felicitascoemeterium und in seiner Bestattung iuxta corporis sanctae Felicitatis martyris äußerte (vgl. LP I, 227f.). Ebensowenig historischer Wert ist der Nachricht des Liber Pontificalis beizumessen, Bonifatius habe an Ostern 419 in S. Agnese getauft - hier dürfte die Legendenbildung um den bei S. Agnese taufenden Bischof Liberius (s. u., S. 465f.) Pate gestanden haben (zum geringen historischen Wert der beiden Nachrichten vgl. auch die Kommentare von Duchesne [1886], in: LP I, 229, Anm. 6 u. 9).

113 Coll. Avell., epist. 29 (23. März 419, Ostern fiel in diesem Jahr auf den 30. März).

114 Ebd., 29, 6: nisi celeri responso ante diem venerabilem paschae quid fieri debeat iusseritis, minantur se populi invicem pugnaturos, dum de Lateranensi basilica alterutrum se aestimant excludendos. $\mathrm{Zu}$ den vorhergehenden Unruhen am Vespasiansforum vgl. ebd., 29, 4. 
in seiner Antwort erneut klar, dass allein dem Bischof von Spoleto die Laterankirche zur Feier der Ostertage offenstehen und Eulalius die Stadt unverzüglich verlassen solle. ${ }^{115}$ Eulalius aber ignorierte die kaiserlichen Anweisungen, versuchte stattdessen, zur Nachtzeit die Lateranbasilika mit einer Schar von Anhängern in seinen Besitz zu bringen und konnte nur mit Gewalt aus der Lateranbasilika und aus der Stadt vertrieben werden. ${ }^{116}$ Erst jetzt sicherte Symmachus die Basilika mit apparitores seines Büros, um erneute Übergriffe der Eulalianer zu verhindern. ${ }^{117}$ Das Schicksal des Eulalius war mit diesen Auseinandersetzungen besiegelt: Für den Kaiser hatte sich Eulalius als möglicher Kandidat für den römischen Bischofsthron durch sein Verhalten selbst disqualifiziert. Da das Problem der Doppelbesetzung des römischen Episkopats durch den Wegfall eines Kandidaten gelöst war, verzichtete Honorius auf die Neuaufnahme einer kaiserlichen Synode und wies am 3. April den Stadtpräfekten an, Bonifatius als dem einzigen verbliebenen Anwärter auf den Bischofsthron den Zugang zur Stadt zu ermöglichen. ${ }^{118}$

Das Verhalten des Eulalius erscheint in hohem Maße erklärungsbedürftig. Die Synode und der Kaiser hatten deutlich gemacht, dass bis zur Klärung der umstrittenen Bischofswahl den beiden Kandidaten der Zutritt nach Rom verwehrt bleiben solle. ${ }^{119}$ Warum ging Eulalius ein Risiko ein, das sich im Endeffekt nicht auszahlte? Und warum maß er erneut der Kontrolle der Lateranbasilika eine so hohe Bedeutung bei, obwohl seine Argumente die Synode in Ravenna offenkundig nicht überzeugt hatten?

Will man Eulalius in seinem Handeln nicht situationsblinden Starrsinn unterstellen, dann muss der Preis, den er zahlte, etwas über den Wert aussagen, den er diesem Schritt beimaß. Die Forschung hat den ungewöhnlichen Schritt des Eulalius damit zu erklären versucht, dass er in einer für ihn aussichtslosen Situation durch die Besetzung der Lateranbasilika ein fait accompli habe schaffen wollen, um seiner Stellung als Bischof Roms Nach-

115 Coll. Avell., epist. 31, 6 (26. März 419): Spolitinus autem episcopus, sicut dudum fuerat definitum, sanctis paschae diebus ordinem festae sollemnitatis implebit. Cui ad celebranda mysteria Lateranensem ecclesiam soli patere decernimus, reliquis qui hoc praesumere voluerint propulsatis. Die erneute Anordnung, Eulalius habe Rom zu verlassen, wird ebd. 3, ausgesprochen.

116 Coll. Avell., epist. 32, 3f.

117 Ebd., 5. Beim Vorgehen gegen die Anhänger des Eulalius an der Lateranbasilika hatten weder der Stadtpräfekt noch der vicarius eingegriffen, sondern Kollegien (corporati) und die maiores regionum die entscheidende Rolle übernommen. Man hat zurecht hervorgehoben, dass der Stadtpräfekt Symmachus von Beginn an Eulalius favorisierte (Pietri 1976, Bd. 1, 457f.; Chantraine 1988); verlässliche Rückschlüsse auf die Anhängerschaften der beiden schismatischen Parteien lassen sich jedoch aus diesem Umstand nicht ziehen.

118 Coll. Avell., epist. 33. Die Synode in Ravenna war vor Ostern mit dem Plan ausgesetzt worden, sie nach den Feiertagen mit einem erweiterten Teilnehmerkreis, in den auch afrikanische und gallische Bischöfe einbezogen werden sollten, wieder aufzunehmen.

119 Coll. Avell., epist. 33, 2. 
druck zu verleihen: ${ }^{120}$ Die Feier des Ostergottesdienstes in der Lateranbasilika musste, so das Kalkül des Eulalius, ein zentrales Argument in der umstrittenen Frage bilden, wer der rechtmäßige Bischof Roms war. Sie wies den Bischof als Leiter der Gemeinde aus, der im Lateran die plebs versammelte und sich am höchsten Kirchenfest des Jahres zugleich in den wichtigsten bischöflichen Funktionen präsentierte: als Zelebrant des Kultes, als disziplinärer Gemeindeleiter, der dort an Gründonnerstag die Rekonziliation der Büßer vornahm, und als Lehrer, der die Katechumenen nach der entsprechenden Unterweisung in der christlichen Lehre durch die Taufe an Ostern in die Gemeinde aufnahm. ${ }^{121}$

Diese Einschätzung der Motive für Eulalius' Handeln ist überzeugend, sein Handeln jedoch weniger als eine Verzweiflungstat zu interpretieren, sondern eher als das konsequente Festhalten an einer „plebiszitären“ Legitimationsstrategie, die er bereits in den Entstehungstagen des Schismas verfolgt hatte. Welchen Einfluss die römische Bevölkerung und die Aristokratie auf den Kaiser ausüben konnte, wenn es in schismatischen Situationen um die Besetzung des römischen Episkopats ging, hatte der Rombesuch von Constantius II. im Sommer 357 gezeigt, als der Kaiser dem Drängen des populus Romanus und von Teilen der Aristokratie nach der Rückberufung des Liberius nachgegeben hatte. ${ }^{122}$ Die erneute Herstellung eines consensus universorum, die Eulalius' Rolle als Leiter der plebs nachdrücklich unterstrich, konnte nach Einschätzung des Eulalius - ebenso wie in den Anfangstagen des

120 So Chantraine 1988, 92f. in Anlehnung an eine ältere Studie von Oost. Eulalius hatte mindestens die einflussreiche Kaiserschwester Galla Placidia gegen sich: Sie versuchte, durch mehrere Schreiben im Vorfeld der Synode, die nach Ostern zusammentreten sollte, die Stimmung der Bischöfe gegen Eulalius zu beeinflussen.

121 Diesen Sachverhalt brachte auch die - allerdings erst von Bischof Hilarus (461-468) - beim Lateranbaptisterium (über dem Eingang der Kapelle für Johannes d. Täufer) angebrachte Inschrift deutlich zum Ausdruck: Hilarus episcopus sancte plebi Dei (de Rossi, Inscr. II, 424, nr. 47). Mit derselben Wendung hatte Sixtus III. (432-440) in der monumentalen Bischofsbasilika S. Maria Maggiore der Gemeindebezogenheit des bischöflichen Selbstverständnisses Ausdruck verliehen (s. o., Anm. 90). Dabei ist zu berücksichtigen, dass die symbolische Vermittlung der Funktionen als Gemeindeleiter im Laufe des 5. Jh. zunehmend nicht mehr allein vom Bischof wahrgenommen wurden: Seit dem beginnenden 5. Jh. lassen sich auch in zahlreichen Titelkirchen Roms Baptisterien nachweisen, die - im Unterschied zum Baptisterium von S. Pietro, das im wesentlichen der Taufe von Pilgern und der umliegenden Bevölkerung diente (s. u., S. 477, Anm. 264), - für die „reguläre“ Taufe römischer Gemeindemitglieder vorgesehen gewesen sein müssen (die jüngste Bestandsaufnahme bei Parmegiani/Pronti 2004, 106f., die archäologisch, epigraphisch oder literarisch belegbare Baptisterien für 13 Titelkirchen aufführen; zur liturgischen Funktion s. Saxer 1989, 931f.). Auch die Rekonziliation der Büßer konnte - unter besonderen Voraussetzungen - dezentral, auf der Ebene der Titelkirchen stattfinden (vgl. Pietri 1976, Bd. 1, 635).

122 S. o., S. 236 mit Anm. 72. 
Schismas - durchaus darauf rechnen, ihm die Anerkennung als rechtmäßiger Bischof der römischen Gemeinde zu sichern. ${ }^{123}$

Ähnlich wie im Schisma zwischen Ursinus und Damasus fehlen auch in der Auseinandersetzung zwischen Bonifatius und Eulalius hingegen überzeugende Hinweise darauf, dass die Heiligentopographie und die apostolischen Kommemorationsstätten den Rivalen eine besondere Legitimation verliehen hätten. Bonifatius, der unmittelbar nach seiner Wahl mit seinen Anhängern zur vatikanischen Petrusbasilika gezogen war, konnte aus seiner Nähe zum wichtigsten Heiligen Roms und ersten Bischof der römischen Gemeinde offensichtlich kein Kapital schlagen. Am 6. Januar des Jahres 419, nur wenige Tage nach Ausbruch des Schismas, finden wir ihn nicht mehr in S. Pietro, sondern in S. Paolo f.l.m., um dort das Fest der Epiphanie zu begehen. ${ }^{124}$ Bonifatius überließ die vatikanische Petrusbasilika an diesem Tag seinem Konkurrenten Eulalius, der die Feier von Epiphanias in S. Pietro als der regulären Station im Rahmen des bischöflichen Stationsgottesdienstes begehen konnte. Aufschlussreicher als dieses - möglicherweise durch die ungleichen Kräfteverhältnisse bedingte - Ausweichen des Bonifatius vor seinem Konkurrenten ist der Umstand, dass Bonifatius am Abend des 6. Januar keine Anstalten machte, erneut nach S. Pietro zurückzukehren, sondern den Versuch unternahm, sich mit seinen Anhängern den Zugang zur Stadt zu erzwingen. ${ }^{125}$ Für die Legitimierung als Bischof war der Traditionsbezug auf den ersten Bischof und wichtigsten Heiligen der Stadt offenkundig sekundär: Was zählte, war die sichtbare und symbolische Verankerung des Bischofs in seiner Gemeinde - eine Voraussetzung, die der Petrusbasilika, obwohl sie ebenfalls den Rang einer Bischofskirche besaß und in dieser Hinsicht der Lateranbasilika in nichts nachgestanden haben dürfte, ${ }^{126}$ fehlte, da sie außerhalb der

123 Man kann nicht davon ausgehen, dass Eulalius vor seinem Schritt mit einer Reaktion rechnete, wie sie Honorius dann unmittelbar nach Bekanntwerden von Eulalius' Rückkehr nach Rom an den Tag legte: Der Kaiser verstieg sich zu der Drohung, Eulalius setze durch sein Verhalten nicht nur seinen Status als Bischof, sondern auch sein Leben aufs Spiel (Coll. Avell., epist. 31, 4).

124 Die im folgenden wiedergegebenen Ereignisse beruhen auf einem Bericht des Stadtpräfekten Symmachus (Coll. Avell., epist. 16 [8. Januar 419]): Nach seiner Auskunft (ebd., 3) spielten sich die Vorgänge an einem Feiertag (sancti diei sollemnitas) ab, am selben Tag, an dem ein kaiserliches Schreiben, das am 3. Januar in Ravenna ausgefertigt worden war (Coll. Avell., epist. 15), in Rom eintraf. Es kann kaum ein Zweifel daran bestehen, dass mit diesem Feiertag das Epiphaniefest gemeint ist, da seine Feier in Rom spätestens um 400 auch durch andere Hinweise gestützt wird (vgl. Förster 2000, 115, 133f.; weitere Anhaltspunkte für die Feier von Epiphanias in Rom zu Beginn des 5. Jh. führt Pietri 1976, Bd. 1, 591f., an).

125 Coll. Avell., epist. 16, 5 f.

126 Die von Chantraine 1988, 82 vorgenommene Charakterisierung der Lateranbasilika als „Papstkirche“ ist unangemessen, da sie eine ausschließliche Konzentration der symbolischen Autorität des Bischofs auf den Lateran als „die“ Kathedrale der Stadt suggeriert. Vielmehr gab es in Rom mehrere Kirchen, die als Bischofskirchen der Autorität des römischen Bischofs unterstanden und die - soweit es sich um innerhalb der Stadt gelegene Basiliken handelte - in den Schismen des 5. und 6. Jh. als konkurrierende Erhebungsorte fungieren konnten (s. die Übersicht bei 
Stadt lag und damit nicht als identitätsstiftendes Zentrum der römischen Gemeinde fungierte.

\section{2. Sondergemeinden}

Ähnlich wie bei den Schismen des 4. und frühen 5. Jh. gilt auch für die zahlreichen häretischen Gemeinden, die sich in diesem Zeitraum in Rom nachweisen lassen, dass allenfalls schlaglichtartige Einblicke in ihre Verortung im römischen Raum möglich sind. Exemplarisch für die engen Begrenzungen, denen die Perspektive auf die häretische Sakral- und Erinnerungstopographie unterliegt, sind die Arianer. Obwohl eine der häretischen Gruppierungen Roms, die vom 4. bis zum 6. Jh. über eine wohl weitgehend konstante und vermittelt über das gotisch-germanische Element in den Truppen der Stadt auch einflussreiche Gemeinde verfügte, bleibt die Geschichte und Lokalisierung der Arianer in Rom dennoch weitestgehend dunkel. Von wenigen Nachrichten literarischer Quellen abgesehen, hat bereits ihre bloße Existenz kaum Spuren hinterlassen, da Nachweise auf arianische Einflüsse und Auseinandersetzungen mit den Arianern in Inschriften und ikonographischen Quellen nur sehr schwer zu führen sind. ${ }^{127}$ Die späte Nachricht, dass sie noch unter Gregor I. (590-604) zwei eigene Kirchen besaßen, die der Bischof in katholische Kultstätten umwandelte, ${ }^{128}$ ist zugleich der wichtigste Anhaltspunkt für die räumliche Präsenz der Arianer in der Stadt, der noch durch den archäologischen Hinweis auf ein weiteres arianisches Kultgebäude in der Nähe der Diocletiansthermen ergänzt wird. ${ }^{129}$

Man hat aus dieser Konzentration von arianischen Kultbauten im Bereich der Subura und des Esquilin den Schluss gezogen, es habe sich bei dieser Gegend im Osten Roms um eine stark arianisch geprägte Gegend gehandelt,

Geertman 1986-1987, 78f., die mit Blick auf das Schisma zwischen Eulalius und Bonifatius I. allerdings zu korrigieren ist [s. o., Anm. 96]).

$127 \mathrm{Zu}$ den methodischen Problemen im Bereich der Epigraphik und Ikonographie vgl. Ferrua 1991, 288-290, Giordani 1992, 238. Zum (vergeblichen) Versuch, nichtorthodoxe Einflüsse in den römischen Märtyrerlegenden nachzuweisen, vgl. u., S. 267-269.

128 Es handelt sich um S. Agata dei Goti, von Flavius Ricimer zwischen 459 und 472 gegründet (Gregor I., dial. 3, 30; LP I, 312), und um S. Severino in Merulana (Gregor I., epist. 3, 19).

129 Testini 1968, 251-258, identifiziert einen im 19. Jh. in der Nähe der Diocletiansthermen gefundenen und zerstörten Kultbau - das sogenannte Oratorium am Monte della Giustizia - mit der Kirche S. Agata in Esquilino und deutet ihn aufgrund der aus anderen arianischen Kirchen bekannten Apsisikonographie (Christus im Kreise der Apostel) als eine arianische Kirche. Daneben begegnet häufig die Vorstellung, dass auch S. Andrea in Catabarbara auf dem Esquilin eine arianische Kirche gewesen sei, da es sich um eine Stiftung des Goten Flavius Valila handelte (vgl. Zeiller 1904, 27; Testini 1968, 256). Diese Annahme erscheint allerdings unvereinbar mit der Tatsache, dass die Kirche nicht vom arianischen, sondern vom katholischen Bischof Simplicius (468-483) im Auftrag des Valila geweiht wurde (de Rossi, Inscr. II, 436, nr. 115). 
in der der Bevölkerungsanteil nicht nur von Arianern, sondern auch von Anhängern anderer nicht-katholischer Gemeinschaften besonders hoch gewesen sei. ${ }^{130}$ Dies mag in Anbetracht der Tatsache, dass Kirchen als pastorale Bezugspunkte von lokalen Identitäten fungierten, zwar durchaus zutreffen; 131 es gibt jedoch keinerlei Anlass zu der Vermutung, Rom sei in regelrechte Viertel zerfallen, die jeweils mehrheitlich von den Anhängern unterschiedlicher christlicher Gemeinden bewohnt wurden. ${ }^{132}$ Die Frage nach städtischen Räumen und Orten, an denen sich die Identität der arianischen Gemeinde Roms formierte, ist dementsprechend mit dem Hinweis auf regional begründete Formen der Identitätsstiftung nicht sinnvoll zu beantworten. Es muss vielmehr - unabhängig von möglichen Ballungen und Konzentrationen arianischer Bevölkerungsteile - lokale Zentren gegeben haben, die eine symbolische Bedeutung für die Existenz der arianischen Gemeinde Roms hatten. ${ }^{133}$ Es fehlen jedoch Hinweise darauf, ob und gegebenenfalls welche Heiligenkulte hierfür irgendeine Rolle spielten ${ }^{134}$ und ob es zu Konkurrenzsituationen mit der katholischen Gemeinde bezüglich bestimmter Orte der Sakral- und Heiligentopographie Roms kam. Nicht einmal über die Lage der arianischen Bischofskirche in Rom sind wir unterrichtet. ${ }^{135}$

Von den Arianern Roms verbleiben somit nicht mehr als versprengte Spuren einer Sakraltopographie, die sich für die Frage nach räumlich vermittelten Identitätskonstruktionen nicht fruchtbar machen lassen. Etwas besser

130 So Zeiller 1904, 26-28; M. Cecchelli 1985-1986, 293-295, die den gesamten Bereich des Esquilin als eine Gegend mit außergewöhnlich starken heterodoxen Einschlägen auffasst (ebenso Pani Ermini 1999, 48); diese Einschätzung beruht allerdings wesentlich auf einer dortigen Lokalisierung von Donatisten und Novatianern, die alles andere als gesichert ist (vgl. dazu u., Anm. $200 f$. und 248).

131 Zur pfarrkirchenartigen Funktion der Titelkirchen in Rom s. o., Anm. 91.

132 Für die Vorstellung einer gleichmäßigen Verteilung schismatischer und häretischer Gruppen im städtischen Raum vgl. die entsprechenden Bemerkungen von McLynn 1992, 20 zur Situation im spätantiken Konstantinopel, die auch für Rom Geltung beanspruchen können.

133 Vgl. in diesem Zusammenhang, dass die stationes von Händlern und Schiffseigentümern unterschiedlicher auswärtiger Gemeinden sich auf den Bereich der via sacra und des Forums konzentrierten - sie orientierten sich am öffentlichen Raum der Stadt, nicht an den Wohn- oder Gewerbevierteln ihrer Inhaber. Ob diese stationes jenseits einer kommerziellen Funktion als Büros eine weiterreichende symbolische Bedeutung als Niederlassungen und Anlaufstellen für Angehörige der jeweiligen Gemeinden in Rom hatten, ist zwar unklar; bemerkenswert ist in jedem Fall, dass die Lokalisierung dieser stationes - in Rom ebenso wie in Ostia - nicht auf die Lage von Wohnvierteln schließen lässt, in denen sich die fremden Ankömmlinge aus denselben auswärtigen Gemeinden und Regionen in Rom möglicherweise bevorzugt zusammenfanden (vgl. Noy 2000, 160-164; ebd. 151f.).

134 Es steht nicht zu vermuten, dass die arianischen Goten Roms mit der katholischen Gemeinde um Orte der römischen Heiligentopographie konkurrierten, da sie über eigene hagiographische Traditionen verfügten; dies verdeutlichen die erhaltenen Fragmente eines arianischen gotischen Heiligenkalenders (vgl. Delehaye 1912, 275-281).

135 Unsere Informationen beschränken sich auf die namentliche Erwähnung eines arianischen Bischofs in einem Papyrus vom Ende des 5. Jh. (vgl. C. Cecchelli 1944, 229f.). 
gestaltet sich die Überlieferungssituation für die Novatianer und Donatisten, die aus verstetigten Schismen hervorgegangene Sondergemeinden bildeten und damit, wie die Arianer, ebenfalls über großkirchliche Strukturen - Trennung von Klerus und Laien, monepiskopale Gemeindeleitung, Kirchengebäude als Versammlungsräume - verfügten. Im folgenden sollen die Möglichkeiten und Grenzen diskutiert werden, durch die Kombination hagiographischer, kalendarischer und archäologischer Hinweise eine topographische "Verortung" dieser beiden Gemeinden vorzunehmen, wobei vor allem die zentrale Frage eine Rolle spielt, inwieweit Novatianer und Donatisten versuchten, durch Bezugnahmen auf die beiden apostolischen Gemeindegründer eine mit den Grablegen am Vatikan und an der via Ostiensis konkurrierende apostolische Sakraltopographie zu etablieren.

\section{2. 1. Novatianer}

Das novatianische Schisma war nach dem Tod des Bischofs Fabian (238-250) während der decischen Verfolgung, die eine länger andauernde Vakanz des römischen Bischofsstuhls zur Folge hatte, im Jahr 251 aus der Doppelwahl zweier Bischöfe, Cornelius (251-253) und Novatianus (251-258 [?]), hervorgegangen und erwies sich als äußerst langlebig und über die Grenzen Roms hinaus bedeutsam. ${ }^{136} \mathrm{Im}$ Unterschied $\mathrm{zu}$ anderen schismatischen und häretischen Gruppierungen konnten sich die rigoristisch ausgerichteten Novatianer, deren Abspaltung von der Großkirche in disziplinären, nicht in dogmatischen Differenzen begründet lag, neben der katholischen Großkirche etablieren und in dieser Position eine begrenzte Akzeptanz erreichen. Ihre zivilrechtlichen Ansprüche wurden unter Konstantin offiziell anerkannt, ${ }^{137}$ und ihre Nähe zur Großkirche trat insbesondere in Krisensituationen, wie etwa in Konstantinopel unter dem arianischen Bischof Makedonios hervor, als die Nizäner ihre Kirchengebäude verloren und es vorzogen, zusammen mit den Novatianern Gottesdienste abzuhalten. ${ }^{138} \mathrm{Zu}$ Beginn des 5. Jh. endete dieser Zustand der Koexistenz: Innozenz I. (401-417) ließ - angeblich als erster römischer Bischof - die Novatianer verfolgen, Caelestinus (422-432) entzog ihnen nur wenige Jahre später ihre Kultgebäude, und die kaiserliche Gesetzgebung schloss seit dieser Zeit auch die Novatianer unter die häretischen Gruppen

\footnotetext{
136 Zum novatianischen Schisma und der Entwicklung der novatianischen Kirche ist nach wie vor grundlegend Vogt 1968.

137 CTh 16, 5, 2 (326) bestätigte den Novatianern den rechtmäßigen Besitz eigener Kirchengebäude und Coemeterien; zum Gesetz vgl. Vogt 1968, 194-196. Auf dem Konzil von Nizaea war zuvor der Status der Novatianer als Sekte bekräftigt worden, doch war ein novatianischer Bischof auf dem Konzil anwesend (ebd., 188-194).

138 Socr., h. e. 2, 38, 25f.; Soz., h. e. 4, 20, 7f.
} 
ein, die der staatlichen Verfolgung und Repression unterlagen. ${ }^{139}$ Unter dem Druck dieser massiven Einschränkungen scheint die novatianische Kirche sehr bald an ihr Ende gekommen zu sein: In Rom stellten die Novatianer offensichtlich schon unter Leo I. (440-461) keine ernsthafte Größe mehr dar. ${ }^{140}$ Westliche Quellen erwähnen sie bis zum Ende des 5. Jh. nur noch sporadisch, und auch im Osten, wo sie sich etwas länger gehalten zu haben scheinen, verlieren sich ihre Spuren etwa hundert Jahre später im Nebel der Geschichte. ${ }^{141}$

Seine dauerhafte, über knapp 200 Jahre bestehende Existenz als eine Sondergemeinde neben der katholischen Kirche führte im Novatianismus zur Ausprägung einer Gruppenidentität mit eigenen Institutionen und Traditionen. Damit stellt sich für die Novatianer die Frage, auf welche Weise der Zusammenhalt dieser religiösen Gruppierung symbolisch aufrechterhalten wurde: Auf welche Räume gründete die novatianische Gemeinde Roms, die noch zu Beginn des 5. Jh. immerhin so bedeutend war, dass mehrere kaiserliche Gesetze gegen sie erlassen wurden, ihre Identität? Und welche Rolle spielten Erinnerungsbezüge für die Konstituierung derartiger topographischer Zentren, die eine novatianische Gruppenzugehörigkeit sichern und stabilisieren sollten?

Konkrete Hinweise auf eine novatianische Erinnerungstopographie in Rom beschränken sich im wesentlichen auf die via Tiburtina, wo im Jahr 1927 in einer Katakombe eine Inschrift mit der Widmung eines Diakons an einen Novatianus martyr aufgefunden wurde. ${ }^{142}$ Seit ihrer Entdeckung hat die Inschrift zu anhaltenden Diskussionen darum geführt, ob es sich bei diesem Novatian um den Gegenbischof des Cornelius oder um einen anderen römischen Märtyrer handele. Insgesamt können sich die Vertreter, die in dem Geehrten den römischen Gegenbischof erkennen, auf die überzeugenderen Argumente berufen, da die Katakombe mit der Novatianusinschrift seit dem beginnenden 5. Jh. - eben zu der Zeit, in der die Novatianer in Rom verboten wurden - außer Gebrauch gekommen zu sein scheint, und da die nur wenige Meter von der Novatianuskatakombe entfernte Hippolytosgrablege aufgrund ihrer räumlichen Nähe die Vorstellung begünstigte, Hippolytos sei ein

139 Zu Innozenz I. und Caelestinus vgl. Socr., h. e. 7, 9, 2 und 11, 2-5. Gesetze: CTh 16, 6, 1 (413); 5, 59 (423); 5, 65, 2 (428). Die Maßnahmen gegen die Novatianer stehen im Kontext eines Vorgehens gegen häretische Gruppierungen, das Innozenz I. in Gang setzte (vgl. Pietri 1976, Bd. 1, 445-447).

140 Vgl. Vogt 1968, 275.

141 Nach 600 erscheinen die Novatianer auch im Osten nur noch in Häresienkatalogen, die zum großen Teil antiquarische Informationen verarbeiten (eine Materialzusammenstellung der späten Belege für den Novatianismus bietet Vogt 1968, 267-290).

142 ICUR VII, 20334. Eine knappe, aber alle wesentlichen Aspekte umfassende Diskussion der Inschrift bietet Ferrua 1944 (a). Ausführlich und mit umfassender Bibliographie der jüngste Beitrag zum Problem von Giordani 1992. 
Presbyter des Bischofs Novatian gewesen. Die oben erwähnte Inschrift ist dabei nicht allein ein Beleg für die Existenz des Novatianusgrabes an der via Tiburtina, sondern zugleich auch ein Hinweis darauf, dass die Grablege für die novatianische Gemeinde eine identitätsrelevante Funktion hatte. Es handelt sich bei der Inschrift nämlich nicht um einen einfachen Grabtitulus, sondern, wie Antonio Ferrua gezeigt hat, um den Teil einer nicht mehr genauer rekonstruierbaren, im 4. Jh. angelegten Monumentalisierung des Novatianusgrabes, die der Ausschmückung des loculus dienen sollte. ${ }^{143}$ Novatian war demnach was angesichts seiner Bedeutung als Gemeindegründer für die novatianische Gemeinschaft auch ohne weiteres nachvollziehbar ist - Objekt eines Kultes, der in einer entsprechenden Ausgestaltung seines Grabes seinen Ausdruck fand.

Die Existenz eines derartigen Novatianuskultes, der allerdings vergleichsweise bescheidene Ausmaße gehabt zu haben scheint, ${ }^{144}$ vorausgesetzt, stellt sich die Frage, ob sich noch weitere Hinweise auf eine novatianische Erinnerungstopographie in Rom erhalten haben. Wir werden dabei nochmals auf die via Tiburtina zu sprechen kommen, zuvor jedoch einen Deutungsversuch diskutieren, der die unter Konstantin errichtete basilica apostolorum und den von ihr überbauten Vorgängerbau - den Trikliahof, in dem zahlreiche Graffiti für Petrus und Paulus gefunden wurden ${ }^{145}$ - als ein novatianisches Zentrum des Apostelkults in Rom auffasst, das in Konkurrenz zu den beiden Kultstätten für Petrus am Vatikan und für Paulus an der via Ostiensis entstanden sei. Da diese Hypothese den Teilsaspekt einer ausgedehnten Forschungsdiskussion um den Stellenwert der basilica apostolorum und ihres Vorgängerbaus im Rahmen der Apostelverehrung in Rom bildet, seien zunächst die Voraussetzungen und Positionen dieser umfassenderen Debatte kurz skizziert.

Die Entdeckung der Kultstätte für die beiden Apostel unter der basilica apostolorum im Jahr 1915 lieferte die archäologische Bestätigung für eine bereits zuvor bekannte Notiz in der depositio martyrum des Chronographen von 354. Der Kalendereintrag der depositio verbindet den 29. Juni, das Kommemo-

143 Ferrua 1944 (a), 233.

144 Die Katakombe und der Bereich um das Novatianusgrab weisen keine Spuren (Verbreiterung der Katakombengänge, Anlage von Treppen) auf, wie sie sonst seit dem 4. Jh. für den Ausbau der Märtyrergräber typisch sind. Giordani 1992 misst der novatianischen Kultstätte eine erhebliche Bedeutung zu, da sie erkläre, warum der Kult des Diakons Laurentius an der via Tiburtina größere Popularität erlangt habe als die Verehrung des Sixtus II. und der übrigen Diakone, die während der valerianischen Verfolgung ums Leben gekommen waren und die im Süden der Stadt, an der via Appia, bestattet lagen: Die katholische Großkirche habe in der Person des Laurentius ein Gegengewicht zur novatianischen Kultstätte an der via Tiburtina schaffen wollen. Für die besondere Popularität des Laurentiuskultes dürften jedoch weniger sein antinovatianischer Reflex als die unter Konstantin erfolgte Monumentalisierung des Laurentiusgrabs und die Errichtung der konstantinischen Basilika, die sich in der Nähe der Grablege erhob, verantwortlich sein (vgl. LP I, 181f. u. o., S. 108f.).

145 Zu diesem Trikliahof s. o., S. 40-42. 
rationsdatum der beiden Apostel Petrus und Paulus, mit dem Konsulardatum des Jahres 258 und lokalisiert das Petrusgedenken nicht am Vatikan, sondern in catacumbas - einem auf die Triklia an der via Appia zu beziehenden Toponym. ${ }^{146}$ Diese Notiz der depositio, die durch den archäologischen Befund der Triklia zusätzlich gestützt wurde, hat Generationen von Forschern beschäftigt, die das Faktum einer Apostelverehrung in catacumbas mit der Tatsache in Einklang zu bringen versuchten, dass der Vatikan und die via Ostiensis bereits um 200 und dann wieder seit konstantinischer Zeit als die Grabstätten der beiden apostolischen Gemeindegründer belegt sind. ${ }^{147}$ Aus der Fülle von Erklärungen, die für diese Duplizität (bzw. Triplizität) der apostolischen Kommemorationsstätten in Rom angeführt worden sind, haben sich im wesentlichen zwei Ansätze herauskristallisiert, die das Datum des 29. Juni 258 entweder mit einer Reliquientranslation in Verbindung bringen oder aber auf ein gemeinsames Fest für Petrus und Paulus beziehen, das im Jahr 258 in catacumbas eingerichtet worden sein soll. ${ }^{148}$ Daneben ist jedoch auch vereinzelt in Erwägung gezogen worden, es könne sich bei der Kultstätte an der via Appia um ein schismatisches, häretisches oder nicht offizielles Kultzentrum gehandelt haben, das im 3. Jh. in Konkurrenz zu den apostolischen Kommemorationsstätten am Vatikan und an der via Ostiensis entstanden und erst spä-

146 Depositio martyrum (MGH AA IX, 71): III kal. Iul. Petri in Catacumbas et Pauli Ostense, Tusco et Basso cons. (= 29. Juni 258). Bemerkenswert ist, dass Paulus an der via Ostiensis verehrt wird, die Petrusbasilika am Vatikan in dieser Notiz hingegen gar keine Erwähnung findet. Man hat daher vorgeschlagen, eine auf der Lesart des Martyrologium Hieronymianum beruhende Emendation des Eintrags zu III. Kal. Iul. Petri in Vaticano et Petri et Pauli in catacumbas et Pauli Ostense vorzunehmen (Lietzmann 21927, 110-114 auf der Grundlage von Kirsch 1924, 20-22; zustimmend u. a. Klauser 1956, 22); dies wird jedoch in der jüngeren Forschung zurecht als unzulässige Harmonisierung der Quellen abgelehnt (vgl. Saxer 1986, 66). Die u. a. von Pietri 1976, Bd. 1, 57 vertretene Erklärung, dass die vatikanische Petrusbasilika zur Abfassungszeit der Deposionsliste noch nicht fertiggestellt gewesen sei, ist nicht überzeugend (vgl. o., S. 109f. mit Anm. 118). In die richtige Richtung dürften hingegen die Überlegungen von Ruysschaert 1969 weisen, der den beiden Kommemorationsorten in catacumbas und am Vatikan unterschiedliche Funktionen der Petrusmemoria zuordnet. Die Kommemorationsstätte in catacumbas akzentuierte das gemeinsam mit Paulus erlittene Martyrium Petri und seine Rolle als apostolischer Gemeindegründer, die allein auf Petrus bezogene Basilika am Vatikan hingegen seine Rolle als erster Bischof der römischen Gemeinde.

147 Die Literatur zu diesem Thema ist Legion; jüngere Überblicke über die wichtigsten Forschungspositionen vermitteln Hack 1997, 13f.; Thümmel 1999, 8-10; Cracco Ruggini 2001.

148 Prominente Anhänger der „Translationshypothese“ sind u. a. Duchesne 1923, bes. 19-22; Lietzmann ${ }^{2} 1927,114-126,222-226$. Da es bereits für die Zeit um 200 Hinweise darauf gibt, dass die Apostel am Vatikan und an der via Ostiensis verehrt wurden, rechnen die Vertreter der Translationshypothese mit einer zweifachen Überführung der Apostelreliquien: Auf eine zwischenzeitliche Verlegung der sterblichen Überreste an die via Appia während der valerianischen Verfolgung im Juni 258 sei zu einem - nicht genauer bestimmbaren - späteren Zeitpunkt die Rückführung an die via Ostiensis und an den Vatikan erfolgt. Anders Delehaye 21933, 264-269, der von einem auf das Jahr 258 zurückgehenden gemeinsamen Festtag für die beiden Apostel an der via Appia ausgeht. 
ter unter amtskirchliche Kontrolle gelangt sei. ${ }^{149}$ Der Liturgiewissenschaftler Leo Kunibert Mohlberg hat diese allgemeinen Überlegungen zu der Hypothese von einer novatianischen Kultstätte in catacumbas zugespitzt, indem er die depositio martyrum im Chronographen von 354, die den Eintrag einer Petrusverehrung an der via Appia überliefert, als einen novatianischen Heiligenkalender zu erweisen versuchte. ${ }^{150}$ Was Mohlberg an Belegen für einen novatianischen Ursprung der depositio martyrum anführt, lässt sich freilich eher in gegenteiliger Hinsicht, nämlich als eine polemische Bezugnahme auf den Novatianismus interpretieren. ${ }^{151}$ Mohlbergs Auffassung ist dementsprechend auch mit Entschiedenheit und guten Gründen zurückgewiesen worden ${ }^{152}$ und für lange Zeit im Inventar der umfangreichen Forschungsdiskussion um die Kultstätte in catacumbas verschwunden.

Aus ihrem Dornröschenschlaf ist die Hypothese von einem novatianischen Apostelkult an der via Appia zuletzt mit neuen Argumenten erweckt

149 Die Vermutung, dass es sich bei der Triklia an der via Appia um eine schismatische oder häretische Kultstätte für die Apostel gehandelt habe, begegnet bereits bei Schäfer 1932, 20; Schneider 1951, 14. Von einer „privaten“ (= kirchlich nicht kontrollierten) Kommemorationsstätte im Unterschied zu den offiziellen kirchlichen Zentren am Vatikan und an der via Ostiensis geht Chadwick 1957, 47f. aus, dessen Hinweis auf den nicht-liturgischen Charakter der dort gefeierten Refrigerien allerdings nicht schlagend ist: Noch um 400 fanden solche Refrigerienfeiern auch in der vatikanischen Petrusbasilika statt (Paul. Nol., epist. 13, 11-14; Aug., epist. 29, 10).

$150 \quad$ Vgl. Mohlberg 1952, bes. 58-68.

151 Mohlberg stützt sich im wesentlichen auf zwei Argumente: 1. Die depositio martyrum enthält zum Tagesdatum der am 10. Juli verehrten Märtyrer den Zusatz, dass einer von ihnen durch Novatianer geraubt worden sei (MGH AA IX, 71: bunc Silanum martirem Novati furati sunt). Dies sei, so Mohlberg, die Glosse eines späteren Bearbeiters der depositio martyrum, dem aufgefallen sei, dass es sich bei der depositio um einen novatianischen Heiligenkalender handelte. 2. Für den 29. Juni den petrinischen Festtag in catacumbas in der depositio martyrum - ist im Martyrologium Hieronymianum die Kommemoration eines römischen Märtyrers namens Novatianus überliefert, in dem Mohlberg den Gegenbischof des 3. Jh. vermutet (zu diesem Eintrag im Martyrologium Hieronymianum, der als Dublette auch am 27. Juni erscheint, vgl. Kirsch 1924, 20-23, der allerdings eine Identifizierung mit dem 251 zum Bischof erhobenen Novatianus ablehnt). Mohlberg erklärt diese Koinzidenz damit, dass die Novatianer die apostolischen Gemeindegründer an demselben Tag gefeiert hätten, an dem sie auch ihres Gründers Novatian gedachten. - Dazu ist folgendes zu bemerken: 1. Warum ein späterer Benutzer der depositio martyrum ausgerechnet bei Silanus die novatianische Kontrolle einer Kultstätte vermerkt haben soll, obwohl es sich doch nach Mohlbergs Ansicht bei allen Heiligen und Gedenkstätten dieses „,novatianischen Kalenders“ um häretische Kultorte hätte handeln müssen, bleibt unverständlich. Der Eintrag macht nur unter umgekehrten Vorzeichen Sinn, dass nämlich die depositio martyrum auf einem katholischen Heiligenkalender beruht und der Verfasser der depositio den „Verlust“ einer ursprünglich katholischen Kultstätte an die Novatianer dokumentieren wollte. 2. Eine Koinzidenz der Tagesdaten spricht nicht, wie Mohlberg meint, für, sondern gegen die Existenz eines novatianischen Kultes in catacumbas. Am 29. Juni waren die Novatianer der Erinnerung ihres Gemeindegründers verpflichtet, dessen Grablege an der via Tiburtina sie zur Abhaltung einer Gedenkfeier aufsuchen mussten. Am selben Tag eine Feier zu Ehren der Apostel am anderen Ende der Stadt durchzuführen, wäre aus rein pragmatischen Gründen dysfunktional gewesen.

152 Vgl. die Stellungnahmen von Klauser 1956, 77; Chadwick 1957, 46f.; Pietri 1976, Bd. 1, 377, Anm. 2; zuletzt Cracco Ruggini 2001, 386. 
worden, die von den römischen Heiligenlegenden, deren Anfänge bis in das 5 . Jh. zurückreichen, ihren Ausgang nehmen. Nach Ansicht von Kate Cooper, die vor einigen Jahren ein eigenes Forschungsprojekt zu den sogenannten gesta martyrum Romanorum ins Leben gerufen hat, haben sich in diesen legendarischen Produkten schismatische, mit der offiziellen Sicht der Amtskirche konkurrierende Perspektiven erhalten, die unter anderem neue Hinweise auf die novatianische Kulttopographie an der via Appia liefern. ${ }^{153}$ Mit ihren Schlussfolgerungen zum Ursprung und zur Funktion der römischen Märtyrerliteratur stößt Cooper die Tür zu einem umfangreichen Literaturbestand auf, der trotz intensiver Forschungsbemühungen zu Beginn des 20. Jh. hinsichtlich der Produktion, Rezeption und literarischen Zirkulation der Texte viele Fragen offen gelassen hat: Es handelt sich um etwa einhundert Passionen, die jeweils mehrere Gruppen von Märtyrern umfassen, und deren Handschriften in die Tausende gehen. ${ }^{154}$ Wegen des umfassenden Zuschnitts von Coopers Ausführungen, die nicht allein die Erinnerungstopographie der novatianischen Gemeinde in Rom betreffen, sondern darüber hinaus die gesta martyrum insgesamt als Medien und als Reflexe von Versuchen begreifen, die römische Heiligentopographie im Interesse von Gruppen zu besetzen, die mit der Amtskirche in Konkurrenz standen, verdienen sie im folgenden eine ausführlichere Stellungnahme, die über die unmittelbare Frage nach der novatianischen Kulttopographie in Rom hinausgeht.

153 Vgl. zum folgenden Cooper 1999. Die Überlegungen der Autorin beruhen auf den Arbeiten einer Projektgruppe, die zur Erforschung der römischen gesta martyrum ins Leben gerufen wurde. Zu den Zielsetzungen dieses an der Universität Manchester angesiedelten Forschungsprojekts zu den gesta martyrum vgl. auch die Einleitung von Cooper zu Early Medieval Europe 9 (2000) und die website www.art.man.ac.uk/cla/Romanmartyrs.htm.

154 Ein Dossier derjenigen Passionen, die römische Märtyrer zum Gegenstand haben, findet sich auf der in der vorigen Anm. angegebenen website der Universität Manchester. Einen anschaulichen Eindruck von den schieren Dimensionen des prosopographischen und handschriftlichen Materials vermittelt die Arbeit von Urbain 1901, der den (missglückten) Versuch unternahm, auf der Grundlage von 96 Heiligenlegenden den römischen Heiligenkalender zu Beginn des 5. Jh. zu rekonstruieren (zu den methodischen Defiziten von Urbains Ansatz vgl. Delehaye 1902). Die Bibliotheca Hagiographica Latina (erstmals 1910 erschienen, seitdem durch zwei umfangreiche Supplemente ergänzt) klassifiziert die Passionen nach unterschiedlichen Varianten; über die von der Société des Bollandistes autorisierte website www.bhlms.fltr.ucl.ac.be wird ein rasches Auffinden der unterschiedlichen Rezensionen und ihres Handschriftenbestandes ermöglicht. Auch die dort aufgeführten Handschriften umfassen jedoch nur diejenigen Exemplare, die von den Bollandisten seit dem Ende des 19. Jh. systematisch katalogisiert wurden; einer der ältesten Textzeugen, die heute in Sankt Petersburg befindliche Handschrift der passio Gallicani, Iohannis et Pauli aus dem späten 6. Jh. (CLA XI, 10, nr. **646; vgl. Philippart 1977, 27-29) ist beispielsweise nicht aufgeführt. Auch die von Verrando 1991 edierte passio Xysti, Laurentii et Hippolyti vetus macht exemplarisch deutlich, dass die über die BHL erreichbaren Varianten und Handschriften nur einen Ausschnitt der Überlieferungstradition darstellen und zum Teil korrekturbedürftig sind (vgl. Verrando 1991, bes. 186f.). 
Den Anlass dafür, Mohlbergs Hypothese vom Apostelkult an der via Appia und der basilica apostolorum als novatianisches Kultzentrum erneut aufzugreifen, findet Cooper in der passio Sebastiani, einem vergleichsweise frühen Produkt unter den römischen Heiligenlegenden, das vermutlich um die Mitte des 5. Jh. entstanden ist. ${ }^{155}$ Zum Abschluss der passio Sebastiani erscheint dieser Heilige, der in einer Grablege unter der basilica apostolorum bestattet und verehrt wurde, nach seinem Martyrium einer römischen Matrone namens Lucina im Traum und bittet sie, ihn iuxta vestigia apostolorum zu bestatten. Cooper interpretiert diese Formulierung als eine gezielte Polemik gegen die vom römischen Bischof beanspruchte Präsenz der Petrusreliquien am Vatikan: Der Verfasser der passio Sebastiani vindiziere, dass die Reliquien der Apostel sich zur Abfassungszeit der passio noch an der via Appia befänden; zumindest jedoch suggeriere er, dass dies zur Zeit, in der Sebastian das Martyrium erlitten habe - also während der diocletianischen Verfolgung zu Beginn des 4. Jh. - der Fall gewesen sei. ${ }^{156}$

Dieselbe Matrone Lucina, eine in den spätantiken römischen Märtyrerund Heiligenviten als Bestatterin überaus populäre Figur, ${ }^{157}$ erscheint auch in der Corneliusvita des Liber Pontificalis, wo sie im Auftrag des Bischofs Cornelius (251-253) die Paulusreliquien von der ad catacumbas gelegenen Stätte an die via Ostiensis überführt, während der Bischof Cornelius eine analoge Translation der Petrusreliquien an den Vatikan vornimmt. ${ }^{158}$ Hier agiert Lucina im Gegensatz zur passio Sebastiani in einem legendarischen Kontext, der die Ansprüche der vatikanischen Basilika auf die Beherbergung der Petrusreliquien unterstreicht. Diesen „Rollentausch“ der bestattenden Matrone Lucina erklärt Cooper als den Versuch, eine mit schismatischen Assoziationen verbundene Figur in eine Protagonistin bischöflicher Interessen zu verwandeln: Die Corneliusvita des Liber Pontificalis, in der Lucina mit der Translation der apostolischen Reliquien von der via Appia an die via Ostiensis bzw. an den Vatikan in Verbindung gebracht wird, spiegele das bischöfliche Bestreben wider, die mit der novatianischen Kultstätte an der via Appia assoziierte Lucina „umzudrehen“ und für die katholische Gegenposition (Lokalisierung der Petrusreliquien am Vatikan) zu vereinnahmen. Eine derartige Umwand-

155 Morin 1913, 347 mit Anm. 1, 367f. zieht aus sprachlichen und inhaltlichen Gründen in Erwägung, dass Arnobius d. J., der um die Mitte des 5. Jh. in Rom wirkte, die passio Sebastiani und weitere römische Heiligenlegenden verfasst haben könnte; Pesci 1945, 183f. möchte die Abfassung der passio Sebastiani mit der Gründung eines Klosters bei S. Sebastiano durch Sixtus III. (432-440) in Verbindung bringen, doch bleibt dies eine reine Vermutung. Der noch zuletzt von Neri 2000, 217f. angeführte kodikologische Befund - eine Datierung der ältesten Handschrift der passio Sebastiani in das späte 5./frühe 6. Jh. - ist überholt: Die Palimpsestblätter werden mittlerweile in das 7. Jh. datiert (vgl. CLA VII, 10, nr. 866).

156 Cooper 1999, 310, 312f.

157 Vgl. u., S. 265.

158 LP I, 150. 
lung sei unter Bischof Symmachus (498-514) propagiert worden, in dessen Regierungszeit die Vorarbeiten für die kurz darauf erfolgte Redaktion des Liber Pontificalis fielen. ${ }^{159}$ Den eigentlichen Ursprung der Aneignung der Matrone Lucina durch bischöfliche Interessen setzt Cooper jedoch in die von zahlreichen innerkirchlichen Konflikten geprägte Zeit des Damasus, der die Titelkirche der Lucina in die Kirche S. Laurentii in Damaso (!) verwandelt und römischen Matronen wie Lucina gegenüber eine Politik der Kooperation und Vereinnahmung verfolgt habe. Diese Haltung des Damasus gegenüber der Matrone Lucina bestärkt Cooper zugleich in ihrer Ausgangshypothese, dass die Schismatikerin Lucina, die in der passio Sebastiani in enger Verbindung mit der novatianischen basilica apostolorum erscheine, eine „novatianist icon“ gewesen sei, da Damasus während seines Pontifikats angeblich erkennbar versucht habe, die novatianische Sondergemeinde in die Großkirche zu integrieren. ${ }^{160}$ Das von Cooper diskutierte Beispiel der Auseinandersetzung um Orte der Heiligenerinnerung durch divergierende hagiographische Legendenbildungen (passio Sebastiani versus vita Cornelii; gesta martyrum versus gesta episcoporum/Liber Pontificalis) liefert ihr schließlich auch einen Schlüssel zum Verständnis der Gattung der gesta martyrum romanorum insgesamt: In der Produktion dieser hagiographischen Literatur spiegele sich eine „competiton among rival cult sites" wider, in der schismatische oder rivalisierende Gruppen ihren Anspruch auf identitätsstiftende Orte des Heiligenkults dem kontrollierenden episkopalen Zugriff von Bischöfen wie Damasus oder Symmachus entgegengesetzt hätten. Dieses polemische Potential habe dazu geführt, dass man den gesta martyrum von bischöflicher Seite eine offizielle Anerkennung als hagiographische Texte verweigert habe. ${ }^{161}$

Der im vorigen resümierte Ansatz, die gesta martyrum als Quelle für schismatische Formen von Identitätsstiftung zu begreifen, die durch eine Bezugnahme der Legenden auf bestimmte Orte der römischen Heiligentopographie vermittelt wurden, verlangt eine eingehendere Auseinandersetzung mit den methodischen Problemen, die sich mit dieser Literaturgattung verbinden. Dies betrifft zum einen die Auffassung, dass die gesta als eine mehr oder weniger einheitliche Gruppe von Texten aufzufassen seien, die ihren Ursprung einer mit der Amtskirche konkurrierenden, polemischen Perspektive verdanken. ${ }^{162}$ Gegen diese Sicht ist einzuwenden, dass sich keine äußeren

159 Zur Abfassungszeit des Liber Pontificalis vgl. u., Anm. 163.

160 Darauf laufen die - nicht immer ganz deutlichen - Ausführungen von Cooper 1999, $313 \mathrm{f}$. hinaus.

161 Ebd., bes. 300; 305-307.

162 Coopers Position in dieser Frage bleibt verschwommen: Einerseits konzediert sie, dass die gesta kein abgeschlossenes Corpus bildeten, andererseits fasst sie die Legenden insgesamt als „,polemical in origin“" und als einen Dorn im Auge der römischen Bischöfe auf, die ihre Lektüre einzuschränken suchten (vgl. Cooper 1999, 305-307). Zu diesen Einschränkungen, die nicht ohne weiteres auf eine polemische Haltung gegenüber den gesta martyrum hindeuten, s. u., S. 269. 
Anzeichen für einen derartigen einheitlichen Ursprung der gesta erhalten haben: Sie sind eine Gattung ohne Autor, ohne Ursprung, ohne einigendes redaktionelles Zentrum. Im Unterschied zum Liber Pontificalis, einer Zusammenstellung bischöflicher Biographien, die vermutlich bereits zu Beginn des 6. Jh. angelegt wurde, ${ }^{163}$ kann für die römischen Heiligenviten eine einheitliche Genese oder Redaktion nicht vorausgesetzt werden. Anders als es ihr in Anlehnung an die gesta episcoporum geprägter Titel suggeriert, sind die römischen gesta martyrum nicht das Ergebnis einer planmäßigen Zusammenstellung, wie sie im Liber Pontificalis für die römischen Bischöfe vorgenommen wurde. Zwar enthält die für die römischen Märtyrerpassionen um 500 gebräuchliche Bezeichnung als gesta martyrum ${ }^{164}$ Anklänge an die als gesta ausgewiesenen Viten des Liber Pontificalis, ${ }^{165}$ doch lässt sich eine dem Liber Pontificalis vergleichbare Zusammenstellung der römischen Passionen zu einem Legendar kodikologisch nicht nachweisen. ${ }^{166}$ Dies schließt wechsel-

163 Die Redaktion des Liber Pontificalis in seiner überlieferten Form setzt Duchesne in die Zeit unter Bischof Vigilius (537-555) (vgl. Duchesne [1886], in: LP I, XXXIII-XLVIII). Diese Auffassung hat sich gegen den alternativen Datierungsversuch von Mommsen, der den Liber Pontificalis erst in das 7. Jh. datiert (Mommsen [1898], in: LP, XIV-XVIII), überwiegend durchgesetzt (vgl. Vogel 1975, 101-108; Sardella 1996, 12-15). Daneben existierte eine leicht abweichende Fassung, von der zwei unterschiedliche Exzerpte erhalten geblieben sind (das felicianische und das kononianische Exzerpt). Duchesne hält diese Variante für die Urfassung bzw. eine 1. Redaktion des Liber Pontificalis, die unter Hormisdas (514-523) angelegt und bis zu Felix IV. (526-530) fortgesetzt worden sei (Duchesne [1886], in: LP I, XLIX-LXVII; dieselbe Relation zwischen 1. und 2. Redaktion vertritt auch Mommsen [1898], in: LP, XIIIf., CXII-CXVIII). In jüngster Zeit ist erwogen worden, dieses Verhältnis zwischen den beiden Fassungen umzukehren und in dem Text, der die Grundlage für die felicianischen und kononianischen Exzerpte bildete, nicht mehr die Urfassung, sondern umgekehrt eine frühe Bearbeitung des Liber Pontificalis zu sehen; vgl. Geertman 2003, 269f., Carmassi 2003, 240-246, die die Anlage des Liber Pontificalis in die Zeit des Symmachus (498-514) verlegt. Dass die Idee zur Sammlung von Bischofsbiographien in dieser Zeit entstanden ist, betont auch Duchesne (1886), in: LP I, XLVII.

164 Vgl. u., Anm. 177.

165 Zur Bezeichnung der Bischofsviten im Liber Pontificalis zusammengestellten Bischofsviten als gesta vgl. das Widmungsschreiben des Ps.-Hieronymus (LP I, 117). Der Liber Pontificalis kann damit als ein frühes Beispiel der gesta episcoporum gelten, die sich aus den Bischofslisten heraus entwickelten (für Oberitalien, wo die Entwicklung der gesta episcoporum stark vom römischen Vorbild des Liber Pontificalis beeinflusst wurde, vgl. Picard 1988, 537-569).

166 Dufourcq 1900-1910/1988, Bd. 1, 77-92, ders. 1906 hatte mit Blick auf ein im ausgehenden 9. Jh. in St. Gallen verfasstes Legendar mit römischen Heiligenlegenden die These aufgestellt, dass es auf einem römischen Vorläufer basiere, der bereits im 6. Jh. zusammengestellt worden sei, und dass es sich bei diesem Archetyp um eine Sammlung von Heiligenlegenden handele, auf die Gregor I. (590-604) in einem Brief an den Patriarchen Eulogius von Alexandria anspielt (Gregor I., epist. 8, 28 [598]). Seine Schlussfolgerung, dass im Rom des 6. Jh. eine dem Liber Pontificalis vergleichbare Sammlung von Heiligenlegenden existiert habe, untermauerte Dufourcq damit, dass sich Einflüsse dieses Legendars im sogenannten martyrologium vetus oder parvum Romanum nachweisen ließen, das Ado von Vienne für sein zwischen 850 und 860 verfasstes Martyrologium heranzog: Dieses parvum Romanum wiederum datierte Dufourcq in das frühe 7. Jh. und vermutete, dass es sich um einen unter Bonifatius IV. (608-615) oder Honorius I. (625-638) redigierten Kalender der römischen Kirche handele (Dufourcq 1900-1910/1988, Bd. 1, 372-375). Quentin 
seitige Abhängigkeitsbeziehungen in der Entstehung dieser Texte nicht aus, erlaubt jedoch nicht, ihnen eine einheitliche Genese und Zielsetzung im Sinne einer polemischen, gegen die Amtskirche gerichteten Literaturproduktion zuzuweisen.

Diese disparaten Ursprünge der gesta martyrum, die es nicht ermöglichen, sie als Textsammlung mit einer bestimmten Aussageabsicht zu verstehen, verweisen auf ein Problem, das sich auch auf der Ebene der einzelnen Texte fortsetzt. Ein strukturelles Charakteristikum der römischen Heiligenviten besteht darin, dass sie sich nicht allein auf einen einzigen Protagonisten konzentrieren, sondern häufig mehrere Märtyrer und Märtyrergruppen umfassen, die durch eine locker konstruierte Rahmenhandlung miteinander verbunden werden. ${ }^{167}$ Die passio Sebastiani bildet dafür ein instruktives Beispiel:

Die passio stellt Sebastianus als einen hohen Offizier dar, der den verfolgten Christen Roms im Geheimen beisteht. Unter ihnen befinden sich auch Marcellianus und Marcus, die Söhne von Tranquillinus und Marcia, die unter dem praefectus urbi Agrestius Chromatius festgenommen und in der domus des primiscrinius Nicostratus inhaftiert werden. Nachdem Sebastian die Frau des Nicostratus, Zoe, von Blindheit geheilt hat, bekehrt sich Nicostratus und weist einen commentariensis Claudius an, alle gefangenen Christen Roms zu seiner domus zu bringen. Daraufhin sucht Sebastian einen Presbyter Polykarp in seinem Versteck auf, damit er im Haus des Nicostratus die Taufe der

1908, 409-464, 649-672 hat jedoch das parvum Romanum als eine archaisierende Fälschung des Ado von Vienne erwiesen und damit Dufourcqs Argumentation die wesentliche Grundlage entzogen (für Skepsis an Dufourcqs Rekonstruktion eines römischen Legendars des 6. Jh. auf der Grundlage des St. Gallener Legendars vgl. bereits Delehaye 1900, 445f.). Es gibt keinen Grund zur Annahme, dass bereits im 6. Jh. ein Legendar mit römischen Märtyrerlegenden existiert hätte: Der älteste handschriftliche Beleg für eine römische passio, die Sankt Petersburger Handschrift der passio Gallicani (s. o., Anm. 154), zeigt, dass die römischen Heiligenlegenden zu dieser Zeit noch in Form eigenständiger libelli zirkulierten (vgl. Philippart 1977, 99-101). Dass auf der Grundlage der römischen gesta Legendare gebildet wurden, die zum Teil die römischen Legendenzyklen aufbrachen, indem sie die in ihnen enthaltenen Heiligen den entsprechenden Kommemorationstagen zuordneten, ist ein Vorgang, der erst später einsetzte. Die ältesten erhaltenen Legendare stammen aus der Zeit seit der Mitte des 8. Jh. (vgl. Philippart 1977, 30f.; dens. 1985, 7); indirekte Zeugnisse legen nahe, dass die Abfassung von Legendaren frühestens seit dem Beginn des 7. Jh. einsetzte (s. Philippart 1994, 623-626). Anders als Dufourcq hat Delehaye sein „légendier romain“ (vgl. Delehaye 1933 [a], dens. 1936) nicht als ein historisches, sondern als ein niemals realisiertes, gleichsam ,virtuelles“ Legendar verstanden (s. dazu Vircillo Franklin 2001, 857-860). Auf welche Weise sich der umfangreiche Bestand an römischen Heiligenlegenden formierte, ist ein offenes Forschungsproblem; zu berücksichtigen ist, dass die römischen gesta auch über die Grenzen Roms hinaus die Produktion der hagiographischen Literatur beeinflusst haben (für die umbrisch-etruskischen Heiligenlegenden vgl. Lanzoni 1903, 11-16; de Gaiffier 1965).

167 Hippolyte Delehaye hat dafür den Begriff der „zyklischen Passion“ geprägt; einzelne Beispiele für diesen Legendentyp, die ein besonders breites Spektrum an Akteuren und Schauplätzen umfassen, führt Delehaye 1934, 34f., ders. 1936, 11f., auf. Die Anlage zyklischer Passionen begegnet in der spätantiken Hagiographie auch außerhalb Roms; sie war dort jedoch besonders stark ausgeprägt (vgl. Delehaye ${ }^{21966,222) .}$ 
Neubekehrten und die Feier der Eucharistie vollzieht. Nachdem Nicostratus zwischenzeitlich auch noch den commentariensis Claudius bekehrt hat, tauft Polykarp neben Nicostratus und Zoe den Bruder des Nicostratus, Castor, den commentariensis Claudius und seine Familie (die Ehefrau Symphorosa und die Söhne Felix und Felicissimus) sowie die Familien von Marcellianus und Marcus (die Eltern Tranquillinus und Marcia, die namentlich nicht genannten Ehefrauen und Kinder), ferner sechs Freunde des Märtyrerpaares (Ariston, Crescentianus, Eutychianus, Urbanus, Vitalis, Iustus). Weiteren Zuwachs erhält diese umfangreiche Zahl an Handlungsträgern noch durch Beatrix und Lucina, die als Mütter von Zoe und Symphorosa erscheinen. Nach einer langatmigen Bekehrungsgeschichte, in deren Verlauf auch der Stadtpräfekt Chromatius und sein Sohn Tiburtius für das Christentum gewonnen und im Haus des Chromatius zusammen mit dessen familia getauft werden, besteht der Rest der passio Sebastiani in Darstellungen des Schicksals einiger ihrer zahlreichen Protagonisten: Nach dem Ausbruch der diocletianischen Verfolgung sammelt sich ein Teil der im Verlauf der passio eingeführten Personen (neu hinzu kommen ein Bruder des Claudius, Victorinus, und dessen Sohn Symphorianus) um den römischen Bischof Gaius und hält sich zunächst im Haus des zetarius palatii Castulus verborgen. Die abschließenden Kapitel (73-90) der passio Sebastiani gelten den Martyrien der einzelnen Märtyrer und ihren stadtrömischen Schauplätzen: Den Auftakt bilden Zoe, die am natale apostolorum (29. Juni) bei S. Pietro ergriffen wird, und Tranquillinus, der dasselbe Schicksal eine Woche später bei der confessio Pauli an der via Ostiensis, erleidet. Abgeschlossen wird der Reigen dieser und weiterer Martyrien durch Sebastian, der zunächst, von Pfeilen durchbohrt, in der domus der Irene (Mutter des Castulus) in der Nähe des Palatin gepflegt, dann auf den gradus Heliogabali erneut festgenommen und im „Hippodrom des Palatin“ hingerichtet wird. Die Matrone Lucina bestattet ihn ad catacumbas und wandelt nach dem Ende der Verfolgungen ihre domus in eine Kirche um.

Diese Inhaltsangabe verdeutlicht gerade wegen ihrer ermüdenden Fülle an Märtyrern, heidnischen und christlichen Handlungsträgern und Schauplätzen innerhalb Roms und des römischen Suburbiums die methodischen Probleme, die römische Märtyrerlegenden wie die Passio des Heiligen Sebastian aufwerfen. Um die prosopographischen und topographischen Bezüge dieser Legenden zu interpretieren, reicht es nicht aus, sich ein einzelnes Element wie die Bestattung des Sebastian durch Lucina herauszugreifen, und dies zum Ausgangspunkt einer Interpretation zu machen. Man muss vielmehr zunächst die Strukturprinzipien verstehen, nach denen das prosopographische und hagiographische Material von legendarischen Produkten wie der passio Sebastiani zusammengesetzt ist. Erst ein Einblick in die Arbeitsweise der römischen Hagiographen bietet eine Handhabe dafür, ob der Verbindung von Lucina und Sebastian ein besonderer Aussagewert beizumessen ist.

Obwohl die Kompositionsprinzipien der römischen gesta martyrum noch nicht systematisch untersucht worden sind, lassen sich zwei leitende Grundsätze für die Zusammenstellung von Märtyrergruppen zu legendarischen Zyklen unschwer bestimmen. Die im Rahmen einer passio vorgestellten Märtyrer konzentrierten sich häufig auf eine bestimmte Region der Stadt und 
seines Suburbiums, ${ }^{168}$ oder sie wurden nach einer kalendarischen Reihenfolge ausgewählt und gruppiert. ${ }^{169}$ Bezeichnenderweise halten die römischen Passionen jedoch weder das topographische noch das kalendarische Gliederungsprinzip strikt ein. Die Verfasser der gesta martyrum bildeten in den dramatis personae ihrer hagiographischen Großerzählungen nicht einfach regionale Identitäten $\mathrm{ab}$, indem sie alle Heiligen einer bestimmten Gegend, beispielsweise der Coemeterien an der via Salaria, in den Gang ihrer Erzählung verflochten und damit einen Erinnerungsraum dieser Region konstruierten. Ebensowenig sind die gesta der Reflex einer Gruppenidentität, deren fundierendes Merkmal eine von allen Mitgliedern der Gruppe geteilte liturgische Zeit war. Vielmehr lieferten die Vielzahl topographischer Orte und kalendarischer Kommemorationsdaten den Verfassern der gesta martyrum einen Fundus an prosopographischem und topographischem Material, das zur Anlage von hagiographischen Großerzählungen verwendet werden konnte. Das Ergebnis waren - in ihren personalen und topographischen Details in begrenztem Umfang erweiter- und veränderbare ${ }^{170}$ - Legenden, in denen nicht selten, wie in der passio Sebastiani, eine große Zahl von Heiligen und Schauplätzen unter den Händen ihrer Verfasser zu großangelegten Passionen verwoben wurden.

Die Anlage derartiger Legendenzyklen, in denen bei einer großen Varianz an Personen und Schauplätzen schablonenartig ein begrenztes Repertoire an Handlungsabläufen und Motiven vorgeführt wird, stellt eines der wesentlichen Merkmale dieser hagiographischen Literaturproduktion dar, in der die Verfasser der spätrömischen Heiligenlegenden ein gewisses Maß an literarischer Kreativität unter Beweis stellten, und das dem Bedürfnis ihrer Leser

168 Vgl. Delehaye 1936, 24f.

169 Z. B. in der passio Polychronii et sociorum (vgl. Delehaye 1933 [a], 35, 40) und in der passio Felicitatis.

170 Die Genese (und Variabilität) der Legenden in ihrer spätantiken Entstehungszeit ist nur indirekt zu erschließen, da die handschriftliche Überlieferung - von vereinzelten Ausnahmen abgesehen - erst im 8. Jh. einsetzt, als die gesta in ihrer Grundstruktur bereits festgelegt waren. Exemplarisch fassbar werden die Bearbeitungsvorgänge in der passio Gallicani, Iohannis et Pauli. Die älteste erhaltene Handschrift der passio Iohannis et Pauli aus dem 6. Jh. - zugleich das älteste Textzeugnis für eine römische Märtyrerpassion überhaupt (s. o., Anm. 154) - ist bereits das Ergebnis einer mehrstufigen redaktionellen Bearbeitung: Die Passio der beiden Heiligen war zunächst aus einem umfassenderen Legendenzyklus (der passio Gallicami) ausgegliedert und danach durch eine Einfügung weiterer Heiliger erweitert worden (zu letzterem vgl. Franchi de' Cavalieri 1915, bes. 43-45. Für die zyklische passio Gallicani selbst vgl. zuletzt Bundy 1987, 18-31, der die Ursprünge der in ihr enthaltenen Legendenkerne aufgrund der Motivstruktur im Bereich der Folklore/popular narrative ansiedelt [daneben sind allerdings auch die Einflüsse zu berücksichtigen, die die Literarisierung der Legenden auf die Standardisierung der Motive hatte, s. dazu u., S. 266]). Auch nach dem 8. Jh. bildeten die hagiographischen Texte eine lebendige, starken Veränderungen unterworfene Gattung, indem die zyklischen Passionen aufgebrochen und das auf die einzelnen Heiligen bezogene Material nach der Abfolge der Kommemorationstage angeordnet wurde (vgl. Diesenberger 2006, 206-208). Veränderlich blieben die gesta auch in topographischer Hinsicht; vgl. z. B. die Varianten der passio Hippolyti, die in der ersten Hälfte des 8. Jh. um neue Details der römischen Topographie bereichert wurde (Follieri 1980-1982). 
nach erbaulicher und zugleich unterhaltsamer Literatur entgegenkam. ${ }^{171}$ Unter diesen Voraussetzungen ist die Annahme, dass die Matrone Lucina in ihrer unterschiedlichen Funktion in der passio Sebastiani (als Bestatterin in der Apostelbasilika ad catacumbas) und in der passio Cornelii (als Apostelbestatterin an der via Ostiensis) die Exponentin rivalisierender Identitätskonstruktionen („novatianist icon“ und katholische Matrone) geworden sei, wenig überzeugend. Lucina erscheint in den römischen Märtyrerpassionen in ihrer Rolle als Bestatterin nicht nur in Verbindung mit der basilica apostolorum und dem Paulusgrab an der via Ostiensis, sondern kam in dieser Funktion auch an der via Aurelia, an der via Portuensis und der via Salaria zum „Einsatz“: ${ }^{172}$ Sie ist damit nicht mehr als ein literarisches Wandermotiv, das in den Händen der spätantiken Hagiographen variabel einsetzbar war, und das in der passio Sebastiani ebensowenig Ausdruck eines häretischen oder orthodoxen Identitätsdiskurses ist, wie in der passio Marcelli oder in der passio Processi et Martiniani. ${ }^{173}$

Der Quellenwert der gesta martyrum für kollektive Identitätsdiskurse ist damit in mehrfacher Hinsicht problematisch. Die Verfasser der Legenden griffen zwar durchaus auf Material zurück, das eine identitätsrelevante Bedeutung für Gruppen hatte (Raum und liturgische Zeit als identitätsrele-

171 Aigrain 1953 (2000), 223-235 macht überzeugend deutlich, dass die Märtyrerlegenden mit ihren repetitiven Motiven und Handlungsabläufen sowie der Einführung immer neuer Protagonisten im Rahmen stereotyper Handlungsmuster eine literarische Erwartungshaltung bedienten, und zieht Parallelen zur französischen Romanliteratur des 19. Jh. (ähnlich auch Achelis 1893, 61f.; Delehaye ${ }^{21966,171-226 ~ h a t ~ f u ̈ r ~ d i e s e n ~ L e g e n d e n t y p ~ d e n ~ B e g r i f f ~ d e r ~ „ p a s s i o n ~ e ́ p i q u e “ ~ g e p r a ̈ g t) . ~}$ Dem Leser des 21. Jh. drängen sich in Anbetracht der dürftigen literarischen Qualität der hagiographischen Produkte Vergleiche mit Erzeugnissen der Trivialliteratur auf, die gezielt mit einem beschränkten und klischeehaften, auf Wiedererkennung angelegten Repertoire an Charakteren und Handlungselementen operiert. In die gleiche Richtung geht auch Huber-Rebenich 1999, die die römischen gesta als eine Form von spätantik-frühmitttelalterlicher Unterhaltungsliteratur begreift. Dieser Unterhaltungsaspekt in der antiken Märtyrerliteratur ist in den letzten Jahren allgemein zunehmend betont worden, vor allem mit Blick auf die in ihnen enthaltenen Darstellungen von Erotik und Gewalt (G. Clark 2004, 44). Bei den römischen Heiligenlegenden tritt dieses Element nicht so stark hervor; sie beziehen ihre literarische Wirkung aus der Einbeziehung einer Vielzahl unterschiedlicher Handlungsschauplätze und Akteure. Zur Leserschaft dieser Legenden s. u., S. 434f.

172 Via Ostiensis (ohne Bezug zu den Paulusreliquien!): passio Marcelli 21 (vgl. Mombritius II, 172, 3641); via Salaria: passio Marcelli 22 (vgl. Mombritus II, 172, 50-52); via Aurelia: passio Processi et Martiniani (Franchi de' Cavalieri 1953, 52, 6-9); via Portuensis: passio Simplicii, Faustini et Beatricis 2 (vgl. Mombritius II, 532, 17-19). Die passio Anthimi greift Motive der passio Sebastiani, der passio Simplicii, Faustini et Beatricis und der passio Marcelli auf (Verrando 1987, 370). Für einen Überblick vgl. auch Lietzmann ${ }^{21927,179-189 . ~}$

173 Ähnlich wie Lucina erscheint auch ein Presbyter namens Iohannes in mehreren römischen Passionen in der stereotypen Rolle des Bestatters - auch er, wie Lucina, nicht mehr als ein wanderndes literarisches Motiv (vgl. die Passio Polychronii 35 [Delehaye 1933 [a], 98]; passio Marcelli 22 [vgl. Mombritius II, 172, 50-52]; passio Simplicii, Faustini et Beatricis 1 [vgl. Mombritius II, 532, 1-4]; passio Gallicani [AASS Iun. V. 160 E]; passio Pigmenii 4 [Delehaye 1936, 262]). Für weitere Namen, die in den römischen Legenden mit der Funktion des Bestatters in Verbindung gebracht werden, vgl. Delehaye 1936, 36. 
vante Faktoren), aber sie gestalteten und organisierten es nach literarischen Gesichtspunkten. Zumindest in ihrer überlieferten Form, in der unterschiedliche Martyrien und Traditionen zu größeren Erzählungen verwoben sind, lassen die gesta martyrum keine direkten Rückschlüsse auf regional, sozial oder religiös begründete kollektive Identitäten zu: Die Legenden sind nicht einfach Reflexe kollektiv geteilter legendarischer Traditionen, sondern artifizielle und literarische Produkte, die in hohem Maße von der individuellen Kombinationsfähigkeit und der Assoziationsbereitschaft ihrer Verfasser lebten. Dabei kam es zu Motivwanderungen, in deren Verlauf stereotype Handlungselemente und -schauplätze ihren Weg in neue legendarische Kontexte fanden. Regelmäßig wiederkehrende Elemente wie die bestattende Matrone oder der bestattende Priester sind das Ergebnis einer literarischen Verselbständigung, in der das legendarische Material - Heilige, die coemeteriale und städtische Kulttopographie ebenso wie die pagane Topographie der Stadt Rom ${ }^{174}$ - zu einem Fundus stereotyper und klischeehafter Handlungselemente in den Händen der Autoren wurde, die diese Texte produzierten.

Die Kriterien, von denen sich die Verfasser der Legenden bei der Auswahl und Komposition ihres Stoffes leiten ließen, lassen sich dementsprechend nicht per se als ein Versuch begreifen, durch die Kombination bestimmter Heiliger und stadtrömischer Schauplätze kollektive Identitätskonstruktionen (z. B. in Form eines novatianischen Erinnerungsraums) vorzunehmen. In den gesta spiegeln sich nicht rivalisierende Ansprüche auf Kultorte wider, sondern vor allem das Gestaltungsvermögen von Autoren, die ihren Produkten durch die Vielzahl der Akteure und Schauplätze (ein bescheidenes Maß an) Farbigkeit und Plastizität verliehen. ${ }^{175}$ Wiederkehrende Motive wie die bestattende Lucina oder der Presbyter Johannes sind typische Erscheinungsformen dieses Genres hagiographischer Trivialliteratur. Dies bedeutet zwar nicht, dass die gesta martyrum grundsätzlich beliebige Kompilationen hagiographischen Materials darstellen: Es ist nicht auszuschließen, dass hinter der Kombination bestimmter Heiliger und legendarischer Traditionen das Bestreben der Verfasser steht, beziehungsreiche Anspielungen und Verbindungen herzustellen. Ein solcher Nachweis erfordert jedoch im Einzelfall eine Auseinandersetzung, die sich nicht auf der Ebene einzelner und isolierter Legendenmotive bewegt, sondern jeweils den Kontext einer ganzen

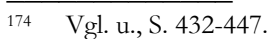

175 Auf diesen Aspekt hat der Bollandist Hippolyte Delehaye nach jahrzehntelanger Beschäftigung mit den römischen Heiligenviten nachdrücklich aufmerksam gemacht (vgl. das Fazit von Delehaye 1936, 7: „le choix [scil. der zu Zyklen zusammengestellten Passionen] est sujet à des modifications commandées par l'usage local ou par des circonstances accidentelles que nous ignorons le plus souvent"; dass diese Zyklen nicht das Abbild kollektiver Identitäten bieten, sondern auf dem individuellen literarischen Gestaltungswillen einzelner Autoren beruhen, die ihr Material nach Belieben zusammenstellten, hebt Delehaye ebd., 14f. hervor). Zustimmend Pietri 1981, 436. 
Legende einbezieht und sie als Text in ihren literarischen Abhängigkeitsbeziehungen und Bezugnahmen auf andere Legenden analysiert. ${ }^{176}$ Die gesta martyrum in dieser Hinsicht aufzuschlüsseln, ist jedoch ein komplexes Unterfangen, das in mancher Hinsicht an die - mit deutlich höherem Forschungsaufwand betriebene - Erschließung der Kaiserbiographien der Historia $A u$ gusta erinnert, und für das bisher noch keine ausreichenden Vorarbeiten geleistet worden sind.

Diese grundlegenden Einschränkungen bezüglich des Aussagewertes der gesta martyrum als Quelle für abgrenzbare Gruppenidentitäten und die Auseinandersetzung um Orte der Heiligenerinnerung in Rom vorausgesetzt, stellt sich als abschließende Frage, ob den gesta martyrum grundsätzlich eine Nähe zu schismatischen (und speziell novatianischen ${ }^{177}$ ) Gruppierungen attestiert werden kann. Es ist zwar unbestreitbar, dass der Typ hagiographischer Literatur, wie er durch gesta martyrum repräsentiert wird, in der römischen Kirche als apokryph abgelehnt wurde und damit Vorbehalten begegnete, die einige der Verfasser derartiger Viten durch apologetische Einleitungen zu ihren Werken aus dem Weg zu räumen versuchten. ${ }^{178}$ Diese offizielle Zurückhal-

176 Für einen entsprechenden Versuch, die literarischen Abhängigkeitsbeziehungen zwischen den unterschiedlichen Passionen mit dem Lucinamotiv herauszuarbeiten und auf diese Weise Verwandtschaften zwischen den Texten ausfindig zu machen, die auf einen gemeinsamen Autor bzw. Entstehungskontext verweisen, vgl. Verrando 1987, 364-373. Bei aller Problematik seiner Ergebnisse im Detail ist seine Einschätzung, dass die passio Cornelii enge Berührungspunkte mit der passio Processi et Martiniani aufweist, beide jedoch mit der passio Sebastiani nichts zu tun haben (ebd., 364: ,poche affinità“), vollkommen zutreffend.

177 Cooper 1999, 305 u. 307 möchte der Nachricht des Liber Pontificalis, Bischof Fabian (236-250) habe eine Sammlung der gesta martyrum veranlasst (LP I, 148), entnehmen, dass die römischen Bischöfe der Legendenproduktion einen bischöfliche Kontrollanspruch entgegengesetzt und die Heiligenlegenden mit einem novatianischen Ursprung assoziiert hätten, da Novatian als Nachfolger Fabians zum Bischof erhoben worden sei. Dabei lässt sie freilich außer Acht, dass gleichlautende Nachrichten von der Zusammenstellung der gesta martyrum im Liber Pontificalis nicht nur mit Fabian, sondern auch mit den Bischöfen Clemens (90/92-99/101) und Anteros (235-236) verbunden werden (vgl. LP I, 52f./123; 62/147).

178 Die amtskirchliche Skepsis gegenüber der hagiographischen Produktion im spätantiken Rom tritt im sogenannten decretum Gelasianum deutlich hervor, einem unter dem Namen unterschiedlicher römischer Bischöfe umlaufenden und Texte unterschiedlicher Entstehungszeit enthaltenden Schriftstück, dessen zwei abschließende Kapitel listenartige Zusammenstellungen kirchlich approbierter und als apokryph eingestufter Literatur enthalten. Datierung und Charakter des decretum sind umstritten: Sein Herausgeber, v. Dobschütz 1912, 334-357 betrachtet es als eine in der ersten Hälfte des 6. Jh. in Oberitalien verfasste Privatarbeit (ähnlich de Gaiffier 1969, 70f.: Ende des 6. Jh.). Chapman 1913, bes. 194-198, 328 tritt hingegen dafür ein, dass das Schriftstück auf den Beschluss einer römischen Synode unter Gelasius I. (492-496) zurückgeht (so auch zuletzt Grossi 2001, bes. 236f., der allerdings keine wesentlichen neuen Argumente beisteuert). Eher unwahrscheinlich ist die Ansicht von McKitterick 1989, 202-204, das decretum Gelasianum sei erst zu Beginn des 7. Jh. im fränkischen Raum entstanden. - Der Verfasser des decretum macht trotz seiner eigenen Hochschätzung der Märtyrer - deutlich, dass die Märtyrerviten in der römischen Kirche nicht auf viel Sympathie stießen; vgl. decret. Gelas. 4, 4, 1: item gesta sanctorum martyrum, quae multiplicibus tormentorum cruciatibus et mirabilibus confessionum triumphis inradiant. quis catholico- 
tung gegenüber den gesta führte jedoch nicht dazu, dass man sie in Rom als häretische Schriften betrachtete. Zwar monierte man von amtskirchlicher Seite an den gesta Eigenschaften, die sie durchaus in die Nähe häretischen Gedankenguts rückten, ${ }^{179}$ doch wurde diese Gleichsetzung von der römischen Kirche bezeichnenderweise nicht konsequent vollzogen: Man verweigerte den gesta zwar die Anerkennung als liturgische Lesungstexte im Stundengebet und im Gottesdienst, wie sie in anderen spätantiken Kirchen üblich war, ${ }^{180}$ stufte sie jedoch nicht als häretisches oder schismatisches Schrifttum ein. ${ }^{181}$ Die von Albert Dufourcq in seiner großangelegten Studie zu den gesta martyrum vertretene These, dass der Manichäismus einen formativen Einfluss auf die Heiligenlegenden ausgeübt habe, hat dementsprechend auch keine Anhänger gefunden. ${ }^{182}$ Bezüglich einer vermeintlichen Nähe der gesta

rum dubitet maiora eos in agonibus fuisse perpessos nec suis viribus sed dei gratia et adiutorio universa tolerasse? sed ideo secundum antiquam consuetudinem singulari cautela in sancta Romana ecclesia non leguntur, quia et eorum qui conscripsere nomina penitus ignorantur et ab infidelibus et idotis superflua aut minus apta quam rei ordo fuerit esse putantur; sicut cuiusdam Cyrici et Iulittae, sicut Georgii aliorumque eiusmodi passiones, quae ab baereticis perbibentur conpositae. propter quod, ut dictum est, ne vel levis subsannandi oriretur occasio, in sancta Romana ecclesia non leguntur. Obwohl das decretum Gelasianum mit den Cyricus und Iulitta- und den Georgs-Akten Beispiele aufführt, die in keiner Beziehung zum Kreis der römischen Heiligenlegenden stehen, ist dennoch sicher, dass auch die römischen gesta martyrum diesem Verdikt unterlagen. Dies wird daraus ersichtlich, dass eine Reihe von römischen Märtyrerlegenden einen Prolog trägt, in dem sich der Verfasser explizit gegen den Vorwurf wendet, die Legenden hätten einen häretisch-apokryphen Charakter (vgl. de Gaiffier 1964). Zur Frage, inwieweit das decretum Gelasianum als Beleg für eine in der ganzen römischen Kirche praktizierte Zurückhaltung bei der liturgischen Lesung der gesta martyrum herangezogen werden kann, vgl. u., S. 434 mit Anm. 114.

179 Das zentrale Kriterium, weswegen die römische Kirche die offizielle Lektüre der gesta ablehnte, entspricht demjenigen, das auch bei Filastrius v. Brescia zur Kennzeichnung apokrypher Literatur begegnet: die Hinzufügung häretischen Gedankengutes durch idiotae bzw. non intelligentes (vgl. die parallelen Wendungen im decret. Gelas. 4, 4, 1: ab infidelibus et idotis superflua aut minus apta quam rei ordo fuerit (scil: addita) esse putantur und bei Filastr. 88: scripturae autem absconditae, id est apocrapha, etsi legi debent morum causa a perfectis, non ab omnibus debent, quia non intelligentes multa addiderunt et tulerunt quae voluerunt haeretici).

180 Zur Verwendung von Märtyrerakten als liturgische Lesungstexte im spätantiken Africa, Gallien und Spanien vgl. de Gaiffier 1954; für Africa s. Saxer 1980, 200-208.

181 Der Verfasser des decretum Gelasianum rubriziert die Heiligenlegenden unter den im 4. Kapitel aufgeführten Werken, deren Lektüre die römische Kirche ad aedificationem zulasse, nicht aber unter den im 5. Kapitel als Apokryphen aufgelisteten Schriften, quae ab haereticis sive scismaticis conscripta vel praedicata sunt (decret. Gelas. V). Für die gesta sanctorum martyrum, die wegen ihrer ungeklärten Verfasserschaft in der römischen Kirche nicht als Lesungstexte verwendet werden, kann dasselbe vorausgesetzt werden wie für die actus Silvestri, auf die der Verfasser des decretum Gelasianum im Anschluss an die gesta martyrum zu sprechen kommt: Der Verfasser der Silvesterakten ist unbekannt, sie werden jedoch im nicht-offiziellen Bereich von vielen katholischen Christen gelesen (actus beati Silvestri..., licet eius qui conscripserit nomen ignoretur, a multis tamen in urbe Roma catholicis legi cognovimus [decret. Gelas. 4, 4, 3]). Die Leserschaft der multi catholici, auf die hier angespielt wird, dürfte sich vor allem aus Laien zusammengesetzt haben, die die Märtyrerpassionen zur privaten Erbauung und Unterhaltung lasen (vgl. u., S. 435, Anm. 115).

182 Zu vermeintlichen manichäischen Einflüssen in der römische Hagiographie vgl. Dufourcq 19001910/1988, Bd. 1, 323-343. Die dort angeführten Belege (vor allem die besondere Wertschät- 
martyrum zu schismatischen bzw. gegen den Kontrollanspruch des römischen Bischofs gerichteten Gruppenidentitäten lassen sich ähnliche Bedenken anführen. Vielmehr gibt der Umstand, dass der Liber Pontificalis an zahlreichen Stellen hagiographisch-legendarisches Material enthält, das direkt aus Märtyrerlegenden stammt oder deren typische Motive verarbeitet, ${ }^{183}$ Anlass, die Nähe zwischen den gesta martyrum und den gesta episcoporum zu betonen. Auch die im Liber Pontificalis mit den Biographien unterschiedlicher Bischöfe verbundene Bemerkung, sie hätten die gesta martyrum von den notarii der Kirchenregionen mit „Eifer und Sorgfalt“ zusammentragen lassen, ${ }^{184}$ deutet nicht auf eine Abwertung der gesta martyrum hin. Die Zurückhaltung der römischen Kirche gegenüber den gesta martyrum als liturgische Lesungstexte lässt sich nicht zu der Schlussfolgerung zuspitzen, mit der bischöflichen Biographieschreibung des Liber Pontificalis sei gleichsam ein offizielles Gegenprogramm zu den römischen Märtyrerlegenden ins Leben gerufen worden. Diese Vorstellung eines strukturellen Gegensatzes zwischen den gesta episcoporum und den gesta martyrum führt in eine falsche Richtung, die sie verbindenden Grundlagen verdeckt: Die Bischofsbiographien des Liber Pontificalis sind eher als Pendant und Ergänzung der in Rom verbreiteten Heiligenlegenden, nicht aber als rivalisierende legendarische Konstruktionen aufzufassen.

Nach diesen grundsätzlichen methodischen Bemerkungen und den Einwänden gegen eine literarische Ortsbestimmung der gesta martyrum als polemische, gegen eine bischöfliche Kontrolle der römischen Heiligentopographie gerichtete Texte können wir uns erneut der passio Sebastiani und der Frage zuwenden, ob die Bestattung Sebastians iuxta vestigia apostolorum durch die Matrona Lucina geeignet ist, die Hypothese von der basilica apostolorum als einer novatianischen Kultstätte zu stützen. Die passio Sebastiani berichtet von einer Bestattung Sebastians iuxta apostolorum vestigia, nicht etwa iuxta apostolos. Dass der Verfasser der passio Sebastiani mit dieser Wendung eine frühere Präsenz der Petrusreliquien ad catacumbas vindizieren und darin in Konkurrenz zur bischöflichen Lokalisierung der Reliquien am Vatikan habe treten wollen,

zung asketischer Leistungen in den römischen Märtyrerakten) überzeugen nicht (vgl. allgemein Monfrin 1988, XXXII; mit Blick auf die Petrusakten des Ps.-Linus Verrando 1983, 408f. mit Anm. 69).

183 Deutlich sind die Einflüsse in den Biographien von Alexander, Urbanus, Cornelius, Gaius, Marcellus (2. Redaktion); weniger ausgeprägt nachweisbar bei Clemens und Callistus. Für Pontian, Anteros und Marcellinus lässt sich vermuten, dass der Redaktor des Liber Pontificalis auf verlorene Passionen zurückgriff. Zur Rolle der gesta martyrum als Quellen des Liber Pontificalis vgl. die Diskussion von Duchesne (1886), in: LP I, XCI-C. Für die Viten von Liberius und Felix II. und ihr Verhältnis zur legendarisch-hagiographischen Überlieferung s. u., S. 449-451, 468f.

184 Vgl. LP I, 52 u. 123 (Clemens): fecit VII regiones et dividit notariis fidelibus ecclesiae qui gesta martyrum sollicite et curiose unusquisque per regionem suam diligenter perquireret); in ähnlicher Form begegnet diese Notiz auch in den Biographien von Anteros und Fabian (vgl. LP I, 62 u. 147; 64 u. 148). 
ist wenig überzeugend. Zwar kann vestigia auch in der Bedeutung als Reliquien verwendet werden, ${ }^{185}$ doch soll die Wendung iuxta vestigia in Verbindung mit der basilica apostolorum vermutlich nichts anderes besagen, als dass der Ort zu Lebzeiten der Apostel ihre Wohnstätte gebildet habe. ${ }^{186}$ Diese Auffassung geht zurück auf die Anfangszeilen eines berühmten Epigramms, das Bischof Damasus (366-384) in der basilica apostolorum anbringen ließ: „Erkenne, dass hier einst die Heiligen Petrus und Paulus gewohnt haben (habitasse) “. ${ }^{187}$ Das damasianische habitasse, dessen Deutung auch in der modernen Forschung umstritten ist, ${ }^{188}$ gab offenbar bereits in der Spätantike Anlass für unterschiedliche Interpretationen: Der Verfasser der wohl um die Mitte des 5. Jh. geschriebenen ${ }^{189}$ passio Sebastiani fasste es offenbar als einen Hinweis auf eine Wohnstätte der Apostel auf; die Corneliusvita des Liber Pontificalis sah darin hingegen eine Anspielung auf eine frühere Bestattung ihrer sterblichen Überreste an der via Appia, bevor sie zu einem späteren Zeitpunkt an den Vatikan und an die via Ostiensis überführt wurden. ${ }^{190}$ Folgt man dieser Deutung, würde ausgerechnet die durch die Corneliusvita repräsentierte „bischöfliche Perspektive“ die einstige Lokalisierung der Apostelreliquien in catacumbas thematisieren, während die vermeintlich novatianisch beeinflusste

185 Vgl. Gaudent., serm. 18, 28; ähnlich auch Paul. Nol., carm. 19, 352.

186 In eben dieser übertragenen Bedeutung als Bezeichnung für eine Wohnstätte erscheint die Wendung in den actus Petri cum Simone 15, wo Simon Magus aufgefordert wird, das Haus zu verlassen, in dem Petrus wohnte: discede... a ianua in qua sanctorum vestigia conversantur. Guarducci 1986, 837-839 u. Luiselli 1986, 848-852 fassen die vestigia wörtlich auf und denken an Fußspuren der Apostel, die man in S. Sebastiano verehrt habe. Zu dieser Annahme besteht jedoch kein Anlass.

187 Damas., epigr. 20: hic habitasse prius sanctos cognoscere debes / nomina quisque Petri pariter Paulique requiris.

188 Für Ferrua spiegelt sich in dem habitasse prius die Auffassung wider, dass Petrus und Paulus in catacumbas bestattet gewesen seien und als Tote dort ihre einstige „Wohnstatt“ gehabt hätten (vgl. Ferrua [1942], in: Epigrammata damasiana, 142; in diesem Sinne auch Duchesne 1923, 7 und zuletzt ausführlich Hack 1997, 19-23). Anders Griffe 1970, 89f.; Luiselli 1986, 843-848; Guarducci 1986, 815-819, die unter Verweis auf die passio Sebastiani meinen, dass Damasus mit seinem Epigramm den römischen Wohnort der Apostel zu ihren Lebzeiten habe bezeichnen wollen. Die passio Sebastiani liefert in dieser Frage keinen Aufschluss, da die Wendung iuxta vestigia ihrerseits auf einer Deutung des Damasusepigramms beruhen dürfte. Insgesamt ist die von Ferrua vertretene Deutung besser geeignet, das auf habitasse bezogene prius zu erklären: So, wie die sterblichen Überreste jetzt am Vatikan und an der via Ostiensis ,wohnen“ (= bestattet sind), haben sie zuerst an der via Appia ,gewohnt". Wenig überzeugend ist hingegen die Auffassung von Ruysschaert 1969-1970; Reutter 1999, 518-520, das bic sei nicht auf die Gedenkstätte in catacumbas, sondern auf Rom zu beziehen und - in Verbindung mit der Lesart habitare statt habitasse - zu übersetzen: „Hier (in Rom) haben die Apostel eher (prius) ihre Wohnung“ (scil. als im Osten) (ähnlich auch Pietri 1976, Bd. 1, 371f.): Eine derartige Verwendung von hic steht nicht in Einklang mit dem üblichen Gebrauch des Wortes durch Damasus, der in zahlreichen Epigrammen auf bic zurückgreift, um damit den konkreten Ort der Verehrung, an dem eine Inschrift angebracht war, zu bezeichnen.

189 S. o., Anm. 155.

190 Ebenso auch der Verfasser der passio Quirini 8: sepilierunt in basilica apostolorum Petri et Pauli, ubi aliquando iacuerunt. 
passio Sebastiani den Ort als eine reine Wohnstätte der Apostel auffasste und damit jeglichen Hinweis auf ein mit den apostolischen Basiliken am Vatikan und der via Ostiensis rivalisierendes Kultzentrum vermissen ließe.

Schließlich kann auch die Hypothese von der Matrona Lucina als einer „novatianist icon“ zur Zeit des Damasus nicht überzeugen. Dass Damasus ähnlich wie auch schon sein Vorgänger Liberius - über ein enges Verhältnis zu den weiblichen Mitgliedern der römischen Oberschicht verfügte, erscheint unbestreitbar, selbst wenn man an der deutlichsten Aussage in diese Richtung, dass nämlich die Matronen Damasus ,,so sehr liebten, dass man ihn Ohrlöffel der Matronen nannte“, wegen ihres polemischen Kontextes gewisse Abstriche machen muss. ${ }^{191} \mathrm{Ob}$ auch die in den Märtyrerakten so häufig auftauchende Matrone Lucina in den Kreis dieser Matronen einzureihen ist, bleibt jedoch reine Spekulation. Das Argument, Damasus habe die Titelkirche der Lucina, in der er zum Bischof gewählt wurde, später in eine Laurentiuskirche umgewandelt, ist sachlich falsch, da es auf einer Verwechslung zwischen dem titulus Lucinae und dem titulus Damasi beruht. ${ }^{192}$ Die Beziehungen zwischen Damasus und Lucina beschränkten sich darauf, dass Damasus in Lucinis, also der Titelkirche der Lucina, zum Bischof gewählt wurde. ${ }^{193}$ Daraus auf eine Kontrolle einer vermeintlichen novatianischen Lucinamemoria durch Damasus zu schließen, bleibt ebenso spekulativ wie die Behauptung, dass Damasus zur Stärkung seiner bischöflichen Autorität die Auseinandersetzung mit den Novatianern gesucht habe. ${ }^{194}$ Von einer „Kontrolle“ der Lucina durch Damasus bleibt damit am Ende ebensowenig übrig wie von der „novatianischen Ikone“ selbst.

191 Vgl. die ursinischen gesta inter Liberium et Felicem (Coll. Avell., epist. 1, 9): quem in tantum matronae diligebant, ut matronarum auriscalpius diceretur. $\mathrm{Zu}$ den historischen Hintergründen dieser polemischen Äußerung vgl. Reutter 1999, 178-180; Lizzi Testa 2004 (a), 108-120.

192 Die Kirche S. Lorenzo in Damaso ist nicht der titulus Lucinae (so Cooper 1999, 313) sondern der titulus Damasi, den Damasus bei seiner Gründung mit einem Laurentiuspatronat versah (vgl. Damas., epigr. 58). Auch die Lucinakirche verfügte (vermutlich spätestens gegen Ende des 5. Jh.) über ein Laurentiuspatrozinium; über den Zeitpunkt von dessen Einrichtung lässt sich jedoch nichts sagen (vgl. u., S. 358 mit Anm. 115).

193 Vgl. o., Anm. 34f. Ferner wurde in der Nähe des titulus Lucinae ein philokalisches Inschriftenfragment gefunden, das jedoch in keinem nachweisbaren Bezug zur Kirche steht (Damas., epigr. 56, vgl. auch den einleitenden Kommentar von Ferrua [1942], in: Epigrammata damasiana, 209).

194 Vgl. Cooper 1999, 311: „An important dimension of Damasus' strategy for consolidating his papal authority is his interest in the schism of Novatian." Dafür gibt es keinen Anhaltspunkt: Unter den zahlreichen schismatischen und häretischen Gruppen, mit denen Damasus während seines Episkopats in Konflikt lag (Ursiner, Luciferianer, Donatisten, Manichäer, Venustianer, Patricianer; vgl. Pietri 1986, 40f.), lassen sich ausgerechnet die Novatianer nicht nachweisen. Selbst wenn man demnach der unwahrscheinlichen Hypothese folgen wollte, dass das Gedenken an Lucina von einer schismatischen Gruppe gepflegt wurde, die in der basilica apostolorum einen rivalisierenden Apostelkult unterhielt, spricht nichts dafür, diesen Befund mit den Novatianern in Verbindung zu bringen. 
Festeren Grund mit Blick auf eine novatianische Heiligentopographie in Rom betritt man, wenn man den Bereich der römischen Märtyrerlegenden verlässt und erneut zur Grablege des Novatian an der via Tiburtina zurückkehrt. In geringer Entfernung von der Novatianuskatakombe befand sich die Grablege des römischen Presbyters Hippolytos, der das Schulhaupt einer Gruppe bildete, die in der ersten Hälfte des 3. Jh. in Konflikt mit den römischen Bischöfen Zephyrinus (199-217) und Kallixt (217-222) geriet und damit anhaltende Spannungen zum römischen Episkopat auslöste, die erst unter Pontian (230-235) ihr Ende fanden, als Pontian und der Presbyter Hippolytos aus Rom nach Sardinien verbannt wurden. ${ }^{195}$ Im Rahmen seiner Ausstattung der römischen Coemeterien mit Epigrammen berücksichtigte der römische Bischof Damasus (366-384) auch den Presbyter Hippolytos an der via Tiburtina und stellte ihn darin als novatianischen Kleriker dar, der zur Zeit der Verfolgung zunächst im Schisma des Novatus verharrt, auf dem Weg zu seinem Martyrium sich aber noch der catholica fides zugewandt und es daher verdient habe, „unser Märtyrer“ (noster martyr ut esset) zu sein. ${ }^{196}$

Die Verbindung zwischen Hippolytos und Novatian, die Damasus hier herstellt, ist sicher nicht historisch. Der Presbyter Hippolytos starb ebenso wie Bischof Pontian in der Verbannung auf Sardinien und wurde noch vor Ausbruch des novatianischen Schismas zusammen mit Pontian unter Bischof Fabian (236-250) nach Rom überführt und bestattet. ${ }^{197}$ Historische Beziehun-

195 Zur Verbannung von Pontian und dem Presbyter Hippolytos vgl. den Catalogus Liberianus im Chronographen von 354 (MGH AA IX, 74f.); die depositio martyrum des Chronographen von 354 belegt, dass Pontian und ein Hippolytos am selben Tag in Rom - Pontian in der Papstgruft an der via Appia, Hippolyt an der via Tiburtina - verehrt wurden. Es kann kein Zweifel daran bestehen, dass es sich bei diesen beiden Hippolyti um ein und dieselbe Person handelt (vermutlich wurden Pontian und Hippolytos gemeinsam aus Sardinien nach Rom überführt und dort am selben Tag beigesetzt). Unter dem Namen des Hippolytos sind eine Reihe von Schriften überliefert, die sich jedoch von unterschiedlichen Autoren verfasst wurden; ihre Zuweisung an den Presbyter Hippolytos führt Allen Brent darauf zurück, dass Hippolytos zu Beginn des 3. Jh. das Haupt einer Schule gewesen sei, die sich in Opposition zum Monarchianismus, wie er von Zephyrin und seinen Nachfolgern vertreten wurde, konstituiert habe (vgl. ausführlich Brent 1995, 115-367).

196 Damas., epigr. 35: Hippolytus fertur premerent cum iussa tyranni / presbyter in scisma semper mansisse Novati. / tempore quo gladius secuit pia viscera matris, / devotus Christo peteret cum regna piorum, / quaesisset populus ubinam procedere posset, / catholicam dixisse fidem sequerentur ut omnes. / sic noster meruit confessus martyr ut esset: / haec audita refert Damasus, probat omnia Christus. Dass dieses nur handschriftlich und durch einige, nicht mehr in situ befindliche Marmorfragmente überlieferte Epigramm am Grab des Hippolytos an der via Tiburtina angebracht war, hat bereits de Rossi 1881 zweifelsfrei erwiesen (gegen Einwände in jüngerer Zeit verteidigt auch von Brent 1995, 30-34). Ein zweites Epigramm, ohne Anspielungen auf die schismatisch-novatianischen Eigenschaften des Hippolytos, war ebenfalls an der via Tiburtina, vermutlich in einer halbunterirdischen Grabbasilika angebracht (Damas., epigr. 351).

197 Zur Verbannung von Pontian und Hippolytos und ihrer gemeinsamen Überführung nach Rom s. o., Anm. 195. Der zu Beginn des 6. Jh. redigierte Liber Pontificalis schreibt Bischof Fabian (236250) diese Überführung der Pontianusreliquien aus Sardinien nach Rom und ihre Bestattung in 
gen zwischen der Schule des Hippolyt und den Novatianern sind nicht nachzuweisen: Mit der Verbannung von Pontian und Hippolytos und ihrer gemeinsamen „Rückkehr“ nach Rom sah man die Spaltung der römischen Gemeinde als beendet an, und das novatianische Schisma, das seine spezifischen Ursachen in disziplinären Differenzen bezüglich der Rekonziliation der lapsi hat, ist ohne eine inhaltliche Verbindung zur Hippolytosschule des frühen 3. Jh. entstanden. ${ }^{198}$ Die Damasusinschrift ist demnach Ausdruck eines retrospektiven Identitätsdiskurses, vermittels dessen der Presbyter Hippolyt zum Novatianer wurde. Wer aber nahm diese Konstruktion vor und welche Aussagen erlaubt sie für die Frage nach der Verbindung von Heiligenerinnerung und kollektiver Identität?

Ein Teil der Forschung plädiert dafür, dass Hippolytos für die Novatianer eine besondere Bedeutung gehabt habe. ${ }^{199}$ Als Argument dafür verweist man auf ein Hippolytosoratorium, das bereits um das Jahr 400 im Bereich des an die Titelkirche S. Pudenziana angrenzenden vicus Patricius existiert haben soll. ${ }^{200}$ Aus der räumlichen Nähe dieses Oratoriums zu den Titelkirchen S. Pudenziana und S. Prassede, die ihrerseits eine Verbindung mit der novatianischen Gemeinde gehabt haben sollen, weil in der Gründungslegende, der vita Potentianae et Praxedis, ein gewisser Novatus eine zentrale Rolle spielt, hat man geschlossen, dass auch das Hippolytosoratorium auf dem Esquilin auf Initiative der Novatianer errichtet worden sei. Da jedoch kein hinreichender Anlass dafür besteht, in dem legendarischen Stifter Novatus eine Anspielung auf den Schismatiker Novatian zu sehen, 201 sind alle weiteren Schlussfolgerungen bezüglich novatianischer Assoziationen des - in seiner Existenz übrigens durchaus umstrittenen - Hippolytosoratoriums als hinfällig zu betrachten. Für die Hypothese, Hippolytos sei ein novatianischer Heiliger gewesen, lässt sich aus dem skizzierten Befund demnach nichts gewinnen. Dasselbe gilt auch für die Deutung, wonach Damasus mit dem rekonzilierten Schismatiker Hippo-

der Papstgruft an der via Appia zu (LP I, 64 u. 145). Diese Angaben werden in der Forschung traditionell zu der Hypothese verbunden, dass es Fabian war, der die Überreste von Pontian und Hippolytos aus Sardinien überführen und an der via Appia bzw. via Tiburtina beisetzen ließ (vgl. Lietzmann 21927, 16f.; zuletzt Borgolte 21995, 33-35; Brent 1995, 34-37, 378f.).

198 Zurecht betont von Vogt 1968, 55, Anm. 84; Brent 1995, $380 \mathrm{f}$.

199 Vgl. zum folgenden C. Cecchelli 1944, 224-228; Llewellyn 1976, bes. 422f.; M. Cecchelli 19851986, 288-291.

200 Bereits diese Existenz dieses Hippolytosoratoriums auf dem Esquilin ist nicht gesichert. Sie beruht auf einer Inschrift (de Rossi 1867, 57), die zwar in dem fraglichen Bereich gefunden, jedoch möglicherweise aus dem suburbanen Coemeterium an der via Tiburtina dorthin verbracht wurde (so Krautheimer, in: Corpus III, 283, Anm. 1; zuletzt Cerrito 2002, 402).

201 Gegen Llewellyn 1976, 420, führen die acta Potentianae et Praxedis nicht auf den 27. Juni, sondern auf den 31. Mai als Todestag des Stifters Novatus, enthalten dementsprechend auch keine Anspielung auf den Feiertag des Novatian, der am 27. oder 29. Juni gefeiert wurde (zu den beiden Einträgen s. o., Anm. 151). Bezüglich einer Identifizierung des Novatus mit Novatian vgl. auch die skeptischen Bemerkungen von Guidobaldi 2002, 1035, Anm. 6. 
lytos an der via Tiburtina nicht die Novatianer, sondern vielmehr die Luciferianer im Blick gehabt habe, die in Porto eine Hippolytosbasilika errichtet und Hippolytos damit einen identitätsrelevanten Status verliehen hätten. ${ }^{202}$ Diese Vorstellung von Hippolytos als einem „luciferianischen Heiligen“ beruht darauf, den in einer Stifterinschrift aus der Hippolytosbasilika in Porto genannten Heracleida mit einem gleichnamigen luciferianischen Bischof aus Oxyrrhynchos zu identifizieren, von dem jedoch nicht bekannt ist, dass er sich jemals im Westen der römischen Reiches aufgehalten hat. ${ }^{203}$ Auch die Annahme, dass sich die Luciferianer - oder gar die Ursiner ${ }^{204}$ - auf Hippolytos als identitätsstiftenden Heiligen bezogen hätten, kann demnach nicht überzeugen.

Was die oben skizzierten Deutungen miteinander verbindet, ist die gemeinsame Annahme, dass Damasus durch die Reklamation des Hippolytos als katholischer Märtyrer (noster martyr ut esset) die Kontrolle über eine schismatische Kultstätte gewinnen wollte, die einer mit dem römischen Bischof konkurrierenden Gruppe - Novatianer, Luciferianer, Ursiner - als identitätsstiftender Bezugspunkt gedient habe. Es stellt sich jedoch die Frage, ob Damasus' Epigramm auf Hippolytos nicht als Teil einer umfassenderen Strategie des römischen Bischofs anzusehen ist. Wie an späterer Stelle noch eingehender verdeutlicht wird, ${ }^{205}$ beabsichtigte Damasus durch seine Monumentalisierungen nicht, eine Auseinandersetzung mit einzelnen schismatischen Gruppen um bestimmte Heiligengräber zu führen: Vielmehr zielten seine Epigramme darauf ab, das gesamte Suburbium Roms mit seiner Vielzahl an Heiligengräbern zur räumlichen Projektionsfläche einer einheitlichen, unter der Leitung des römischen Bischofs stehenden Gemeinde zu machen - unabhängig davon, ob bestimmte dieser Gräber als symbolische Zentren für rivalisierende Identitätskonstruktionen dienten oder nicht. Dies ist auch bei Damasus’ Epigramm auf den „bekehrten Novatianer“ Hippolytos in Rechnung zu stellen. In der Geschichte vom rekonzilierten Märtyrer, der im Anblick der Verfolgung für den katholischen Glauben eintrat, formulierte Damasus keine spezifisch gegen die Novatianer gerichtete Aussage. Nicht nur im Epigramm auf Hippolytos, sondern auch in zahlreichen weiteren seiner Heiligenepigramme thematisierte Damasus die in inneren und äußeren Bedrohungen bewahrte Glaubensstärke der Märtyrer, um sie als beispielhafte historische

\footnotetext{
$202 \quad$ So Testini 1989, 18-22; Brent 1995, 385-388.

203 Es ist nur bekannt, dass Heraclidas von Oxyrrhynchos vom luciferianischen Bischof der römischen Gemeinde, Ephesius, besucht wurde (Krüger 1886, 90-93); es gibt jedoch keinen Hinweis darauf, dass er Oxyrrhynchos jemals verlassen hat

204 In dieser Variante zuletzt Blair-Dixon 2002, 348f., mit der völlig haltlosen Behauptung, dass die Ursiner „claimed the (!) Heracleida came to Rome to take part in anti-Damasan politics with Ursinus."

205 S. u., S. 294-307.
} 
Vorbilder und exempla einer gegen alle Auflösungserscheinungen erfolgreich aufrechterhaltenen Gemeindeidentität zu präsentieren.

Dass sich in dieser Akzentuierung des Märtyrergedenkens Probleme und Konfliktlagen widerspiegelten, denen sich Damasus im Verlauf seines spannungsgeladenen Episkopats ausgesetzt sah, kann als sicher gelten. Es besteht jedoch kein Grund zu der Annahme, dass Damasus mit der „Vereinnahmung" des Hippolytos als katholischem Märtyrer auf konkurrierende Identitätskonstruktionen reagieren und eine schismatische Kultstätte für die katholische Gemeinde reklamieren wollte. Die räumliche Nähe des Hippolytosgrabs zur Kultstätte des Novatian, die zu Damasus' Zeit noch intakt war, bedeutet für die Geschichte des Hippolytos und seines Kultes vermutlich nicht mehr, als dass sie Damasus die wirksame Möglichkeit bot, eine bereits knapp 150 Jahre zurückliegende Kirchenspaltung, die mit dem Namen des Hippolyt verknüpft war, mit einem noch gegenwärtig sichtbaren Schisma zu verbinden, um auf diese Weise seinen Zeitgenossen die Charakterisierung Hippolyts als Schismatiker plastischer vor Augen führen zu können. ${ }^{206}$ Es ist bezeichnend, dass sich in der hagiographisch-legendarischen Tradition, die das Martyrium des Hippolytos mit der Gruppe der Märtyrer um Laurentius verband, indem sie Hippolytos zum Wächter des Laurentius machte, keinerlei Reflex von Hippolyts Verbindung zu Novatian findet. ${ }^{207}$ Was die Hippolytosforschung meist als eine spätere Umformung der Legende deutet, die sich von einer durch Damasus repräsentierten Überlieferung entfernt habe, ${ }^{208}$ ist eher ein Hinweis darauf, dass Damasus mit seinem Epigramm eine eigenwillige Konstruktion vornahm, die seinen spezifischen Zielsetzungen entsprach. Diese von außen vorgenommene Zuschreibung einer novatianischen Identität des Hippolytos erlaubt keine Rückschlüsse darauf, ob Hippolytos für die Novatianer eine identitätsrelevante Funktion hatte: Dass Damasus Hippolytos zu einem novatianischen Presbyter machte, ist eine Sache - der Stellenwert, den die Novatianer Hippolytos zuwiesen, jedoch eine vollkommen andere (und angesichts der Überlieferungssituation nicht beantwortbare) Frage.

Für die Rekonstruktion eines novatianischen Erinnerungsraums in Rom fällt diese Bilanz insgesamt ernüchternd aus: Ein derartiger Erinnerungsraum ist und bleibt, von der Grablege des Gemeindegründers an der via Tiburtina abgesehen, verloren. Dennoch haben die obigen Beobachtungen das Ver-

206 Dies ist auch der Grund dafür, dass Damasus in seinem Epigramm nicht einfach eine Erzählung vom rekonzilierten Presbyter Hippolytos präsentierte, sondern eine Verbindung zu Novatian herstellte: Die Anbindung des Hippolytos an ein noch bestehendes Schisma ließ seine Eigenschaft als (wieder eingegliederter) Schismatiker nachdrücklicher hervortreten.

207 Zur hagiographischen Tradition, in der Hippolytos als Wächter des Laurentius erscheint, vgl. die passio Xysti, Laurentii et Hippolyti vetus und die passio Polychronii. Als Novatianer wird Hippolytos einzig bei Prud., perist. 11, 28-30 dargestellt, der seine Informationen jedoch nachweislich aus der Inschrift des Damasus bezog (vgl. Brent 1995, 33f.). 
ständnis für die methodischen Probleme im Umgang mit den hagiographischen Quellen vertieft und ein zentrales Thema - die Rolle der petrinischen bzw. apostolischen Topographie für die Identitätskonstruktionen schismatischer Gruppen in Rom - angeschnitten. In methodischer Hinsicht bleibt festzuhalten, dass die römischen gesta martyrum nicht als polemische Gegenentwürfe zu den Bischofsviten des Liber Pontificalis anzusehen sind und die in den gesta vorgenommenen Gruppierungen an Handlungsträgern und Schauplätzen keine unmittelbaren Rückschlüsse auf lokal oder religiös begründete kollektive Identitäten, die sich um Orte des Heiligengedenkens in Rom formierten, erlauben. Die Verfasser von Legenden wie der passio Sebastiani nutzten die Vielzahl stadtrömischer Heiliger und die Bühne der städtischen und coemeterialen Topographie zur Anlage einer hagiographischen Trivialliteratur, die ihre Wirkung aus der Verbindung einer möglichst großen Zahl von Handlungsträgern mit stereotypen Handlungsabläufen und literarischen Wandermotiven (wie dem Typ der bestattenden Matrone) bezog. Polemische oder schismatische Identitätskonstruktionen auf der Ebene der Heiligenlegenden waren von den Verfassern dieser Erbauungs- und Unterhaltungsliteratur nicht intendiert. Nur wenige Texte dieses Genres wie die symmachianischen Fälschungen, die während des Schismas zwischen Symmachus und Laurentius (498-504/6) geschrieben wurden, lassen eine derartige Zielsetzung erkennen. ${ }^{209}$

Was die Petrus- und Apostelerinnerung betrifft, geben die kalendarische und hagiographische Überlieferung keinen Anlass, von einer konkurrierenden petrinischen Kultstätte der Novatianer in S. Sebastiano an der via Appia auszugehen. $\mathrm{Ob}$ die Petruserinnerung für Sondergemeinden wie die Novatianer eine identitätsrelevante Funktion hatte und zu Rivalitäten mit der katholischen Großkirche Anlass gab, lässt sich mit Blick auf den Novatianismus nur als eine offene Frage formulieren. Etwas anders gestaltet sich in dieser Hinsicht die Überlieferung für die Donatisten, die nach dem Ende der diocletianischen Verfolgung über mehrere Jahrzehnte hinweg eine eigene Kirche in Nordafrika begründeten und seit den Anfangstagen ihres Bestehens auch über eine Gemeinde in Rom verfügten.

\section{2. 2. Donatisten}

Afrikanischen Ursprungs, hat das donatistische Schisma die Geschicke der dortigen Kirche bis in das frühe 5. Jh. hinein maßgeblich bestimmt und seinen Niederschlag in zahlreichen Auseinandersetzungen gefunden, die von der Konkurrenz und den Konflikten zwischen katholischer und donatistischer

209 Vgl. u., S. 468. 
Kirche Zeugnis geben. Auch eine der wichtigsten Informationen zur donatistischen Gemeinde Roms hat sich in diesem Zusammenhang erhalten. Optatus von Mileve verfasste - in erster Redaktion vermutlich zwischen 364 und $367^{210}$ - eine antidonatistische Schrift, contra Parmenianum, in der er nicht nur den Donatismus in Afrika bekämpfte, sondern sich auch mit der Existenz einer donatistischen Gemeinde in Rom auseinandersetzte, die dort vermutlich bereits seit dem im Jahr 313 geführten Prozess Bestand hatte, der unter der Leitung des römischen Bischofs den Streit zwischen Caecilianus und Maiorinus um den Bischofssitz von Karthago entscheiden sollte. ${ }^{211}$ Um die Position der Donatisten zu schwächen, kommt Optatus auch auf die donatistische Gemeinde in Rom und auf deren Verhältnis zu den Apostelgräbern zu sprechen:

„Auch ihr" - die Donatisten - „behauptet, in der Stadt Rom eine Partei zu haben; ein Zweig eures Irrtums ist dies, der Lüge entsprossen, nicht der Wurzel der Wahrheit. Denn wenn man von Macrobius Auskunft verlangte, wo er seinen Sitz habe, könnte er dann etwa behaupten: auf der cathedra Petr? Ich weiß nicht, ob er die jemals mit eigenen Augen gesehen hat; zu seiner (scil. Petri) Grablege ist er jedenfalls nie gegangen, da er gleich wie ein Schismatiker gegen das Gebot des Apostels handelt, der sagt: ,in Gemeinschaft mit den Gräbern der Heiligen' (memoriis sanctorum communicantes). Nun denn: Dort sind die Grablegen zweier Apostel gegenwärtig. Sagt mir also, ob er die betreten durfte und dort Gottesdienst gefeiert hat, wo, wie es feststeht, sich die Gräber der Heiligen befinden?" 212

Die zitierte Textstelle ist Teil einer übergeordneten Argumentationslinie, die Optatus im ersten Teil des 2. Buches verfolgt. ${ }^{213}$ Über die umstrittenen Legitimitätsansprüche zwischen donatistischer und katholischer Kirche in Afrika entscheidet nach Optatus die Universalität der letzteren, da sie sich im Unterschied zu den Donatisten nicht allein auf Nordafrika beschränkt, sondern in communio mit allen Regionen des Mittelmeerraumes steht. ${ }^{214}$ Neben diese regionale Konzeptualisierung von Universalität stellt Optatus das ekklesiologische Symbol der bischöflichen cathedra, die für den Bischof von

210 Zur Datierung von contra Parmenianum vgl. das Vorwort zur Ausgabe von Labrousse (1995), 1214. Einer Angabe des Hieronymus ist zu entnehmen, dass Optatus sein Werk unter der gemeinsamen Herrschaft von Valentinian I. und Valens verfasste (Hier., vir. ill. 110). Da jedoch die römische Bischofsliste, die Optatus zu Beginn des zweiten Buches präsentiert, bis zu Siricius (384-399) reicht, muss die Schrift in der überlieferten Form eine zweite Redaktion darstellen, die etwa zwanzig Jahre nach der ersten Fassung erstellt wurde.

211 Zum Prozess vor Miltiades vgl. Girardet 1975, 26-33; zu den Ursprüngen der donatistischen Gemeinde in Rom s. u., Anm. 233.

212 Optat. 2, 4, 1f.: sed et habere vos in urbe Roma partem aliquam dicitis; ramus est vestri erroris, protentus de mendacio, non de radice veritatis. Denique si Macrobio dicatur ubi illic sedeat, numquid potest dicere in cathedra Petri? Quam nescio si vel oculis novit, et ad cuius memoriam non accedit quasi schismaticus contra apostolum faciens, qui ait: "memoriis sanctorum communicantes". Ecce praesentes sunt ibi duorum memoriae apostolorum. Dicite si ad has ingredi potuit aut obtulit illic ubi sanctorum memorias esse constat.

213 Vgl. ebd. 2, 1-6.

214 Ebd. 2, 1. 
Mileve nicht allein die einzelne Bischofsherrschaft in einer lokalen Kirche, sondern die Kirche in ihrer Gesamtheit repräsentiert. Die Kirche ist auf einen einheitlichen Ursprung zurückführbar, verkörpert durch die erste cathedra, die nach Optatus von Petrus in Rom errichtet wurde. Sie allein ist der Ursprung jeder bischöflichen Herrschaft und Symbol der kirchlichen Einheit: Eine bischöfliche cathedra, die gegen diese cathedra Petri errichtet wird, muss konsequenterweise als schismatisch gelten. ${ }^{215}$ Optatus demonstriert durch eine Sukzessionsreihe von Petrus bis Siricius (384-399), dass der zeitgenössische Bischof, mit dem die katholische Kirche in Gemeinschaft steht, auf dieser petrinischen cathedra sitzt. ${ }^{216}$ Die Donatisten verfügen zwar auch über eine von einem Bischof geleitete Gemeinde in Rom, doch dessen cathedra ist nicht die petrinische, sondern lässt sich nur bis auf Victor v. Garba zurückführen, der als dritter Bischof vor Macrobius, dem zur Zeit von Optatus lebenden donatistischen Bischof in Rom, von Afrika nach Rom gekommen war. ${ }^{217}$ Wiewohl ebenfalls in Rom lokalisiert, kann die donatistische cathedra also keinen Anspruch darauf erheben, die prima cathedra und damit der Ursprung der Kirche zu sein: Dieser Rang kommt allein der römischen cathedra Petri zu, mit der die katholische Kirche in Nordafrika in communio verbunden ist und daher, so das Fazit des Optatus, ihren Anspruch auf Katholizität zurecht erhebt. ${ }^{218}$

Auch Optatus' eingangs zitierte Ausführungen zu den apostolischen Grablegen stehen im Kontext dieser Argumentation: Die Kontrolle über die Gräber der Apostel entschied darüber, welcher der römischen Bischöfe - der katholische oder der donatistische - zurecht den Anspruch darauf erheben konnte, auf der cathedra Petri zu sitzen und welche der beiden christlichen Gemeinden Roms als die rechtmäßige gelten konnte. Obwohl Optatus damit die Grablegen der Apostel Petrus und Paulus zu Argumenten eines lokalen, innerrömischen Konfliktes um die Identität der römischen Gemeinde erklärte, rekurrierte er mit der Rede von der cathedra Petri auf ein universalkirchliches Symbol. Bereits Cyprian v. Karthago verwendete die cathedra Petri als Schlüsselbegriff, um den einheitlichen Ursprung aller bischöflichen Gewalt und damit die Einheit der Kirche gegen schismatische Spaltungen zu be-

215 Ebd. 2, 2: quia probavimus eam esse ecclesiam catholicam quae sit in toto terrarum orbe diffusa, eius iam commemoranda sunt ornamenta et videndum ubi sint quinque dotes..., inter quas cathedra est prima... videndum est quis et ubi prior cathedram sederit... igitur negare non potes scire te in urbe Roma Petro primo cathedram episcopalem esse collatam, in qua sederit omnium apostolorum caput Petrus... in qua una cathedra unitas ab omnibus servaretur ne ceteri apostoli apostoli singulas sibi quisque defenderent ut iam schismaticus et peccator esset, qui contra singularem cathedram alteram collocaret.

216 Optat. 2, 3. Da Optatus zwischen 364 und 367 schrieb, muss die Fortführung der apostolischen Sukzession bis auf Siricius eine spätere Erweiterung darstellen (vgl. o., Anm. 210); entsprechendes gilt auch für die donatistische Bischofsreihe in 2, 4, 5 .

217 Ebd. 2, 4.

218 Ebd. 2, 6, 1: cathedra... prima, quam probavimus per Petrum nostram esse. 
zeichnen. ${ }^{219}$ Auch im 4. Jh. waren die cathedra Petri und verwandte Ausdrücke - sedes Petri, sedes apostolica 220 - gängige Symbole universalkirchlicher Einheitsstiftung: Dort wo Streitigkeiten und Auseinandersetzungen um die Rechtmäßigkeit der Lehre oder der Gemeindeleitung geführt wurden, wurde das Argument einer communio mit dem petrinischen oder apostolischen Bischofsstuhl von unterschiedlichen Seiten ins Feld geführt. ${ }^{221}$ Dass Optatus bei seiner Polemik gegen die Donatisten mit dem Verweis auf die cathedra Petri ein gängiges Argument bemühte, zeigen auch die Äußerungen des Augustinus, der eine Generation nach Optatus die Donatisten mit demselben Symbol katholischer Kircheneinheit und mit ähnlichen Vorstellungen konfrontierte: Es war die Gemeinschaft mit der ecclesia Romana, in qua semper apostolicae cathedrae viguit principatus, und mit den Kirchen der übrigen Gegenden des Reiches, die dem katholischen Bischof von Karthago gegen seine schismatischen Gegner den Rücken stärkte. ${ }^{222}$ Auch führte Augustinus, ebenso wie Optatus, eine Bischofsliste von Petrus bis zum römischen Bischof Anastasius I. (399-401) auf, um zu verdeutlichen, dass es tatsächlich die cathedra Petri war, auf der der gegenwärtige Bischof Roms seinen Platz eingenommen hatte. ${ }^{223}$

Bewegte sich Optatus demnach mit dem Begriff der cathedra Petri auf gewohntem Terrain, so ist hingegen seine Anspielung auf die Grablegen der Apostel und die dadurch assoziierte Lokalisierung der cathedra Petri in der stadtrömischen Heiligentopographie bemerkenswert. Indem Optatus die fehlende communio der Donatisten mit der cathedra Petri auch auf die memoriae apostolorum übertrug, nahm er eine feste und ausschließliche Verankerung der cathedra Petri in Rom vor: Während die cathedra Petri als ein Symbol der bischöflichen Amtsgewalt von jedem Bischof der Kirche in Anspruch genommen werden konnte, ${ }^{224}$ war die Gemeinde der Stadt Rom die einzige

219 Die cathedra Petri erscheint bei Cyprian sowohl als ein die Gesamtkirche bezogenes Einheitssymbol (epist. 43, 5 und unit. eccl. 4f.) als auch als Bischofssitz der römischen Ortskirche, die als eine von unterschiedlichen Ortskirchen die apostolische Tradition verkörpert und in communio mit den übrigen katholischen Bischofskirchen steht (Cypr., epist. 59, 14; vgl. ausführlich Koch 1930, 32154, bes. 105). Zur Bedeutung der cathedra-Symbolik im Rahmen von Cyprians Ekklesiologie vgl. auch Maccarrone 1962, 286-290.

220 Im Brief des Konzils von Serdica (341/342) an den römischen Bischof Iulius begegnet erstmals die Wendung sedes Petri, im Jahr 354 in einem Brief des Bischofs Liberius erstmals der Ausdruck sedes apostolica. Unter Damasus wurde die Rede von der sedes apostolica - nicht als einem, sondern als dem apostolischen Sitz schlechthin - üblich; zu diesen Varianten und zu der in die Richtung eines Jurisdiktionsprimats weisenden Leitungsbefugnis, die Damasus mit der sedes apostolica verband, vgl. Wojtowytsch 1981, 138-141; Maccarrone 1991, 280-287.

221 Belege bei Maccarrone 1962, 291.

222 Aug., epist. 43, 3, 7.

223 Aug., epist. 53, 1, 2f.; vgl. die Diskussion dieser und weiterer Belege bei Marone 2001, 467-471.

224 Gaudent., serm. 16, 9-11 über Ambrosius v. Mailand (anlässlich des ersten Jahrestages der Bischofsweihe des Gaudentius gehalten): tamquam Petri successor apostoli ipse erit os universorum circumstantium sacerdotum. Dass damit kein kirchenpolitischer Anspruch für den Mailänder Bischof verbunden war, ist allgemein anerkannt; vgl. Ludwig 1952, 71f.; Lizzi 1989, 106; Rapisarda 2002, 
Kirche, die über die Gräber des Petrus und des Paulus verfügte. Dies war insofern bemerkenswert, als die cathedra Petri seit Cyprian nicht nur als Bischofssitz der römischen Ortskirche, sondern als einheitlicher Ursprung der Bischofsgewalt überhaupt aufgefasst wurde. Mit seiner Bindung der cathedra Petri an die apostolischen Kommemorationsstätten gab der Bischof von Mileve einem universalkirchlichen Symbol demnach eine spezifisch römische Färbung. Dass Optatus damit einen Schritt mit weitreichenden Konsequenzen für die Stellung der römischen Gemeinde innerhalb der Reichskirche vornahm, wird daraus ersichtlich, dass ihm Augustinus, obwohl er in der Argumentation seiner antidonatistischen Schriften vieles von Optatus übernahm, ${ }^{225}$ darin nicht gefolgt ist. Anders als bei der communio mit der cathedra Petri und der ununterbrochenen bischöflichen Sukzessionsreihe, die von Petrus bis zum gegenwärtigen römischen Bischof reichte, zeigte sich Augustinus auffällig zurückhaltend, was die Verbindung der cathedra Petri mit den Grablegen der Apostel Petrus und Paulus betraf. ${ }^{226}$

In seiner Argumentation zeigte sich der nordafrikanische Bischof von Mileve beeinflusst von Vorstellungen, die aus vereinzelten Äußerungen römischer Bischöfe bereits in der ersten Hälfte des 4. Jh. erkennbar werden. Vor der Gerichtssynode von Arles (314) hatte der römische Bischof Silvester (314335) eine - sich sprachlich am Rande der Verständlichkeit bewegende und gerade deswegen besonders aussagekräftige - Verbindung zwischen dem Bischofssitz und den Apostelgräbern hergestellt, um damit sein Fernbleiben von der Synode zu begründen: Er habe in jenen Gegenden bleiben müssen, „wo die Apostel täglich residieren (sedere), und wo ihr Blut ohne Unterlass den Ruhm Gottes bezeugt. "227 Eine vergleichbare Situation ergab sich während des Konzils von Serdika (342/343), als Bischof Julius (337-352), ebenso wie sein Vorgänger Silvester im Jahr 314, dem Konzil fern blieb und dieses Ver-

109f. Zur universalkirchlichen Rolle der Petrusgestalt bei Ambrosius vgl. Haendler 1993, 112114.

225 Marone 2001, 459f.

226 Augustinus nahm die apostolischen Grablegen zwar zum Anlass, um die Identität Roms als christliche Stadt herauszustellen; wo es jedoch - wie bei der Auseinandersetzung mit den Donatisten - um die Stellung der Gemeinde Roms in Bezug auf die Reichskirche ging, wurden die memoriae apostolorum nicht thematisiert (s. Coyle 2001). Seine Zurückhaltung, in ähnlicher Weise wie Optatus die cathedra Petri ausschließlich auf Rom zu beziehen bzw. durch die Bezugnahme auf die apostolischen Grablegen die Einzigartigkeit der römischen Kirche zu betonen, tritt an mehreren Stellen seines Werkes explizit hervor: Petrus empfing die Binde- und Lösegewalt stellvertretend für die Gesamtkirche; der römische Bischof hatte zwar die cathedra Petri inne, bezog daraus jedoch keine höhere Autorität als der Bischof von Jerusalem, der ebenfalls auf der cathedra eines Apostels saß (vgl. Wojtowytsch 1981, 246-249).

227 Vgl. den Brief der in Arles versammelten Bischöfe an Silvester: quoniam recedere a partibus illis minime potuisti, in quibus et apostoli cotidie sedent et cruor ipsorum sine intermissione Dei gloriam testatur (CSEL 26, 207; Turner 1899-1933 [EOMIA], Bd. 1, 382). Zum Kontext und den Motiven für Silvesters Verhalten s. Caspar 1930/1933, Bd. 1, 115. 
halten des römischen Bischofs den Synodalen Anlass gab, über die Verbindung von Grablege und cathedra Petri und die dadurch bedingte Unverrückbarkeit der römischen cathedra zu spekulieren. Die okzidentalischen Bischöfe, die das in den Konzilscanones festgelegte Prinzip, den römischen Bischof zur Appellationsinstanz für synodale Gerichtsurteile über Bischöfe zu machen, mit der Ehrfurcht vor der memoria sanctissimi Petri apostoli begründeten, ${ }^{228}$ hoben in einem Begleitschreiben zu den Konzilscanones, das sie an Julius schickten, um ihn von der Synode zu unterrichten, hervor, es sei „das weitaus angemessenste, wenn die Bischöfe des Herrn aus den einzelnen Provinzen an das Haupt, das heißt an den Sitz des Apostels Petrus (ad Petri apostoli sedem), Bericht erstatten. "229 Auch wenn die relatio, die die Bischöfe in ihrem Synodalschreiben vornahmen, formal etwas anderes war als die Appellation an den römischen Bischof, die in den Konzilscanones festgelegt wurde, steht hinter beidem eine verbindende Vorstellung: Die sedes Petri war das unverrückbare Haupt der Kirche, an das die zur Synode zusammengekommenen Bischöfe Bericht erstatteten und das in gleicher Weise zum Zentrum für synodale Schreiben in Jurisdiktions- und Appellationsangelegenheiten wurde. ${ }^{230}$ Die Ehrfurcht vor der memoria Petri - das Petrusgedenken, das in der apostolischen Grablege in Rom seinen Bezugspunkt hatte ${ }^{231}$ - und das referre ad sedem Petri wurden demnach unmittelbar auf einander bezogen; die bereits bei Silvester angedeutete Verbindung von apostolischer Grablege, sedes Petri und

228 C Sard., can. 3: si aliquis episcopus indicatus fuerit in aliqua causa et putat bonam causam babere ut iterum iudicium renovetur... sanctissimi Petri apostoli memoriam honoremus: scribatur vel ab his qui examinarunt vel ab episcopis qui in proxima provincia morantur Romano episcopo; si iudicaverit renovandum esse iudicium, renovetur et det iudices, si autem probaverit talem causam esse ut ea non refricentur, quae acta sunt, quae decreverit confirmata erunt.

229 Brief der okzidentalischen Synode von Serdika an Bischof Iulius: hoc enim optimum et valde congruentissimum esse videbitur, si ad caput, id est ad Petri apostoli sedem, de singulis quibusque provinciis domini referant sacerdotes (CSEL 65, 127). Zur Deutung des ad sedem Petri referre, das hier noch nicht einen römischen Jurisdiktionsprimat impliziert, vgl. Wojtowytsch 1981, $107 \mathrm{f}$.

230 In diesem Sinne auch Hess 1958, 117.

231 Die Wendung memoriam Petri honoremus beinhaltet eine Mehrdeutigkeit, die sich mit der Übersetzung als „Gedächtnis“ (Caspar 1933/1933, Bd. 1, 160) oder „Andenken Petri“ (Wojtowytsch 1981, 115), nicht adäquat erfassen lässt. Memoria begegnet bereits im klassischen Latein als Bezeichnung für eine Grabstätte und wird im christlichen Sprachgebrauch der Spätantike ein allgemein gebräuchlicher Terminus, um den Gedenkbau für einen Märtyrer zu bezeichnen (zur

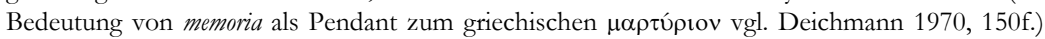
Auch wenn man die memoria Petri, von der im 3. Kanon von Serdika die Rede ist, nicht mit „Grabstätte Petri“ übersetzen möchte, verweist die Wendung eindeutig auf die Grablege des Apostels in Rom als das Ziel des ehrenden Gedenkens. Richtig gesehen auch von Maccarrone 1976, 159 f. 
Unverrückbarkeit des kirchlichen Hauptes fand in Serdika ihre Fortsetzung und Bestätigung. ${ }^{232}$

$\mathrm{Ob}$ diese in der römischen Kirche während der ersten Hälfte des 4. Jh. entwickelte Auffassung auch für die Selbstwahrnehmung der donatistischen Gemeinde Roms repräsentativ war, ist allerdings fraglich. Dass die Donatisten wirklich, wie es Optatus suggeriert, eine bischöfliche Gemeinde in Rom errichteten, um auf diese Weise einen Anspruch auf Rom als das Zentrum der Katholizität und auf die römische cathedra als Quelle der bischöflichen Gewalt zu erheben, ist nicht so sicher, wie es von der Forschung gemeinhin angesehen wird. ${ }^{233}$ Die Ekklesiologie des donatistischen Bischofs Parmenianus, soweit sie sich aus den Darstellungen des Optatus und Augustins rekonstruieren lässt, räumte dem römischen Bischofsstuhl nicht die fundierende Bedeutung für den Episkopat und die Kirche ein, die ihm Optatus gab: Die cathedra Petri galt Parmenianus zwar durchaus als Symbol der kirchlichen Einheit, war jedoch nicht in besonderer Weise an Rom gebunden, sondern eine Gabe der Kirche, die jeder Bischof für sich in Anspruch nehmen konnte. ${ }^{234}$ Wenn die Donatisten - nicht zu der Zeit, in der Optatus schrieb, sondern erst zu Beginn des 5. Jh. - die römischen Bischöfe Marcellinus, Marcellus, Miltiades und Silvester mit dem Vorwurf konfrontierten, sie seien ebenfalls Traditoren gewesen, dann nicht, um die katholische Sukzessionsfolge auf der cathedra Petri zu unterbrechen, sondern um das Bischofsgericht des Miltiades von $313 \mathrm{zu}$ diskreditieren. ${ }^{235}$ In Optatus' Bild von einer donatistischen Gemeinde, die in Rom mit der katholischen Kirche um die apostolische Sukzession und die römische cathedra Petri konkurrierte, wird demnach eine von außen vorgenommene Konstruktion fassbar, die kaum mit denjenigen Symbolen und Erinnerungsbezügen übereinstimmt, die die donatistische Gemeinde Roms

232 Zu den Parallelen zwischen Arles und Serdika und zu dem durch Silvester begründeten Prinzip, dass der römische Bischof nicht zu Konzilen reiste, sondern sich durch Legaten vertreten ließ, vgl. Caspar 1930/1933, Bd. 1, 115, 159; Wojtowytsch 1981, 107.

233 Die Auffassung, dass die Donatisten in Rom eine Bischofsgemeinde gegründet hätten, um ihrem Anspruch auf Katholizität durch die Existenz einer donatistischen cathedra Petri in Rom symbolischen Ausdruck zu verleihen, vertreten Frend 1952, 164 u. 181; Monachino 1964, 28-30.

234 Zu Parmenians Ekklesiologie, die Cyprians Interpretation von der cathedra Petri und dem Primat des Petrus als kirchliches Einheitssymbol in einer bestimmten Richtung - nämlich unter Absehung einer der cathedra Petri auf Rom - weiter entwickelte, vgl. Labrousse (1995), in: Optatus, Bd. 1, 111-115. Demgegenüber oszilliert Optats Begriff der cathedra Petri zwischen einem universalkirchlichen Verständnis in Cyprians Sinne (als Ausdruck der unitas ecclesiae) und ihrer Gleichsetzung mit dem römischen Bischofsstuhl; zur Verbindung dieser beiden Vorstellungen vgl. Koch 1930, 108-110.

235 Vgl. die im Jahr 410 verfasste Schrift des Augustinus, un. bapt. 16, 27f., in der Augustinus auch deutlich macht, dass die Vorwürfe erst in jüngster Zeit erhoben wurden (quid nunc inanes tam sero conectunt calumnias?). Die Zielrichtung dieser Strategie wird auf der großen Synode von 411 erkennbar, bei der sich die Traditorenvorwürfe der donatistischen Partei auf Miltiades konzentrierten (Aug., coll. c. Don. 3, 18, 34f.). 
für sich selbst als identitätsrelevant begriff. Dementsprechend sind auch Versuche, die Äußerungen des Optatus mit der hagiographischen Überlieferung der römischen Heiligenlegenden zu verbinden, und legendarische Traditionen zu einer cathedra an der via Nomentana, auf der Petrus zuerst gesessen haben soll, zur donatistischen Gemeinde Roms in Beziehung zu setzen, ${ }^{236}$ als unplausibel zurückzuweisen. Gerade die Leichtigkeit, mit der Optatus ein derartiges Vorgehen im Fall der Donatisten der Lächerlichkeit preisgeben konnte - der donatistische Bischof, der auf der cathedra Petri sitzen wollte, hatte ja nicht einmal je die apostolischen Grablegen gesehen - kann als untrüglicher Hinweis darauf gewertet werden, dass die Donatisten nicht auf eine derartige Strategie zurückgegriffen haben. ${ }^{237}$

Unberührt von der Frage, inwieweit Optatus' Argumentation Rückschlüsse auch auf die Perspektive der donatistischen Kirche erlaubt, ist festzuhalten, dass seine Bemerkungen zur cathedra Petri und den apostolischen Kommemorationsstätten Roms Teil eines universakirchlichen Identitätsdiskurses sind. Obwohl sich Optat mit der Frage auseinandersetzte, welche der beiden römischen Gemeinden die rechtmäßige katholische ecclesia Roms repräsentierte, sind die lokalen Aspekte dieses Konflikts zweitrangig: Die apostolische Erinnerungstopographie Roms fungierte für Optatus als eine Instanz zwischen zwei rivalisierenden afrikanischen - nicht in Rom selbst lokalisierten - Kirchen, deren Anspruch auf Katholizität auf der communio mit der römischen Kirche und ihrem rechtmäßigen Bischof gründete. ${ }^{238}$ Optatus lässt es mit diesem Nachweis, dass die Donatisten nicht mit derjenigen Gemeinde Roms in Gemeinschaft standen, die über die cathedra Petri verfügte, jedoch nicht sein Bewenden haben. Vielmehr wendet er sich im Anschluss an die oben zitierte Stelle der Frage zu, ob der Stuhl, auf dem die donatistischen Bischöfe Roms sitzen, überhaupt als eine bischöfliche cathedra bezeichnet werden kann:

„Eurem Macrobius bleibt also nichts anderes übrig als zu gestehen, als dass er dort gesessen habe, wo einst schon Encolpius gesessen hat. Und könnte man Encolpius

236 So etwa Ruysschaert 1973, bes. 297-299, der die petrinische cathedra der Donatisten im coemeterium maius an der via Nomentana lokalisieren möchte, einem Ort, an dem nach der hagiographischen Überlieferung Petrus zuerst auf seiner cathedra gesessen und getauft haben soll; dazu u., S. 466, Anm. 223).

237 Vgl. Monachino 1964, 29, der völlig zurecht darauf hinweist, dass ein derartiges Vorgehen der Donatisten ein „espediente che ha certo del puerile“ gewesen wäre, daraus allerdings nicht die Konsequenz zieht, die ganze Deutung einer römischen Gemeindegründung durch die Donatisten zum Zweck, dadurch einen begründeten Anspruch auf Katholizität erheben zu können, als ein eigenwilliges Konstrukt durch Optatus v. Mileve zu begreifen.

238 Dementsprechend wird die eingangs zitierte Passage üblicherweise als ein Beleg dafür gelesen, dass donatistischen Pilgern im Unterschied zu nordafrikanischen Katholiken, die nach Rom pilgerten, der Zugang zu den Apostelgrablegen verwehrt gewesen sei; vgl. neben Saxer 1980, 127 (,le pèlerinage aux tombes apostoliques était donc considéré une profession de foi catholique") auch Maccarrone 1980, 394; Saxer 1995, 40; Marone 2001, 462. 
fragen, würde er antworten, er habe dort gesessen, wo zuvor Bonifatius von Vallis gesessen hat. Und wenn dieser wiederum befragt werden könnte, würde er antworten: ,dort, wo Victor von Garba saß` - er, der vor langer Zeit aus Africa (nach Rom), zu einer kleinen Gruppe von Irregeleiteten, geschickt wurde... Victor wurde also (nach Rom) geschickt: ein Sohn ohne Vater, ein Rekrut ohne Vorgesetzten, ein Schüler ohne Lehrer, ein Nachfolger ohne Vorgänger, ein Mieter ohne Haus, ein Gast ohne Hospiz, ein Hirt ohne Herde, ein Bischof ohne Gemeinde. Denn die wenigen, die unter vierzig und mehr Basiliken keinen Ort gefunden haben, an dem sie sich hätten versammeln können, können wohl kaum als Herde oder als Gemeinde bezeichnet werden. So zäunten sie also eine Höhle außerhalb der Stadt ein, um in dieser Zeit einen Versammlungsort zu haben, und von daher rührt auch ihre Bezeichnung als Montenses. Wenn man also... Victor fragen würde, wo er gesessen habe, könnte dieser weder auf einen Vorgänger verweisen, der an dieser Stelle gesessen habe, noch überhaupt irgendeine Cathedra vorzeigen außer einer „Cathedra der Pestilenz" (cathedra pestilentiae, vgl. Psalm 1, 1).239

Es ist deutlich, dass Optatus in diesem Abschnitt einen Wechsel in der Argumentation vornimmt und einen neuen Aspekt ins Spiel bringt. Nach dem von ihm erbrachten Nachweis, dass die von den Donatisten errichtete cathedra in Rom nicht mit der cathedra Petri, der ersten cathedra der Kirche, identisch ist, wirft Optatus nun die Frage auf, welchen Anspruch die Donatisten überhaupt haben, mit Blick auf Rom von einer cathedra im Sinne einer bischöflich geleiteten Gemeinde sprechen zu können. Die zahlreichen Vergleiche, die er heranzieht, um Victor von Garba als Gründer und ersten Bischof einer Gemeinde zu diskreditieren und die cathedra der Donatisten als eine reine Chimäre, als cathedra pestilentiae, zu erweisen, greifen die Sukzessionthematik zwar erneut auf (filius sine patre, sequens sine antecedente), zielen jedoch auf einen anderen Sachverhalt ab. Er wird in den beiden abschließenden Bildern sichtbar, in denen Optatus' Serie von Vergleichen kulminiert: Victor ist ein pastor sine grege, ein episcopus sine populo. Es ist diese Feststellung, die Optatus zur Grundlage seiner weiteren Ausführungen macht. Die Donatisten haben in Rom keinen Ort, an dem sie sich versammeln und damit ihre Identität als populus und als Bischofsgemeinde unter Beweis stellen könnten. Ähnlich wie bei der Sukzession auf der cathedra Petri, auf die die Donatisten keinen Anspruch erheben konnten, weil diese petrinische cathedra in den apostolischen Grablegen verankert war, findet der Umstand, dass sie über keine

239 Optat. 2, 4, 2-5: Ergo restat ut fateatur socius vester Macrobius se ibi sedere ubi aliquando sedit Encolpius. Si et ipse Encolpius interrogari posset, diceret se ibi sedere ubi ante sedit Bonifatius Vallitanus. Deinde si et ipse interrogari posset, diceret ubi sedit Victor Garbensis a vestris iamdudum de Africa ad paucos erraticos missus... Missus ergo est Victor; erat ibi filius sine patre, tiro sine principe, discipulus sine magistro, sequens sine antecedente, inquilinus sine domo, hospes sine hospitio, pastor sine grege, episcopus sine populo. non einim grex aut populus appellandi fuerant pauci qui inter quadraginta et quod excurrit basilicas locum ubi colligerent non habebant. Sic speluncam quamdam foris a civitate cratibus saepserunt, ubi ipso tempore conventiculum habere potuissent, unde Montenses appellati sunt. Igitur... si Victori diceretur ubi sederet, nec ante se aliquem illic fuisse monstraret nec cathedram aliquam nisi pestilentiae ostenderet. 
Bischofsgemeinde in Rom verfügen, demnach auch seinen räumlichen Ausdruck: Als Schismatiker finden Donatisten keinen Versammlungsraum innerhalb der Stadt; sie sind darauf angewiesen, sich in eine spelunca außerhalb der Stadt - gemeint ist vermutlich ein Hypogäum im Suburbium Roms ${ }^{240}$ zurückzuziehen, um dort ein marginales Dasein in Verborgenheit und Ausgrenzung zu führen.

Diese Bemerkungen des Optatus stellen eine wichtige Ergänzung zu seinen vorausgehenden Ausführungen dar. Hatte die apostolische Erinnerungstopographie mit den beiden vor den Toren der Stadt gelegenen Grabstätten der Apostel am Vatikan und an der via Ostiensis den suburbanen Raum in das Zentrum konkurrierender Identitätskonstruktionen gerückt, kehrte sich das Verhältnis zwischen Stadt und Suburbium nun um: Nur eine innerhalb der Stadt gelegene Versammlungsstätte konnte als Raum für eine reguläre Gemeinde dienen, nur sie eine räumlich vermittelte Identität des legitimen römischen Bischofs an der Spitze seiner Herde begründen. Dieser scheinbar paradoxe Befund wird jedoch verständlich, wenn man berücksichtigt, dass Optatus die römische Gemeinde zum Bezugspunkt zweier unterschiedlicher, einander überlagernder Identitätsdiskurse machte. Die cathedra Petri, die Optatus mit den apostolischen Grablegen assoziierte, war nicht nur der Bischofsstuhl der römischen Ortskirche, sondern zugleich ein universalkirchliches Symbol: Sie zeigte den römischen Bischof und die ecclesia Romana in ihrer Bedeutung für die Gesamtkirche. Davon zu unterscheiden ist das Verständnis der römischen Gemeinde als Ortskirche, das Optatus’ Ausführungen in der zweiten der beiden oben zitierten Passagen bestimmt: Um gegenüber der römischen Gemeinde - nicht der Universalkirche - als römischer Bischof auftreten zu können, war es notwendig, im städtischen Raum Präsenz zu zeigen. Das symbolische Kapital, das die Apostel- und Heiligentopographie vor den Mauern der Stadt vermittelte, war demgegenüber sekundär, wenn nicht sogar dysfunktional, da es die Marginalität konkurrierender Gemeinden auch räumlich versinnbildlichte und polemischen Äußerungen wie denen des Optatus von „Hirten ohne Herde“ Vorschub leistete.

Es empfiehlt sich, diese beiden Identitätsdiskurse voneinander zu unterscheiden, auch wenn sie, wie das Zeugnis des Optatus zeigt, eng beieinander lagen. Die cathedra Petri, die seit dem frühen 4. Jh. mit den apostolischen Grablegen Roms verbunden wurde, war zwar einerseits der römische Bischofsstuhl, erlangte ihre eigentliche Bedeutung jedoch durch die Tatsache, dass sie ein universalkirchliches Symbol war. Wirksamkeit auf dieser Ebene entfaltete sie vor allem in einem negativen Sinne: Aus Sicht der katholischen Kirche war der Verweis auf die cathedra Petri und die apostolischen Kommemorationsstätten ein geeignetes Mittel, um häretischen Gruppen ihre Identität

$240 \quad$ Zu dieser Deutung vgl. Maier 1995, 246. 
als römische Gemeinde abzusprechen. Dies bestätigt sich auch mit Blick auf die novatianische Gemeinde in Rom. Etwa zur selben Zeit, in der Optatus v. Mileve schrieb, dass den Donatisten der Zugang zu den apostolischen Grablegen in Rom verwehrt sei, gab Ambrosius v. Mailand ein ähnliches Urteil auch über die Novatianer Roms ab: non habent enim Petri hereditatem, qui Petri sedem non habent. ${ }^{241}$ Bezogen auf die römische Gemeinde in ihrer lokalen Dimension und die Frage, in welcher Weise Sondergemeinden wie die Novatianer und Donatisten innerhalb Roms ihren Anspruch darauf, als Gemeinde anerkannt zu werden, begründeten, war die cathedra Petri hingegen eine eher abstrakte Größe ohne eine wirklich identitätsrelevante Bedeutung. Es besteht kein Anlass zu der Annahme, dass häretische Gruppen wie die Donatisten oder Novatianer in Rom alternative Orte einer apostolischen Tradition neben den Grablegen am Vatikan und an der via Ostiensis geschaffen hätten, um auf diese Weise ihrem Anspruch darauf, als rechtgläubige römische Gemeinde zu gelten, Ausdruck zu verleihen - in der basilica apostolorum an der via Appia ebenso wenig wie im coemeterium maius an der via Nomentana. Der städtische Raum, nicht die apostolische Kommemorationstopographie, bildete den räumlichen Bezugspunkt, um die Identität der Donatisten und Novatianer als römische Bischofsgemeinde symbolisch zum Ausdruck zu bringen. Auch hier tritt den auf die Donatisten bezogenen Ausführungen des Optatus ein Zeugnis zur Seite, das die Gültigkeit dieser Aussage auch für die Novatianer in Rom unterstreicht. Der Kirchenhistoriker Sokrates, der starke Sympathien für die Novatianer hegte, übte scharfe Kritik am Vorgehen des römischen Bischofs Caelestinus (422-432), der den Novatianern die Kirchen, die sie in Rom besaßen, wegnahm, und den Bischof der novatianischen Gemeinde, Rusticola, dazu zwang, Gottesdienste in überfüllten Privathäusern abzuhalten. Dem stellte Sokrates das Verhalten von Caelestinus' bischöflichem Amtskollegen in Konstantinopel entgegen, der es zugelassen habe, dass sich die Novatianer ,innerhalb der Stadt“ (๕̌ $\delta \delta o v \pi o ́ \lambda \varepsilon \omega \varsigma)$ zu Gottesdiensten versammelten. ${ }^{242}$ Wie insbesondere aus dem prononcierten Hinweis auf den städtischen Raum hervorgeht, ging es in dieser Angelegenheit um mehr als nur rein pragmatische Fragen. Sich nicht mehr innerhalb der Stadt in eigens

241 Ambr., paen. 1, 7, 33 (geschrieben zwischen 387 und 390). Die sedes Petri ist hier nicht verstanden als Symbol für die katholische Kirche schlechthin, sondern als der Bischofsstuhl der römischen Ortskirche. Dies wird einerseits daraus ersichtlich, dass Ambrosius im unmittelbaren Anschluss an diese Stelle eine Ausweitung von der sedes Petri auf die Gesamtkirche vornimmt; andererseits daraus, dass Ambrosius hier die Vorstellung vom römischen Bischof als heres Petri aufnimmt, wie sie seit Siricius (384-399) von den römischen Bischöfen verbreitet wurde (s. dazu u., S. 323). Richtig gesehen von Ludwig 1952, 65f.; auf die konzeptionelle Verwandtschaft zwischen Ambrosius und Optatus macht Fellermayr 1979, 390 aufmerksam.

242 Socr., h. e. 7, 11, 2-6. 
als Kirchen ausgewiesenen Kultbauten versammeln zu können, ${ }^{243}$ führte nicht nur zu praktischen Koordinationsproblemen, sondern beraubte die Novatianer vor allem auch der zentralen symbolischen Grundlage, als eine anerkannte Gemeinde gelten zu können. Das Zurückdrängen aus der städtischen Sakraltopographie in den privaten Raum der domus und in das Suburbium vor den Toren der Stadt war gleichbedeutend mit dem Verlust der Gemeindeidentität. Die symbolische Auseinandersetzung um die ecclesia konzentrierte sich nicht auf bestimmte lokale Zentren, wie sie durch die Apostel- und Heiligentopographie repräsentiert wurden, sondern auf den städtischen Raum als solchen: Die Identität als Gemeinde beruhte - in dieser Hinsicht den städtischen Gemeinden der griechisch-römischen Antike vergleichbar - auf der Vorstellung eines Personenverbandes, der im städtischen Raum seinen symbolischen Ausdruck fand. ${ }^{244}$

Man mag dagegen einwenden, dass eine öffentlich sichtbare Präsenz im städtischen Raum von häretischen Gruppen nur in begrenztem Maße gezielt angestrebt wurde. Wie Harry Maier vor einigen Jahren in einem Beitrag zur „topography of heresy and dissent“ im Rom des ausgehenden 4. Jh. gezeigt hat, gab es zu dieser Zeit eine ganze Reihe von häretischen Gruppierungen, die sich vorwiegend in aristokratischen domus und kleinen asketischen Zirkeln bewegten. Dabei handelte es sich jedoch häufig um Gruppen, die, wie vor allem die Pelagianer, aber auch die Manichäer und Montanisten, hohe rigoristische Ansprüche an ihre Anhängerschaft stellten und damit zum einen von vornherein keine Gründung einer „Großkirche“ zum Ziel hatten und zum anderen an eine asketische Elitenfrömmigkeit appellierten, die ihnen in den Häusern der aristokratischen Oberschicht eine adäquate Aufnahme und Heimat bot. ${ }^{245}$ Wo jedoch, wie im Falle der Novatianer oder der Donatisten, der Anspruch im Raum stand, eine Gemeinde zu gründen und diesem Ziel durch die Einsetzung eines Bischofs Ausdruck zu verleihen, war klar, dass ein identitätsrelevantes räumliches Zentrum nicht in räumlicher Anlehnung an die Heiligentopographie außerhalb der städtischen Mauern, sondern nur innerhalb der Stadt seinen Ort haben konnte. ${ }^{246}$ Für die Donatisten Roms ist die

243 Theodosius I. (379-395) erließ 383 ein gegen die Arianer gerichtetes Verbot, domus durch die Umgestaltung ihrer Fassaden als Kirchengebäude auszuweisen (CTh 16, 5, 11). Auf diese Weise wurde innerhalb der Stadt ein als solcher wahrnehmbarer (gemeinde-)öffentlicher Raum geschaffen, der darüber entschied, ob christliche Gruppen als reguläre Gemeinden anerkannt waren oder nicht.

244 Zu diesem Doppelaspekt der antiken polis bzw. civitas - ihrer Existenz als territoriale Einheit und als Bürgerverband - vgl. Jacques/Scheid 1998, 239 f.

245 Maier 1995, 235-241. Zur starken Verbreitung des Pelagianismus innerhalb der römischen Oberschicht s. auch Brown 1968.

246 Arnob. iun., praedest. 1, 86 erwähnt zwar, dass die - dort als Tertullianisten bezeichneten Montanisten, vermittelt durch die Patronage einer Dame namens Octaviana, vom Usurpator Maximus (in Wirklichkeit Eugenius [392-394], vgl. Maier 1995, 248) eine kaiserliche Verfügung 
Existenz einer derartigen Gemeindekirche durch Hieronymus verbürgt, der erwähnt, dass die donatistische Gemeinde Roms zunächst (primum) über eine Kirche auf einem der Hügel Roms verfügt habe. ${ }^{247}$ Es gibt Anzeichen dafür, dass diese Kirche auf dem Esquilin gelegen haben könnte. ${ }^{248}$ Wichtiger als alle Spekulationen ${ }^{249}$ über die genaue Lage einer donatistischen Kirche in Rom ist jedoch die Tatsache, dass die Randexistenz im Suburbium Roms, die die Donatisten zur Zeit des Optatus fristeten, das eindeutige Ergebnis einer Verdrängung aus der Stadt und kein Versuch war, die Apostel- und Märtyrertopographie vor der Stadt zu nutzen, um dadurch der eigenen Existenz als Sondergemeinde eine besondere Legitimation zu verleihen. Auch für eine Stadt wie Rom mit ihrer ausgeprägten Heiligentopographie galt der Grundsatz, dass eine bischöfliche Kirche die personale Verbindung des Bischofs mit (s)einer Gemeinde räumlich zum Ausdruck bringen musste, und

erwirkt hätten, ein collegium im römischen Suburbium errichten zu dürfen und sich bei dieser Gelegenheit die Kultstätte der Märtyrer Processus und Martinianus an der via Aurelia angeeignet hätten (zu den - allerdings nicht zahlreichen - Grabinschriften aus dem Bereich der via Aurelia, die montanistische Einflüsse aufweisen, vgl. Ferrua 1936). Bereits der Begriff collegium, der auf die Strukturen des römischen Vereinswesens verweist, macht jedoch deutlich, dass hinter dieser montanistischen Gemeinschaft nicht der Anspruch stand, eine regelrechte Gemeinde zu gründen.

247 Hier., chron. ad ann. 355 (Helm 31984, 239): Donatus, a quo supra Donatianos in Africa dici memoravimus, Carthagine pellitur. Quidam sectatores eius etiam Montenses vocant eo, quod ecclesiam Romae primum in monte habere coeperint. Hieronymus kannte die stadtrömischen Verhältnisse aus eigener Anschauung, da er sich als Jugendlicher, vermutlich zwischen 359 und 363 in Rom aufgehalten hatte. Seinem Zeugnis ist daher hoher dokumentarischer Wert beizumessen; es handelt sich nicht einfach um eine vulgäretymologische Erklärung für die in Italien allgemein verbreitete Bezeichnung der Donatisten als Montenses (vgl. Optat. 2, 4, 5; Arnob. iun., praedest. 1, 69; CTh 16, 5, 43 [409]).

248 Die von Hieronymus hervorgehobene Lage auf einem mons könnte auf den Esquilin verweisen, dessen Erhebung in der Wahrnehmung eine bestimmende Rolle gespielt zu haben scheint: Ein Indiz dafür ist, dass beinahe alle frühmittelalterlichen Lesungstexte, die an den Stationstagen in S. Maria Maggiore verlesen wurden, auf die Hügellage der Basilika anspielen (vgl. Gamber 1970, 197f.).

249 Cecchelli 1985-1986, 291 meint, es habe sich bei der donatistischen Gemeindekirche um die basilica Liberii gehandelt, da diese Kirche für die Ursiner eine wichtige Rolle gespielt und enge Verbindungen zwischen Ursinern und Donatisten bestanden hätten. Für letzteres gibt es jedoch keine Anhaltspunkte: Zwar beklagte die römische Synode von 378 in ihrem Schreiben an die Kaiser, dass Damasus sich zahlreichen Anfeindungen, darunter der factio Ursini und des donatistischen Bischofs Claudianus ausgesetzt sähe (Ambr., extra coll. 7, 7f.). Doch kann man daraus nicht folgern, dass zwischen Ursinern und Donatisten eine innere Verbindung bestanden hätte (gegen Monachino 1964, 28); vielmehr sind bei einer derartigen Zusammenstellung polemische Absichten in Rechnung zu stellen, die die Ursiner dadurch, dass man sie in einem Atemzug mit Häretikern nannte, in Misskredit zu bringen suchten (analog dazu führte die Synode von Aquileia auch die Umtriebe der Arianer in Mailand auf das Wirken des Ursinus zurück; vgl. Ambr., extra coll. 5, 2f.). 
dies war nur dann der Fall, wenn sie sich dort erhob, wo der populus episcopi lebte: innerhalb der städtischen Mauern. ${ }^{250}$

\section{3. Damasus und die Märtyrer Roms}

Die Epigramme, die der römische Bischof Damasus (366-384) in großer Zahl an den Gräbern der römischen Heiligen anbringen ließ, ${ }^{251}$ und von denen 55 durch Fragmente und mittelalterliche Abschriften erhalten geblieben sind, ${ }^{252}$ bedeuten in der Geschichte der römischen Heiligenverehrung eine überaus wichtige Etappe, die ihn aus Sicht des 19. Jh. in den Rang eines ersten christlichen Archäologen erhob ${ }^{253}$ und ihm noch in jüngerer Zeit das Prädikat eines

250 Damit soll selbstverständlich nicht der Eindruck erweckt werden, als sei das Suburbium Roms nicht oder nur schwach besiedelt gewesen: Studien insbesondere der letzten Jahre haben die Vitalität des vorstädtischen Bereiches als Lebensraum deutlich herausgearbeitet. Dennoch bleibt festzuhalten, dass sich die aurelianische Mauer insbesondere durch den Ausbau der christlichen Coemeterialtopographie während des 4. Jh. zu einer markanten Grenze zwischen der Stadt und dem außerstädtischen Bereich entwickelte und eine symbolische Trennung zwischen der Stadt als dem Raum der Lebenden und dem immer stärker funeral geprägten Suburbium akzentuierte (vgl. dazu auch u., S. 405 mit Anm. 6).

251 Unter den Studien, die sich mit den damasianischen Epigrammen insgesamt oder zentralen Einzelaspekten beschäftigen, sind besonders hervorzuheben Schäfer 1932; der Kommentar von Ferrua (1942) zu seiner Edition der Epigrammata damasiana; Pietri 1961; Chadwick 1962; Fontaine 1986; Février 1992; Spera 1994; Guyon 1995; Sághy 1998, 217-290; dies. 1999; dies. 2000; Wesch-Klein 1999; Reutter 1999, 62-165; Curran 2000, 148-155; Trout 2005.

252 Antonio Ferrua geht in seiner immer noch maßgeblichen Edition der Epigrammata damasiana von 59 authentischen, von Damasus selbst oder von Klerikern in seinem Auftrag verfassten Epigrammen aus. Nicht alle Damasusepigramme gehören in den monumentalen Kontext römischer Heiligengräber: Damas., epigr. 1 und 2 sind keine Steinepigramme, sondern rein literarischer Natur (vgl. Ferrua [1942], in: Epigrammata damasiana, 12); das Epigramm für Felix von Nola (nr. 59) befand sich nicht in Rom, sondern in der nolanischen Basilika des Heiligen. Epigramm 41 dokumentiert die Restitution eines damasianischen titulus durch Bischof Vigilius, liefert jedoch keine Anhaltspunkte für den ursprünglichen Wortlaut des Damasusepigramms; ähnlich das Epigramm auf Chrysanthus und Daria (nr. 45). Drei Epigramme sind Grabtituli für Damasus selbst, seine Mutter und seine Schwester verfasst (nr. 10-12, die erhaltenen Fragmente für die Schwester und die Mutter zeigen, dass Damasus für diese Inschriften nicht, wie bei den Märtyrerepigrammen, auf den Kalligraphen Philocalus zurückgriff). Die Epigramme 3 u. 4 sind Stiftungsinschriften aus dem vatikanischen Baptisterium, darunter nur die letztere mit einem Bezug zur Apostelverehrung. Zwei Stiftungsinschriften, die sich auf den titulus Damasi beziehen (nr. 57f.), stammen zwar nicht aus Coemeterien, nr. 58 zeigt allerdings, dass Damasus die Heiligenverehrung nicht nur an den Gräbern thematisierte (haec Damasus tibi, Christe deus, nova tecta dicavi, / Laurenti saeptus martyris auxilio). Einen Sonderfall bildet auch das Grabepigramm der 383 verstorbenen Proiecta (nr. 51). Unter den verbleibenden Inschriften sind eine ganze Reihe in einem so fragmentarischen Zustand überliefert, dass sie nur Hinweise auf die äußere Gestaltung (Inschriftenform; mit der Inschrift verbundene Monumentalisierungen) erlauben, inhaltliche Aussagen, in welcher Weise Damasus die Märtyrer und sein Verhältnis zu ihnen stilisierte, jedoch nicht ermöglichen (vgl. nr. 5; 6; 9; 13; 14; 22; 23; 26; 27; 29; 30; 34; 36; 49; 52-56).

253 Vgl. Trout 2005, $298 \mathrm{f}$. 
„Vaters der christlichen Epigraphik“254 eingetragen hat. Mit Damasus verbinden sich jedoch nicht nur eine Erweiterung des römischen Heiligenkalenders ${ }^{255}$ sowie äußere Umgestaltungen der Märtyrergrablegen, die mit Epigrammen versehen, durch Marmorausstattungen monumentalisiert und durch Umbaumaßnahmen größeren Gruppen von Menschen zugänglich gemacht wurden. ${ }^{256}$ Über diese deutlich sichtbare Aufwertung der Märtyrerverehrung hinaus ist mit den Damasusepigrammen zugleich - erstmals seit den Graffiti unter S. Sebastiano - erneut ein römischer Denkmälerbestand gegeben, der substantielle Anhaltspunkte für die Rekonstruktion der Haltungen, die man gegenüber den Heiligen einnahm, liefert. Im Unterschied zum dürren Gerüst kalendarischer Kommemorationsdaten, das die beiden Depositionslisten des Chronographen von 354 enthalten, und anders als bei den zwar ausgesprochen reichen, jedoch nur eingeschränkt datierbaren und in ihren mentalitätsgeschichtlichen Implikationen schwer zu deutenden - archäologischen Befunden der Katakombeninschriften und -malerei, erlauben die damasianischen Epigramme Aussagen darüber, in welche Relation zu den Heiligen Damasus sich selbst und die Leser seiner Epigramme setzte: Damasus beschränkte sich nicht darauf, den Heiligen durch seine monumentalen Inszenierungen Denkmäler zu setzen, sondern thematisierte sein Verhältnis zu ihnen und zu den Besuchern der Grabstätten, indem er die Leser der Epigramme ansprach und sich in seinen Epigrammen zum Vermittler noch lebendiger mündlicher Traditionen über die römischen Blutzeugen machte. Die Heiligen und die Orte, an denen sie verehrt wurden, wurden damit zu Bezugspunkten von Identitätsdiskursen, die von der Person des römischen Bischofs abhängig waren, der für die Monumentalisierungen der Heiligengräber verantwortlich war und auf ihnen seine deutlich sichtbare Handschrift als Urheber dieser Umgestaltungen hinterließ.

Für die Frage nach der identitätsstiftenden Funktion der durch die damasianischen Epigramme propagierten Heiligenerinnerung erscheint es sinnvoll, sich zunächst kurz die unterschiedlichen Kontexte zu verdeutlichen, in denen die damasianischen Heiligen eine identitätsrelevante Bedeutung erlangen

\footnotetext{
$254 \quad$ Wesch-Klein 1999.

255 Vgl. hierzu Schäfer 1932, 1-8. Zwischen der Abfassung der Deposionslisten im Chronographen von 354 (erste Redaktion unter Bischof Marcus [336]) und dem stadtrömischen Festkalender, der sich für die Zeit kurz nach 422 aus dem Martyrologium Hieronymianum rekonstruieren lässt (s. dazu u., S. 456, Anm. 186), ist ein beträchtlicher Zuwachs an Heiligen zu verzeichnen. Angesichts der Tatsache, dass Damasus nachweislich neue Heiligenkulte ins Leben rief (s. u., Anm. 311), liegt es nahe, einen erheblichen Anteil an dieser Entwicklung seiner Initiative zuzuschreiben.

$256 \mathrm{Zu}$ den medialen Aspekten (philokalische Buchstaben und Monumentalepigraphik) vgl. Ferrua (1942), in: Epigrammata damasiana, 21-35; Wesch-Klein 1999, 17f. Zur Umgestaltung der Grablegen in Verbindung mit der Anbringung der Inschriftentafeln vgl. Tolotti 1986; Weiland 1994; Spera 1994; Guyon 1995. Zum Ausbau der römischen Katakomben, die durch infrastrukturelle Maßnahmen einer größeren Anzahl von Besuchern zugänglich gemacht wurden, s. u., S. $322 f$.
} 
konnten. Als Bischof von Rom stand Damasus im Zentrum dreier unterschiedlicher Bezugsgruppen, die als bedeutsam für seine soziale Position und sein Handeln einzustufen sind: Er war Leiter der katholischen ecclesia Roms und in dieser Stellung über die gesamte Zeit seines Episkopats hinweg Herausforderungen durch interne Konkurrenten und häretische Gemeinden ausgesetzt, denen gegenüber er diese Position als Gemeindeleiter behaupten musste. Er war ferner Bischof in einer Stadt, deren Eliten seit dem letzten Drittel des 4. Jh. ihre finanziellen Ressourcen verstärkt in den kirchlichen Bereich zu investieren begannen, und in der sich mit zunehmender Konversion der Bevölkerung der römische Bischof nicht nur für die christliche, sondern auch für die städtische Gemeinde zu einer zentralen Figur entwickelte. Er war schließlich auch Nachfolger des Petrus auf der cathedra Petri und nahm damit innerhalb der Reichskirche einen Rang ein, der ihm besonderes Ansehen und Autorität sicherte.

Mit Blick auf die Motive und die identitätsstiftenden Ziele, die Damasus bei seiner Monumentalisierung der römischen Heiligentopographie verfolgte, hat sich die Forschung bisher vor allem auf die städtische Gemeinde Roms und auf die römische ecclesia konzentriert. Seit einem bahnbrechenden Aufsatz von Charles Pietri zum Motiv der concordia apostolorum und der Entwicklung der christlichen Romidee ${ }^{257}$ gilt Damasus als der Wegbereiter einer christlichen Transformation Roms, die etwa einhundert Jahre später, unter Bischof Leo I. (440-461), ihren vorläufigen Abschluss gefunden habe. Leo I., der in seinen Predigten die Apostel Petrus und Paulus als neue Gründer Roms pries und sie an die Stelle von Romulus und Remus setzte, ${ }^{258}$ habe damit einen symbolischen Transformationsprozess vollendet, dessen Anfänge sich bereits unter Damasus abgezeichnet hätten. Durch seine Bezeichnung der Märtyrer als römische Bürger (cives) und durch die verdeckte Attribuierung der Apostel Petrus und Paulus als „neue Dioskuren“ habe Damasus den ersten Schritt zu einer Entwicklung getan, in deren Verlauf die urbs Roma und die traditionelle Vorstellung von Rom als symbolischem Zentrum des Reichs und als caput mundi christianisiert worden sei - ein kultureller Wandel städtischer Identität, unter dessen Eindruck sich zugleich die traditionellen Träger einer universalistischen Romidee, die stadtrömische Aristokratie, zum Christentum bekehrt hätten.

257 Vgl. zum folgenden Pietri 1961, bes. 302, 310-322. Die Transformation der universalen Leitungsund Ordnungsfunktion des caput mundi, die in Anbetracht der schwindenden Rolle der Stadt als politisches Zentrum in christlicher Form weiterlebte, und die damit einhergehende Christianisierung der städtischen Eliten sind auch das zentrale Thema von Pietris monumentaler Thèse zur „Roma christiana“ zwischen 311 und 440 (programmatisch Pietri 1976, Bd. 1, IXf.; vgl. auch das Schlusskapitel zur christlichen Romidee in der Spätantike [ebd., Bd. 2, 1627-1651]). 
Pietris Auffassung, in Damasus den Begründer eines neuen, christlichen Rom zu sehen, hat in der Forschung allgemein großen Anklang gefunden und wird übereinstimmend als ein wesentliches Motiv der vielschichtigen Epigramme des Damasus angesehen. ${ }^{259}$ Einen anderen Akzent setzen demgegenüber Interpretationsansätze, die eine gezielte Förderung des Märtyrerkultes durch Damasus mit den innerkirchlichen Konflikten in Verbindung bringen, in die Damasus über die gesamte Zeit seines Episkopats hinweg verwickelt blieb. ${ }^{260}$ Nach dieser Deutung war für die Monumentalisierung der römischen Heiligentopographie durch Damasus das Bemühen ausschlaggebend, seine Autorität als Bischof der christlichen Gemeinde Roms zu stärken: ${ }^{261}$ Die Heiligen hätten durch ihre Macht als heilige Patrone eine umkämpfte Autoritätsressource gebildet, die Damasus als römischer Bischof unter seine Kontrolle zu bringen und gegen rivalisierenden Ansprüche, die von schismatischen oder häretischen Gruppen erhoben wurden, zu behaupten suchte. ${ }^{262}$ Durch den Heiligenkult sei es Damasus ferner gelungen, Teile der stadtrömischen Aristokratie, die in den Heiligen ein neues Feld der Patronage erkannt hätten, auf seine Seite zu ziehen und durch ein erfolgreiches „net-

259 Die innere Einheit zwischen Damasus und Leo I. und einer von ihnen propagierten christlichen Romidee betonen u. a. Huskinson 1982, 81f.; Guyon 1996, 914; Inglebert 1996, 563; WeschKlein 1999, 29. Reutter 1999, 165 sieht in den Epigrammen „in erster Linie eine Christianisierung Roms“ am Werk; ähnlich urteilt Klein 2003, 92. Trout 2005, 300 hebt hervor, dass die Damasusepigramme eine neue städtische Identität begründet hätten (,exploring new modes of self-understanding... reshaping civic identity and public memory“; ähnlich ders. 2005 [a], 173). Für die durch die damasianischen Heiligen bewirkte Transformation der Stadt Rom und der städtischen Identität vgl. auch Curran 2000, 153-155. Zu den Bemühungen des Damasus, durch den an den klassischen Bildungsautoren geschulten Stil der Epigramme eine Christianisierung der römischen Aristokratie herbeizuführen, vgl. die gleichlautenden Einschätzungen von Brändle 1992, 210 u. Reutter 1999, 163-165, die das Signal an die römische Oberschicht, „daß Christianisierung nicht gleichzeitig auch Verzicht auf Bildung bedeutet“, als das zentrale Anliegen der Epigramme betrachtet.

260 Zum Schisma zwischen Damasus und Ursinus s. o., S. 224-242. Für die zahlreichen schismatischen und häretischen Gruppen, mit denen sich Damasus während seines Episkopats auseinandersetzte, vgl. Pietri 1986, $40 \mathrm{f}$.

261 Als Schlüssel zum Verständnis der Epigramme begriffen von Février 1992, 499-505; Sághy 2000, 281-285. Auch in denjenigen Studien, die die religiösen Transformation zur urbs Roma christiana als das zentrale Motiv der Damasusepigramme ansehen, findet dieser Aspekt Beachtung (vgl. Wesch-Klein 1999, 23f.; Curran 2000, 151-155).

262 Besonders ausgeprägt zuletzt Blair Dixon 2002, bes. 344f., die die Kontrolle der Märtyrerkultstätten als den „key to the agonistic competition between various factions in Rome“ begreift. Auch Sághy 2000, 283 deutet die Epigramme des Damasus als regulierende Eingriffe in die römische Coemeterialtopographie, mit denen Damasus potentielle Ressourcen von Autorität seiner eigenen Kontrolle unterstellte und so seine Gegner einer wichtigen Möglichkeit beraubte, sich außerhalb des von ihm kontrollierten kirchlichen Bereichs um die Gräber heiliger Patrone als Zentren kollektiver Identitätsbildung zu formieren. 
working“ seine Position als Bischof der Gemeinde gegenüber Konkurrenten zu sichern. ${ }^{263}$

Im folgenden soll demgegenüber die These vertreten werden, dass beide Interpretationsansätze an den Voraussetzungen und Intentionen der durch Damasus betriebenen Monumentalisierung der stadtrömischen Heiligentopographie vorbeigehen. Zwar zielten Damasus' Aktivitäten im römischen Suburbium durchaus darauf ab, seine - nicht selten angefochtene - Position als Gemeindeleiter zu stärken. Anders als es die Vorstellung von der stadtrömischen Heiligentopographie als einem von unterschiedlichen kirchlichen Gruppen umkämpften Feld von einzelnen heiligen Zentren suggeriert, waren die damasianischen Märtyrer jedoch keine mächtigen Patrone, die ihrem Klienten Damasus Schutz und Hilfe gewährten und ihren Einfluss an den einzelnen Verehrungsstätten geltend machten. Damasus unterstellte sich nicht der Macht heiliger Patrone - vielmehr gliederte er die Heiligen in die Gemeinde ein, der er als Bischof vorstand. Durch die äußere Gestaltung der Grablegen und die Art der in den Epigrammen entwickelten Erinnerungsbezüge entwarf Damasus gezielt einen Typ „des“ römischen Heiligen, der die individuellen Züge der einzelnen Blutzeugen in den Hintergrund treten ließ, und der nicht als gegenwärtiger Patron wirkte, sondern als ein Denkmal der heroischen Zeit der Verfolgungen den Ruhm der römischen Gemeinde - und damit ihres bischöflichen Leiters - mehrte.

Diese spezifische Haltung des Damasus gegenüber den Heiligen fand ihren Ausdruck auch in deren Bezeichnung als „Bürger“ Roms. Der Terminus unterstrich die Ambitionen des Damasus, den römischen Heiligen eine gemeindebezogene Ausrichtung zu geben. Die in ihren Gräbern liegenden „Bewohner“ des Suburbiums wurden durch die Bürgerterminologie Teil der Stadt - und damit zugleich der christlichen Gemeinde, für die von jeher nicht das Suburbium, sondern der städtische Raum den ideellen Bezugspunkt der Identitätsstiftung gebildet hatte. Die mit der politischen Terminologie einhergehende Romanisierung der Heiligenverehrung entfaltete ihre eigentliche Wirksamkeit nicht auf lokaler, sondern vor allem auf universalkirchlicher Ebene: Nicht nur durch die Bezeichnung der Heiligen als „Bürger“ bediente sich Damasus in seinen Epigrammen gezielt einer durch die kulturelle Tradition Roms geformten „Sprache“, ${ }^{264}$ um mittels des Heiligenkults die Semantik des caput mundi für dessen christliche Gemeinde verfügbar zu machen und so den Führungsanspruch der römischen ecclesia innerhalb der Universalkirche zu artikulieren. Eine komplementäre Christianisierung der urbs, wie sie seit Pietri allgemein mit Damasus in Verbindung gebracht wird, war damit jedoch nicht intendiert: Damasus bediente sich zwar traditioneller kultureller Modelle

\footnotetext{
263 So Sághy 1998, 151; 217-242.

264 Zur Erläuterung des Begriffs s. u., Anm. 330.
} 
städtischer Identitätsstiftung, war jedoch nicht darauf aus, diese christlich zu transformieren. Erst in den Jahren nach Damasus' Tod wurden mit Hilfe der Heiligen Identitätsdiskurse über Rom als christliche Stadt geführt - eine diskursive Christianisierung der urbs Roma, die Damasus zwar vorbereitet, aber nicht selbst betrieben hatte.

Die Auffassung, Damasus habe den Ausbau der römischen Heiligenverehrung mit Blick auf die prekären Anfänge seines Episkopats betrieben, gründet u. a. darauf, dass die damasianischen Epigramme auffällig häufig Spaltungen und Konflikte innerhalb der römischen Gemeinde zum Gegenstand haben. Zwei der Epigramme erinnern an bischöfliche Vorgänger des Damasus, Marcellus (307/308) und Eusebius (308/310), die wegen ihrer Haltung in der Gefallenenfrage in innergemeindliche Konflikte verwickelt wurden und im Exil als „Märtyrer“ starben. ${ }^{265}$ Dieselbe Thematik begegnet auch in der Geschichte des Hippolytus, der von Damasus als novatianischer Presbyter dargestellt wird: Er vollzieht angesichts des bevorstehenden Martyriums die erneute Hinwendung zur fides catholica und wird dadurch zum Sinnbild einer überwundenen Kirchenspaltung. ${ }^{266}$

Dieses Muster einer Störung der innerhalb der Gemeinde bestehenden Eintracht bleibt nicht allein auf schismatische Situationen beschränkt, sondern liefert auch einen fruchtbaren Interpretationsansatz für weitere Gedichte, in denen Damasus das Schicksal der in den Verfolgungen umgekommenen Märtyrer thematisierte. Als die mit Abstand häufigste unter den zahlreichen stehenden Wendungen der damasianischen Epigramme begegnet die Zeile tempore quo gladius secuit pia viscera matris, um damit die Zeit der Verfolgungen zu bezeichnen. ${ }^{267}$ Das Durchschneiden der viscera machte auch die Verfolgung selbst zu einem Sinnbild von Spaltung und Zertrennung, die sich in den Konflikten um den Umgang mit den Gefallenen, wie sie durch Hippolytus, Eusebius und Marcellus repräsentiert wurden, fortsetzte: Beides war eine Störung des kirchlichen Friedens. ${ }^{268}$ Der innere Zusammenhang zwischen beiden Arten der Trennung wird besonders deutlich im Epigramm auf Hippolytus, wo es „die Zeit, da das Schwert das Herz der Kirche zerschnitt“, ist, die Hippolytus zum Märtyrer und damit zum kirchlichen Einheitsstifter

$\overline{265}$ Damas., epigr. 18 (Eusebius); 40 (Marcellus).

266 Ebd. 35 (Hippolytus). Auch der Novatianismus ist aus divergierenden Ansichten zum Umgang mit den lapsi erwachsen; die Epigramme auf Hippolytus, Eusebius und Marcellus thematisieren daher denselben Sachverhalt in unterschiedlichen Varianten.

267 Vgl. Damas., epigr. 17; 31; 35; 43; 46.

268 In ähnlicher Weise stellte auch Cyprian den Zusammenhang von (äußerer) Verfolgung und (innerer) Auseinandersetzung in der Gefallenenfrage heraus; beides sind für ihn zwei Seiten derselben Medaille, nämlich eine Störung des gemeindlichen Friedens, der pax (vgl. Cypr., laps. 16). 
werden ließ.269 Auch wenn die übrigen Epigramme des Damasus den hier deutlich formulierten Zusammenhang von Verfolgung und Einheitsstiftung durch die Märtyrer nicht in derselben expliziten Weise herausstellen, ${ }^{270}$ dürfte es als unbestreitbar gelten, dass die Störung der pax in den Märtyrerepigrammen des Damasus eine geradezu leitmotivische Bedeutung hat: Es ist ein zentrales Thema, mit dem sich Damasus in seinen Märtyrerepigrammen auseinandersetzte.

Diese prononcierte Thematisierung von Spaltung und Einheitsstiftung ist fraglos signifikant bei einem Bischof, der sich von den Tagen seiner Wahl an über die gesamte Dauer seines Pontifikates hinweg in Auseinandersetzungen mit rivalisierenden - schismatischen und häretischen Gruppen - verstrickt sah. Es liegt dementsprechend nahe, in den wiederholten Anspielungen auf die durch innere und äußere Bedrohungen gefährdete Einheit der Gemeinde eine gezielte Bezugnahme auf die eigene Zeit und die Anfechtungen zu sehen, denen Damasus als Gemeindeleiter ausgesetzt war. Dies allein erklärt jedoch noch nicht, in welcher Weise sich Damasus der römischen Märtyrer und seines Verhältnisses zu ihnen bediente, um seine Autorität als römischer Bischof zu stärken. Vor allem seit den Studien von Peter Brown zur spätantiken Heiligenverehrung ist unser Bild der Heiligen maßgeblich von ihrer Eigenschaft als Patrone und mächtige Fürsprecher und von den topographischen Implikationen, die diese Wahrnehmung vor allem im Westen des römischen Reiches hatte, geprägt worden: In den Heiligen konzentrierte sich eine große Macht, die in den sterblichen Überresten und Gräbern - den Orten, „an denen sich die Pole von Himmel und Erde trafen“271 - erfahrbar wurde und damit diese Grablegen zu Zentren der Verehrung und zu Kraftfeldern machten, deren Besitz und Kontrolle Autorität vermittelte. Dieses Deutungsmuster einer auf die Märtyrergrablegen fokussierten Patronagebeziehung zwischen den Heiligen und ihren Verehrern vorausgesetzt, erscheint es auf den ersten Blick naheliegend, auch die damasianische Monumentalisierung der römischen Märtyrertopographie als einen Versuch des Damasus zu interpretieren, sich der Macht möglichst vieler dieser Helfer zu versichern, um auf diese Weise seine angefochtene Stellung als Bischof gegenüber seinen Wider-

269 Die Tatsache, dass Hippolytus als noster martyr in betonter Abgrenzung von seiner novatianischen Vergangenheit bezeichnet wird (Damas., epigr. 35, 7), ändert nichts an dem Befund, dass sich Hippolytus aus der Perspektive des Damasus als ein Einheitsstifter präsentierte: sein Bekenntnis hat beispielhaften Charakter für die Gemeinde (sequerentur ut omnes). Dass das novatianische Schisma durch den Tod des Hippolytus nicht beseitigt wurde, ist demgegenüber sekundär.

270 Unica gloria in Damas., epigr. 25 als Ausdruck von Einheit zu sehen, wie Février 1992, 503, vorschlägt, ist sprachlich nicht haltbar (unicus muss hier ,einzigartig“ heißen); ebenso wenig wird im Epigramm auf die Apostel Petrus und Paulus (Damas., epigr. 20) das Thema der concordia apostolorum angeschlagen (anders Sághy 2000, 278; Curran 2000, 153).

271 Brown 1981, 3. 
sachern behaupten zu können, ${ }^{272}$ und um seine Eigenschaft als Mittler zwischen den Heiligen und der Gemeinde unter Beweis zu stellen. ${ }^{273}$

Gegen eine solche Deutung der römischen Heiligentopographie, nach der Damasus in den Märtyrergräbern einzelne Pole und lokale Zentren der Verehrung unter seine Kontrolle gebracht hätte und darin jüngst sogar als ein Wegbereiter der mittelalterlichen Stadt angesprochen wurde, ${ }^{274}$ lassen sich jedoch eine ganze Reihe von Einwänden geltend machen. Zum einen setzte Damasus in seinen Epigrammen sich und die Leser in eine spezifische Relation zu den Heiligen, die deren Bedeutung als Patrone dezidiert nicht akzentuierte: Weder begab sich Damasus selbst gegenüber den Heiligen in die Rolle eines Klienten, noch evozierte er auf seiten der Leser seiner Epigramme eine derartige Haltung. Nahezu regelmäßig thematisierte Damasus in den Epigrammen nicht nur seine Verfasserschaft, sondern vor allem auch seine Rolle als Übermittler einer auf den jeweiligen Heiligen bezogenen Tradition: Damasus präsentierte sich gegenüber den Lesern als Lehrer und Katechet, der eine gehörte Tradition in Erfahrung gebracht hatte, weitergab und guthieß,275 ferner als Gewährsmann von Authentizität, der die Leser der Epigramme zur

272 So Wirbelauer 1994, 410, der die besondere Wertschätzung, die Damasus den römischen Märtyrern erwies, als einen Versuch des Bischofs interpretiert, einen Mangel an Charisma, das ihm aufgrund seiner umstrittenen Wahl fehlte, durch seine enge Verbindung zu den Heiligen auszugleichen, denen besondere Macht zugeschrieben wurde. Grundsätzlich problematisch an diesem Ansatz ist, dass er einen theologischen und einen soziologischen, an Max Weber orientierten Charismabegriff (ebd., 389-394) miteinander verbindet: Die Weitergabe von Charisma, wie sie die Traditio apostolica durch die Handauflegung der weihenden Bischofs vorgenommen wird, ist prinzipiell nicht von der immer wieder aktualisierten Akzeptanz und Zuschreibung abhängig, die Weber als konstitutiv für seinen herrschaftssoziologischen Charismabegriff definiert. Die charismatische, auf Zuschreibung beruhende Macht der Heiligen hat mit einem theologischen Charismabegriff, wie ihn die traditio apostolica zugrunde legt, wenig mehr gemein als die identische Bezeichnung. Hinzu kommt, dass die entscheidende Quelle für eine Dynamisierung des Amtscharismas in der römischen Kirche, die Traditio apostolica, bereits seit geraumer Zeit nicht mehr dem Hippolyt von Rom zugeschrieben wird (vgl. die Bilanz der Forschung der letzten 20 Jahre von Markschies 1999).

273 Zu Damasus' Rolle als Mittler zwischen den Heiligen und der plebs Dei vgl. Curran 2000, 150. Ähnlich auch Sághy 1998, 241f., 258f., die diese Mittlerfunktion des Damasus mit Blick auf die stadtrömische Aristokratie betont: Damasus habe das Interesse der römischen Eliten auf die Heiligen gelenkt und sich damit als Vermittler von Ressourcen betätigt, die das Interesse und die Investitionsbereitschaft aristokratischer Patrone gefunden hätten. Soziologisch tritt der römische Bischof damit als Makler in Erscheinung: Er beschränkt sich darauf, in Form der Heiligen ein spirituelles Kapital zu vermitteln, das er aber nicht selbst generiert (zum Modell der Maklerpatronage vgl. Flaig 1992, 104-107).

274 Curran 2000, 155.

275 Damas., epigr. 15 (Tarsicius): par meritum quicumque legis conosce duorum / quis Damasus rector titulos post praemia reddit, 20 (Petrus und Paulus): cognoscere debes; 28 (Petrus und Marcellinus): Marcelline tuum pariter Petrique sepulcrum / percussor retulit Damaso mibi cum puer essem; 35 (Hippolytus): haec audita refert Damasus - probat omnia Christus; 40 (Marcellus): haec breviter Damasus voluit conperta referre, / Marcelli ut populus meritum cognoscere possit. Auch in Damas., epigr. 37 (Agnes) und 48 (Hermes) thematisiert Damasus die Wiedergabe einer Tradition über die Heiligen (fama refert). 
Kenntnisnahme des Gelesenen und sowie zur gläubigen Verehrung des Heiligen aufforderte, ${ }^{276}$ und als gläubiger Verehrer der Heiligen, dessen Worte durch das Epigramm wiedergegeben wurden. ${ }^{277}$ Dass, wie in den Epigrammen für Sixtus II. und für Eusebius, ${ }^{278}$ von Damasus die Geschichte eines Heiligen oder die Situation seines Martyriums ohne kommentierende Zusätze seitens des römischen Bischofs evoziert wurde, bleibt die Ausnahme.

Damasus führte die Heiligen den Besuchern ihrer Grablegen damit in einer Weise vor, die nicht darauf ausgerichtet war, im Leser eines Epigrammes den Eindruck zu erwecken, er trete vor dem Grab in eine unmittelbare Beziehung zu einem ihm persönlich verbundenen Patron. Der römische Bischof beschränkte sich in seinen Epigrammen nicht allein darauf, dem Leser ein Bild der verehrten Heiligen zu vermitteln. Vielmehr wurde der Blick des Besuchers auf den Heiligen gleichsam gefiltert durch den römischen Bischof, der durch die Selbstthematisierung als kommentierender Übermittler einer Tradition zwischen die Heiligen und die Leser der Epigramme trat. In gleicher Weise distanzierend wirkte die historische Dimension, die Damasus mit Blick auf die römischen Märtyrer gezielt akzentuierte. Durch stereotype Wendungen wie fertur, fama refert, comperta referre ${ }^{279}$ gab Damasus zu erkennen, dass er sich auf Traditionen über die Heiligen bezog, und rief damit dem Leser der Epigramme die Geschichtlichkeit der römischen Blutzeugen ins Bewusstsein. Der Bischof unterlief auf diese Weise die für die spätantike Verehrung der heiligen Patrone zentrale Erfahrung der helfenden Gegenwart (praesentia) der Heiligen, ${ }^{280}$ indem er vielmehr die Vergangenheit und die Erinnerung an die Heiligen in den Vordergrund stellte. Die Unterschiede zwischen diesen beiden modi memorandi werden exemplarisch im Vergleich eines Damasusepigramms auf die Diakone Felicissimus und Agapetus, die zusammen mit dem übrigen Klerus Sixtus' II. 258 das Martyrium erlitten, mit denjenigen Worten deutlich, mit denen Ambrosius von Mailand die im Jahr 386 erfolgte Reliquienerhebung von Gervasius und Protasius - zugleich einer der frühesten Belege für die Rede von den Heiligen als patroni - kommentierte: ${ }^{281}$

276 Ebd. 42 (ornavit Damasus tumulum, cognoscite, rector); 8 (Nereus und Achilleus): credite per Damasum possit quid gloria Christi; 21 (Eutychius): expressit Damasus meritum - venerare sepulcrum;

277 Ebd. 46 (Saturninus): supplicis haec Damasi vox est. Derartige „Autorenvermerke“ finden sich in den meisten der damasianischen Epigramme.

278 Ebd., 17 u. 18.

279 Für Belege vgl. u., Anm. 295f.

280 Zur helfenden praesentia als zentralem Charakteristikum der spätantiken Heiligen in ihrer Funktion als Patrone vgl. Brown 1981, bes. 86-105; Merkt 1997, 243-248.

281 Ambrosius hatte den Begriff patronus für die himmlischen Fürsprecher bereits früher verwendet, z. B. in der um 377 verfassten Schrift de viduis (Ambr., vid. 54). Eine umfangreiche Zusammenstellung von Belegen für den gegen Ende des 4. Jh. allgemein aufkommenden Sprachgebrauch bietet Orselli 1965, 39-56. 
„Blick her: Auch dieses Grab enthält die himmlischen Glieder von Heiligen, die das Reich des Himmels uns plötzlich entriss. Diese - zugleich Diener und Gefährten des unbesiegbaren Kreuzes - folgten dem Verdienst und dem Glauben ihres heiligen Leiters und gelangten in die himmlischen Wohnstätten und das Reich der Frommen. In ihnen frohlockt der einzigartige Ruhm der römischen Gemeinde, weil sie sich, damals unter der Führung des Sixtus, den Triumph Christi verdienten. - Für die heiligen Märtyrer Felicissimus und Agapetus hat Bischof Damasus dies errichtet.“282

„Obwohl wir sie (die Heiligen) nicht sehen können, spüren wir sie dennoch. Unsere Augen waren geschlossen, solange die begrabenen Körper der Heiligen verborgen waren. Der Herr öffnete unsere Augen: wir sehen nun die Helfer, von denen wir schon immer beschützt worden sind... Mit unseren Augen, von denen das Siegel genommen wurde, blicken wir auf die Herrlichkeit des Herrn, die sich vor langer Zeit im Leiden der Märtyrer zeigte, in der Gegenwart aber in ihrer wunderbaren Macht (in operatione praesenti) offenbart... Wir hatten Patrone (patromi), ohne es zu wissen; ... das Wissen um die heiligen Märtyrer, das sie (scil. unsere Vorfahren) verloren hatten, haben wir wieder gewonnen." 283

In beiden Zeugnissen, die sich trotz der gattungsbedingten Unterschiede auch in formaler Hinsicht miteinander vergleichen lassen, ${ }^{284}$ werden die Dimensionen Vergangenheit und Gegenwart - die beiden Pole jeglichen Erinnerns ${ }^{285}$ als Aspekte des Heiligengedenkens thematisiert. Dennoch sind die Akzente unterschiedlich gesetzt: Damasus erinnert an die unerschütterliche Haltung, die die beiden Diakone in weit zurückliegender Zeit zum Martyrium führte Ambrosius weiß von den historischen Vorgängen um Gervasius und Protasius nichts zu berichten. Der Bischof von Mailand wiederum akzentuiert die gegenwärtig erfahrbare operatio praesens der heiligen Patrone, in der sich die Herrlichkeit des Herrn offenbart - für seinen römischen Kollegen ist der einzigartige Ruhm der römischen Gemeinde eine historisch begründete Tatsache, die auch in der eigenen Gegenwart nachwirkt. ${ }^{286}$ Damasus schuf mit seinen Epigrammen und Monumentalisierungen Denkmäler, die das Wirken

282 Damasus, epigr. 25: Aspice, et bic tumulus retinet caelestia membra / sanctorum subito rapuit quos regia caeli. / hi crucis invictae comites pariterque ministry / rectoris sancti meritumque fidemque secuti / aetherias petiere domos regnaque piorum. I unica in his gaudet romanae gloria plebis, / quod duce tunc Xysto Christi meruere triumphos. / Felicissimo et Agapeto sanctis martyribus Damasus episcopus fecit.

283 Ambr., epist. 77 (22), 11: nos etsi eos videre non possumus sentimus tamen. erant clusi isti oculi quamdiu obruta sanctorum delitescebant; aperuit oculos nostros dominus, videmus auxilia quibus sumus saepe defensi... ita reseratis oculis gloriam domini speculamur, quae est in martyrum passione praeterita et operatione praesenti... patronos babebamus et nesciebamus... sanctorum martyrum cognitionem quam illi amiserunt nos adepti sumus.

284 Ambrosius referiert im oben zitierten Brief an seine Schwester Marcellina eine Predigt, mit der er sich nach der Überführung der Gervasius- und Protasiusreliquien in die basilica Ambrosiana an seine Gemeinde wandte. Seine Ausführungen gehören damit in denselben Kommunikationskontext wie die damasianischen Epigramme, die gleichfalls kurze Ansprachen des römischen Bischofs an die Besucher der Heiligenstätten darstellen.

285 Jegliches Erinnern macht durch Vergegenwärtigung die Vergangenheit für die Gegenwart verfügbar (vgl. Assmann 21997, 42-45).

286 Gaudet romanae gloria plebis ist nicht als historisches Präsens aufzufassen; vgl. auch u., Anm. 304. 
der römischen Heiligen in Erinnerung riefen und vergegenwärtigten, nicht aber Orte, an denen die praesentia der Heiligen durch ihre wundertätige Macht als Patrone erfahrbar wurde. ${ }^{287}$

In den Damasusepigrammen erscheinen die Märtyrer zwar durchaus als Adressaten einer besonderen Wertschätzung und Verehrung, als Helfer und als Fürsprecher. Aber die kommentierenden Selbstthematisierungen des Damasus in seinen Epigrammen stifteten in zweifacher Hinsicht Distanzen und Brechungen: Zum einen war das Bild, das sich der Besucher einer Grablege von einem Heiligen machte, und damit auch die Relation, in die er zu ihm trat, durch Damasus vermittelt. Zum anderen rückte dadurch, dass sich der römische Bischof zum Übermittler einer Tradition über die Heiligen stilisierte, deren geschichtliche Dimension in den Vordergrund. Anstelle der vergegenwärtigenden praesentia, die für die Verehrung des Märtyrers als eines fürsprechenden Patrons von fundamentaler Bedeutung war, wurde von Damasus eine historisierende Perspektive auf den Heiligen akzentuiert: Seine Epigramme zeigten nicht die Macht und Größe der Heiligen in ihrer Gegenwärtigkeit, sondern setzten den römischen Märtyrern Monumente, die den Lesern die Zeugen einer ruhmreichen Vergangenheit in Erinnerung riefen.

Dasselbe gilt auch für das Bild, das Damasus von sich selbst in seinem Verhältnis zu den Märtyrern entwarf: Das Patron-Klient-Verhältnis war für die Art und Weise, wie Damasus seine eigene Relation zu den Heiligen gegenüber den Lesern kommunizierte und damit die Heiligenverehrung als Ressource für die Begründung der eigenen Autorität verfügbar machte, nicht bestimmend. Zwar lassen die damasianischen Epigramme deutlich erkennen, dass Damasus den Heiligen große Bedeutung als mächtige Helfer zuschrieb, indem er sich vereinzelt mit Bitten an sie wandte, ${ }^{288}$ seine Monumentalisierungen als Votivstiftungen auswies ${ }^{289}$ oder auch konkret die Hilfe der Heiligen bei der Beilegung der internen Konflikte, die Damasus' Stellung als Bischof von Rom untergruben, thematisierte. ${ }^{290}$ Dennoch zielen die Epigramme nicht darauf ab, die Macht der Märtyrer als helfende Patrone herauszustellen. Diese Eigenschaft der Heiligen ist eine fundierende Qualität, die an unterschiedlichen Stellen der damasianischen Texte hervortritt, doch machte

287 Auf die grundlegende Differenz, die zwischen einem historisch und einem gegenwartsorientierten Erinnern im antiken Märtyrergedenken bestand, hat auch Martin 1990, bes. 443-450, 455-462 hingewiesen.

288 Vgl. die folgenden Wendungen und Ausdrücke: ut Damasi precibus faveas precor (Damas., epigr. 31; 37; 48); supplex (33; 44; 39); supplicis vox (46). Ähnlich das Laurenti saeptus martyris auxilio (58) in der Titelkirche des Damasus.

289 Reddit sua vota (Damas., epigr. 39; 42); mea vota rependo (46).

290 Ebd. 42 (Märtyrer im coemeterium Thrasonis): ornavit Damasus tumulum, cognoscite, rector / pro reditu cleri Christo praestante triumphans. / martyribus sanctis reddit sua vota sacerdos. Der reditus cleri muss sich auf die Wiedereingliederung des ursinischen Klerus beziehen (vgl. den Kommentar von Ferrua [1942], in: Epigrammata damasiana, 184). 
Damasus die Patronagebeziehung zwischen dem Heiligen und ihm als dem Bischof der Stadt nicht zum eigentlichen Thema der Relation zwischen sich und den Heiligen. Auch Damasus selbst nahm gegenüber den Heiligen die distanzierte Rolle eines Erzählers ein, der sich allenfalls in abschließenden Sätzen den Märtyrern in direkter Anrede zuwandte, ${ }^{291}$ ansonsten jedoch mit dem Leser der Inschriften kommunizierte oder im Stil eines auktorialen Erzählers die Größe des Martyriums pries oder das Schicksal des Heiligen referierte. ${ }^{292}$ Dies ist um so auffälliger, als das einzige Epigramm, in dem Damasus die Haltung eines Klienten einnimmt, der den verehrten Märtyrer direkt anspricht, zugleich das einzige der damasianischen Epigramme ist, das nicht aus Rom stammt, sondern aus Nola, wohin Damasus eine Pilgerreise an das Grab des Heiligen Felix unternommen hatte, um ihm für seine Hilfe zu danken:

„An Leib, Geist und Seele und ebenso dem Namen nach Felix, in der Heiligen Schar teilhabend an Christi Triumphen! Der Du denen alles gewährst, die bekümmert zu Dir kommen, und niemanden traurig lässt heimkehren: weil ich durch Dich errettet die Fesseln des Todes zerriss, löse ich, Damasus, nach Vernichtung der Feinde, die Lügen geredet, Dir durch dieses Gedicht bittflehend meine Gelübde.“293

Diese Selbststilisierung als Klient des Heiligen, die Damasus als Pilger im fernen Nola offenbar problemlos einnehmen konnte, war kein Modus der Interaktion mit den Heiligen, den der römische Bischof innerhalb seiner eigenen Gemeinde propagiert hätte.

Die römischen Heiligen trugen demnach nicht als Helfer und Patrone, sondern auf einem anderen Wege dazu bei, die Stellung des Damasus als Leiter der römischen Gemeinde zu festigen. Damasus referierte in seinen Epigrammen nicht nur die Geschichte(n) der römischen Märtyrer, er tat dies auch auf eine spezifische Art und Weise, nämlich als Vermittler einer mündlichen Tradition. Zum Teil, wie in den Epigrammen auf Hippolytus, Marcellus sowie Petrus und Marcellinus, sprach Damasus die Tatsache, dass er hier „Gehörtes wiedergab“ (haec audita refert Damasus) explizit aus. ${ }^{294}$ In anderen

291 Vgl. Damas., epigr. 31; 37. Im Epigramm auf Hermes (48) spricht Damasus den Heiligen zwar das ganze Gedicht über direkt an, doch die Interjektion quod fama refert gleich in der ersten Zeile des Gedichtes macht deutlich, dass Damasus trotz des Kommunikationsmodus auch in diesem Epigramm als distanzierter Berichterstatter auftritt.

292 So auch Sághy 1999, 531.

293 Damas., epigr. 59: Corpore mente animo pariterque et nomine Felix, / sanctorum in numero Christi sociate triumphis, / qui ad te sollicite venientibus omnia praestas, / nec quemquam tristem pateris repedare viantem; / te duce servatus mortis quod vincula rupi, / hostibus extinctis fuerant qui falsa locuti ,/ versibus bis Damasus supplex tibi vota rependo. (Übers. Schäfer 1932, 150).

294 Damas., epigr. 35 (Hippolytus): Hippolytus fertur premerent cum iussa tyranni... baec audita refert Damasus - probat omnia Christus; 40 (Marcellus): haec breviter Damasus voluit conperta referre, / Marcelli ut populus meritum cognoscere possit, 28 (Petrus und Marcellinus): Marcelline tuum pariter Petrique sepulcrum / percussor retulit Damaso mibi cum puer essem. 
Fällen, wie bei Agnes und Hermes, beschränkte sich der römische Bischof darauf, auf die fama zu verweisen, und dem Leser den impliziten Schluss zu überlassen, dass es der Verfasser des Epigrammes, Damasus, war, der dem, was „man sich erzählte“ (quod fama refert), schriftlichen Ausdruck verlieh. ${ }^{295}$ Warum rekurrierte Damasus auf diese spezifische Form des „Autorenvermerks", indem er sich nicht einfach darauf beschränkte, autoritativ die merita der Märtyrer zu verkünden, sondern die mündlich übermittelten Tradition (audita, fama) als Quelle seines Wissens thematisierte?

Ein Teil der Forschung sucht die Antwort auf diese Frage im Spannungsverhältnis von mündlicher Tradition und Authentizität: Das „Gehörte“ sei ein Synonym für eine legendarische, hinsichtlich ihrer Glaubwürdigkeit wenig vertrauenswürdige Tradition, deren zweifelhaften Wert der römische Bischof erkannt und durch das relativierende fertur signalisiert habe. ${ }^{296}$ Dem ist jedoch entgegenzuhalten, dass zum einen Damasus kaum die fehlende Glaubwürdigkeit der von ihm verkündeten Erzählungen durch Hammer und Meißel in Stein hätte verewigen lassen, und dass zum anderen die Gleichsetzung von mündlicher Überlieferung/zweifelhafter historischer Glaubwürdigkeit versus schriftlicher Dokumentation/historischem Quellenwert ein modernes Verständnis von historischer Authentizität widerspiegelt. ${ }^{297}$ Dass Damasus sich

295 Ebd. 37 (Agnes): fama refert sanctos dudum retulisse parentes / Agnen...; 48 (Hermes): iam dudum, quod fama refert, te Graecia misit.

296 So Schäfer 1932, 60f.; ähnlich Brent 1995, 369-372 u. 388, der die (prinzipiell berechtigte) Frage aufwirft, warum Damasus gegenüber seinem Publikum die Unsicherheit der Überlieferung in einem Epigramm wie dem auf Hippolytus durch Wendungen wie haec audita refert signalisieren sollte, und dies als ein bewusstes Signal des römischen Bischofs interpretiert: Damasus habe durch die Mündlichkeit vor sich selbst eingestehen wollen, dass die von ihm hergestellte Verbindung zwischen Hippolytus und dem novatianischen Schisma unhistorisch sei. Abgesehen davon, dass die Infragestellung einer selbst vorgenommenen Konstruktion wenig einleuchtend erscheint und mit dieser Deutung zum Hippolytusepigramm die Thematisierung mündlicher Tradition in den anderen damasianischen Epigrammen noch nicht erklärt ist, beruhen diese Überlegungen auf einem modernen Verständnis, das historische Glaubwürdigkeit an schriftliche Überlieferung knüpft.

297 In der antiken Historiographie hatte Geschichte weniger mit einem Studium schriftlicher Quellen als mit der autoritativen Rede über Vergangenheit zu tun (vgl. Momigliano 1960, 32f.), und auch in der spätantiken Hagiographie fiel die Bewertung ,historischer Wahrheit“" von Martyrienberichten keineswegs vorbehaltlos und eindeutig zugunsten schriftlich fixierter Nachrichten aus. Vgl. den Brief des unter Kaiser Iustin I. (518-527) lebenden Bischofs Theodor v. Ikonium, der von einem Amtskollegen wegen der weitverbreiteten, stark mirakulösen Märtyrerakten von Cyricus und Iulitta angeschrieben worden war, um in Ikonium, dem Herkunftsort der beiden Märtyrer, aus der lokalen mündlichen Überlieferung eine Version des Martyriums zu erstellen, die an die Stelle der schriftlich überlieferten martyrii historia treten sollte (vgl. Acta graeca sincera Cyrici et Iulittae [1882], 201-207). Obwohl in der spätantiken Hagiographie die Berufung auf schriftliche Aufzeichnungen und Gerichtsakten eine zentrale Authentifizierungsstrategie darstellt (vgl. dazu Prud., perist. 1, 73-78; Ronchey 2000, 741-744), macht diese Episode exemplarisch deutlich, dass neben den schriftlichen Zeugnissen auch der mündlichen Tradition Bedeutung für die Bewahrung authentischer Tradition zugemessen wurde. 
in seinen Epigrammen auf die fama berief, ist also nicht etwa als ein offen bekundeter Reflex eigener Unsicherheit in Ermangelung einer vertrauenswürdigen schriftlichen Überlieferung aufzufassen. Umgekehrt ist es freilich ebenso unwahrscheinlich, dass Damasus mit seinem Verweis auf die fama und die mündliche Tradition einfach die realen Quellen seines Wissens über die Heiligen benennen wollte. ${ }^{298}$ Plausibler erscheint vielmehr die Vermutung, dass Damasus die Unsicherheit der mündlichen Tradition gezielt thematisierte, um das eigene autoritative Urteil als römischer Bischof, der in der Lage war, Traditionen auf ihre Glaubwürdigkeit hin beurteilen zu können, profilierter hervortreten zu lassen. ${ }^{299}$

Ein in dieser Frage bisher nicht hinreichend beachteter Gesichtspunkt dürfte in den spezifischen biographischen Voraussetzungen zu suchen sein, die Damasus bei seiner Wahl zum Bischof mitbrachte. Um das Jahr 305 geboren, hatte Damasus die Sechzig bereits überschritten, als er zum Nachfolger des Liberius bestimmt wurde. ${ }^{300}$ Als er im Jahr 384 hochbetagt starb, war er einer der wenigen noch verbliebenen Überlebenden, deren Lebenszeit bis an die letzten Verfolgungen heranreichte, die in Form der Märtyrer den „klassischen" Typ des Heiligen produziert hatten, dem der römische Bischof in seinen Epigrammen ein Denkmal setzte. Er selbst thematisierte diese biographische Verbindung auch explizit, indem er in seinem Epigramm auf Petrus und Marcellinus dem Leser verkündete, er, Damasus, habe als kleiner Junge die Geschichte der beiden Märtyrer noch persönlich aus dem Munde ihres Henkers erfahren. ${ }^{301}$ Es liegt nahe, in dieser Ausgangslage auch den Ansatzpunkt für die prononcierten Verweise auf die Überlieferung zu sehen, die Damasus vornahm: Er akzentuierte damit einen Traditionszusammenhang zwischen der Zeit der Märtyrer und der eigenen Gegenwart, den er in eigener Person verkörperte. Darin lag ein Moment affirmativer Identitätsstiftung für die römische Gemeinde (und für Damasus in seiner Funktion als Gemeindeleiter) in einer historischen Situation, die, wie Robert Markus überzeugend gezeigt hat, für die Kirche fundamentale Identitätsprobleme aufwarf: Unter den veränderten Bedingungen der nachkonstantinischen Zeit drohte die Kirche die identitätsstiftende Verbindung zur zurückliegenden „heroischen“

298 So Pietri 1976, Bd. 1, 607-613.

299 Die Verlässlichkeit einer Rekonstruktion war unter diesen Voraussetzungen weniger eine Frage der Quellen als der Urteilsfähigkeit derer, die sie benutzten. Eine instruktive Parallele bietet das Vorgehen Herodots, der als Kriterium für die historische Glaubwürdigkeit nicht den „Quellenwert“ einer mündlichen Tradition (der ókớ) zu ermitteln sucht, sondern die eigene Anschauung (ő $\psi \varsigma$ ) und rationale Beurteilung ( $\gamma v \omega ́ \mu \eta)$ des Überlieferten zugrunde legt (vgl. Luraghi 2001, 142f.).

300 Damasus war nach dem Zeugnis des Hieronymus im Jahr 384 beinahe 80 Jahre alt (Hier, vir. ill. 103).

301 Damas., epigr. 28, 1f.: Marcelline tuum pariter Petrique sepulcrum / percussor retulit Damaso mihi cum puer essem. 
Zeit der Verfolgungen zu verlieren. ${ }^{302}$ Indem Damasus diesem generation gap die fama, ein Wissen, das durch lokale Gemeinschaften bewahrt und tradiert wurde, ${ }^{303}$ entgegensetzte, stellte er einen Traditionszusammenhang zwischen der Gegenwart der römischen Gemeinde und der Kirche der Märtyrer der ersten drei Jahrhunderte her. ${ }^{304}$ Erinnerung und Tradition wurden auf diese Weise zu einem zentralen Moment in der Konzeptualisierung einer Gruppenidentität: Die römischen Märtyrer waren Teil einer Gemeinschaft, innerhalb derer die Erinnerung an sie weitergegeben und bewahrt wurde - und das war die römische Gemeinde mit ihrem Bischof Damasus an ihrer Spitze.

Unterstützung findet diese Deutung, wonach Damasus die römischen Märtyrer gleichsam zu einem Teil der Gemeinde machte, die er als römischer Bischof leitete, im entindividualisierenden Stil und im einheitlichen äußeren Erscheinungsbild der Epigramme und Märtyrermonumente: Die römischen Heiligen bilden eine Gruppe, in der die individuellen Züge einzelner Heiliger gezielt in den Hintergrund treten. Bereits in ihrer äußeren Form der Inszenierung lassen die Epigramme des Damasus erkennen, dass sie auf Wiedererkennung und Vereinheitlichung ausgerichtet waren: ${ }^{305}$ Inschriftentafeln von einer standardisierten Größe, ${ }^{306}$ beschrieben in der Schrift des Kalligraphen Philocalus, die gerade wegen ihrer Unverwechselbarkeit einen hohen Wiedererkennungswert hatte, und metrische Mehrzeiler von charakteristischer Struktur, in denen bestimmte formalhafte Wendungen immer wieder begegneten ${ }^{307}$ - dies

302 Markus 1990, 90-92; ähnlich ders. 1994, bes. 269-271.

303 Dies entspricht einer in der griechisch-römischen Antike weit verbreiteten Anschauung: Herodots Historien bauen auf der Vorstellung eines innerhalb lokaler Gemeinschaften durch mündliche Tradition übermittelten Wissens auf (Luraghi 2001, bes. 150f., 153); ähnlich Cic., leg. 2, 15 in seiner Bemerkung über die Erinnerung der Lokrer an den Gesetzgeber Zaleukos.

304 Vgl. die treffende Einschätzung von Pietri 1986, 57, wonach die damasianischen Heiligen der römischen Gemeinde eine Identität als plebs sancta vermitteln sollten: „le peuple est saint par ses saints.“ Zur Formel plebs sancta für die Gläubigen vgl. Damas., epigr. 13 a; 351; 63. Vgl. in diesem Zusammenhang auch die Schlusszeilen des oben zitierte Epigramms auf die Diakone Felicissimus und Agapetus: unica in his gaudet romanae gloria plebis, / quod duce tunc Xysto Christi meruere triumphos. Die Märtyrer waren und sind (gaudet) der Ruhm der plebs sancta - damals unter der Führung des Sixtus (duce tunc Xysto), heute, dies ist die implizite Botschaft, unter der des Damasus.

305 Auf diesen Aspekt hat nachdrücklich Guyon 1995 aufmerksam gemacht.

306 Die Inschriftentafeln orientieren sich an einem Standardmaß, das in den acht erhaltenen Platten in der Breite zwischen 1,75 und 3,42m, in der Höhe zwischen 35 und 104,5cm variierte; die Buchstabenhöhe bewegte sich durchschnittlich zwischen ca. 5 und 6,5 cm (nr. 3, 7, 8, 13, 18, 21, 25, 26, 27, 28, 37, 47, 49, 54, 55, 56) mit leichten Abweichungen nach unten (nr. 17, 18, 19, 34, $35,51,52$ ) und oben (nr. 22f., 24, 38, 48, 53). Die Einheitlichkeit der philokalischen Buchstabenformen hebt Ferrua (1942), in: Epigrammata damasiana, 25 hervor; zur dadurch bewirkten „Familienähnlichkeit“ der damasianischen Epigramme vgl. auch Guyon 1995, $162 \mathrm{f}$.

307 Die Zeile tempore quo gladius secuit pia viscera matris erscheint gleich in fünf der damasianischen Epigramme, die sich auf vier Coemeterien an unterschiedlichen Ausfallstraßen Roms verteilten (Sixtus II. im coemeterium Callisti/via Appia [nr. 17]; Tiburtius im coemeterium ad duas lauros/via Labicana [nr. 31]; Hippolytus in seinem Coemeterium an der via Tiburtina [nr. 35]; eine Gruppe von 62 Märtyrern [nr. 43] und Saturninus, beide im coemeterium Thrasonis/via Salaria [nr. 46]). Ähnlich 
alles waren deutliche Signale, dass diese Werke aus einer einheitlichen Feder stammten. Dieser stereotype Zug im Stil und Aufbau der Epigramme sowie im äußeren Erscheinungsbild der Inschriften setzte sich auch in den Monumentalisierungen der Gräber fort. Wie Untersuchungen zu mehreren Grablegen in unterschiedlichen Coemeterien nahe legen, folgte die Ornamentierung einem einheitlichen Muster, bei dem die loculi, in denen die Märtyrer bestattet waren, durch Säulen flankiert und durch einen ciboriumartigen Bogen überspannt wurden; komplettiert wurde die Anlage durch die Anbringung (zwischen den Säulen oder oberhalb des vorgeblendeten Pseudociboriums) der Schrifttafel mit dem Elogium für den Märtyrer und durch eine mensa, die entweder neben dem Grab errichtet oder über den Gräbern durch eine Vertiefung der Wand oberhalb der loculi angebracht wurde und die für die Ablage von Oblationen über oder neben dem Grab bestimmt war. ${ }^{308}$

Beim Betrachter und Besucher der Anlagen wurde durch diese Art der Heiligeninszenierung weniger die Disposition geweckt, sich einem einzelnen Heiligen besonders zuzuwenden, als vielmehr, die Märtyrertopographie Roms als einen einheitlichen Raum wahrzunehmen. Diese Absicht des Damasus spiegelt sich auch in der geographischen Verteilung der Epigramme wider. ${ }^{309}$ Eine besondere Konzentration der damasianischen Aktivitäten auf bestimmte Regionen des römischen Suburbiums oder auf Coemeterien, die durch die

formelhaft ist die Wendung pulsus/captus feritate tyranni (vgl. nr. 18; 40; 43); die Beispiele ließen sich leicht weiter vermehren.

308 In der Praetextatuskatakombe wurde eine derartige Ornamentierung an zwei Heiligengräbern vorgenommen, die Francesco Tolotti mit den Grablegen des Ianuarius und der beiden Heiligen Felicissimus und Agapetus identifiziert. Zum Ianuariusgrab vgl. Tolotti 1977, 58-71 mit Abb. S. 69. Problematischer ist Tolottis Rekonstruktion der Monumentalisierung der Grablege Ak (ebd., 71-87 mit Abb. S. 85), in der Tolotti das Grab der Heiligen Felicissimus und Agapetus vermutet. Der Abstand zwischen den beiden Säulchen bietet nicht ausreichend Platz für die Inschriftentafel mit dem Elogium der beiden Heiligen, deren Größe sich zu 100 x $250 \mathrm{~cm}$. ergänzen lässt (vgl. Ferrua [1942], in: Epigrammata damasiana, 152); folgt man der von Tolotti, ebd., 82-84 vorgenommenen Lokalisierung, hätten die beiden Säulen die Inschrift am Rande verdeckt. Zudem sprechen weitere Gründe gegen die Annahme, die Grablege von Felicissimus und Agapetus habe sich in Ak befunden (vgl. Spera 1994, 122; für weitere Korrekturen an der von Tolotti vorgenommenen Lokalisierung der Heiligengräber in der spelunca magna der Praetextatuskatakombe vgl. dies. 1998). Trotz dieser Einschränkungen bleibt festzuhalten, dass auch die Umwandlung der Grablege in Ak dem allgemeinen Muster damasianischer Umgestaltungen von Heiligengräbern gefolgt zu sein scheint. Für weitere Beispiele solcher Umbauten, die unter Damasus vorgenommen wurden, vgl. die Gräber der Heiligen Petrus und Marcellinus in der Katakombe ad duas lauros an der via Labicana (s. Guyon 1987, 381-389 mit Abb. S. 384) und der Heiligen Felix und Adauctus in der Commodillakatakombe in der Nähe der via Ostiensis (s. Weiland 1994 und Abb. S. 632). Zur Funktion der mensae als Oblationstische (nicht als eucharistische Altäre) vgl. Tolotti 1986.

309 Vgl. dazu die Übersicht von Guyon 1995, 161. 
konstantinischen Basiliken monumentalisiert worden waren, ${ }^{310}$ lässt sich nicht ausmachen. Damasus' Ziel waren nicht einzelne Kultzentren, sondern der gesamte Raum der suburbanen römischen Märtyrertopographie: Bis auf die via Latina ist für jede der großen Ausfallstraßen der Stadt mindestens ein Coemeterium nachgewiesen, in dem Damasus eines oder mehrere seiner Epigramme anbringen ließ. Diese Absicht, eine möglichst flächendeckende damasianische Heiligentopographie im römischen Suburbium zu implementieren, ging vermutlich so weit, dass der römische Bischof auch in Coemeterien, die nachweislich erst nach dem Ende der Verfolgungszeit angelegt worden waren, Heilige ,auffand“ und zum Objekt der Verehrung erklärte. ${ }^{311}$ Die Frömmigkeit und die Verehrung der Besucher sollten nicht einem einzelnen Märtyrer, sondern „den“ römischen Heiligen gelten, deren individuelle Gestalt in einer auf Einheitlichkeit und Wiedererkennung ausgerichteten Märtyrertopographie zu verschwinden drohte.

Diese Tendenz setzte sich zum Teil auch auf der inhaltlichen Ebene der Epigramme fort, in denen sich Damasus den Lesern und Besuchern der Grabstätten zuwandte. Von der Forschung ist immer wieder auf die eigentümliche Gesichtslosigkeit zahlreicher damasianischer Heiligen hingewiesen worden, die man auf unterschiedliche Weise zu erklären suchte, als Beleg für eine um die Mitte des 4. Jh. noch nicht so stark ausgeprägten Legendenbildung $^{312}$ ebenso wie als Ausdruck einer bewussten Absetzung des römischen Bischofs von derartigen Legenden. ${ }^{313}$ Die Frage nach den legendarischen Traditionen in damasianischer Zeit ist insofern rein spekulativ als sich neben

310 Gegen Sághy 2000, 278f., die davon ausgeht, dass Damasus sich bevorzugt Märtyrerkultstätten, in denen die konstantinische Familie Sakralbauten errichtet hatte, zugewandt hätte, um so den kirchlichen Anspruch auf diese Märtyrer zu signalisieren.

311 Dies trifft mit hoher Wahrscheinlichkeit auf die Heiligen Felix und Adauctus im Commodillacoemeterium zu, das erst seit der Mitte des 4. Jh. ausgebaut wurde. Ferrua 1938 (a), 408-412 u. Carletti 1994, 5f. versuchen die Präsenz von Märtyrern in einem nachkonstantinischen Coemeterium durch die Bestattung der beiden Heiligen in einer privaten Anlage zu erklären, an deren Stelle erst seit der Mitte des 4. Jh. eine gemeindeeigene Grablege getreten sei, die eine allgemeine coemeteriale Nutzung der Region seit dieser Zeit nach sich gezogen habe. Naheliegender erscheint die Annahme, dass der Heiligenkult sich zusammen mit der Grabregion erst in nachkonstantinischer Zeit entwickelte (für vergleichbare Phänomene von kultisch verehrten Gräbern in nachkonstantinischen Katakombenregionen vgl. z. B. Fasola 1982-1984). Dass Damasus auf eine Legende, dort seien Märtyrer bestattet, reagierte, ist ebenfalls unwahrscheinlich: Da es keine Hinweise darauf gibt, dass die fragliche Region der Commodillakatakombe vor Damasus für Bestattungen genutzt wurde, dürfte Damasus' Einrichtung eines Heiligenkultes auf eine gezielte Initiative des römischen Bischofs zurückzuführen sein.

312 So Schäfer 1932, 158-166. Ähnlich deutet Guyon 1995, 169f. die schematischen, nur selten durch Details bereicherten Darstellungen in dem Sinne, dass Damasus sich eher darauf beschränkte, bestehende legendarische Traditionen aufzugreifen, als neue Inhalte zur Legendenbildung um die Heiligen beizutragen (,son œuvre consacre plus qu'elle n’innove“).

313 In diesem Sinne Pietri 1976, Bd. 1, 607: (Damasus), ,succombe très rarement à la tentation de l'anecdote“; ebd., 616: ,il veut publier, sans s'attarder aux anecdotes pieuses, la valeur exemplaire de leur témoignage pour aider la conversion“. 
den Epigrammen selbst keine Zeugnisse dafür erhalten haben. Davon unberührt bleibt jedoch die Erkenntnis, dass Damasus in der Tat das Verhältnis der Besucher zu den Heiligen, deren Grabstätten sie aufsuchten, in einer spezifischen Weise zu beeinflussen suchte. Von zahlreichen Märtyrern erfuhr der Besucher wenig mehr als nur ihre Namen (mitunter nicht einmal diesen). ${ }^{314}$ In derartigen Fällen erschöpften sich die Epigramme in wortreichen Ausführungen über die Glaubensstärke der Märtyrer und den Wert des Martyriums. ${ }^{315}$ Als Monumente einer glorreichen Vergangenheit, deren Größe und historisierende Distanz zur eigenen Zeit thematisiert wurde, teilten manche der damasianischen Märtyrer die Eigenschaften der Epigramme, die ihren Kult äußerlich monumentalisierten. So formelhaft wie die wiederkehrenden sprachlichen Wendungen, so stereotyp wirkt der gemeinsame Nenner eines in der Vergangenheit begründeten Ruhmes, der die damasianischen Heiligen untereinander verband. Nicht ein individueller Patron, sondern der Typ des römischen Märtyrers war es, den man so an den unterschiedlichen Gräbern aufsuchte und in den damasianischen Epigrammen überall in den Coemeterien des römischen Suburbiums wiedererkannte. ${ }^{316}$

Die Heiligentopographie im römischen Suburbium war demnach kein polyzentrischer Raum, in dem Damasus - gleichsam Coemeterium für Coemeterium - eine Auseinandersetzung mit schismatischen Konkurrenten um die Gunst und Macht heiliger Patrone führte. Gegen die Infragestellung der bischöflichen Autorität, der sich Damasus während seines Episkopats von unterschiedlichen Seiten ausgesetzt sah, setzte er die Märtyrertopographie als idealisierende historische Projektionsfläche: Die Heiligen waren exempla und historische Vorbilder einer gegenüber den äußeren und inneren Gefährdungen des Gemeindefriedens aufrecht erhaltenen Zugehörigkeit zur ecclesia romana. Schismen, Spaltungen und Störungen der gemeindlichen Eintracht,

314 So bei den 62 Märtyrern im coemeterium Thrasonis an der via Salaria (Damas., epigr. 42 u. 43).

315 Z. B. bei Felix und Adauctus (nr. 7); Tiburtius (nr. 31); Gorgonius (nr. 32); Laurentius (nr. 33); Felix und Philippus (nr. 39); Protus und Hyacinthus (nr. 47). Das Epigramm nr. 16 ist nicht wesentlich mehr als eine Aufzählung der in der Papstgruft bestatteten Heiligen. Im Epigramm auf Hermes erfährt der Leser nur, dass der Heilige aus Griechenland kam (nr. 48); der reine Name erscheint bei Ianuarius (nr. 24).

316 Diese Vereinheitlichung äußert sich allerdings nicht in der Ausbildung eines besonderen Heiligentyps. Die Behauptung von Sághy 2000, 278, 286f., Damasus habe ausschließlich martyrisierte Kleriker kommemoriert und - mit der Ausnahme von Agnes - auf Laien, Soldaten und Frauen verzichtet, trifft nicht zu (vgl. die Soldatenmärtyrer Nereus und Achilleus [nr. 8]; bei den folgenden Märtyrern enthalten weder die damasianischen Epigramme einen Hinweis auf ein Klerikeramt, noch gelten die Heiligen in der späteren legendarischen Tradition als Kleriker: Faustinus und Viatrix [nr. 6]; Eutychius [nr. 21]; Ianuarius [nr. 24 mit dem Kommentar von Ferrua (1942), in: Epigrammata damasiana, 152]; Tiburtius [nr. 31]; Gorgonius [nr. 32]; Felix und Philippus [nr. 39]; die 62 Märtyrer im Coemeterium Thrasonis [nr. 42f.]; Maurus [nr. 44]; Saturninus [nr. 46]; Protus und Hyacinthus [nr. 47]; Hermes [nr. 48]). 
die Damasus in mehreren seiner Epigramme thematisierte, ${ }^{317}$ verraten dabei mehr über den diskursiven Gestaltungswillen des römischen Bischofs als über den Stellenwert, den die Grablegen als identitätsstiftende Zentren für einzelne schismatische Gruppierungen hatten. Dass Damasus in den römischen Heiligen sichtbare Zeichen einer gemeindlichen Einheitsstiftung propagierte, fand auch darin seinen Ausdruck, dass er nicht einzelne Grablegen bestimmter Märtyrer privilegierte, sondern eine Vereinheitlichung der suburbanen Heiligentopographie anstrebte. Durch ihre Gleichförmigkeit, die sich im äußeren Erscheinungsbild der Epigramme ebenso niederschlug wie in der Formelhaftigkeit der Inhalte und der gleichmäßigen topographischen Verteilung im gesamten römischen Suburbium, traten die Heiligen dem Betrachter gleichsam als ein Teil der römischen Gemeinde gegenüber: Sie waren der „einzigartige Ruhm der römischen plebs“318 und reihten sich kollektiv unter die übrigen Mitglieder der römischen Gemeinde ein, der Damasus als Bischof vorstand.

Bezogen auf die symbolische Dimension des städtischen Raums für die Identitätsstiftung der römischen Gemeinde lässt sich dies zu der Aussage zuspitzen, dass Damasus sich nicht auf einzelne heilige Zentren stützte, sondern auf das Suburbium als ganzes, indem er ein traditionelles Muster der Begründung bischöflicher Autorität - das auf den städtischen Raum bezogene Leitbild vom Bischof inmitten seiner grex - auf den außerhalb der Stadt gelegenen Bereich ausdehnte. Die Konsequenz war gleichsam eine Extrapolierung des städtischen Raums, der nun auch die in ihren Gräbern liegenden „Bewohner“ des Suburbiums als Mitglieder der Gemeinde umfasste.

Diese symbolische Einbeziehung des Suburbiums in die Stadt spiegelt sich auch darin wider, dass Damasus in mehreren Epigrammen die Vorstellung äußerte, die Heiligen seien durch ihr Martyrium zu Bürgern der Stadt, zu cives romani, geworden. ${ }^{319}$ Die Stadt Rom als Schauplatz ihres Martyriums vermittelte den Heiligen eine Identität als römische Bürger, auch wenn sie als Fremde nach Rom gekommen waren. Dies machte Damasus sowohl für Saturninus, der aus Karthago stammte, als auch für Hermes, den Graecia misit, geltend. ${ }^{320}$ Ihren auffälligsten Ausdruck fand diese „Einbürgerung“ durch das in Rom erlittene Martyrium jedoch mit Blick auf die beiden Apostel Petrus

\footnotetext{
317 Vgl. o., Anm. 265f.

318 Damas., epigr. 25, 6: unica in his gaudet romanae gloria plebis. Die hier von Damasus artikulierte Vorstellung, dass die Märtyrer der Ruhm der Gemeinde seien, begegnet in ähnlicher Form auch bei Cypr., epist. 10, 5, 2.

319 Für die Nachweise vgl. die folgende Anm.

320 Damas., epigr. 46, 4f. (Saturninus): sanguine mutavit patriam nomenque genusque / Romanum civem sanctorum fecit origo; 48, 1-3 (Hermes): iam dudum, quod fama refert, te Graecia misit; / sanguine mutasti patriam, civemque fratrem / fecit amor legis.
} 
und Paulus. Für sie ließ Damasus in der basilica apostolorum das wohl bekannteste seiner Epigramme, den folgenden Mehrzeiler, anbringen:

„Wenn Du nach den Namen von Petrus und Paulus fragst, sollst Du wissen: Hier hatten die Heiligen früher ihre Wohnung. Der Orient sandte diese Jünger - das gestehen wir freiwillig zu - aber nachdem sie um des Verdienstes ihres Blutes willen und Christus über die Sterne hin folgend in den Schoß des Himmels und das Reich der Frommen gelangt sind, verdiente es Rom eher (scil. als andere Städte), sie als seine Bürger zu beanspruchen. Dies will Damasus zu Eurem Lobe verkünden, ihr neuen Gestirne!“‘321

In diesen beziehungsreichen und vielschichtigen Zeilen sticht neben der Bezeichnung der Apostel als cives vor allem ihre Apostrophierung als nova sidera ins Auge. Es kann kein Zweifel daran bestehen, dass sich Damasus mit dieser Wendung - ähnlich wie mit dem Bürgerbegriff - einer dezidiert römischen kulturellen und politischen Semantik bediente. Zwar hatte Polykrates von Ephesos in einem berühmten, auch noch im 4. Jh. mehrfach zitierten Schreiben an den Bischof Victor von Rom (189-199) für die Apostel die Bezeichnung „Sterne“ ( $\sigma \tau о \chi \varepsilon \tau \tilde{\imath} \alpha)$ verwendet. ${ }^{322}$ Doch dürfte Damasus mit seiner Gestirnsmetaphorik weder auf dieses konkrete Schreiben ${ }^{323}$ bzw. auf die allgemein verbreitete Praxis, Heiligengräber als Sterne zu bezeichnen, ${ }^{324}$ Bezug genommen noch eine allgemein übliche Bezeichnung für die beiden Apostel aufgegriffen haben, für die im Westen wie im Osten die Benennung als duo lumina - in der Bedeutung als Sonne und Mond ${ }^{325}$ - nicht aber als sidera gebräuchlich war. ${ }^{326}$ Vielmehr spielte Damasus mit den „Gestirnen“ auf

321 Ebd. 20: hic habitasse prius sanctos cognoscere debes / nomina quisque Petri pariter Paulique requiris. / discipulos Oriens misit, quod sponte fatemur; / sanguinis ob meritum Christumque per astra secuti / aetherios petiere sinus regnaque piorum: / Roma suos potius meruit defendere cives. / haec Damasus vestras referat nova sidera laudes.

322 Vgl. Eus., h. e. 3, 31, 3 u. 5, 24, 2 u. die folgende Anm.

323 Das Schreiben des Polykrates war im 4. Jh. im Westen allgemein bekannt; vgl. Hier., vir. ill. 45,

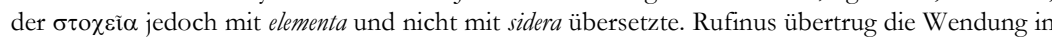
seiner Übersetzung der Kirchengeschichte des Euseb mit lumina bzw. luminaria (vgl. Koch 1919/1920, 176). Dass Damasus mit den nova sidera in seinem Apostelepigramm auf den Polykratesbrief anspielte - als eine Replik auf die gegen Rom gerichtete Vindizierung einer apostolischen Tradition, wie sie Polykrates gegenüber Victor vorgebracht hatte - ist demnach unwahrscheinlich.

324 Vgl. Paul. Nol., carm. 19, 14-19. Die zugrunde liegende Vorstellung von Verstirnung der Seele nach dem Tod ist nicht christlichen Ursprungs; vgl. Brown 1981, 2.

325 Verg., georg. 1, 5f., vgl. Apul., Socr. 1.

326 Vgl. Gaudent., serm. 20, 5; Ven. Fort., carm. 3, 7, 3; Aldhelm, carm. eccl. 1, 3 (MGH, AA XV, 11); vgl. ferner Beda, b. e. 3, 29, 3 (Brief Vitalians [657-672]: duo luminaria caeli. Arator, act. 2, 12191222 unterscheidet zwischen den beiden Aposteln als den duo lumina mundi und dem Glanz, den ihre sidera - eine Anspielung auf ihr gemeinsames Martyrium in Rom - verstrahlen. In Verbindung mit der Metapher Roms als caput mundi konnte die in dem Begriff lumina enthaltene Bedeutungsebene „(Augen-)Licht, Augen“ akzentuiert werden: Die apostolischen lumina wandelten sich von den beiden Himmelskörpern Sonne und Mond hin zu den beiden Augen des Hauptes der Welt (vgl. Ps.-Aug., serm. 381 (PL 39, 1684). Für den Osten vgl. Chrys., hom. in Rom. 
die beiden Dioskuren Castor und Pollux an, ${ }^{327}$ deren traditionelle Bedeutung als mythische Retter Roms seit dem frühen 4. Jh. noch dadurch eine besondere Steigerung erfuhr, dass sie auf Münzen zusammen mit der römischen Wölfin und mit Romulus und Remus abgebildet wurden. ${ }^{328}$ Indem Damasus Petrus und Paulus in Analogie zu dem mit den Gründern Roms assoziierten Dioskurenpaar setzte, evozierte er ein kulturelles Symbol, das wie kaum ein anderes die Identität der urbs Roma und ihre auf der religio der Römer und der Hilfe der Götter gründende politische Herrschaftsstellung zum Ausdruck brachte.

Die im Apostelepigramm vollzogene bedeutungsschwere Verwendung von Begriffen und Symbolen, die in das Zentrum römischer Identitätsstiftung zielten, steht in einem weiteren Kontext vergleichbarer semantischer Bezugnahmen. Damasus bediente sich in signifikanter Weise einer römischen „Sprache“329 und rombezogenen Semantik, um das zu erzielen, was weiter oben als die Konstruktion „des“ römischen Märtyrers bezeichnet wurde. Seine als hexametrische Dichtungen verfassten Epigramme zeigen einen an

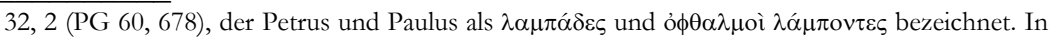
den syrischen Paschahymnen des Ephraim v. Nisibis (gest. 373) ist möglicherweise von den beiden Aposteln als sidera die Rede; vgl. Ephr., bymni de crucifixione 7, 8 (von Beck 1964 mit „Sternenpaar“ übersetzt; Rouwhorst 1985 übersetzt hingegegen „les deux luminaires“). Möglicherweise auf die basilica apostolorum in Rom $\mathrm{zu}$ beziehen ist eine in einer frühmittelalterlichen Sylloge überlieferte stadtrömische Inschrift, in der Petrus und Paulus als mundi duo lumina bezeichnet werden (de Rossi, Inscr. II, 248, nr. 17: hic Petru/s] et Paulus mundi [duo] lumina praesunt / quos c[a]elum similes hos habet aula pares). Es besteht allerdings kein Anlass, diese Inschrift mit Marucchi 1921 Pammachius, dem Zeitgenossen des Hieronymus und Gründer des titulus Pammachii (s. u., S. 355-357), zuzuschreiben.

327 Dieser Deutung neigt der überwiegende Teil der Forschung zu; vgl. Caspar 1930/1933, Bd. 1, 252; Pietri 1961, 316; Huskinson 1982, 81f.; Brändle 1992, 212; Reutter 1999, 162; zuletzt Trout 2005, 304f; anderer Ansicht ist Ferrua (1942), in: Epigrammata damasiana, 144. Zum Stern als gebräuchlichem ikonographischen Attribut der Dioskuren vgl. Furtwängler 1884-1886, bes. 1162f., 1171f.; Geppert 1996, 120-122.

328 Eine Bronzeprägung des Maxentius aus Ostia (RIC VI, 403, nr. 16-19; 309 geprägt) zeigt die Wölfin zwischen den beiden Dioskuren, über denen jeweils ein Stern schwebt. Konstantin griff das Motiv in seinen nach 330 entstandenen Prägeserien mit den Tychen von Rom und Konstantinopel auf dem Avers erneut auf: Auf der Rückseite wurde die Wölfin zwischen Romulus und Remus, denen jeweils ein auf die Dioskuren verweisender Stern als Attribut beigegeben wurde, dargestellt (Bronzeprägungen: RIC VII,336, nr. 331; Medaillons: Maurice 1908-1912, Bd. 1, 253). Das Bildmotiv der Wölfin mit den beiden Sternen entfaltete offenbar eine erhebliche Wirkung: Es wurde noch unter Theoderich und Athalarich erneut aufgegriffen (vgl. zum ganzen Dulière 1979, Bd. 1, 183-186; Bd. 2, 98-100).

329 „Sprache“ hier und im folgenden verstanden in einem umfassenderen Sinn, wie er von den Vertretern der Intellectual History, insbesondere der Cambridge School um Quentin Skinner und John Pocock, entwickelt wurde (zum Konzept vgl. prägnant Landwehr 2001, 40-45). Darunter fallen nicht nur sprachliche Äußerungen (,paroles"), sondern auch der durch kulturelle, rhetorische und stilistische Vorgaben geprägte sprachliche Rahmen („langue“), innerhalb dessen die Äußerungen stehen (vgl. Pocock 1987, bes. 21: ,idioms, rhetorics, specialised vocabularies and grammar, modes of discourse or ways of talking"). 
den klassischen Schul- und Bildungsautoren geschulten Stil mit ausgeprägten Reminiszenzen insbesondere an Vergil ${ }^{330}$ - denjenigen lateinischen Autor, der wie kein anderer Maßstäbe für die literarische Bildung setzte und dabei zugleich ein autoritatives Bild der römischen Geschichte und ihrer exempla vermittelte. 331 Ihren unverwechselbaren Charakter erhielten die Damasusepigramme durch die Schrift des Furius Dionysius Philocalus, eines von der römischen Aristokratie hoch geschätzten Kalligraphen, ${ }^{332}$ dessen Tätigkeit in Diensten des Damasus den Märtyrern einen äußeren Anstrich verlieh, der sie literarischen Klassikern wie Vergil zur Seite stellte und zugleich den bischöflichen Auftraggeber im Kontext einer Elitenkultur verankerte, deren Pflege des literarischen Erbes sich nicht nur in der Klassikerlektüre, sondern auch in der Anlage bibliophiler Handschriften materialisierte. ${ }^{333}$

Wie bereits eingangs angedeutet, wird diese ausgeprägte Romanisierung der Damasusepigramme von weiten Teilen der Forschung als erste diskursive Etappe einer christlichen Transformation Roms aufgefasst: Durch die mit vergilischen Reminiszenzen durchzogenen Epigramme seien die damasianischen Heiligen in den Rang von fundierenden exempla einer neuen, nunmehr christlichen römischen Geschichte erhoben worden, ${ }^{334}$ und in der Verbindung von traditionellen Formen der Literarisierung mit christlichen Inhalten sei ein programmatischer Anspruch auf eine Christianisierung der traditionel-

330 Zur stilistischen und motivischen Orientierung des Damasus an Vergil vgl. Ihm 1895, bes. $194 \mathrm{f}$. Eine ausführliche Analyse der Klassikerreminiszenzen und der intertextuellen Anspielungen im epigrammatischen Werk des Damasus bietet Reutter 1999, 73-105, 148-162. Zur Verbindung von klassischer Sprache und christlichen Inhalten in den Damasusepigrammen vgl. Fontaine 1986.

331 Dass die Vorstellung von römischer Geschichte in der Spätantike eng mit den literarischen Texten eines Bildungskanons von Klassiker- und Schulautoren verbunden ist, der ein Wissen von der römischen Vergangenheit und den vetustatis exempla vermittelte, hat zuletzt Eigler 2003, bes. 77-96 herausgearbeitet.

332 Das außergewöhnliche Prestige des Philocalus dürfte wohl darin begründet gelegen haben, dass er selbst der Aristokratie entstammte (so Cameron 1992, 142f.).

333 Beispiele für bibliophile Klassikerausgaben bilden die berühmten Vergilhandschriften, die im 4. u. 5. Jh. in Italien entstanden und deren archaisierende capitalis rustica und capitalis quadrata eine Nähe zur philocalischen Schrift erkennen lässt (vgl. Ferrua [1942], in: Epigrammata damasiana, 28f.; Seider 1976, 130f., 138-153, 170f.). Dass die Klassikerlektüre und die (professionelle, nicht von den Aristokraten selbst betriebene) Handschriftenpflege jenseits der Religionszugehörigkeit für die spätantike Elite Roms von hoher Bedeutung war, hebt Cameron 1999, 118-121, hervor; ähnlich Niquet 2000, 167-172; zum Faktor „Bildung“ als identitätsrelevanter Kategorie der Aristokratie in der Spätantike vgl. allgemein Salzman 2002, 209-211. Der hohe Stellenwert der Kalligraphie in der Spätantike wird auch aus den Begleitgedichten ersichtlich, mit denen die Kopisten ihre Texte versahen und die auf ein deutlich gestiegenes Ansehen dieser Tätigkeit schließen lassen (vgl. Cameron 2002, bes. 128-130).

334 Eine solche Deutung der damasianischen Vergilimitatio im Sinne einer Einschreibung der römischen Heiligen in den römischen Vergangenheitsraum vertreten u. a. Fontaine 1986, 143f.; Trout 2005, bes. 302-304. 
len Kultur enthalten gewesen. ${ }^{335}$ Insbesondere hat jedoch das oben zitierte Epigramm auf Petrus und Paulus, in dem die beiden Apostel als cives romani und als nova sidera bezeichnet werden, Anlass zu der These gegeben, dass Damasus eine symbolische Christianisierung der Stadt Rom, vermittelt durch die Märtyrer als cives romani und Petrus und Paulus als neue Dioskuren, habe vornehmen wollen. ${ }^{336}$ Nach dieser Deutung bildete Damasus' Anspielung auf die Dioskuren gleichsam den Vorgriff auf das, was Leo I. (440-461) gut zwei Generationen später in einer seiner Predigten auf die Apostelfürsten formulierte:

„Das sind (scil. Rom) deine heiligen Väter und wahren Hirten, die in viel besserer und glücklicherer Weise als deine Gründer tätig waren, um deine Eingliederung in das himmlische Reich zu bewirken, als jene bis auf den Brudermord zerstrittenen Zwillinge. Durch den heiligen Sitz des seligen Petrus zum Haupt des ganzen Erdkreises erhoben, solltest du als heiliges Geschlecht, als erwähltes Volk und priesterliche und königliche Stadt durch die göttliche Religion in weiterem Umkreis herrschen als durch irdische Herrschaft. “337

Was von Leo I. hier explizit geäußert wurde, soll in nuce bereits für Damasus selbst gelten: Die Gründer der römischen Gemeinde seien bei Damasus an die Stelle der mythischen Stadtgründer Roms getreten und hätten der urbs eine neue Identität als christliche Stadt verliehen. ${ }^{338}$

Problematisch an dieser Deutung erscheint vor allem die Kontinuitätslinie, die über eine Zeitspanne von etwa 80 Jahren hinweg - von Damasus (366-384) über Autoren wie den eine Generation später schreibenden Paulinus von Nola ${ }^{339}$ bis hin zu Leo I. (440-461) - reicht und Damasus’ „Einbürgerung" und Romanisierung der Apostel im Lichte einer späteren Entwicklung interpretiert, die jedoch für die damasianische Zeit nicht ohne weiteres vorausgesetzt werden kann. Wie insbesondere Robert Markus mit seiner These vom „end of ancient christianity“ deutlich gemacht hat, kam es im lateinischen Westen gegen Ende des 4. Jh. zu einer nachhaltigen Umgestal-

335 Reutter 1999, 152-155, 163-165; ähnlich Nazzaro 1977.

336 S. dazu o., S. 291.

337 Leo I., serm. 82, 1 (Fassung A): Isti sunt sancti patres tui verique pastores, qui te (scil. Romam) regnis caelestibus inserendam multo melius multoque felicius quam illi discordes usque ad parricidium gemini condiderunt, ut gens sancta, populus electus, civitas sacerdotalis et regia, per sacram beati Petri sedem caput totius orbis effecta, latius praesideres religione divina quam dominatione terrena. Der Text dieser Passage ist noch in einer zweiten, leicht abweichenden Version überliefert, die jedoch am Sinn der Ausführungen nichts ändert (vgl. die Edition von Chavasse 1973).

338 In diesem Sinne Pietri 1961, 316. Auch Guyon 1996 (a), 914 betont die innere Einheit zwischen Damasus und Leo I., indem er im Bild der Apostel als Dioskuren ,jene Themen einer christlichen Romidee“ angeschlagen sieht, ,die erst um die Mitte des Jahrhunderts mit Leo dem Großen zu ihrer vollen Ausformung gelangen sollten." S. auch o., Anm. 259.

339 Vgl. die die beinahe identischen Aussagen von Leo I. (per sacram beati Petri sedem caput totius orbis effecta, latius praesideres religione divina quam dominatione terrena) und Paul. Nol., carm. 13, 29f.: prius imperio tantum et victricibus armis, nunc et apostolicis terrarum est prima sepulchris. 
tung christlicher Identitätsdiskurse. Ob und in welcher Weise das Christsein mit der traditionellen Kultur vereinbar sei, wurde seit der theodosianischen Zeit $\mathrm{zu}$ einer bestimmenden (und vielfach in einem rigoristischen Sinne beantworteten) Frage: Christliche Identität entwickelte sich zu einer weite Teile der Existenz umfassenden kulturellen Konstruktion, die auf zahlreichen Feldern der traditionellen Kultur, die bis dahin aus christlicher Perspektive nicht als identitätsrelevant aufgefasst worden waren, Abgrenzungen zwischen einem profanen und einem zunehmend von asketischen Idealen geprägten christlichen Leben produzierte. ${ }^{340}$ Diese religiöse Qualifikation zahlreicher Lebensbereiche hatte insbesondere auch Auswirkungen auf die Bewertung der Stadt und der ludischen Festkultur, die die Rhythmen des städtischen Lebens bestimmte: Im Zuge der Diskurse um das Wesen christlicher Existenz wurde der neutrale, jenseits einer religiösen Qualifikation angesiedelte Charakter dieser städtischen Kultur infrage gestellt ${ }^{341}$ - mit der Konsequenz, dass auch traditionelle Räume und Monumente, die eine städtische Identität symbolisch vermittelten, religiös qualifiziert wurden und aus christlicher Perspektive eine Verlagerung auf alternative Zentren erforderlich war, die geeignet waren, die Identität einer neuen, christlichen Stadt adäquat zum Ausdruck zu bringen. ${ }^{342}$

340 Darunter fielen u. a. die Teilnahme an städtischen Festen, die Benennung von Wochentagen nach paganen Göttern und die Lektüre nichtchristlicher Bildungsautoren; vgl. Markus 1990, bes. 1-17; zustimmend Brown 1995, 20-26. Kritisch zuletzt Piepenbrink 2005, bes. 18-20, 392-397, die auf nicht-asketisch geprägte Diskurse über das Christsein und auf vermittelnde Positionen verweist, die es den Christen auch weiterhin erlaubt hätten, an den kollektiven Ritualen des städtischen Lebens teilzunehmen. Die Beobachtung von Markus, dass sich das Thema „Identität“ im ausgehenden 4. Jh. zu einem umstrittenen Problem innerhalb der christlichen Gemeinden entwickelte, wird dadurch jedoch nicht wirklich entkräftet: Entscheidend ist, dass seit dem ausgehenden 4. Jh. eine Tendenz erkennbar ist, die Identitätsfrage in Bezug auf zahlreiche, bis dahin nicht religiös qualifizierte Lebensbereiche zu stellen - ob man sie vermittelnd oder rigoristisch beantwortete, erscheint demgegenüber zweitrangig. In Rom machte sich diese Entwicklung vor allem durch die Einflüsse einer rigoristischen asketischen Bewegung innerhalb der senatorischen Oberschicht bemerkbar, die seit den 380er Jahren das Christentum der „respectable christianity“ in Frage stellte und intensive Debatten über die Radikalität asketischer Forderungen zur Folge hatte (zu den eng mit der Person des Hieronymus verbundenen Kontroversen vgl. zuletzt Curran 2000, 280-319).

341 Vgl. Markus 1990, bes. 107-123, erläutert am Beispiel des Augustinus. Die kaiserliche Gesetzgebung des ausgehenden 4. Jh. zielte umgekehrt darauf ab, den säkularen Charakter von Tempelbauten und ludi zum Ansatzpunkt für eine städtische Identitätsstiftung jenseits einer religiösen Qualifizierung zu machen (vgl. dazu Meier 1996, 366-369; Lim 1999, 267-269).

342 Auch wenn das polare Gegensatzpaar „christlich“ und „heidnisch“ natürlich schon vor dieser Zeit existierte, wurde es durch die genannten Entwicklungen in einer Weise neu konstituiert: Die Identität als „Christ“ oder „Polytheist“ war um 400 eine andere als in der Mitte oder zu Beginn des 4. Jh. In Rom zeigt sich dies vor allem durch die Einflüsse einer rigoristischen asketischen Bewegung innerhalb der senatorischen Oberschicht, die seit den 380er Jahren das Christentum der „,respectable christianity“ in Frage stellte und intensive Debatten über die Radikalität asketischer Forderungen zur Folge hatte (zu den eng mit der Person des Hieronymus verbundenen Kontroversen vgl. zuletzt Curran 2000, 280-319). 
In diesen historischen Kontext gehören auch Identitätsdiskurse, die seit dem ausgehenden 4. Jh. Schriftsteller wie Prudentius, Hieronymus, Paulinus v. Nola, Augustinus und Orosius mit den apostolischen Grablegen und der Heiligentopographie Roms verbanden. Die räumliche Gegenüberstellung von traditionellem städtischen Zentrum und coemeterialer, von den Aposteln und den Märtyrern bevölkerter Peripherie entwickelte sich bei diesen Autoren geradezu zu einem der prägnantesten Bilder, um einen Identitätswandel Roms von einer paganen zu einer christlichen Stadt zu versinnbildlichen. In einem 400 verfassten Brief ließ sich Hieronymus „die Stadt von ihren Sitzen hinweg heben“ und von den „spinnwebenbedeckten Tempeln“ hinaus zu den Märtyrergräbern ziehen. ${ }^{343}$ Prudentius formulierte zeitgleich ähnliche Vorstellungen von einer Inversion der Stadt durch den Zug der Bewohner hinaus zu den Gräbern der Heiligen und verknüpfte dieses Bild insbesondere mit den Grablegen der beiden Apostel Petrus und Paulus: Vom tarpeischen Felsen begab sich die Senatskurie zur Vatikanbasilika, um dort die Taufe zu empfangen; am 29. Juni, dem Festtag der Apostel, strömte auf zwei Straßen die Bevölkerung der Stadt in einem geteilten Strom hinaus zu den beiden Basiliken am Vatikan und an der via Ostiensis: ${ }^{344}$ Die durch die suburbane Heiligentopographie Roms gegebene Umkehrung des traditionellen Verhältnisses von Zentrum und Peripherie diente Prudentius als räumliche Versinnbildlichung dessen, dass die beiden Apostel und die römischen Märtyrer an die Stelle der alten Götter der urbs traten. ${ }^{345}$ Die symbolische Bedeutung der römischen Heiligentopographie für die Identität Roms als einer nunmehr christlichen Stadt, die ihre pagane Vergangenheit hinter sich gelassen hatte, wird in denselben Jahren auch bei Augustinus fassbar, der die konkurrierenden städtischen Identitäten auf die räumliche Alternative zwischen der memoria Petri und dem templum Hadriani bzw. Romuli zuspitzte. ${ }^{346}$ In ähnlicher Weise

343 Hier., epist. 107, 1 (vgl. auch o., S. 83f.).

344 Prud., c. Symm. 1, 548-551; ders., perist. 12, 57-66. Das Bild des Hinausströmens der Bevölkerung aus der Stadt und der damit verbundenen Inversion der städtischen Topographie gebraucht Prudentius in seinem Peristephanon auch für die Festtage weiterer römischer Heiliger; vgl. die Hymnen auf Hippolytos (ebd. 11, 199: urbs angusta suos vomit effunditque Quirites) und auf Laurentius: Die Römer verlassen ihre Tempel und ,die Zierde des Senates küsst die Schwellen der Apostel und Märtyrer“" (Prud., perist. 2, 499-520: ipsa et senatus lumina... apostolorum et martyrum exoscolantur limina).

345 Vgl. Prud., perist. 2, 9-16 (durch den Kampf des Märtyrers Laurentius, der den schmutzigen Juppiter bezähmt, bezwingt die urbs die feritas gentium) u. 457-472 (Iuppiter soll Rom zugunsten der beiden Apostelfürsten freigeben).

346 Vgl. Aug., in psalm. 44, 23 (CC 38, S. 511): ostendatur mibi Romae in honore tanto templum Romuli, in quanto ibi ostendo memoriam Petri; an anderen Stellen seines Psalmenkommentars bezeichnet Augustinus denselben Sachverhalt als einen räumlichen Gegensatz zwischen der memoria piscatoris und dem templum imperatoris (Aug., in psalm. 86, 8 u. 140, 21; ders., serm. [Dolbeau] 22, 4; ähnlich Ps.-Aug., serm. 381 [PL 39, 1684]). Romulus ist hier demnach nur ein allgemeines Sinnbild für die Kaiserapotheose; konkret stand Augustinus mit dem templum Romuli das Hadriansmausoleum vor 
gab die Einnahme Roms durch die Goten im Jahr 410 und die Tatsache, dass Alarich die beiden Apostelmemorien zu Asylstätten erklärt hatte, dem Historiker Orosius den Anlass zur Darstellung einer pia pompa der christlichen Bewohner, die die liturgischen Gefäße hinaus zu den sedes sanctorum trugen und damit die identitätsstiftenden Symbole der Stadt Rom vor dem Untergang bewahrten. ${ }^{347}$

Diese im Abstand von nur wenigen Jahren entstandenen Zeugnisse lassen sämtlich die Vorstellung von einer diskursiven Neubestimmung städtischer Identität um die Wende vom 4. zum 5. Jh. erkennen, in der die römische Apostel- und Heiligentopographie als räumlicher Kristallisationspunkt für den Wandel Roms von einer paganen zur christlichen Stadt fungierte. Dieselbe Vorstellung veranlasste in derselben Zeit Paulinus v. Nola dazu, auf der Grundlage der Heiligenverehrung eine neue Geographie der Städtelandschaft im römischen Reich zu entwerfen. Gott, der cunctorum hominum sator, sorgte dafür, dass die Reliquien der Heiligen in alle Gegenden der Welt gelangten und dort ,gleichsam als Samen des Lebens in den unterschiedlichen Orten ausgestreut wurden." Das Ergebnis war nicht nur eine umfassende Christianisierung des gesamten Erdkreises durch Reliquientranslationen, sondern auch eine Neuformierung städtischer Identität auf sakraler Grundlage, die über Rang- und Hierarchiefragen der Städte entschied: Der Besitz der apostolischen Andreas- und Timotheusreliquien war es, der Konstantinopel den Anspruch darauf ermöglichte, als eine Rivalin Roms, der Stadt der beiden Apostelfürsten, aufzutreten. ${ }^{348}$

Diese zahlreichen und in etwa zeitgleichen Äußerungen unterschiedlicher christlicher Autoren, die seit dem ausgehenden 4. Jh. begannen, die Rolle der Apostel und der römischen Heiligen als symbolische Bezugspunkte einer neuen städtischen Identität zu thematisieren, geben Anlass dazu, die Deutung,

\footnotetext{
Augen, das sich in der unmittelbaren Nachbarschaft der vatikanischen Petrusbasilika auf der rechten Tiberseite erhob und mit ihr - vermutlich bereits in damasianischer Zeit - durch eine Portikus verbunden war (vgl. dazu u., S. 412, Anm. 30). Ersichtlich wird dies aus einer Predigt, in der Augustinus anlässlich eines kaiserlichen adventus in Rom der memoria Petri das templum Hadriani als konkurrierendes topographisches Identitätssymbol entgegenstellte (Aug., serm. [Dolbeau] 25, 26). Dieselbe räumliche Gegenüberstellung von Hadriansmausoleum und vatikanischer Petrusbasilika begegnet auch in einer unter dem Namen Leos I. überlieferten Predigt (PL 54, 511D; vgl. Dolbeau [1996], in: Augustin, Vingt-six sermons, 627f.).

347 Oros., hist. 7, 39, 1-14. Fraschetti 1993, 680-684 weist auf die Verwandtschaft des orosianischen Berichtes mit der livianischen Darstellung der Einnahme Roms im Jahr 390 v. Chr. hin, als die vestalischen Jungfrauen die pignora imperii aus der Stadt brachten - eine literarische Anspielung, die den Symbolwert der apostolischen Stätten für die Identität der urbs Roma nachhaltig unterstreicht.

348 Paul. Nol., carm. 19 (geschrieben 405), 307-362, bes. 307 (cunctorum hominum sator) u. 358f. (sacri cineres quasi semina vitae diversis sunt sparsa locis). Zur Konkurrenz zwischen Konstantinopel und Rom auf der Grundlage der in den beiden Städten präsenten Apostel s. ebd., 329-342. Die Bedeutung der Apostel Petrus und Paulus für Roms führende Stellung als erste Stadt im Reich hatte Paulinus v. Nola bereits in seinem carmen 13 aus dem Jahr 396 betont (s. o., Anm. 339).
} 
wonach bereits Damasus - ähnlich wie später Leo I. - mit seiner Rede von den Aposteln als nova sidera den Anspruch auf eine Christianisierung Roms artikuliert habe, kritisch zu überdenken: Wenn Leo I. die Apostelfürsten zu Symbolen einer christlichen urbs Roma erklärte, die als Gründerfiguren an die Stelle der Zwillinge Romulus und Remus traten, dann geschah dies auf der Grundlage einer diskursiven Neubestimmung städtischer Identität, wie sie die oben zitierten Autoren um die Wende vom 4. zum 5. Jh. artikulierten.

Dass erst in dieser Zeit die konzeptionellen Grundlagen dafür gelegt wurden, die Heiligen zu Bezugspunkten städtischer Identitätsdiskurse zu machen, wird deutlich, wenn man die Funktion in Betracht zieht, die die Heiligen mit Blick auf die „neue“ Stadt übernahmen: Die Rolle der Apostelfürsten als Garanten einer christlich transformierten städtischen Identität ist bei Leo I. untrennbar mit ihrer Eigenschaft als Patrone und Beschützer der Stadt verbunden. ${ }^{349}$ Bezeichnenderweise ist dies jedoch eine Vorstellung, die bei Damasus noch nicht begegnet. Als Patrone einer Gemeinschaft wurden die Heiligen erstmals von Ambrosius im Jahr 386 mit Blick auf die katholische Gemeinde Mailands angesprochen, ${ }^{350}$ und seit dieser Zeit entwickelten sich die heiligen Patrone zu einem kulturellen Modell, das sich - wohl nicht zuletzt unter dem bestimmenden Einfluss von Ambrosius' Persönlichkeit rasch verbreitete und von mehreren oberitalischen Bischöfen kurze Zeit später auch auf ihre städtischen Gemeinden übertragen wurde. ${ }^{351}$ Dass

349 Vgl. den Schluss der o., Anm. 337, erwähnten Predigt: Die Apostel und Märtyrer umgeben die Stadt wie ein pupurfarbenes Gemmendiadem und lassen ihr ihren patronalen Schutz (praesidium) zuteil werden (Leo I., serm. 82, 6f.).

$350 \mathrm{Zu}$ der anlässlich der Auffindung und Rekondierung der Gervasius- und Protasiusreliquien von Ambrosius artikulierten Patronatsidee s. o., Anm. 283. Obwohl Ambrosius in seiner Ansprache an die Gemeinde ausführte, die civitas (!) habe ihre verlorenen Märtyrer wiedergefunden (Ambr., epist. 77 [22], 12), drehen sich seine Ausführungen um die Identität nicht der Stadt, sondern der Gemeinde: Ambrosius versteht die Heiligen als ein Integrationsangebot an den arianischen Kaiserhof und als Möglichkeit, den innergemeindlichen Konflikt des Jahres 386 beizulegen (zu dieser Deutung vgl. McLynn 1994, 209-219). Zur Entwicklung des Stadtpatronats der Heiligen vgl. Orselli 1965, 42-90; ebd. 43 zum Aspekt der durch den Begriff patronus signalisierten Schutzfunktion.

351 Zu der gegen Ende des 4. Jh. aufkommenden Praxis, die Heiligen als patroni zu bezeichnen, s. o., Anm. 281. Für die Übertragung des Begriffs von der christlichen auf die städtische Gemeinde vgl. die Predigt des Gaudentius v. Brescia auf seinen Vorgänger Filastrius (Gaudent., serm. 21, 24 [nach 387/397]): Auch wenn die Wendung patronus noster vermutlich eine spätere Hinzufügung ist, verkörpert Filastrius die Rolle des Patrons, dessen Schutz sich auf die ganze Stadt erstreckt (so auch Lizzi 1989, 132-137). Etwa zur selben Zeit (ca. 400/420) hob Maximus v. Turin in einer Predigt auf die Turiner Märtyrer Adventor, Octavus und Solutor hervor, dass sie für ihre Mitbürger gelitten hatten (Max. Taur., serm. 12, 1: martyr enim cum patitur, non sibi tantum patitur sed et civibus). Entsprechend ihrer städtischen Schutzfunktion werden die Märtyrer und die Reliquien häufig mit dem räumlichen Symbol der städtischen Mauer bezeichnet; so Paulinus v. Nola über die Reliquien von Andreas und Lukas in Konstantinopel, die mit denen der beiden Apostel Petrus und Paulus in Rom verglichen wurden und in gleicher Weise als doppelte Türme die Mauern der Stadt verstärken (Paul. Nol., carm. 19, 329-342). Im Osten äußerte Johannes Chry- 
entsprechende Vorstellungen von den Heiligen als Patronen einer neuen Stadt seit dem ausgehenden 4. Jh. auch von den römischen Bischöfen geteilt wurden, darf vorausgesetzt werden, auch wenn sich sichere Belege dafür erst bei Leo I. finden lassen. ${ }^{352}$ Es besteht jedoch kein Anlass, von dieser Annahme bereits für Damasus auszugehen: ${ }^{353}$ Die Vorstellung, dass die Märtyrer eine derartige Schutzfunktion hätten, wird in den damasianischen Epigrammen nirgendwo ausgesprochen, und die Vorstellung von den Märtyrern als Patrone ist bei Damasus insgesamt nur schwach ausgeprägt. 354

Es wurde bereits in anderem Zusammenhang darauf hingewiesen, dass Damasus einer anderen Generation angehörte als diejenigen Bischöfe und christlichen Schriftsteller, die in theodosianischer Zeit der Vorstellung von den Heiligen als Patronen ihrer Gemeinde und christlichen Symbolen städtischer Identitätsstiftung zum Durchbruch verhalfen. ${ }^{355}$ Obwohl Damasus und Ambrosius bischöfliche Amtskollegen und Zeitgenossen waren, die über einen längeren Zeitraum hinweg miteinander in Verbindung standen, 356 agierten sie auf der Grundlage unterschiedlicher kultureller Voraussetzungen. In der Forschung besteht eine weitgehende Einigkeit, dass in Rom unter Constantius II. und der valentinianischen Dynastie mit Blick auf einzelne kulturelle Felder eine weitaus geringere religiöse Polarisierung zwischen „pagan“ und „christlich“ wirksam gewesen sei als in der theodosianischen Zeit, in der ab den 380er Jahren Kernelemente der römischen Tradition wie der kaiserlicher pontifex maximus-Titel und der Victoriaaltar in der Senatscurie einer stärkeren religiösen Qualifikation als Relikte einer heidnischen Vergan-

sostomos dieselbe Vorstellung, Rom sei uneinnehmbar, da die Stadt von den beiden Aposteln wie von einer Mauer umschlossen sei (hom. in epistulam ad Romanos 22, 4 [PG 60, Sp. 680]; ähnlich auch schon Basileios d. Gr. über die 40 Märtyrer von Sebaste als „Türme“ (hom. in quadraginta martyres 8 [PG 31, Sp. 521]). Vgl. auch Prud., perist. 14, 3f.: Die Heilige Agnes „wacht in Sichtweite der städtischen turres über das Wohl der Quiriten“. Weiteres - auch inschriftliches - Material findet sich zusammengestellt bei Gagov 1958, 488-493.

352 Vgl. außer dem o., Anm. 349 zitierten Beleg auch Leo I., serm. 84. Zur Patronage- und Schutzfunktion der Apostelfürsten und Heiligen in den Predigten Leos I. und den Leo I. zugeschriebenen Messformularen des Sacramentarium Veronense vgl. Orselli 1965, 91-96.

353 Anders Pani Ermini 1995, 202, die annimmt, dass die Monumentalisierungen der konstantinischen und damasianischen Zeit im stadtrömischen Suburbium die Stadt mit einer Schutzmauer aus Heiligen umgeben hätten.

354 S. dazu o., S. 296-299.

355 Damasus wurde um 305 geboren, Ambrosius eine ganze Generation später (ca. 333/339). Das Geburtsdatum seiner oberitalischen Amtskollegen Gaudentius v. Brescia und Maximus v. Turin (s. o., Anm. 351) ist um die Mitte des 4. Jh. anzusetzen. Dasselbe gilt für diejenigen christlichen Schriftsteller, die seit dem ausgehenden 4. Jh. die stadtrömische Heiligentopographie zum räumlichen Bezugsraum eines städtischen Identitätsdiskurses machten: Hieronymus wurde 347 geboren, Prudentius 348, Paulinus v. Nola 353/354.

356 Über ihre Beziehungen ist allerdings wenig Genaues bekannt, vgl. Reutter 1999, 19-23. 
genheit unterworfen wurden. ${ }^{357}$ So sind etwa literarische Produkte wie der biblische Vergilcento der Proba, der zu einem nicht näher bestimmbaren Zeitpunkt nach 353 verfasst wurde, nicht aus dem Bestreben heraus entstanden, den als heidnisch bewerteten Klassiker Vergil zu christianisieren oder ihn durch eine christliche epische Dichtung zu ,ersetzen“.358 Vielmehr bediente sich Proba der traditionellen literarischen Formensprache, um auf diese Weise eine Poetisierung des Bibeltextes zu erzielen und dies mit einer spezifisch christlichen Funktion von Literarisierung, die auf Erbauung und Andacht des Lesers abzielte, zu verbinden.

Dieser Vorgang literarischer Aneignung lässt sich nicht als eine Christianisierung, sondern angemessener als eine Form der Romanisierung begreifen, die nicht auf eine christliche Transformation der traditionellen Kultur ausgerichtet war, sondern sich umgekehrt ihrer Ausdrucksmöglichkeiten bediente, um Aussagen in eigener Sache zu treffen. Eine solche Haltung ist auch für Damasus (der Probas Dichtung offenbar geschätzt und rezipiert hat) ${ }^{359}$ und für seine Epigramme mit ihrer ausgeprägt römischen Sprache und rombezogenen Symbolik in Rechnung zu stellen. Mit seiner Rede von den Aposteln Petrus und Paulus als nova sidera kam es Damasus nicht darauf an, die städtische Identität Roms durch ein apostolisches Dioskurenpaar zu christianisieren. Vielmehr bediente er sich - im Sinne einer Romanisierung - eines traditionellen kulturellen Modells römischer Identität, um eine Aussage zu treffen, die mit einer Qualifizierung Roms als pagane oder christliche Stadt nichts $\mathrm{zu}$ tun hatte, sondern als Argument in einem innerkirchlichen Autoritätsdiskurs diente.

Dass die Apostel nicht als „neue Sterne“ an die Stelle der mythischen Stadtgründer treten und den Wandel Roms von einer paganen zu einer christlichen Stadt symbolisieren sollten, ist durch den Inhalt des Apostelepigramms und die historische Situation, auf die es Bezug nahm, hinreichend gesichert: „Der Orient sandte diese Jünger, das gestehen wir willig zu - Rom aber verdiente es eher, sie als seine Bürger für sich in Anspruch nehmen. “360 Wie in der Forschung längst erkannt wurde, nahm Damasus damit auf entsprechende Äußerungen der Kirchen des Ostens Bezug, die die traditionell auf Petrus und Paulus gründende Vorrangstellung der römischen Kirche

357 Die Differenzierung betonen Markus 1974, bes. 2-5; Salzman 1990, 193-231 (beide beziehen Damasus nicht in ihre Überlegungen mit ein).

358 Vgl. hierzu und zur Verortung des Damasus in der literarischen Kultur der Zeit nach 350 Diefenbach (i. Druck). Anders Jacques Fontaine, der Damasus als ,premier grand poète de l'âge théodosien“ ansieht, in dem sich die unter Prudentius und Paulinus v. Nola erfolgte Ablösung der traditionellen durch eine spezifisch christliche Dichtung bereits ankündige (Fontaine 1986, bes. 145).

359 Für Abhängigkeiten der damasianischen Epigramme von Probas Cento vgl. Green 1995, 561.

360 Damas., epigr. 20, 3/6: discipulos Oriens misit, quod sponte fatemur; / . . Roma suos potius meruit defendere cives. 
bereits seit den 340er Jahren mit dem Hinweis auf die östliche Herkunft der beiden Apostel relativiert hatten. ${ }^{361}$ Damasus beschränkte sich jedoch nicht darauf, die Apostelfürsten als Gemeindegründer für die römische ecclesia zu vindizieren, sondern brachte in diese Auseinandersetzung einen neuen Aspekt ein, indem er die beiden Apostelfürsten nicht mehr nur als die Gründer der römischen Gemeinde, sondern auch als Bürger der Stadt und als nova sidera des caput imperii für sich beanspruchte: Auf diese Weise machte Damasus die traditionelle Semantik der urbs als politisches Zentrum des Reichs auch für die ecclesia romana - die Kirche der Stadt Rom - verfügbar.

Nur in diesem Sinne einer in den kirchlichen Bereich übertragenen Denkfigur traten die Apostel als nova sidera an die Stelle von Castor und Pollux. Ähnlich wie für Proba auf Vergil griff Damasus auf ein kulturelles Modell zurück, das geeignet war, den hierarchischen Rang der römischen Kirche zum Ausdruck zu bringen. In beiden Fällen ging es nicht um eine Christianisierung kultureller Modelle, sondern umgekehrt um deren - romanisierende - Übertragung in einen neuen Kontext: Damasus sprach in seinen Epigrammen nicht über Rom, sondern als Römer. ${ }^{362}$ Dabei ging es ihm wohl kaum oder zumindest nicht in erster Linie um die „Missionierung“ der senatorischen Oberschicht, die für ein den traditionellen Herrschaftsanspruch Roms in ein christliches Gewand kleidendes Rombild gewonnen werden sollte. Vielmehr kommunizierte der römische Bischof seinen universalkirchlichen Führungsanspruch in einer Sprache und auf der Grundlage kultureller Leitvorstellungen, die als mentale Voraussetzung religionsunabhängig wirksam waren und in den Worten von Hervé Inglebert - eine „urbizentrische“ Perspektive auf Roms Verhältnis zum Reich begründeten. ${ }^{363}$

Dieser Interpretationsansatz liefert nicht nur einen Schlüssel zum Verständnis des Apostelepigramms, sondern zu Damasus' umfassender Inszenierung der römischen Heiligentopographie insgesamt, die sich ja nicht allein auf die apostolischen Kommemorationsstätten beschränkte. Roms Stellung als caput innerhalb der Kirche und die damit verbundene Verfügung über das symbolische Kapital, das Rom als Lenkerin des Imperiums bereitstellte, beruhte für Damasus nicht allein auf der Einbürgerung der beiden Apostel, die traditionell den Leitungsanspruch der römischen Gemeinde innerhalb der

361 Der römische Bischof Iulius I. (337-352) hatte auf seine Initiative, Rom zum Tagungsort einer Gerichtssynode über Athanasius v. Alexandria zu machen, im Januar 341 eine ablehnende Antwort der orientalischen Bischöfe erhalten, die u. a. ins Feld führten, die Apostel seien als Lehrer aus dem Osten gekommen (vgl. u., Anm. 368). Während Damasus' Episkopat wurde auf dem Konzil von Konstantinopel (381) erneut mit der Herkunft der Apostelfürsten aus dem Osten gegen einen Vorrang der römischen Kirche innerhalb der Reichskirche argumentiert (Gr. Naz., de vita sua 1690-1694). Zu diesen Hintergründen der damasianischen Ausführungen vgl. Schäfer 1932, 23; Chadwick 1957, 35 f.

362 Nach Damas., epigr. 57 war bereits Damasus' Vater Angehöriger des römischen Klerus gewesen.

363 Vgl. Inglebert 1996, bes. 548-550, 560-565. 
Gesamtkirche verkörperten. Wie bereits erwähnt, verlieh Damasus in anderen Epigrammen auch noch mit Blick auf andere Märtyrer, die nicht aus Rom stammten, der Vorstellung Ausdruck, sie seien durch ihr Martyrium Bürger Roms geworden. ${ }^{364}$ Hinter dieser umfassenden „Einbürgerung““ der Märtyrer, die in Rom ihre neue Heimstatt erhielten, wird eine traditionelle Denkfigur sichtbar, wonach Rom alle Kulte des römischen Reichs in sich vereint, allen Göttern eine neue Heimstatt geboten und damit ihre Herrschaft über das Imperium gesichert habe. ${ }^{365}$ Übersetzt in den christlichen Bereich wurde diese Vorstellung von einer „Stadt der Götter“, wie sie noch Ausonius, ein Zeitgenosse des Damasus, nannte, zu einer Stadt der Märtyrer, deren Zahl in Rom, wie wenig später Prudentius bemerkte, unermesslich war. ${ }^{366}$ Ähnlich wie bei der Bezeichnung der Apostel als nova sidera, ging es Damasus auch hier nicht darum, Rom durch die an die Stelle der Götter tretenden Märtyrer zu christianisieren, sondern umgekehrt darum, das Potential eines traditionellen kulturellen Modells für einen christlichen Diskurs verfügbar zu machen: Der Führungsanspruch der römischen Kirche innerhalb der Gesamtkirche artikulierte sich im traditionellen Bild einer die religiöse Geographie des Reichs in sich vereinenden urbs sacra.

Dass Damasus gewillt war, die politische Tradition Roms als Zentrum und Haupt des Reichs mit dem Primatsanspruch der römischen Kirche und ihres Bischofs zu verbinden, ließ er bereits zu einem frühen Zeitpunkt seines Episkopats erkennen. In einem vermutlich aus dem Jahr 371 datierenden Synodalschreiben an die Bischöfe von Illyrien, in dem er den römischen Bischof als sanctissimus episcopus urbis Romae bezeichnete, ${ }^{367}$ machte Damasus deutlich, dass die politische Bedeutung der Stadt, innerhalb derer die Gemeinde angesiedelt war, der er als Bischof vorstand, auch sein Selbstverständnis in der Kommunikation mit den auswärtigen Kirchen prägte: Dama-

364 S. o., Anm. 320.

365 Mit Blick auf das Apostelepigramm bereits betont von Chadwick 1962; mit Blick auch auf die übrigen Märtyrer von Hack 1997, 23 f.

366 Auson., carm. 24, 1 (Green): prima urbes inter, divum domus, aurea Roma (geschrieben 388/89); Prud., perist. 11, 1f.: innumeros cineres sanctorum Romula in urbe vidimus.

367 Das in der Forschung als Dam., epist. 1 geführte Schreiben ist in zwei Varianten überliefert: Einer im Rahmen einer spätantiken Aktensammlung überlieferten lateinischen Fassung stehen zwei griechische Versionen bei Soz., h. e. 6, 23, 7-15 und Thdt., h. e. 2, 22, 1-12 gegenüber. Nur die lateinische Fassung enthält die Wendung vom römischen Gemeindeleiter als Bischof der urbs Roma; sie steht jedoch nach dem Urteil des überwiegenden Teils der Forschung dem Original näher als die griechischen Übersetzungen und ist diesen vorzuziehen (so u. a. Schwartz 1936; Richard 1951; vgl. die ausführliche Forschungsdiskussion bei Reutter 1999, 262-296). Zur umstrittenen Frage der Adressaten und zu den unterschiedlichen Datierungsansätzen der römischen Synode, aus der dieses Schreiben hervorging, vgl. Wojtowytsch 1981, 431 u. zuletzt Reutter 1999, 297-325, die für ein an die illyrischen Bischöfe gerichtetes Synodalschreiben aus dem Jahr 371 plädiert. 
sus war Bischof nicht der ecclesia Romana, sondern der urbs Roma. ${ }^{368}$ Noch deutlicher - und vor allem mit Blick auf die Verbindung von römischen Primatsansprüchen und römischer Heiligentopographie instruktiv - tritt diese Haltung in den kirchenrechtlichen Verlautbarungen hervor, die eine römische Synode im Jahr 382 erließ. ${ }^{369}$ In Reaktion auf das Konzil von Konstantinopel von 381, das die Rangstufen der wichtigsten Bischofssitze des Reichs nach der politischen Bedeutung der Bischofssitze festgelegt hatte, ${ }^{370}$ betonte die römische Synode, dass nicht die politische Gliederung des Reiches den Ausschlag für die Rangfolge der Bischofssitze geben dürfe. Zu diesem Zweck wurde die führende Stellung Roms zum einen mit dem Verweis auf das Herrenwort Mt. 16, 18f., zum anderen mit dem auf dem Martyrium von Petrus und Paulus beruhenden Rang der römischen Kirche begründet. ${ }^{371}$ Während die Untersuchungen zur Kirchen- und Papstgeschichte vor allem der petrinischen Argumentation mit Mt. 16, 18f. entscheidende Bedeutung im

368 Vgl. den treffenden Kommentar von Caspar 1930/1933, Bd. 1, 199: „echt römisch und ein eigener Ton, der den neuen Mann auf Petri Stuhl ankündigte“. Ein vergleichbarer „Ton“ war von Damasus' Vorgängern nicht angeschlagen worden. Im Jahr 339 hatte Bischof Iulius (337352) die Anhänger des Eusebius v. Nicomedia aufgefordert, sich nach Rom zu begeben, um auf einer dort stattfindenden Synode ihr Urteil über Athanasius v. Alexandrien und weitere von ihnen abgesetzte Bischöfe einer Prüfung zu unterziehen (Soz., h. e. 3, 8, 3). In ihrer Antwort auf dieses Schreiben gestanden die Eusebianer dem römischen Bischof zu, Rom sei eine „Medita-

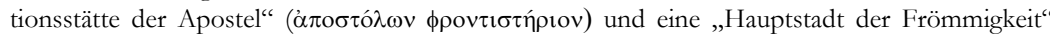

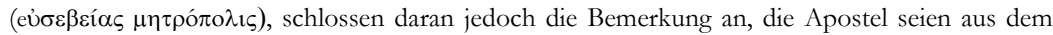
Osten nach Rom gekommen und die östlichen Kirchen würden wegen ihrer geringeren Größe nicht hinter Rom zurückstehen (Soz., h. e. 8, 5; zum Antwortschreiben der Eusebianer vgl. ausführlich Girardet 1975, 157-162.). In welcher Weise Iulius in seinem Einladungsschreiben die politische Semantik der urbs Roma ins Spiel gebracht haben könnte, lässt sich aus der Wendung

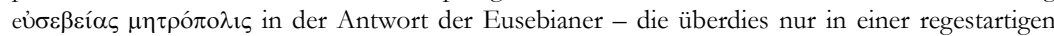
Zusammenfassung durch Sozomenos erhalten ist - allerdings nicht entnehmen. Zwar ist der

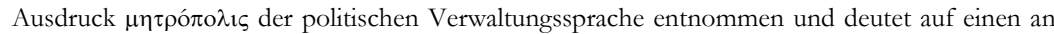
der Provinzialgliederung orientierten, ,reichskirchlichen“ Aufbau der Kirche hin. Doch brachte die Bezeichnung als $\mu \eta \tau \rho o ́ \pi \circ \lambda ı \varsigma$ den Rang Roms als caput imperii nicht adäquat zum Ausdruck. Auch beruhte Iulius' Initiative zur Einberufung einer römischen Synode insgesamt nicht auf einem reichskirchlichen Selbstverständnis des römischen Bischofs als Spitze der Reichskirche, sondern auf einer Sorge der römischen Kirche um die übrigen Ortskirchen, die bereits in vorkonstantinischer Zeit wiederholt artikuliert worden war, sowie auf dem Prinzip, regionale Synodalentscheidungen wechselseitig zur Kenntnis zu bringen und anerkennen zu lassen; zur Verwurzelung des Iulius in den Prinzipien der vorkonstantinischen Kirchenorganisation vgl. bei unterschiedlicher Akzentuierung - übereinstimmend Caspar 1930/1933, Bd. 1, 149-151, Girardet (wie oben) u. Wojtowytsch 1981, $101 \mathrm{f}$.

369 Zur Frage der Echtheit dieser römischen Synode und ihrer Datierung vgl. Caspar 1930/1933, Bd. 1, 247-249, 598f.; Pietri 1976, Bd. 1, 866-872, 881-884; Wojtowytsch 1981, 430 f.

370 C. Const. (381), can. 3 billigte Konstantinopel als dem „neuen Rom“ den Rang nach Rom zu und drängte damit die Patriarchatssitze Alexandria und Antiocheia zurück.

371 Decret. Gelas. 3, 1f. [v. Dobschütz 1912, 7, 29-31]: sancta Romana ecclesia ... evangelica voce Domini... primatum obtinuit (es folgt Mt. 16, 18f.)... pariter supradictum sanctam Romanam ecclesiam Christo Domino consecrarunt (scil. die Apostel Petrus und Paulus), aliisque omnibus urbibus in universo mundo sua praesentia adque venerando triumpho praetulerunt. 
Sinne eines wegweisenden Meilensteins hin zur Entwicklung eines päpstlichen Primats zumessen, gilt die Berufung auf die Doppelapostolizität und das römische Martyrium von Petrus und Paulus als überholt und altmodisch. ${ }^{372}$ Diese Einschätzung übersieht jedoch, dass Damasus mit seinem Verweis auf die Doppelapostolizität der römischen Gemeinde und das Martyrium der beiden Apostel in Rom nicht einfach nur eine bereits im 2. Jh. begegnende Anschauung ${ }^{373}$ wiederholte. So heißt es in dem Synodalbeschluss, dass Petrus und Paulus gemeinsam die Kirche (ecclesia) gegründet und ihr vor allen übrigen Städten (urbes) der gesamten Welt durch ihr Martyrium einen Vorrang verliehen hätten. ${ }^{374} \mathrm{Im}$ charakteristischen Wechsel von ecclesia zu urbs liegt ein innovatives Potential, das Damasus dieser herkömmlichen Vorstellung dadurch verlieh, dass er die Apostel durch ihr Martyrium in Rom „einbürgerte“: 375 Jenseits einer Bindung der Apostel an die christliche Gemeinde, rekurrierte er damit auf die politische Semantik der Stadt Rom. Einer an der Bedeutung der politischen Zentren orientierten Rangfolge der Bischofssitze, wie sie auf dem Konzil von Konstantinopel vorgenommen worden war, setzte Damasus eine Neudefinition der urbanen Geographie des Reiches entgegen, die nicht einfach der aktuellen politischen Gliederung entsprach, sondern auf der Grundlage der Martyrien neu definiert wurde.

Die Synode von 382 macht deutlich, dass Damasus in den stadtrömischen Heiligenepigrammen ein auf die universalkirchliche Stellung der römischen ecclesia bezogenes Selbstverständnis artikulierte, das auch seine kirchenpolitischen Verlautbarungen prägte. ${ }^{376}$ Dass Damasus mit seinen Epigrammen Botschaften kommunizierte, die auch kirchenpolitische Wirkung entfalteten, zeigt exemplarisch die - in diesem Zusammenhang von der Forschung kaum beachtete - Reaktion des homöischen Bischofs Palladius von Retiaria auf dem Konzil von Aquileia, das im Frühsommer des Jahres 381 unter der Leitung des Bischofs Ambrosius v. Mailand Palladius und einen

372 Exemplarisch Caspar 1930/1933, Bd. 1, 249f., dem das bereits im 2. Jh. bei Irenäus und Tertullian begegnende Argument einer auf dem römischen Martyrium von Petrus und Paulus beruhenden Doppelapostolizität als ,altertümlich“ und „,veraltet“ gilt; ähnlich auch Wojtowytsch 1981, 139-141. Ullmann 1981, 22f. geht in seiner Beurteilung des Synodalbeschlusses sogar so weit, dass „mit der Zuspitzung auf den Apostel Petrus... der monokratische Gedanke (scil. des Papsttums) sichtbaren Ausdruck" erhalten habe.

373 Vgl. Iren., haer. 3, 2; Tert., praescr. 36; Dionysios v. Korinth (ca. 170) bei Eus., b. e. 2, 25, 8.

374 S. o., Anm. 371. Obwohl die maßgebliche Handschriftengruppe das urbibus nicht enthält, scheint der Text durch die bald nach 424/425 entstandene praefatio longa zu den Konzilskanones von Nicaea gesichert (vgl. Turner 1899-1933 [EOMIA] 1, 157).

375 Tertullians Bemerkung, Paulus habe durch sein Martyrium unter Nero das römische Bürgerrecht erlangt (Tert., Scorp. 15, 3), gehört nicht in diesen Zusammenhang: Tertullian nimmt damit auf den Umstand Bezug, dass Paulus als römischer Bürger nach Rom gebracht wurde, um dort seinen Prozess zu erwarten.

376 Die Ausführungen der römischen Synode lesen sich wie ein Kommentar zum damasianischen Epigramm auf die Apostel Petrus und Paulus; zur Verbindung vgl. auch Reutter 1999, 516-526. 
weiteren Amtskollegen, Secundianus v. Singidunum, verurteilte. ${ }^{377}$ Damasus hatte an diesem Konzil nicht persönlich teilgenommen, jedoch mehrere Briefe geschickt, die von Ambrosius verlesen wurden. ${ }^{378}$ Den Ausführungen des Palladius lässt sich entnehmen, dass er von Damasus unter anderem mit dem Argument konfrontiert worden war, Rom habe die Martyrien der beiden Apostel gesehen und verdiene es, ihre heiligen Reliquien zu besitzen (Roma, que videre passiones apostolorum et reliquias eorum sanctas meruit possidere). ${ }^{379} \mathrm{Die}$ sprachlichen Anklänge dieser Wendung an die Zeile Roma suos potius meruit defendere cives aus dem Damasusepigramm auf Petrus und Paulus sind so eng, dass an einer Verbindung nicht gezweifelt werden kann: ${ }^{380}$ Damasus artikulierte in seinen Epigrammen Botschaften, die auch in den kirchenpolitischen Diskussionen als Argument für den Vorrang und die Führungsstellung Roms Verwendung fanden. ${ }^{381}$

Dies ist ein auf den ersten Blick durchaus überraschender Befund. Obwohl sie in ihrer unmittelbaren kommunikativen Wirkung auf die Märtyrertopographie in Rom selbst beschränkt waren und nicht in einem weiteren literarischen Raum zirkulierten, ${ }^{382}$ zielten die damasianischen Epigramme nicht auf eine Transformation lokaler städtischer Identität ab, sondern kommunizierten die universale Bedeutung der römischen Kirche, indem sie Roms Rang als caput mundi auf die kirchliche Organisationsstruktur und einen christlichen Diskursraum ausdehnten. Dies wirft konsequenterweise auch die Frage nach der Rezeption der Damasusepigramme auf, die in den unterirdischen Anlagen der römischen Katakomben einen weit über die Grenzen Roms hinausreichenden Autoritätsanspruch kommunizierten. Insbesondere das Pilgerwesen dürfte den Botschaften, die der römische Bischof in seinen Epigrammen artikulierte, eine breite Kenntnis und Aufnahme auch außerhalb Roms gesichert haben. Zwar sind die literarischen Nachrichten über Rombesuche hochrangiger Kleriker und die Entwicklung der Rompilgerschaft im späteren 4. Jh. nicht

377 Zu den Vorgängen vgl. Pietri 1976, Bd. 1, 748-754; McLynn 1994, 124-137.

378 Pallad., c. Ambr. 81 (122), fol. 344r.

379 Pallad., c. Ambr. 93 (139), fol. 348 . Palladius setzte dem entgegen, dass es in Rom nicht nur die apostolischen Reliquien, sondern auch den Senat gebe und forderte eine Wiederaufnahme des Verfahrens vor diesem Gremium; zur Ernsthaftigkeit dieses Plans vgl. McLynn 1991, bes. 69-75.

380 Vgl. auch Pietri 1976, Bd. 2, 1649.

381 Ob Palladius mit seiner Äußerung auf die Schriftstücke des Damasus reagierte, die auf der Synode verlesen wurden, oder ob ihm das stadtrömische Damasusepigramm auf Petrus und Paulus unmittelbar vor Augen schwebte, ist nicht sicher zu sagen. In jedem Fall bezeugt die Äußerung des Palladius, dass die in den Epigrammen vorgetragenen universalkirchlichen Ansprüche nicht auf ein römisches Publikum beschränkt blieben, sondern auch die kirchenpolitischen Diskussionen der Zeit beeinflussten.

382 Eine Aufnahme und Verbreitung der Damasusepigramme in literarischen Epigrammsammlungen (Syllogen) ist vor der 1. Hälfte des 7. Jh. nicht nachweisbar; vgl. Ferrua (1942), in: Epigrammata damsiana, 14f. 
sehr umfangreich, ${ }^{383}$ doch erlauben die archäologischen Hinweise Rückschlüsse darauf, dass das Pilgerwesen in diesen Jahren einen entscheidenden Aufschwung erfuhr: Die Anlage von breit ausgebauten Ab- und Aufstiegstreppen, die Ausmauerung von Verbindungsgängen zwischen einzelnen Katakombenregionen, die Anlage von Lichtschächten und die Stilllegung von Katakombenbereichen ohne verehrte Gräber deuten darauf hin, dass auf diese Weise Pilger- und Besucherströme durch das unübersichtliche und stark verzweigte Gangsystem der römischen Katakomben gelenkt und gezielt zu den verehrten Gräbern der Heiligen geleitet werden sollten. ${ }^{384}$

Zieht man von hier aus nochmals eine Verbindung zu der Art und Weise, in der Damasus sich der römischen Heiligen gegen konkurrierende Ansprüche auf den römischen Bischofsstuhl bediente, wird deutlich, dass beide Motive der damasianischen Märtyrerverehrung - die bischöfliche Autorität innerhalb der römischen Gemeinde und der Führungsanspruch der ecclesia romana innerhalb der Universalkirche - einer einheitlichen Konzeption entsprangen. Damasus' Monumentalisierung der römischen Heiligentopographie stellte sich nicht als ein Ringen um einzelne Gräber und heilige Orte dar, sondern bezog ihre Wirkung daraus, dass sie die individuellen Heiligen in den Zusammenhang der römischen Märtyrer integrierte und diese zu einem Teil der christlichen Gemeinde Roms machte, der Damasus als Bischof vorstand. Dasselbe episkopale Selbstverständnis zeigt sich auch im universalkirchlichen Primatsanspruch, den Damasus mittels der römischen Märtyrer artikulierte. Aus der für die nachfolgende Entwicklung des päpstlichen Primats so folgenreiche Berufung auf Mt. 16, 18f., die er auf der römischen Synode von 382 vornahm, leitete Damasus einen Primat nicht des römischen Bischofs, sondern der römischen Kirche ab. ${ }^{385}$ Während Damasus' unmittelbare Nachfolger als Erben Petri auftraten, in deren Person der Apostel Petrus selbst fortlebte, ${ }^{386}$

383 Zur Rompilgerschaft vgl. die Zusammenstellung der einschlägigen Zeugnisse bei Bardy 1949. Auch bei Rombesuchen hochrangiger Kirchenmänner wie Petrus von Alexandrien (zwischen 373 und 378; s. Reutter 1999, 16f.), konnten die Damasusepigramme eine kommunikative Wirkung entfalten; dasselbe gilt für Synoden: Damasus ist der erste römische Bischof, von dem bekannt ist, dass alljährlich am natalis, dem Jahrestag seiner Bischofsweihe, die Bischöfe aus Italien zu einer Synode zusammenkamen (vgl. coll. Avell., epist. 1, 13).

384 Vgl. Fiocchi Nicolai 1995, 763-769; Spera 1998 (a), 36-48. Zu der in sprachlicher Diktion und äußerer Gestaltung (philokalische Buchstabenformen; architektonische Einbindung) auf Wiedererkennbarkeit und auf Pilger, die unterschiedliche Heiligengräber nacheinander besuchten, ausgerichteten Vereinheitlichung der Damasusepigramme s. o., S. 303f. Die literarische und epigraphische Überlieferung bezeugt eine umfassende Rezeption der Damasusepigramme, noch bevor sie Eingang in literarische Inschriftensammlungen fanden (vgl. Ferrua [1942], in: Epigrammata damasiana, 13f.).

385 Romana ecclesia... primatum obtinuit (s. o., Anm. 371).

386 Zum römischen Bischof als heres Petri und der damit einhergehenden Vorstellung, dass Petrus in seinem Erben gegenwärtig sei, vgl. Fellermayr 1979, 347-416; grundlegend Schmidt 1935, bes. 
und damit eine Deutung begründeten, unter deren Vorzeichen sich Mt. 16, 18f. zum wichtigsten Pfeiler der päpstlichen Primatslehre entwickeln sollte, ${ }^{387}$ hat Damasus die an Petrus ergangene Binde- und Lösegewalt auf den primatus der römischen Kirche bezogen: Der Vorrang des Damasus vor seinen bischöflichen Amtskollegen beruhte demnach nicht auf seiner Petrusnachfolge, sondern auf der römischen Gemeinde, der er als Leiter vorstand. Damit nahm Damasus eine Deutung von Mt. 16, 18f. auf die römische ecclesia vor, die in dieser Form vermutlich weder Vorgänger noch Nachfolger hatte. ${ }^{388}$ Auch dies unterstreicht nachdrücklich, in welchem Maße Damasus seine Stellung innerhalb der Reichskirche auf Rom und seine christliche Gemeinde stützte - und damit auf die Märtyrer, die zugleich die gloria plebis und cives romani waren.

\section{4. Ergebnisse}

Die Frage nach der identitätsstiftenden Bedeutung der Heiligenerinnerung und -topographie für die römische Gemeinde im Verlauf des 4. Jh. wird vor allem anlässlich von Konfliktsituationen sichtbar: Konkurrierende Ansprüche auf die Besetzung des Bischofsamtes und die Existenz rivalisierender Sondergemeinden, die in gleicher Weise wie die katholische Gemeinde vom Selbstverständnis getragen waren, als die rechtgläubige ecclesia Roms zu gelten, brachten sowohl Handlungsstrategien als auch sprachlich vermittelte Identitätsdiskurse hervor, die artikulierten, wo die römische Gemeinde in Rom ihren Ort hatte. Der Umstand, dass die römische ecclesia nicht nur eine lokale christliche Gemeinde wie viele andere im römischen Reich war, sondern

273-275. Diese Verbindung von hereditas Petri und der Vergegenwärtigung Petri im römischen Bischof begegnet erstmals bei Damasus' Nachfolger Siricius (384-399), s. Siric., epist. 1, 1 (vgl. Fellermayr 1979, 391-397; Ullmann 1960, 30, 44 weist die Konzeption dieser zu Beginn von Siricius' Pontifikat ausgestellten Dekretale noch Damasus selbst zu, ohne dies allerdings näher zu begründen).

387 Dass durch unmittelbare Beziehung der römischen Bischöfe auf Petrus die Begründung des päpstlichen Primats auf eine völlig neue Grundlage gestellt wurde, die den entscheidenden Schritt hin zu einem Papsttum mittelalterlicher und neuzeitlicher Prägung bedeutete, hat Ullmann 1960, bes. 25-29 zurecht hervorgehoben.

388 Dass Mt. 16, 18f. vor Damasus jemals von einem römischen Bischof auf die römische Kirche bezogen worden war, lässt sich nicht sicher nachweisen. Harnack 1927, 149-152 hat dies - unter Heranziehung von Tert., pudic. 21, 9 - für Bischof Kallixt (217-222) vermutet, doch hat sich seine Deutung der Wendung ecclesia Petri propinqua nicht durchgesetzt; seit der von Poupon 1986 vorgenommenen überzeugenden Emendation von propinqua in provincia (übernommen auch von Micaelli und Munier für die jüngste Edition von de pudicitia [SC 394, Paris 1993]) ist Harnacks Deutung auch die textliche Grundlage genommen. Wahrscheinlicher ist, dass Stephan I. (254257) seinen Anspruch, als römischer Bischof die cathedra Petri innezuhaben, mit Mt. 16, 18f. verbunden hat, doch ist auch dies nicht sicher zu erweisen (s. Wojtowytsch 1981, 49f. mit Anm. 124). 
zugleich eine universalkirchliche Bedeutung hatte, führte in dieser Hinsicht zu unterschiedlichen diskursiven Bewertungen der römischen Heiligentopographie, die zwar beide auf die ecclesia romana bezogen waren, jedoch klar voneinander unterschieden werden müssen.

Ein Charakteristikum schismatischer Auseinandersetzungen nach Doppelwahlen römischer Bischöfe ist, dass sie sich auf den innerhalb der Mauern gelegenen städtischen Raum konzentrierten, der in dieser Zeit - von vereinzelten Heiligenpatrozinien abgesehen, die möglicherweise bereits im 4. Jh. den Weg in die römischen Titelkirchen gefunden hatten ${ }^{389}$ - eine Zone bildete, in der die Heiligenverehrung noch nicht Fuß gefasst hatte: Die Heiligentopographie war auf das Suburbium beschränkt, wo die Märtyrer, ebenso wie die „normalen“ Toten, in den ausgedehnten Katakombenanlagen und Grabarealen ihre letzte Ruhestätte gefunden hatten. Seine exzentrische Lage vor den Mauern der Stadt machte diesen Raum zu einem denkbar ungeeigneten Ort, um einen Anwärter auf den römischen Bischofsstuhl in derjenigen Eigenschaft zu zeigen, die für das Bischofsamt von konstitutiver Bedeutung war, nämlich als Leiter der Gemeinde, der er als Hirte vorstand. Dieses fundamentale Leitbild vom episcopus als Hirte und Hüter seiner Herde verlangte nicht nur pragmatisch, sondern auch symbolisch nach Präsenz innerhalb der Stadt, dem Lebensraum der Gemeinde. In Rom, das bereits seit der Mitte des 4. Jh. über eine in bischöfliche Basiliken und presbyterale Titelkirchen differenzierte christliche Sakraltopographie verfügte, fungierten dabei insbesondere die Bischofskirchen als diejenigen Orte, die dieses episkopale Selbstverständnis wirkungsvoll versinnbildlichten. Anders als im 5. Jh., als eine ausgefeilte bischöfliche Stationsliturgie den sakralen Raum der Stadt durch ein abgestuftes System von Prozessionen und Gottesdiensten hierarchisierte, brachten die bischöflichen Basiliken des 4. Jh. vermutlich einen unmittelbareren, nicht liturgisch vermittelten Leitungsanspruch des Bischofs über seine Gemeinde zum Ausdruck: Sie zeigten den Bischof inmitten seiner Gemeinde, der plebs Romana, die der Anerkennung ihres Bischofs durch akklamatorische Akzeptanzrituale Ausdruck verlieh, die eine erkennbare Nähe zur politischen Kultur der Zeit aufweisen.

Der legitimierende Bezug auf die Heiligen, insbesondere auf die apostolischen Gemeindegründer Petrus und Paulus, trat gegenüber dieser gemeindebezogenen Auffassung des Bischofsamtes auffällig in den Hintergrund. Obwohl die apostolische Sukzession seit der Entstehung des Monepiskopats im 2. Jh. ein wesentliches Argument für die Begründung bischöflicher Herrschaft gebildet hatte, schlug sich diese legitimatorische Bedeutung von Traditions- und Sukzessionsbezügen nicht in Strategien der Raumbesetzung nieder.

389 Für das Gros der Titelkirchen lassen sich Heiligenpatrozinien frühestens ab der Wende vom 4. zum 5. Jh. nachweisen, vgl. das Dossier u., S. 341-358. 
Die außerhalb der Stadt gelegenen Kommemorationsstätten für Petrus am Vatikan und Paulus an der via Ostiensis waren nicht in der Lage, eine Gemeindeidentität symbolisch zu vermitteln, und spielten daher in schismatischen Auseinandersetzungen keine erkennbare Rolle. Dies galt nicht nur für die Apostelgräber, sondern für die gesamte Märtyrertopographie vor den Toren Roms, die unter diesem Gesichtspunkt ausgesprochen dysfunktional war: Ihre „Attraktivität" bestand nicht in der identitätsstiftenden Kraft der Märtyrergräber als Pole und Zentren der Verehrung, sondern darin, dass der suburbane Raum ein schwer kontrollierbares Gebiet bildete, gleichsam einen Rückzugsraum, sobald der reale und symbolische Kampf um die Stadt verloren war.

Bestätigt und zugleich modifiziert werden diese Beobachtungen durch Sondergemeinden wie die Novatianer und Donatisten, die als schismata inveterata über eine ähnliche Gemeindestruktur verfügten wie die Großkirche und damit in vergleichbarer Weise wie die schismatischen Kandidaten bei Doppelwahlen um die Identität der römischen Gemeinde konkurrierten. Zwar begegnet eine Rekonstruktion der Bedingungen, unter denen Prozesse der Identitätsstiftung in den Sondergemeinden Roms diskursiv wirksam wurden, erheblichen methodischen Problemen, da aufgrund der begrenzten Quellenlage praktisch keine Selbstäußerungen dieser Gruppen zu fassen sind. Insbesondere die römischen gesta martyrum lassen sich nicht als solche Identitätsdiskurse interpretieren, da sie in ihrer vielfältigen Kombination von literarischen Motiven, Heiligen und legendarischen Traditionen nicht einfach kollektive Erinnerungshorizonte widerspiegeln, sondern als literarische Produkte einzustufen sind, die in der Aufnahme und Variation aus anderen Legenden übernommener Wandermotive und der Anlage komplexer Handlungsstränge einen primär literarischen Gestaltungswillen ihrer Verfasser erkennen lassen, die unter der Bezugnahme auf Texte neue Texte produzierten. Da sich die genauen Entstehungs- und Rezeptionsbedingungen dieser Heiligenlegenden unserer Kenntnis entziehen, ist es nicht möglich, diese hagiographischen Produkte zu bestimmten Gruppen in Beziehung zu setzen, deren kollektive Identität durch die Lektüre der Legenden gestärkt oder gestiftet werden sollte.

Unter dieser Prämisse, dass man sich mit Blick auf die in Rom angesiedelten Sondergemeinden auf die - polemisch gefärbte - Außenperspektive katholischer Identitätsdiskurse beschränken muss, zeichnet sich dieselbe Tendenz ab, auf die auch die Handlungsstrategien schismatischer Parteien nach Doppelwahlen hindeuten: Auch für „verstetigte Schismen“ galt, dass der Anspruch darauf, die rechtmäßige Gemeinde Roms zu verkörpern, symbolisch durch die Präsenz innerhalb der Stadt gesichert wurde, nicht durch die Bezugnahme auf die Apostel- und Heiligentopographie vor den Toren Roms. Anders als im Falle von Schismen, die anlässlich von Doppelwahlen entstan- 
den, hatten die Differenzen zwischen der römischen Großkirche und den dort ansässigen Gemeinden der Novatianer und Donatisten jedoch auch eine universalkirchliche Bedeutung, die über die lokalen Grenzen Roms hinaus reichte: Die Frage, wer die rechtmäßige Gemeinde Roms bildete, hatte Konsequenzen auch für die katholischen, novatianischen und donatistischen Gemeinden in den übrigen Städten des römischen Reichs, die sich in communio mit der cathedra Petri befanden. Aus dieser universalkirchlichen Perspektive auf die römische Gemeinde kehrten sich auch die Voraussetzungen um, unter denen die konkurrierenden Gemeinden ihren Anspruch darauf, die rechtmäßige Gemeinde Roms zu sein, zu legitimieren suchten. Die apostolischen Kommemorationsstätten außerhalb der Stadt gewannen dort, wo es um die universale Dimension der ecclesia romana ging, eine legitimierende Bedeutung, die sie in den lokalen Auseinandersetzungen um die Identität der römischen Gemeinde nicht hatten. Abhängig von den diskursiven Kontexten, in denen man die Identität der römischen Gemeinde thematisierte, fanden dementsprechend sie und die cathedra, das Symbol der bischöflichen Autorität als Gemeindeleiter, in unterschiedlichen Räumen der Stadt ihre diskursive Verortung: Während die römische Bischofscathedra ihren Platz innerhalb der Stadt hatte, befand sich die cathedra Petri an den Gräbern der apostolischen Gemeindegründer außerhalb der Mauern der Stadt.

Diese identitätsstiftende Bedeutung der römischen Heiligentopographie für die ecclesia Romana in ihrer universalkirchlichen Dimension zeigte sich auch im monumentalen Ausbau, den Bischof Damasus durch die Umgestaltung der Grablegen und das Anbringen inschriftlicher Epigrammdichtungen an den Gräbern der Heiligen betrieb. In der äußeren Gestaltung, der stilistischen Form und insbesondere der Symbolik und Terminologie seiner Epigramme bediente sich Damasus einer dezidiert römischen Sprache, die darauf berechnet war, kulturelle Modelle städtischer Identitätsstiftung auf die christliche Gemeinde der Stadt Rom zu übertragen und auf diese Weise das symbolische Kapital der urbs Roma als caput mundi auch für die Autoritätsansprüche der ecclesia Romana innerhalb der Reichskirche verfügbar zu machen: Mit der Rolle Roms als urbs sacra und den Dioskuren evozierte Damasus eine Symbolik, die für die städtische Identität von elementarer Bedeutung war, und übertrug sie auf die Heiligen und auf das apostolische Gründerpaar. Die römische Heiligentopographie wurde damit zum räumlichen Bezugspunkt eines Identitätsdiskurses, der die universalkirchliche Führungsstellung der römischen Gemeinde unterstrich. Dieses auch in kirchenrechtlichen Verlautbarungen des Damasus vorgetragene Selbstverständnis, seinen Rang innerhalb der Reichskirche aus der Vorrangstellung der Kirche der urbs abzuleiten, blieb in seiner kommunikativen Wirkung sicher nicht auf die Stadt Rom und ihre Umgebung beschränkt. Dadurch, dass Damasus seine Monumentalisierung der Heiligengräber mit umfassenden Aus- und Umbaumaßnahmen innerhalb der Kata- 
komben verband, sicherte er seinen Botschaften eine breite Rezeption durch Pilger, denen der Zugang zu den verehrten Gräbern gewiesen wurde, und die im ausgehenden 4. Jh. eine beachtliche Zahl erreicht haben dürften.

Gleichzeitig dienten die damasianischen Heiligen jedoch auch dem bischöflichen Autoritätsanspruch, den Damasus - dessen Episkopat von starken Spannungen geprägt war - gegenüber seiner Gemeinde geltend machte. Kennzeichnend ist, dass Damasus sich dabei nicht dem Schutz und der Hilfe heiliger Patrone unterstellte: Er propagierte gegenüber den Glaubenzeugen einen spezifischen modus memorandi, der nicht auf die patronale praesentia der Heiligen und die Vergegenwärtigung ihrer Macht abzielte, sondern in Form eines retrospektiven Erinnerns ihre vorbildhafte und für die römische Gemeinde ruhmvolle Glaubensstärke vor Augen führte. Als „Ruhm der Gemeinde“ wurden die Heiligen dieser auch äußerlich eingegliedert. In der Gestaltung der Grablegen und ihrer Epigramme betrieb Damasus architektonisch wie inhaltlich eine gezielte Vereinheitlichung, hinter der die spezifischen Züge einzelner heiliger Patrone in den Hintergrund traten.

Als ein Ausdruck dieser Vereinheitlichung kann auch die Bezeichnung der Heiligen als cives romani gelten, die - jenseits der politischen Semantik, die durch diesen Begriff abgerufen wurde - die Eingliederung der Heiligen in die Gemeinschaft der römischen Gemeinde signalisierte. Die Terminologie verdeutlicht zugleich, dass als legitimatorischer Bezugsraum für den römischen Bischof auch unter Damasus die Stadt und der durch sie symbolisierte Personenverband der Gemeinde maßgeblich blieben: Mit der Bezeichnung der Heiligen als cives wurde die Vorstellung vom Bischof, der an der Spitze seiner Gemeinde stand, auch auf diejenigen Mitglieder seiner römischen Gemeinde übertragen, die außerhalb der Mauern in den Gräbern der suburbanen Coemeterien „lebten“: Durch eine flächendeckende Erfassung der Märtyrergräber im gesamten römischen Suburbium dehnte Damasus den identitätsstiftenden Raum der ecclesia über die Stadtgrenze hinaus aus und integrierte die Märtyrer auch räumlich in seine Gemeinde.

Ähnlich wie für Konstantin bildeten damit auch für Damasus städtischer Raum und Suburbium eine konzeptionelle Einheit. Dies änderte sich wenige Jahre nach Damasus' Tod, als um die Wende vom 4. zum 5. Jh. zahlreiche christliche Schriftsteller begannen, das Suburbium Roms mit seiner Heiligentopographie dem städtischen Raum gegenüberzustellen und zum räumlichen Bezugspunkt einer neuen städtischen Identität zu machen. Diese unmittelbar mit dem Aufkommen der Vorstellung von einem städtischen Heiligenpatronat verbundenen Identitätsdiskurse brachten gegenüber der damasianischen Zeit nachhaltige Veränderungen mit sich. Sie waren die Grundlage dafür, dass die romanisierende Aneignung kultureller Modelle städtischer Identitätsstiftung, die Damasus betrieben hatte, nun auf die Identität der Stadt zurückwirkte: Während Damasus durch die Rede von den Heiligen als Bürgern und 
den Aposteln als neuen Dioskuren die politischen Traditionen der urbs für einen christlichen Identitätsdiskurs verfügbar gemacht hatte, erfolgte in der folgenden Generation eine gegenläufige Christianisierung dieser kulturellen Modelle: Die Heiligen und die Heiligentopographie wurden zu Sinnbildern einer christlichen Transformation Roms. Damasus war damit zum Wegbereiter einer Entwicklung geworden, an der er selbst keinen Teil hatte. 